\title{
Contribuições ao Estudo das Cúpulas Metálicas
}

Autor: Eng. Luciano Barbosa dos Santos Orientador: Prof. Dr. José Jairo de Sáles

Tese de doutorado apresentada à Escola de Engenharia de São Carlos da Universidade de São Paulo, como parte dos requisitos para obtenção do título de Doutor em Engenharia de Estruturas.

São Carlos (SP), 2005 
Às minhas filhas Luma e Lorena.

Em memória de minha mãe, Margarida, de quem sinto muita falta.

Ao meu pai, Rosivaldo, que muito se sacrificou para que os filhos pudessem estudar. Ao humilde povo de Craíbas, uma cidadezinha empoeirada no agreste alagoano onde passei parte de minha infância e adolescência, e onde desenvolvi o sonho de me formar engenheiro. 


\section{Agradecimentos}

A realização deste trabalho não teria sido possível sem a ajuda que recebi de professores, parentes, amigos e de algumas instituições e empresas.

Ao Prof. Jairo, pela extrema paciência e boa vontade com que vêm me orientando há quase dez anos, período em que se inclui o mestrado, o doutorado e boa parte de minha atuação profissional como engenheiro e professor.

À minha esposa Marilene, aos meus irmãos Roberto e Suzana, que sempre me ajudaram e incentivaram.

À CAPES e à FAPESB, Fundação de Amparo à Pesquisa do Estado da Bahia, pela concessão de bolsas de estudos.

À EPLAN Engenharia, na pessoa do Engenheiro Admilson Aparecido Bortolino, que forneceu informações sobre a estrutura tomada como exemplo neste trabalho.

Ao SET/EESC/USP, por fazer todo o possível para que os pós-graduandos possam trabalhar adequadamente.

Ao Prof. Armando Sá Ribeiro Júnior, da Universidade Federal da Bahia, que sempre se dispôs a ajudar nas dificuldades que senti no uso do programa computacional ANSYS.

Ao amigo Gustavo Alves Tristão, doutorando no SET/EESC/USP, à Profa. Maria Cristina Vidigal, da Universidade Federal de Uberlândia, ao Prof. Luiz Fernando Loureiro Ribeiro, da Universidade Federal de Ouro Preto, e ao Eng. Cassius Morais, que se dispuseram a ajudar esclarecendo algumas dúvidas que surgiram durante o desenvolvimento do trabalho.

A todos os amigos do "doutorado", em especial aos casais Alex e Silvana, Faustino e Marisa, Julio e Gabriela, Márcio e Aline, Patrick e Renata e Romel e Paula, que tornaram a vida em São Carlos extremamente agradável e divertida, apesar das dificuldades inerentes ao curso.

Aos amigos do Departamento de Construção e Estruturas da Universidade Federal da Bahia, e do Departamento de Engenharia Estrutural da Universidade Federal de Alagoas, que sempre incentivaram e apoiaram o desenvolvimento deste trabalho. 


\section{Sumário}

Lista de Figuras vii

Lista de Siglas e Abreviaturas $\quad$ xi

Lista de Símbolos $\quad$ xii

Resumo xvi

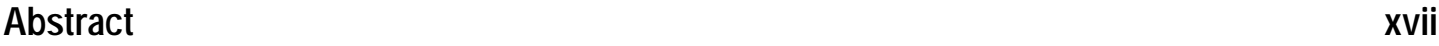

$\begin{array}{ll}\text { 1. INTRODUÇÃO } & 01\end{array}$

1.1. Sobre o projeto de grandes coberturas em aço 01

1.2. Sobre as coberturas em cúpula 02

1.3. Sobre as contribuições apresentadas 05

1.4. Oportunidade de desenvolvimento do trabalho e sua inserção nas pesquisas do SET/EESC/USP $\quad 06$

2. REVISÃO BIBLIOGRÁFICA 07

$\begin{array}{ll}\text { 2.1. Definições } & 07\end{array}$

2.2. Classificação das cúpulas 08

2.2.1. Classificação quanto à flecha 08

2.2.2. Classificação quanto à forma em planta 09

2.2.3. Classificação quanto à forma dos meridianos 09

2.2.4. Classificação quanto à forma construtiva $\quad 10$

2.2.5. Classificação quanto à disposição do vértice 11

2.3. Breve resumo do comportamento das cascas de revolução 11

2.4. Sobre as cúpulas treliçadas 16

2.4.1. Tipos de coberturas em cúpula $\quad 16$

2.4.1.1. Cúpulas nervuradas 17

2.4.1.2. Cúpulas Schwedler 19

2.4.1.3. Cúpulas com malha em três direções (Three-Way) 21

2.4.1.4. Cúpulas de nós rígidos $\quad 22$

2.4.1.5. Cúpulas lamelares 23

2.4.1.6. Cúpulas geodésicas $\quad 24$

2.4.1.7. Cúpulas em reticulado tridimensional 26

2.5. Histórico e evolução das pesquisas realizadas no Brasil e no mundo 28

2.5.1. Pesquisas sobre coberturas em cúpula 28

2.5.2. Pesquisas sobre ligações $\quad 30$

2.5.3. Pesquisas sobre a análise não-linear de estruturas $\quad 30$

2.6. Considerações finais sobre a revisão bibliográfica 31

3. SOBRE O SISTEMA ESTRUTURAL ESTUDADO 33 
3.1. Introdução

3.2. Ligações típicas do sistema estrutural estudado 36

3.2.1. Emendas dos arcos 37

3.2.2. Ligações dos anéis com os arcos 38

3.2.3. Ligações dos arcos com as bases de concreto (aparelhos de apoio) 39

\section{SOBRE O ESTUDO DAS LIGAÇÕES}

4.1. Introdução 43

4.2. Estudo das ligações dos anéis com os arcos 43

4.2.1. Aspectos gerais das curvas momento-rotação 45

4.2.2. Sobre as ligações com dupla tala de alma parafusada 48

4.2.3. Avaliação da rigidez inicial $\quad 50$

4.2.3.1. Ajuste do fator de rigidez $\alpha \quad 54$

4.2.4. Avaliação do momento último 60

4.2.4.1. Determinação do momento último em função da resistência das talas 60

4.2.4.2. Determinação do momento último em função da resistência dos parafusos 61

4.2.4.3. Considerações finais sobre a determinação do momento último 62

4.2.5. Curvas momento-rotação 62

4.3. Estudo das emendas dos arcos 66

4.3.1. Introdução 66

4.3.2. Métodos para avaliação dos esforços nos parafusos 66

4.3.3. Avaliação dos esforços nos parafusos da alma 68

4.3.3.1. Método 1: a conexão da alma absorve uma parcela de $M_{d}$ proporcional à inércia da alma do perfil 68

4.3.3.2. Método 2: a conexão da alma absorve uma parcela de $M_{d}$ proporcional à inércia das talas que ligam a alma do perfil $\quad 68$

4.3.3.3. Método 3: todo o momento fletor $M_{d}$ é absorvido pela conexão das mesas 69

4.3.3.4. Método 4: recomendações de SALMON \& JOHNSON (1996) 69

4.3.4. Estudo comparativo 70

4.3.5. Simulação numérica via elementos finitos 75

$\begin{array}{ll}\text { 4.3.6. Proposta de modelo de cálculo } & 79\end{array}$

4.3.7. Emendas solicitadas axialmente 82

4.3.8. Considerações finais e conclusões 83

4.4. Estudo dos aparelhos de apoio - dimensionamento 83

4.4.1. Introdução 83

4.4.2. Alguns aspectos do dimensionamento de bases de pilares 85

4.4.3. Determinação dos momentos fletores máximos 88

4.4.3.1. Distribuição das tensões na placa de base 88

4.4.3.2. Critério adotado por TIMOSHENKO \& KRIEGER (1959) 89

4.4.3.3. Critérios propostos neste trabalho 90

4.4.4. Proposta para determinação dos momentos fletores máximos 92

4.4.5. Exemplo de aplicação do modelo proposto 102

4.4.5.1. Momento máximo no setor A 103

4.4.5.2. Momento máximo no setor B 103 
4.4.5.3. Determinação da espessura mínima da placa 104

4.4.5.4. Simulação numérica em elementos finitos 104

4.4.6. Considerações finais e conclusões 105

4.5. Estudo dos aparelhos de apoio - avaliação da rigidez 105

4.5.1. Generalidades 105

4.5.2. Avaliação da rigidez em bases engastadas submetidas à força axial de 106 compressão

4.5.2.1. Bases parcialmente comprimidas $\quad 106$

4.5.2.2. Influência da ancoragem no concreto 110

4.5.2.3. Determinação do momento último 111

4.5.2.4. Bases totalmente comprimidas 111

4.5.2.5. Comparação de resultados e validação do modelo proposto 111

4.5.2.6. Adaptação do modelo para bases nervuradas 116

$\begin{array}{ll}\text { 5. ESTUDO DE CASO } & 118\end{array}$

5.1. Introdução 120

5.2. Ações consideradas 120

5.2.1. Ações permanentes 120

5.2.2. Ações variáveis 121

5.2.3. Combinações de ações 124

5.3. Características das ligações 124

$\begin{array}{ll}\text { 5.4. Sobre a análise estrutural } & 124\end{array}$

5.4.1. Critérios para escolha do tipo de análise estrutural 125

$\begin{array}{ll}\text { 5.5. Sobre os elementos finitos utilizados } & 127\end{array}$

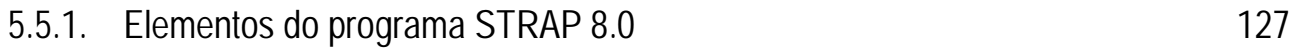

5.5.2. Elementos do programa ANSYS 7.1 128

5.6. Influência do tipo de contraventamento 130

5.6.1. Comparação dos deslocamentos máximos 130

5.6.2. Comparação dos esforços internos nos arcos 122

5.6.3. Comparação dos esforços internos nos anéis 134

5.6.4. Considerações finais 136

5.7. Influência da rigidez das ligações 136

5.7.1. Comparação dos deslocamentos máximos $\quad 137$

5.7.2. Comparação dos esforços internos nos arcos 138

5.7.3. Comparação dos esforços internos nos anéis 139

$\begin{array}{ll}\text { 5.8. Influência da variação de temperatura } & 140\end{array}$

6. CONCLUSÕES 141

6.1. Recapitulação 141

6.2. Sobre o estudo das ligações 141

6.3. Sobre a influência do contraventamento 142

6.4. Sobre a influência da rigidez das ligações 142

6.5. Sugestões para continuação do trabalho 143

7. REFERÊNCIAS BIBLIOGRÁFICAS 144 


\section{Lista de Figuras}

Figura 1.01 - Cobertura do Shopping Pátio Higienópolis 02

Figura 1.02 - Ópera do Arame em Curitiba - PR 03

Figura 1.03 - Ginásio Poliesportivo de São Carlos - SP 04

Figura 1.04 - Centro Regional de Eventos em São José do Rio Preto - SP 04

Figura 2.01 - Cascas de revolução e translação 08

Figura 2.02 - Ruptura dos meridianos 08

Figura 2.03 - Classificação das cúpulas quanto à flecha 08

Figura 2.04 - Classificação das cúpulas quanto à forma em planta 09

Figura 2.05 - Classificação das cúpulas quanto à forma dos meridianos 10

Figura 2.06 - Classificação das cúpulas quanto à forma construtiva 10

Figura 2.07 - Cúpula metálica contínua 11

Figura 2.08 - Classificação das cúpulas quanto à disposiçãa do vértice 11

Figura 2.09 - Elemento de casca 12

Figura 2.10 - Vistas do elemento de casca em estudo 12

Figura 2.11 - Casca esférica sujeita ao peso próprio 14

Figura 2.12 - Apoios inclinados 15

Figura 2.13 - Apoios com anel de borda 15

Figura 2.14 - Casca com compressão nos meridianos e nos paralelos 15

Figura 2.15 - Perturbação de borda 15

Figura 2.16 - Cúpula nervurada com anéis treliçados 17

Figura 2.17 - Cúpula nervurada com anéis em alma cheia 18

Figura 2.18 - Comportamento de um cabo biapoiado 18

Figura 2.19 - Comportamento de um arco biapoiado 19

Figura 2.20 - Exemplo de cúpula Schwedler 20

Figura 2.21 - Funcionamento dos elementos em diagonal do sistema Schwedler 20

Figura 2.22 - Cúpula com malha em três direções (three-way) 21

Figura 2.23 - Cúpula com malha simples em três direções 21

Figura 2.24 - Cúpula com malha dupla em três direções 22

Figura 2.25 - Cúpula de nós rígidos 22

Figura 2.26 - Exemplo de cúpula lamelar 23

Figura 2.27 - Exemplo de cúpula lamelar 23 
Figura 2.28 - Cúpula lamelar/Kiewitt 24

Figura 2.29 - O superdome de Louisiana - EUA 24

Figura 2.30 - Bola geodésica na Flórida - EUA 25

Figura 2.31 - Poliedro utilizado em cúpulas geodésicas 26

Figura 2.32 - Cúpula em reticulado tridimensional 27

Figura 2.33 - Ligação em estrutura metálica espacial: "nó típico" 27

Figura 3.01 - Exemplo de cúpula Schwedler com contraventamento flexível 34

Figura 3.02 - Exemplo de cúpula Schwedler com contraventamento rígido 34

Figura 3.03 - Sistema Schwedler enrijecido 35

Figura 3.04 - Sistema Schwedler com elementos treliçadas 36

Figura 3.05 - Nomenclatura dos elementos componentes do sistema estrutural estudado 36

Figura 3.06 - Emenda dos arcos sem variação da seção 37

Figura 3.07 - Emenda dos arcos com variação de seção 37

Figura 3.08 - Ligação dos anéis com os arcos 38

Figura 3.09 - L Ligação dos anéis com os arcos (vista superior) 38

Figura 3.10 - Esquema da união entre a ligação de extremidade e a base do pilar 39

Figura 3.11 - Aparelho de apoio para cúpula metálica com e sem mísula 40

Figura 3.12 - Aparelho de apoio com variação da seção (Tapered haunch, em inglês) 40

Figura 3.13 - Aparelho de Apoio com trechos curvos (Curved haunch, em inglês) 40

Figura 3.14 - Curvas momento x rotação de ligações de extremidades de pórticos planos 41

Figura 4.01 - Exemplos de ligações viga-pilar 45

Figura 4.02 - Exemplos de curvas momento-rotação de alguns tipos de ligações 46

Figura 4.03 - Curva momento-rotação experimental e sua representação simplificada $\quad 47$

Figura 4.04 - Ligação com dupla tala de alma parafusada 49

Figura 4.05 - Transferência de esforços na ligação com dupla de alma parafusada dos anéis com os arcos $\quad 49$

Figura 4.06 - Esquema estático para determinação do giro da ligação 51

Figura 4.07 - Esquema estático dos modelos simulados numericamente 55

Figura 4.08 - Elemento finto SOLID 45

Figura 4.09 - Modelo em elementos finitos analisado no ANSYS $7.1(2000)$

Figura 4.10 - Comportamento $\eta \times \alpha \quad 58$

Figura 4.11 - Comportamento $\eta \times \alpha$ (Eqs. 4.27 e 4.28) 58

Figura 4.12 - Comportamento $\eta \times \alpha$ (Eq. 4.29) 59

Figura 4.13 - Modelo elastoplástico bilinear 63 
Figura 4.14 - Modelo em elementos finitos no qual foi considerado o comportamento nãolinear do material e o contato entre os parafusos e as chapas do perfil, das talas e da nervura

Figura 4.15 - Curva momento-rotação (Caso 1) 64

Figura 4.16 - Curva momento-rotação (Caso 2) 65

Figura 4.17 - Detalhe típico de emenda parafusada em perfis I de aço 66

Figura 4.18 - Excentricidade da força cortante em relação ao centróide da ligação da alma 67

Figura 4.19 - Variação do esforço no parafuso mais solicitado do exemplo 4

Figura 4.20 - Exemplo extraído de SÁLES et al. (1994) 75

Figura 4.21 - Modelo analisado numericamente 76

Figura 4.22 - Modelo em elementos finitos analisado no ANSYS 7.1 (2000) 77

Figura 4.23 - Redistribuição dos setores da seção transversal do perfil para cálculo de $\alpha$ e $\beta$

Figura 4.24 - Bases típicas para pilares metálicos 84

Figura 4.25 - Pilar apoiado em grelha metálica 84

Figura 4.26 - Pilar apoiado sobre viga travessa 85

Figura 4.27 - Esquema de base de pilar nervurada 85

Figura 4.28 - Balanços externos (Método do AISC (1986)) 86

Figura 4.29 - Alguns tipos de bases nervuradas $\quad 87$

Figura 4.30 - Setores encontrados em bases nervuradas 88

Figura 4.31 - Distribuição das tensões em bases de pilares 88

Figura 4.32 - Placa estudada por TIMOSHENKO \& KRIEGER (1959) 89

Figura 4.33 - Distribuição das tensões: situação real x simplificação 91

Figura 4.34 - Setores analisados e seus carregamentos 93

Figura 4.35 - Base de pilar estudada por ANDRADE (1997) 103

Figura 4.36 - Detalhe nervurado 103

Figura 4.37 - Distribuição dos momentos fletores máximos no detalhe nervurado 104

Figura 4.38 - Bases de pilares com força normal de compressão 105

Figura 4.39 - Base engastada com força normal de compressão 106

Figura 4.40 - Giro em ligações com placa de extremidade 108

Figura 4.41 - Esquema estático para determinação do afastamento da placa de base $\quad 109$

Figura 4.42 - Sugestão de algoritmo para determinação de $M_{u}$ em função da resistência da placa de base 112

Figura 4.43 - Exemplo 1 (comparação de resultados) 113

Figura 4.44 - Exemplo 2 (comparação de resultados) 114 
Figura 4.45 - Exemplo 3 (comparação de resultados) 114

Figura 4.46 - Exemplo 4 (comparação de resultados) 114

Figura 4.47 - Exemplo 5 (comparação de resultados) 115

Figura 4.48 - Exemplo 6 (comparação de resultados) 115

Figura 4.49 - Comparação de resultados - ERMOPOLOUS \& STAMATOPOULOS $x$ ASTANEH et al. (1992) 116

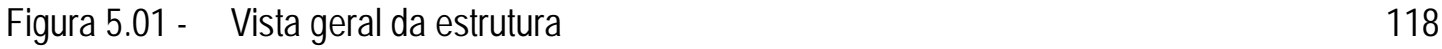

Figura 5.02 - Vista do arco principal 119

Figura 5.03 - Designação dos perfis empregados na estrutura 119

Figura 5.04 - Esquema da elevação de uma cúpula apoiada sobre paredes cilíndricas 122

Figura 5.05 - Linhas Isobáricas dos coeficientes de pressão externa para f/d = 1/2 e h/d =1/2 122

Figura 5.06 - Linhas isobáricas dos coeficientes de pressão externa para f/d=1/10 e h/d = 123

Figura 5.07 - Coeficientes de pressão total na cúpula tomada como exemplo 124

Figura 5.08 - Elemento finito de viga no espaço 127

Figura 5.09 - Recurso "Beams-End-Releases" 128

Figura 5.10 - Elemento BEAM4 128

Figura 5.11 - Elementos LINK8 e LINK10 $\quad 129$

Figura 5.12 - Elemento COMBIN39 129

Figura 5.13 - Nós cujos deslocamentos foram comparados 130

Figura 5.14 - Barras cujos esforços internos foram comparados 132

Figura 5.15 - Barras cujos esforços internos foram comparados 135

Figura 5.16 - Elementos COMBIN39 representando as ligações semi-rígidas 136

Figura 5.17 - Subdivisão dos modelos com contraventamento flexível sem contraventamento 137

Figura 5.18 - Barras escolhidas para comparação de resultados 138 


\section{Lista de Siglas e Abreviaturas}

AISC - American Institute of Steel Construction

ASCE - America Society of Civil Engineering

ASD - Allowable Stress Design

ASTM - American Society for Testing and Materials

LRFD - Load and Resistance Factor Design

MBCEM - Manual Brasileiro para Cálculo de Estruturas Metálicas

NBR - Norma Brasileira Registrada

MEF - Método dos Elementos Finitos

SET/EESC/USP - Departamento de Engenharia de Estruturas da Escola de Engenharia de São Carlos da Universidade de São Paulo. 


\section{Lista de Símbolos}

\section{Letras Latinas Maiúsculas}

$A_{p}=\quad$ Área da seção transversal de uma parafuso.

$A_{s}=\quad$ Área dos grupo de parafusos tracionados em uma placa de base.

$A_{t}=\quad$ Área de um conjunto de talas.

$B=\quad$ Largura de uma placa de base.

$C=\quad$ Comprimento de uma placa de base.

$E_{c}=\quad$ Módulo de elasticidade do concreto.

$E_{s}=\quad$ Módulo de elasticidade do aço.

$E=\quad$ Módulo de elasticidade do aço.

$F_{b}=\quad$ Componente de força em um binário.

$F_{d}=\quad$ Valor de cálculo da força de cisalhamento máxima em um grupo de parafusos sob cisalhamento excêntrico.

$F_{m x}=\quad$ Componente de força no parafuso mais solicitado em um grupo de parafusos sob cisalhamento excêntrico.

$F_{v y}=\quad$ Componente de força no parafuso mais solicitado em um grupo de parafusos sob cisalhamento excêntrico.

$F_{m y}=\quad$ Componente de força no parafuso mais solicitado em um grupo de parafusos sob cisalhamento excêntrico.

$H=\quad$ Altura de um perfil $\mathrm{I}$.

$H_{v}=\quad$ Altura de uma viga em perfil I.

$I_{t}=\quad$ Inércia de um conjunto de talas, somatório da inércia das talas da alma e das mesas.

$I_{t m}=\quad$ Inércia das talas utilizadas na conexão das mesas.

$I_{t w}=\quad$ Inércia das talas utilizadas na conexão da alma.

$I_{w}=\quad$ Inércia em torno do eixo x-x (maior inércia) da alma de um perfil I.

$I_{x}=\quad$ Inércia em torno do eixo $\mathrm{x}-\mathrm{x}$ (maior inércia) de um perfil $\mathrm{I}$.

$I_{\text {wred }}=$ Inércia reduzida da alma de um perfil, onde é desconsiderada a parcela correspondente a diferença entre a altura da alma e a altura do conjunto de talas utilizadas na emenda.

$I_{\text {comp }}=$ Parcela de inércia correspondente à região compreendida pela diferença entre a altura da alma e a altura do conjunto de talas utilizadas na emenda.

$L=\quad$ Vão, distância, largura, comprimento.

$L_{g}=\quad$ Distância entre os centróides das conexões na ligação com dupla tala de alma parafusada. 
$L_{t}=\quad$ Comprimento de um chumbador.

$L_{t}=\quad$ Comprimento (distância horizontal) de uma tala, ou de um conjunto de talas.

$M=\quad$ Momento fletor aplicado.

$M_{d}=\quad$ Valor de cálculo do momento fletor.

$M_{u}=\quad$ Momento Último de uma ligação.

$M_{w}=\quad$ Parcela do momento fletor atuante absorvido pela conexão da alma em uma emenda de perfil I.

$M_{m}=\quad$ Parcela do momento fletor atuante absorvido pela conexão das mesas em uma emenda de perfil I.

$M_{1}=\quad$ Parcela do momento fletor atuante proporcional a relação entre as inércias da alma de um perfil e a inércia total desse perfil.

$M_{p}=\quad$ Momento fletor em uma placa.

$P C=\quad$ Quantidade de planos de corte em uma ligação.

$R_{x}=\quad$ Raio de curvatura na direções $\mathrm{x}$.

$R_{y}=\quad$ Raio de curvatura na direções y.

$S_{i}=\quad$ Rigidez inicial de uma ligação.

$T_{x}=\quad$ Componente de força por unidade de comprimento na direções $\mathrm{x}$.

$T_{y}=\quad$ Componente de força por unidade de comprimento na direções $\mathrm{y}$.

$T_{m}=\quad$ Tensão nos meridianos de uma casca.

$T_{p}=\quad$ Tensão nos paralelos de uma casca.

$T_{s}=\quad$ Força de tração no grupo de parafusos tracionados de uma placa de base.

$V=\quad$ Força cortante aplicada.

$V_{d}=\quad$ Valor de cálculo da força cortante.

$W_{x t}=\quad$ Módulo elástico resistente de um conjunto de talas.

\section{Letras Latinas Minúsculas}

$a=\quad$ Largura, distância, comprimento. Fator de forma no modelo COLSON (1991).

$b=\quad$ Largura, distância, comprimento.

$b_{f}=\quad$ Largura das mesas em um perfil I.

$d_{c h}=$ Diâmetro de um chumbador.

$d_{p}=\quad$ Diâmetro de um parafuso.

$e=\quad$ Excentricidade de aplicação de uma força.

$f_{c}=\quad$ Tensão de compressão no concreto.

$f_{y}=\quad$ Tensão de escoamento do aço. 
$f_{s}=\quad$ Tensão de tração nos chumbadores.

$f_{u}=\quad$ Tensão de ruptura do aço.

$h_{b}=\quad$ Distância entre centróides das partes superior e inferior em uma ligação com dupla tala de alma parafusada.

$k=\quad$ Constante introduzida por ANDRADE (1995) para determinação da posição da linha neutra da seção.

$k_{m}=$ Constante de rigidez à translação no modelo constitutivo para avaliação do comportamento momento-rotação de aparelhos de apoio.

$k_{r}=\quad$ Constante de rigidez à rotação no modelo constitutivo para avaliação do comportamento momento-rotação de ligações com dupla tala de alma parafusada, este parâmetro está relacionado com a ligação das talas com o pilar ou com a viga de apoio.

$m=\quad$ Balanço fictício para cálculo de placas de base.

$n=\quad$ Fator de forma no modelo KISHI \& CHEN (1990). Balanço fictício para cálculo de placas de base.

$p=\quad$ Componente de um carregamento normal à superfície de uma casca. Largura tributária de um parafuso para avaliação da força alavanca.

$q=\quad$ Valor de um carregamento linear ou por superfície.

$q_{1}, q_{2}=$ Valores inicial e final em um carregamento trapezoidal.

$t_{f}=\quad$ Espessura das mesas em um perfil $\mathrm{I}$.

$t_{\text {arg }}=\quad$ Espessa da camada de regularização com argamassa em um aparelho de apoio.

$t_{p}=\quad$ Espessura de uma placa de base.

$t_{\text {porca }}=$ Espessura da porca de fixação de um chumbador.

$t_{\text {placa }}=$ Espessura de uma placa de base.

$t_{w}=\quad$ Espessura da alma em um perfil I.

$t_{t t}=\quad$ Espessura total de um conjunto de talas.

$h_{p}=\quad$ Metade da diferença entre a altura da alma de um perfil I e altura das talas.

$h_{t}=\quad$ Altura de uma tala, ou de um conjunto de talas.

$h_{w}=\quad$ Altura da alma em um perfil I.

\section{Letras Gregas}

$\alpha=\quad$ Ângulo. Fator de rigidez. Relação entre inércias.

$\beta=\quad$ Ângulo. Relação entre inércias. Parâmetro para cálculo da flexão em placas.

$\delta=\quad$ Deslocamento.

$\varepsilon_{s}=\quad$ Deformação elástica no aço.

$\varepsilon_{c}=\quad$ Deformação elástica no concreto. 
$\phi=\quad$ Rotação angular.

$\phi_{0}=\quad$ Rotação plástica de referência.

$\gamma=\quad$ Coeficiente para cálculo de placas aplicável ao caso de carregamento trapezoidal.

$\eta=\quad$ Parâmetro para determinação do fator de rigidez de ligações com dupla tala de alma

$\mu=\quad$ Parâmetro para cálculo da posição da linha neutra em aparelhos de apoio.

$\rho=\quad$ Parâmetro para cálculo da posição da linha neutra em aparelhos de apoio. 


\section{Resumo}

SANTOS, L.B. (2005). Contribuições ao estudo das cúpulas metálicas. 152 p. Tese (Doutorado). Escola de Engenharia de São Carlos da Universidade de São Paulo. São Carlos (SP), Brasil.

Este trabalho aborda, de uma forma geral, os sistemas estruturais normalmente adotados no projeto de cúpulas metálicas. Foi dado ênfase a um arranjo derivado do sistema Schwedler, recentemente utilizado em projetos desenvolvidos no interior do estado de São Paulo. O trabalho pode ser divido em duas partes, a primeira delas versando sobre as ligações que compunham o sistema estrutural estudado, e a segunda versando sobre a influência dessas ligações no comportamento da estrutura e sobre a influência da forma de contraventamento. As ligações foram estudadas sob dois aspectos diferentes, que foram: a) revisão e aperfeiçoamento dos critérios de dimensionamento adotados em algumas ligações, e b) proposição de modelos para descrição do comportamento momento-rotação de ligações com dupla tala de alma parafusada e de aparelhos de apoio. A influência do tipo de contraventamento e da rigidez das ligações foi investigada por meio do efeito exercido nos deslocamentos verticais e na distribuição de esforços internos da estrutura. Para tanto, foram utilizados programas computacionais de uso já consagrado, cujos resultados foram comparados entre si.

Palavras Chaves: estruturas de aço; grandes coberturas; ligações semi-rígidas; simulação numérica; contraventamento. 


\section{Abstract}

SANTOS, L.B. (2005). Contributions to the study of the metallic domes. 152 p. Ph.D. thesis. São Carlos Engineering School. University of São Paulo. São Carlos (SP), Brasil.

In a general way, this work deals with structural systems usually adopted in the project of metallic domes. Emphasis was given to a derived arrangement derived of the Schwedler system, recently used in projects developed the state of São Paulo. The work can be divided in two parts, the first one is about the connections that compose the structural system studied, and second one treats the influence of those connections in the structure behavior and the influence in the brace configuration. The connections were studied under two different aspects, that were: a) revision and improvement of the design criteria adopted in some connections, and b) proposition of models for the momentrotation description for double plate connections of web. The influence of the brace type and of the rigidity of the connections were investigated by means of the effect in the vertical displacements and in the distribution of internal efforts of the structure. So, two commercial softwares were used, and the results were compared.

Key words: $\quad$ Steel structures; large span domes; semirigid connections; numerical simulation; braced domes. 


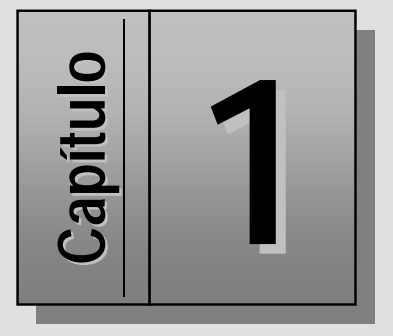

\section{1 - Sobre o Projeto de Grandes Coberturas em Aço}

As estruturas de aço são amplamente empregadas quando se deseja construir edificações leves e com grandes áreas livres. Isso se deve, em princípio, à elevada resistência mecânica do aço e às formas geométricas com as quais os perfis são fabricados, que permitem criar barras altamente eficientes do ponto de vista estrutural com um consumo de material relativamente pequeno.

Entre as obras que necessitam de grandes áreas livres encontram-se alguns tipos de coberturas destinadas ao abrigo de grandes quantidades de pessoas, como os centros esportivos, os templos religiosos, os auditórios e as instalações para eventos. Nesse tipo de obra as estruturas metálicas são as mais utilizadas, o que se justifica, também, pelos seguintes motivos:

a) A praticidade existente durante as fases de fabricação, transporte e montagem da estrutura e a rapidez com que a obra pode ser executada.

b) A aparência de leveza e harmonia que essas estruturas normalmente apresentam costumam causar boa impressão nos profissionais envolvidos com o projeto e nos usuários em geral.

O projeto de tais coberturas muitas vezes assusta os profissionais da área, uma vez que implica, indubitavelmente, na aceitação de grande responsabilidade perante o cliente e a sociedade. Por esse motivo muitos profissionais desistem da oportunidade de desenvolverem projetos dessa natureza, deixando-os a cargo dos calculistas mais experientes ou solicitando, com justa razão, consultorias às instituições de ensino e pesquisa, que muitas vezes detêm o conhecimento tecnológico necessário para desenvolver o projeto ou para auxiliar no seu desenvolvimento. 
Mesmo com todo o conhecimento tecnológico e com as ferramentas computacionais disponíveis atualmente, não são raras as situações onde o profissional mais experiente, ou mesmo 0 pesquisador mais renomado, se depara com dificuldades de maior vulto. É o que ocorre, por exemplo, quando se precisa construir um edifício, uma ponte ou uma cobertura de dimensões muito acima do habitual, ou com características muito diferentes daquilo que normalmente é executado.

Tratando especificamente do projeto de grandes coberturas em aço, que é onde se encaixa 0 presente trabalho, pode-se afirmar que o comportamento estrutural e as particularidades de projeto de muitos sistemas construtivos ainda não estão suficientemente descritos na literatura técnica, 0 que pode gerar dúvidas e incertezas para muitos calculistas.

Diante disso, e em face da grande responsabilidade que o projeto exige, um estudo criterioso dos sistemas estruturais empregados nas grandes coberturas se faz necessário para que as multidões, e a sociedade de uma maneira geral, possam usufruir com segurança das instalações destinadas a grandes eventos, e os profissionais possam encarar com mais segurança e tranqüilidade o projeto de tais edificações sem serem tentados a surperdimensioná-las.

\section{2 - Sobre as Coberturas em Cúpula}

A construção metálica apresenta muitas opções para cobertura de grandes áreas. A escolha do tipo mais adequado depende de diversos fatores que devem ser cuidadosamente analisados pelos profissionais envolvidos com a obra (proprietários, arquitetos, empreiteiros e calculistas).

Tendo em vista a considerável variedade de soluções para o projeto de grandes coberturas, que inclui, entre os tipos não monolíticos, as estruturas metálicas e as tenso-estruturas, será abordado neste trabalho apenas um tipo específico de cobertura com planta circular que é conhecido como cúpula ou domus. A Figura 1.1 ilustra esse tipo de cobertura.

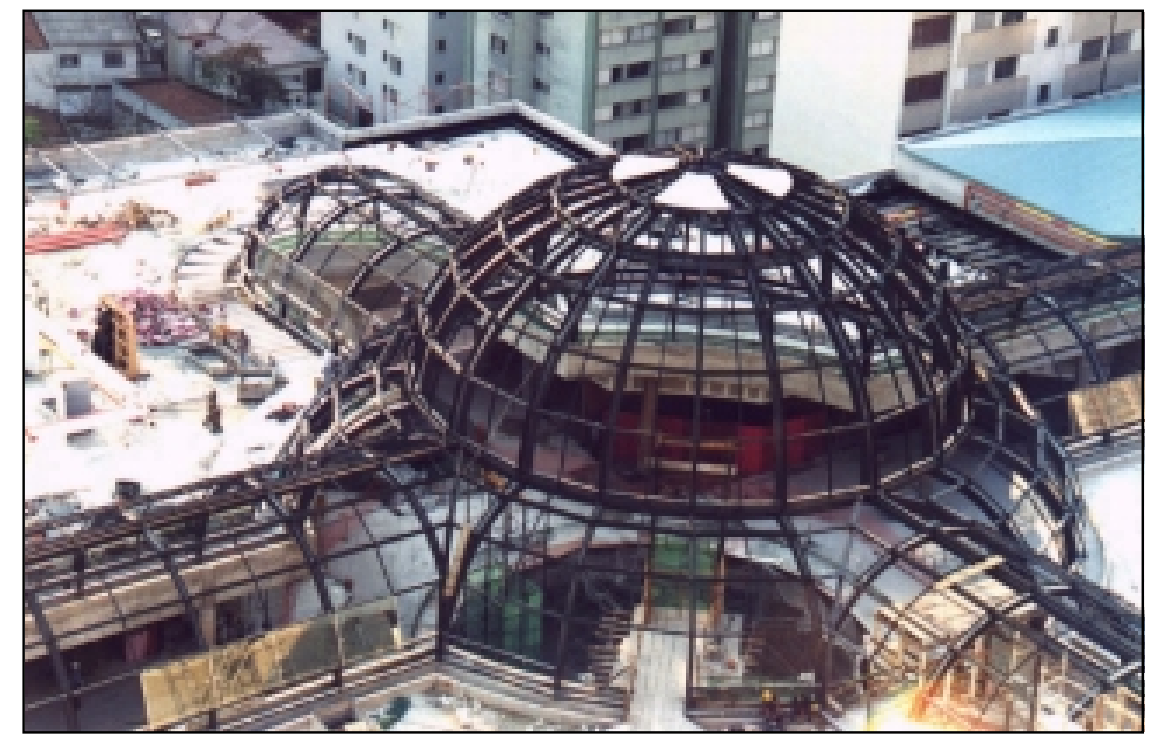

Figura 1.1 - Cobertura do Shopping Pátio Higienópolis - São Paulo (Fonte: SAE INFORMÁTICA (2002))

Embora a construção de cúpulas metálicas seja algo relativamente antigo, pois segundo VENDRAME (1999) a primeira delas foi construída em 1811, são poucos os textos a serem 
consultados sobre 0 assunto, principalmente em língua portuguesa. Alguns sistemas estruturais, por exemplo, são apenas citados na literatura técnica, não havendo, portanto, nenhuma descrição mais detalhada sobre o comportamento estrutural ou sobre as particularidades dos processos de fabricação e montagem.

A literatura técnica apresenta relatos da construção de coberturas com diâmetros acima de $200 \mathrm{~m}$, como citam MAKOWSKI (1984) e ZIELINSKI (1984). No Brasil, porém, os vão cobertos até o momento são bem mais modestos, variando entre 30 e 100m. Como exemplos de obras nacionais pode-se citar:

a) A cobertura metálica central do Shopping Pátio Higienópolis (Figura 1.1), em São Paulo, composta por duas cúpulas sobrepostas, onde foram utilizados perfis vazados de seção retangular com fechamento em vidro. $O$ diâmetro da cúpula inferior apresenta diâmetro de $26 \mathrm{~m}$ e a superior de $18 \mathrm{~m}$. 0 consumo de aço foi de $58 \mathrm{t}$.

b) A ópera do Arame em Curitiba, que apresenta uma cúpula com $34 \mathrm{~m}$ de diâmetro coberta por chapas de policarbonato transparente (Figura 1.2).

c) A cúpula do Ginásio Poliesportivo da cidade de São Carlos, no interior de São Paulo, que apresenta diâmetro de $80,4 \mathrm{~m}$ e consumo total de aço em torno de 340t (Figura 1.3). Uma característica interessante dessa estrutura é que ela possui uma plataforma para circulação de pessoas e instalação de equipamentos fixada a ela.

d) O Centro Regional de Eventos em São José do Rio Preto, no interior de São Paulo, que apresenta uma cobertura com diâmetro aproximado de $72 \mathrm{~m}$ e consumo de aço de $88 \mathrm{t}$ (Figura 1.4).

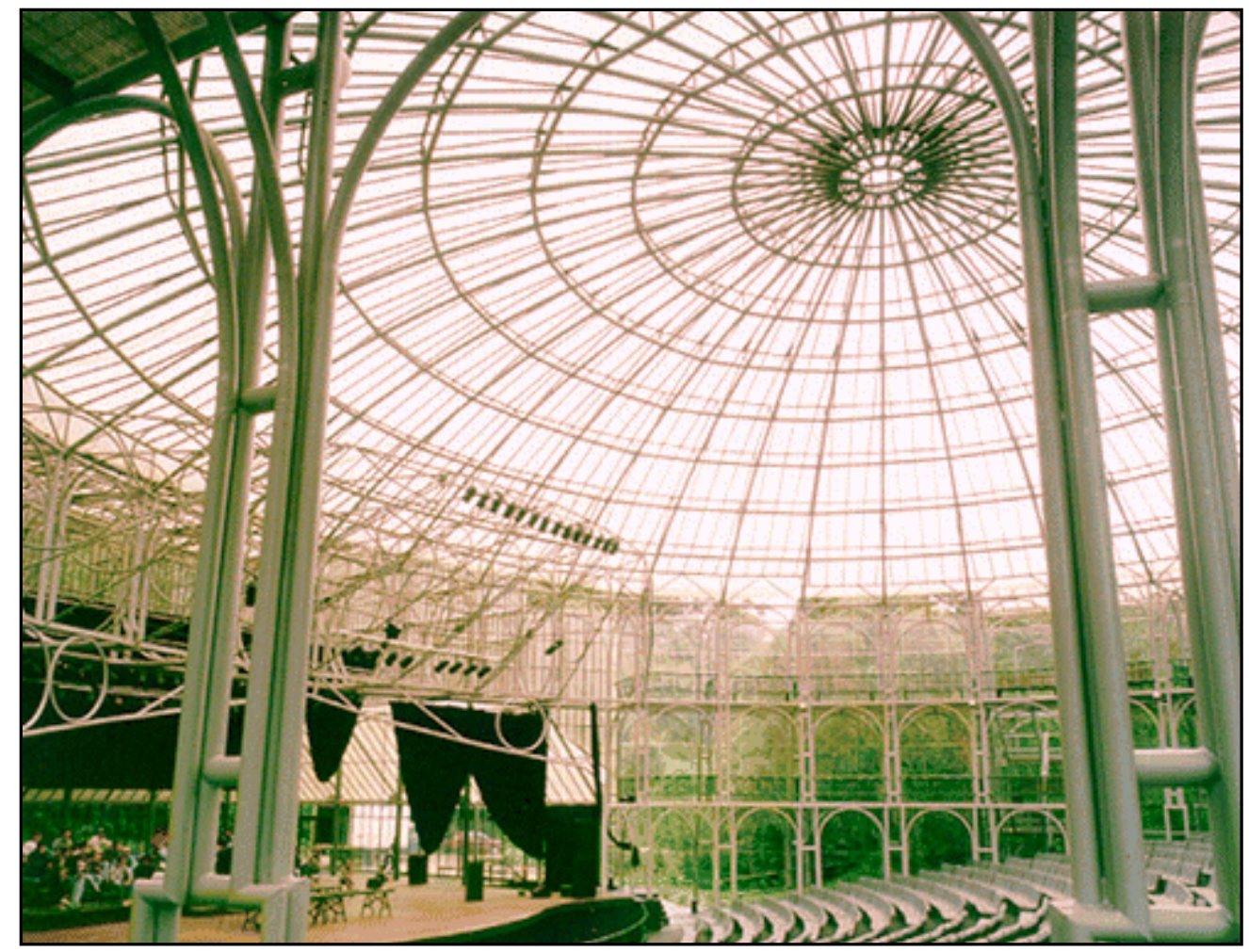

Figura 1.2 - Ópera do Arame em Curitiba - PR (Fonte: USIMINAS (1998)) 


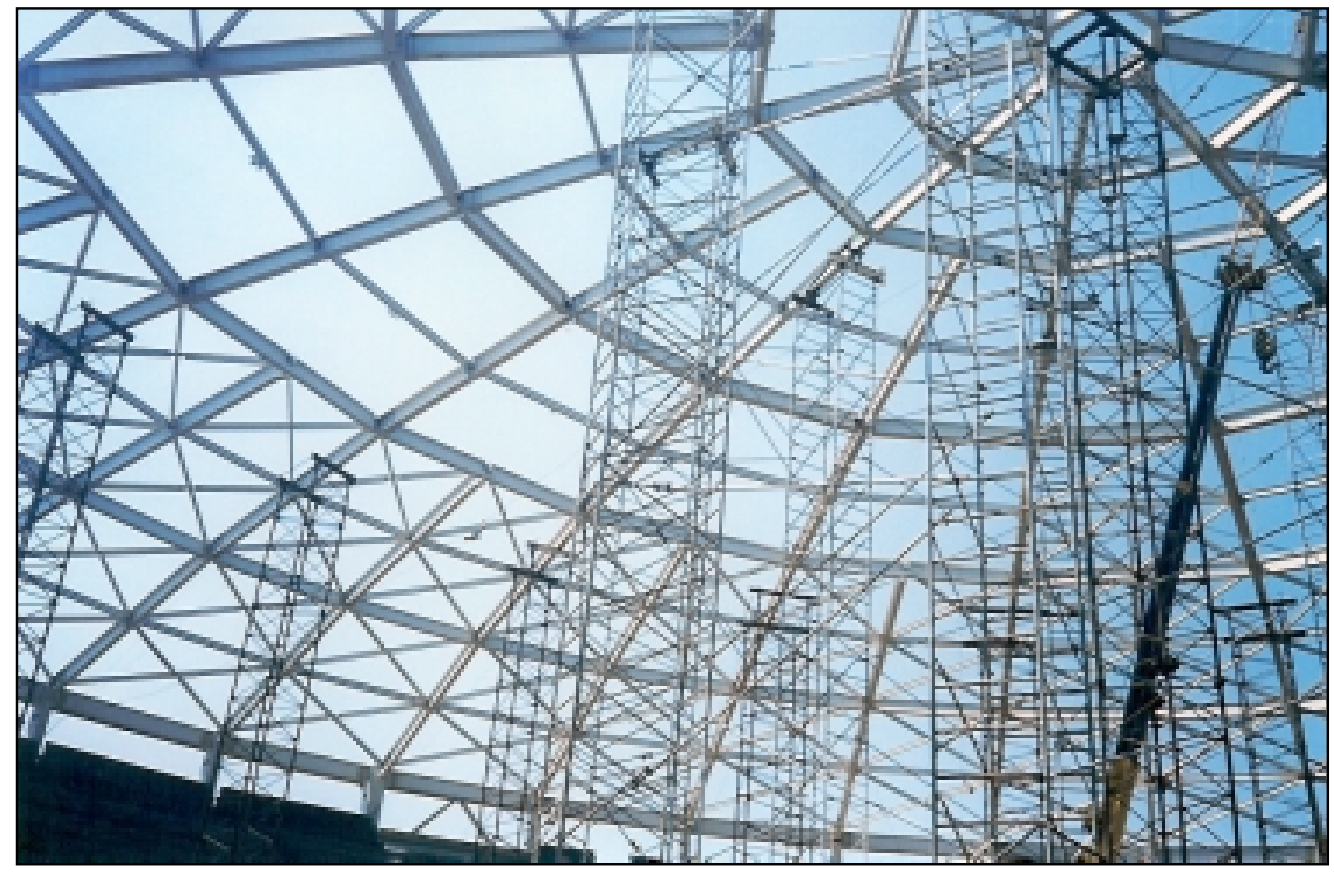

Figura 1.3 - Ginásio Poliesportivo de São Carlos (SP) (Fonte: Arquivo do autor)

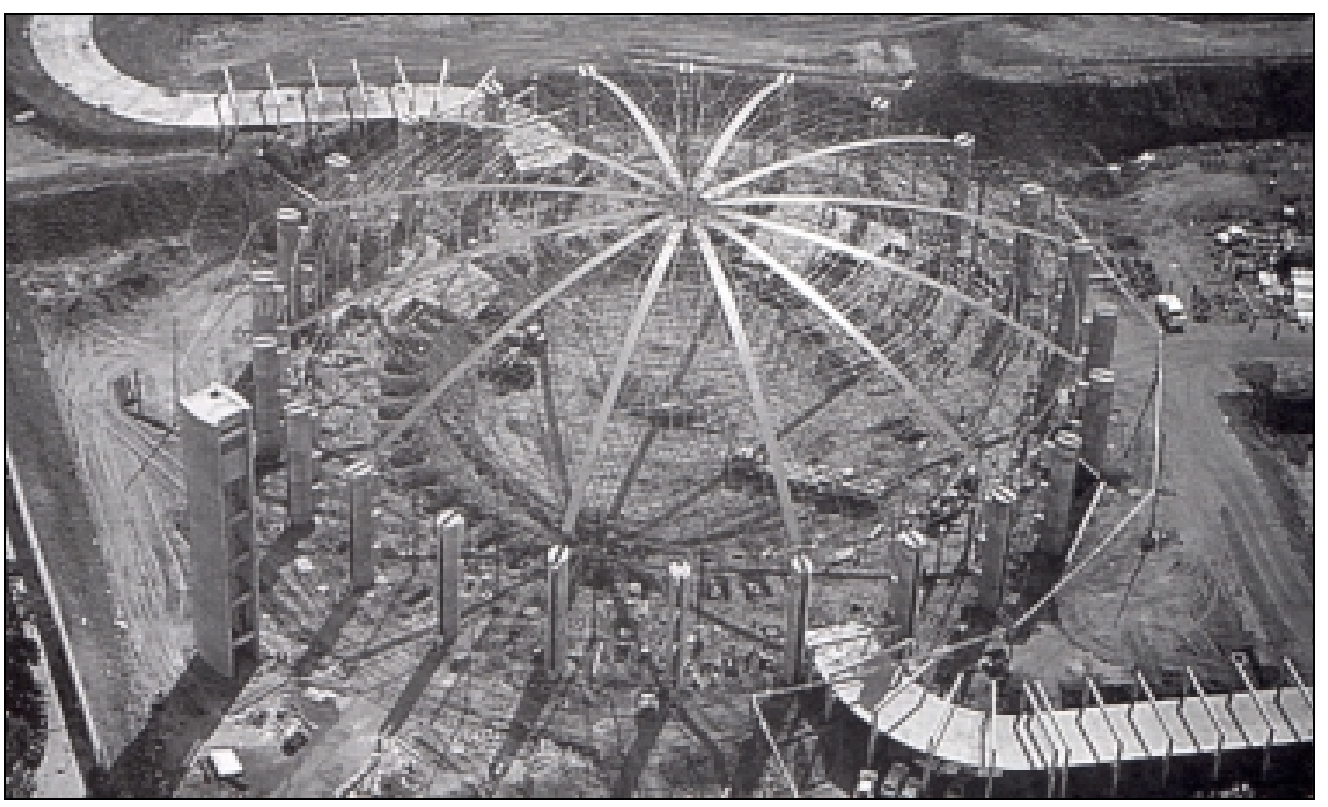

Figura 1.4 - Centro Regional de Eventos em São José do Rio Preto (SP) (Fonte: DIAIS (1997))

Cada uma dessas obras apresenta um sistema estrutural diferente. A Ópera do Arame, por exemplo, é composta por uma série de arcos em perfis tubulares de seção variável. Já a cobertura do Ginásio Poliesportivo de São Carlos é composta por perfis I em alma cheia e anéis horizontais, enquanto o Centro Regional de Eventos em São José do Rio Preto é composto por um reticulado tridimensional com perfis tubulares (estrutura espacial). 
Cada um desses sistemas estruturais apresenta características próprias no que se refere ao comportamento estrutural e aos processos de fabricação e montagem, e isso pode, dependendo do caso, gerar dúvidas para os profissionais que precisam projetar estruturas desse tipo e que precisam escolher uma entre as várias tipologias construtivas disponíveis.

\section{3 - Sobre as Contribuições Apresentadas}

Vários tópicos sobre as coberturas em cúpula podem ser objeto de estudo, muitos deles, inclusive, com relevância suficiente para serem temas de teses e dissertações.

Pelo fato de existem poucas publicações sobre cúpulas metálicas treliçadas no Brasil deu-se inicialmente um enfoque geral ao assunto, numa tentativa de fazer uma breve recapitulação dos sistemas estruturais existentes e em especial daqueles mais utilizados pela engenharia nacional. Deu-se, em seguida, uma maior atenção a um tipo específico de cobertura em cúpula, cujas características serão apresentadas mais adiante, que foi utilizado recentemente em algumas obras no interior do estado de São Paulo. Basta dizer, por enquanto, que nesse sistema estrutural o contraventamento pode ser executado de diferentes formas, e que isso tem grande implicação em seu comportamento.

Na proposta inicial de elaboração desta tese foram aventados vários itens para estudo, alguns deles relacionados com o projeto e o comportamento estrutural em si, e outros relacionados com a fase de construção e montagem, como consta em SANTOS (2002).

O estudo dos processos de construção e montagem, embora interessante e profícuo, foi logo descartado, uma vez que devido sua importância, abrangência e particularidades, mostrou-se merecedor de um trabalho específico. Sendo assim, este trabalho ficou limitado ao estudo de um determinado sistema estrutural de cobertura em cúpula, e as contribuições apresentadas ficaram inseridas no estudo das ligações e do contraventamento desse sistema.

O interesse em investigar tal influência fundamentou-se no fato de que, no sistema estudado, determinadas ligações podem ser projetadas como rígidas ou como articuladas, o que evidentemente acarreta modificações na distribuição de esforços, deslocamentos e no consumo de material.

Por outro lado, sabe-se de estudos realizados desde o início do século $\mathrm{XX}$, que nenhuma ligação desenvolve o comportamento idealizado normalmente admitido no projeto estrutural, e isso conduziu este trabalho à investigação da influência exercida pela rigidez das ligações no comportamento da estrutura.

As ligações foram estudadas sob dois aspectos diferentes, o primeiro deles relacionado com os critérios de dimensionamento usualmente adotados, e o segundo relacionado com a previsão do comportamento momento-rotação.

No primeiro caso o estudo conduziu ao aperfeiçoamento dos métodos de dimensionamento utilizados em algumas ligações, e no segundo à elaboração de modelos teóricos para descrição do comportamento momento-rotação. Vê-se, com isso, que algumas das contribuições apresentadas neste trabalho mostram-se relevantes para a construção metálica como um todo, e não apenas para a construção de cúpulas. 
De posse de uma ferramenta para descrição da curva momento-rotação das ligações, foi desenvolvido um estudo numérico para determinação da influência que elas exerciam na distribuição dos esforços internos e deslocamentos desse tipo de estrutura. Os resultados obtidos permitiram tirar conclusões que podem ser entendidas como contribuições ao assunto, uma vez que até então não haviam sido encontradas na literatura técnica.

\section{4 - Oportunidade de Desenvolvimento do Trabalho e sua Inserção nas Pesquisas do SET/EESC/USP}

Nos últimos anos o SET/EESC/USP1 esteve envolvido com consultorias na área de estruturas para grandes coberturas. Com base em observações feitas em campo e em consultas bibliográficas percebeu-se a necessidade de pesquisas que permitissem conhecer melhor 0 comportamento de tais estruturas. Para tanto, foram desenvolvidas até o momento três dissertações de mestrado e uma tese de doutorado sobre estruturas reticuladas tridimensionais de malha plana ${ }^{2}$, e uma dissertação de mestrado sobre estruturas reticuladas tridimensionais com malha curva ${ }^{3}$. Esses trabalhos originaram vários artigos nacionais e internacionais onde os resultados obtidos foram divulgados.

O trabalho aqui apresentado dá continuidade às pesquisas já desenvolvidas pelo SET/EESC/USP sobre grandes coberturas, abordando, desta vez, um sistema estrutural ainda não estudado no Brasil e muito pouco discutido na literatura internacional.

${ }^{1}$ Departamento de Engenharia de Estruturas da Escola de Engenharia de São Carlos da Universidade de São Paulo.

2 MAGALHÃES (1996), SOUZA (1998), MAIOLA (1999) e SOUZA (2003)

3 VENDRAME (1999) 


\section{REVISÃO BIBLIOGRÁFICA}

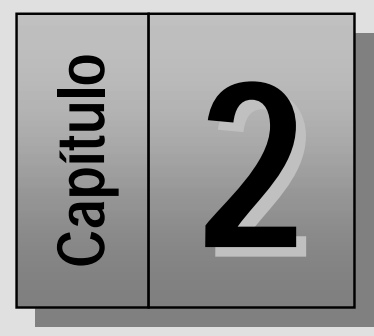

\section{1 - Definições}

Cúpulas são estruturas ditas espaciais ou tridimensionais, pois se desenvolvem no espaço tridimensional por meio da rotação ou translação de elementos unidimensionais, freqüentemente em arco ou em formas poligonais que se aproximam do arco. Apresentam superfície convexa, com dupla curvatura, o que as torna muito propícias para o uso em coberturas.

Dentre os diversos tipos de estruturas existentes na prática, as cúpulas podem ser consideradas como estruturas em casca, as quais recebem esse nome por conta da semelhança de sua geometria com alguns elementos encontrados na natureza, como a casca do ovo e o casco de alguns animais, como a tartaruga, por exemplo.

As cascas de revolução, que englobam os tipos de cúpulas estudados neste trabalho, são obtidas pela rotação de uma curva em torno de um eixo, como mostrado na Figura 2.1 (a). Outros tipos de cascas são obtidos pela translação de uma curva, como indicado na Figura 2.1(b).

A casca é chamada de cúpula quando o eixo de rotação é vertical e a curva geratriz intercepta esse eixo durante a rotação. A curva geratriz, ou de revolução, é chamada de meridiano, e o plano que a contém de plano meridiano da superfície. Os planos horizontais que cortam a casca são chamados de paralelos (vide Figura 2.1(a)).

Dependendo do tipo de carregamento aplicado, a existência de curvaturas normalmente confere grande rigidez, eficiência e economia a esse tipo de estrutura, pois permite que as cargas aplicadas na superfície sejam transmitidas aos apoios apenas por meio de tensões de tração e compressão, 0 que permite reduzir consideravelmente o consumo de material. 


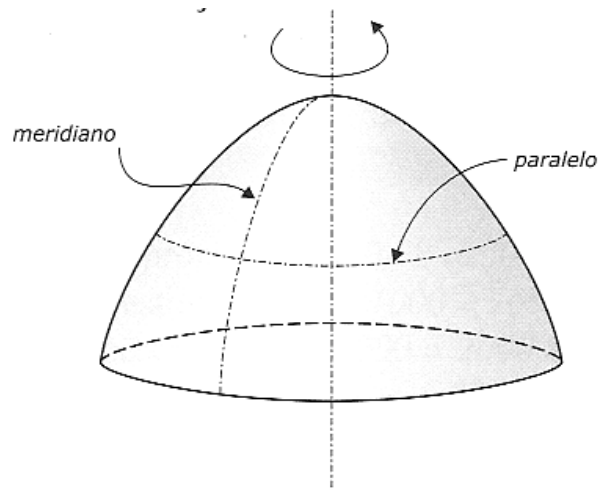

a) Casca de revolução (obtida por rotação de uma curva em torno de um eixo) - Fonte: MARGARIDO (2003)

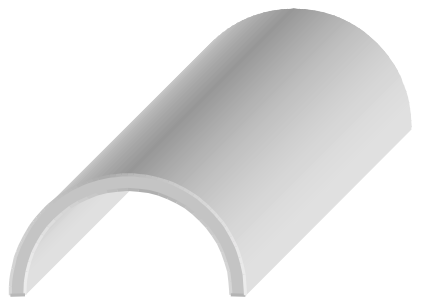

b) Casca cilíndrica (obtida por translação de uma curva)

Figura 2.1 - Cascas de revolução e translação

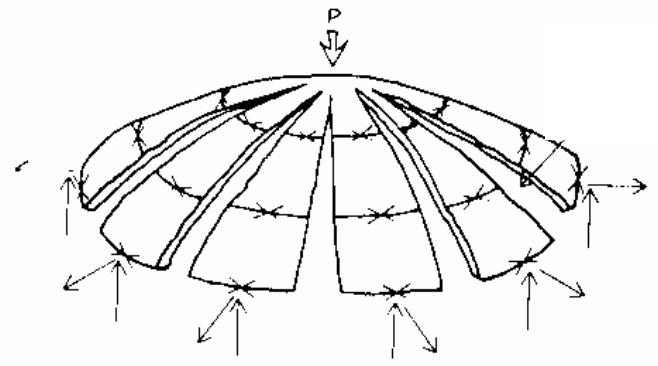

Figura 2.2 - Ruptura dos meridianos (Fonte: LIN \& STOTESBURY (1988))

\section{2 - Classificação das Cúpulas}

As cúpulas podem ser classificadas de diversas formas, como será visto neste item. Os sistemas de classificação existentes são muito genéricos, de forma que uma única cúpula pode ser encaixada em vários deles.

\subsection{1 - Classificação Quanto à Flecha}

Com relação à flecha, GUERRIN (sem data) classifica as cúpulas em abatidas, em arco pleno e em elevadas, como mostra a Figura 2.3.

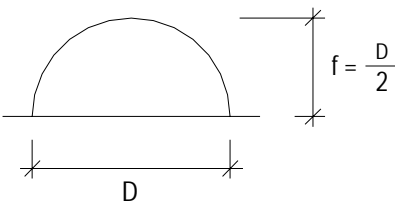

b) Cúpula em Arco Pleno
As cascas de revolução são especialmente eficientes graças à existência da dupla curvatura, pois a superfície que se origina da rotação de uma curva em torno de um eixo é do tipo não desenvolvível, ou seja, não pode ser retificada ou aplainada sem que ocorra ruptura dos meridianos, como mostra a Figura 2.2. a) Cúpula Abatida

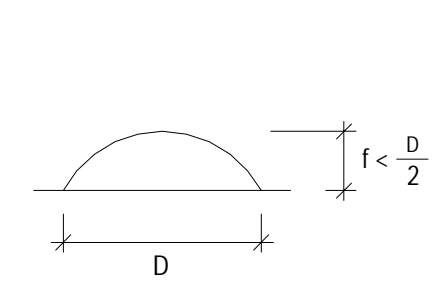

a) Cúpula Abatida

Figura 2.3 - Classificação das cúpulas quanto à flecha 
A altura da cúpula tem considerável influência no consumo de material e na distribuição de esforços internos na estrutura. Quanto mais próxima da configuração hemisférica for sua geometria, menores serão os esforços internos, e quanto mais abatida, maiores os esforços.

Tudo isso influi no consumo de material, pois aumentando a flecha necessita-se de peças menos robustas, porém de maior comprimento; enquanto que diminuindo a flecha precisa-se de peças de menor comprimento, porém de seção transversal mais robusta. A situação que fornece o menor volume de material depende de diversos fatores, entre os quais pode-se citar o tipo e a intensidade do carregamento aplicado. Na prática é usual trabalhar com relações $f / D$ variando de $1 / 10$ a $1 / 5$. (SÁLES et al. (1994))

\subsection{2 - Classificação Quanto à Forma em Planta}

Segundo a forma em planta as cúpulas podem ser classificadas como:

a) Cúpulas em planta circular.

b) Cúpulas de planta elíptica.

c) Cúpulas em planta poligonal.

A Figura 3.4 fornece alguns exemplos.

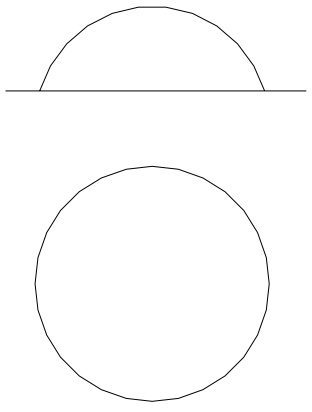

a) Cúpula em Planta Circular
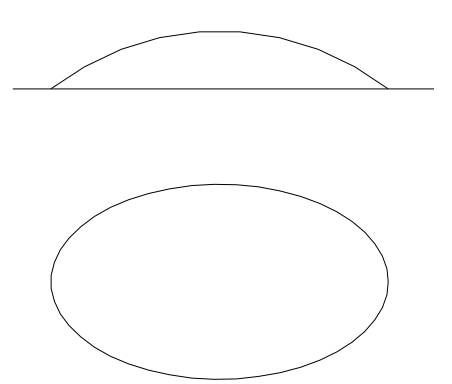

b) Cúpula em Planta Elíptica
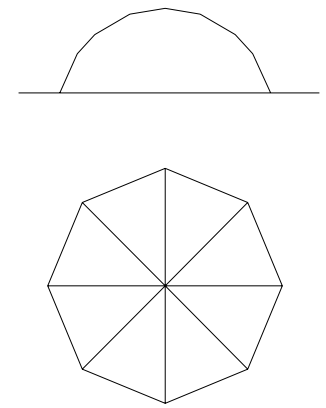

c) Cúpula em Planta Poligonal

Figura 2.4 - Classificação das cúpulas quanto à forma em planta

A Figura 2.4(c) ilustra uma cúpula em planta octaédrica, porém outros polígonos podem ser utilizados como base desse tipo de cobertura. Nas cúpulas metálicas, em especial, que utilizam freqüentemente elementos pré-fabricados unidimensionais para comporem toda a estrutura, as plantas poligonais são muito comuns. Alguns polígonos muitas vezes apresentam tantos lados que dão um aspecto aproximadamente curvo à planta.

\subsection{3 - Classificação Quanto à forma dos meridianos}

Qualquer curva pode ser utilizada para gerar cascas de revolução, e, conforme a equação da curva geratriz utilizada, as cúpulas podem ser classificadas em:

a) Cúpula com meridianos circulares.

b) Cúpula com meridianos elípticos. 
c) Cúpula com meridianos parabólicos.

d) Cúpula em forma de ogiva.

e) Cúpula em forma cônica.

A Figura 2.5 ilustra esses tipos de cúpulas.

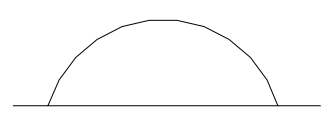

a) em forma circular

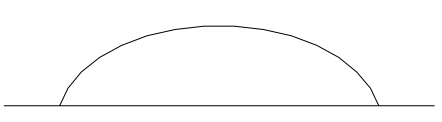

b) em forma elíptica

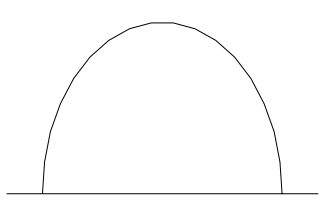

c) em forma parabólica

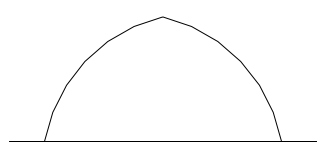

d) em forma de ogiva

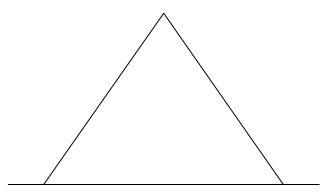

e) em forma cônica

Figura 2.5 - Classificação das cúpulas quanto à forma dos meridianos

\subsection{4 - Classificação Quanto à forma construtiva}

Com relação à forma construtiva as cúpulas podem ser classificadas em monolítica, se forem empregados materiais como o concreto e a argamassa armada, que permitem distribuir massa em toda a extensão da estrutura, e em reticuladas, se forem empregados elementos estruturais discretos, como costuma ocorrer nas estruturas metálicas e nas estruturas de madeira. A Figura 3.6 ilustra esse tipo de classificação.

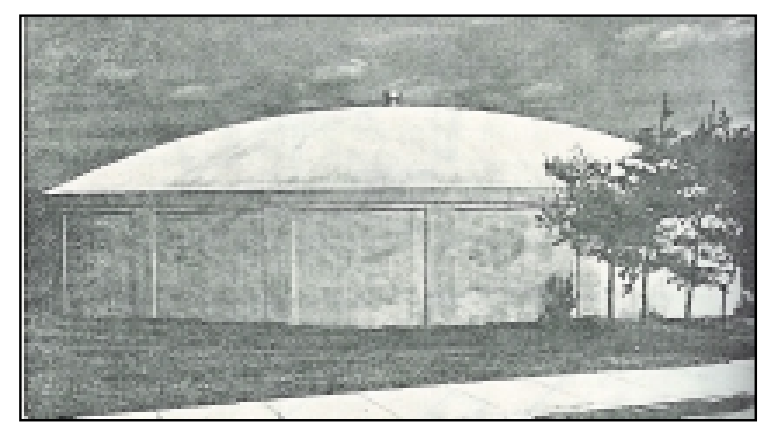

a) Cúpula monolítica (Fonte: BILLINGTON (1982))

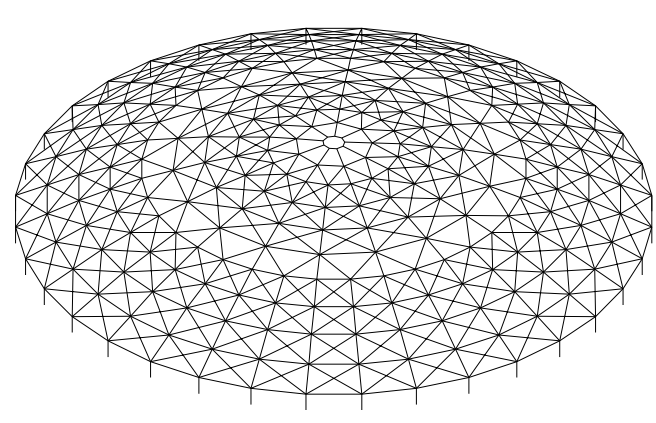

b) Cúpula treliçada

Figura 2.6 - Classificação das cúpulas quanto à forma construtiva

Eventualmente é possível construir cúpulas metálicas monolíticas, como mostra a Figura 2.7. № entanto, por questões de praticidade e economia, as cúpulas metálicas normalmente são executadas em sistemas estruturais treliçados, principalmente nos casos onde se tem grandes áreas a serem cobertas. 


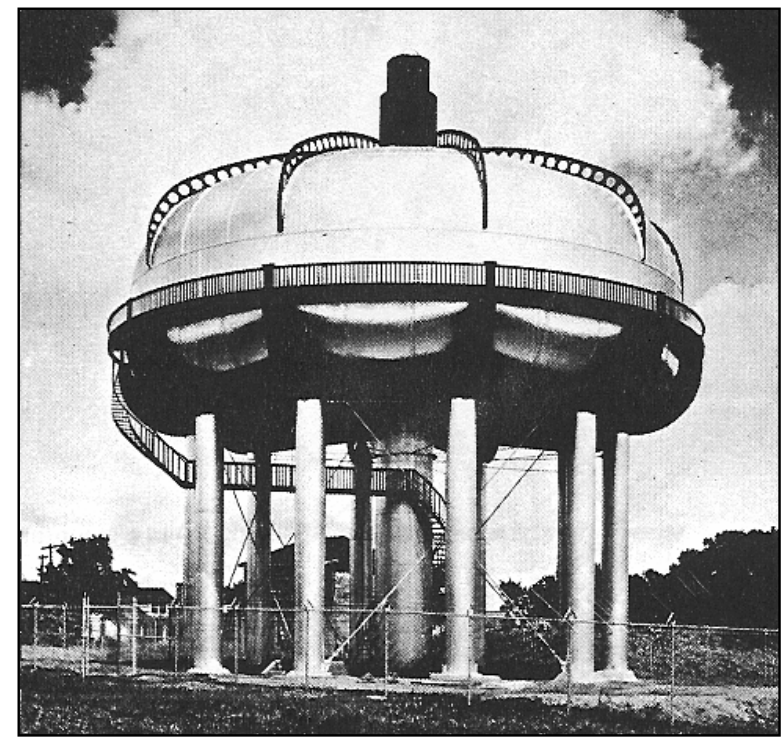

Figura 2.7 - Cúpula metálica contínua (Fonte: PFEIL (1986))

Ainda com relação às disposições construtivas, as cúpulas podem ter espessura constante ou variável, independentemente de serem monolíticas ou treliçadas.

As cúpulas treliçadas ainda são divididas em um grande número de tipos e subtipos, como será visto mais adiante.

\subsection{5 - Classificação Quanto à disposição do vértice}

De uma maneira geral, as cúpulas podem ter o vértice fechado ou aberto, como ilustrado na Figura 2.8. Em alguns tipos de cúpulas reticuladas o vértice costuma ser aberto, pois isso facilita bastante 0 processo de montagem. As cúpulas abertas normalmente suportam uma outra cúpula em seu topo, de modo a permitir a vedação da cobertura, e, em alguns casos, auxiliar na iluminação interna da edificação.

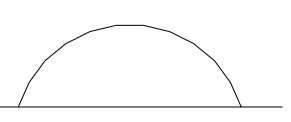

a) Cúpula fechada

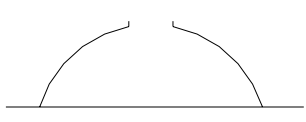

b) Cúpula aberta

Figura 2.8 - Classificação das cúpulas quanto à disposição do vértice

\section{3 - Breve Resumo do Comportamento das Cascas de Revolução}

Como foi visto no início deste capítulo, seccionando uma casca de revolução por dois planos, um vertical e outro horizontal, definem-se respectivamente os meridianos e os paralelos da superfície. Uma vez carregada a casca, os meridianos tendem a se movimentar na direção perpendicular a superfície e são impedidos pelos paralelos, que funcionam como anéis horizontais de travamento. Esse efeito permite que surjam na casca apenas tensões de tração, compressão e cisalhamento, situação esta que é conhecida como "estado de membrana". 
As cascas com comportamento de membranas são mais fáceis de calcular e resultam em estruturas mais leves, pois, não havendo tensões de flexão, é possível aproveitar o máximo do material.

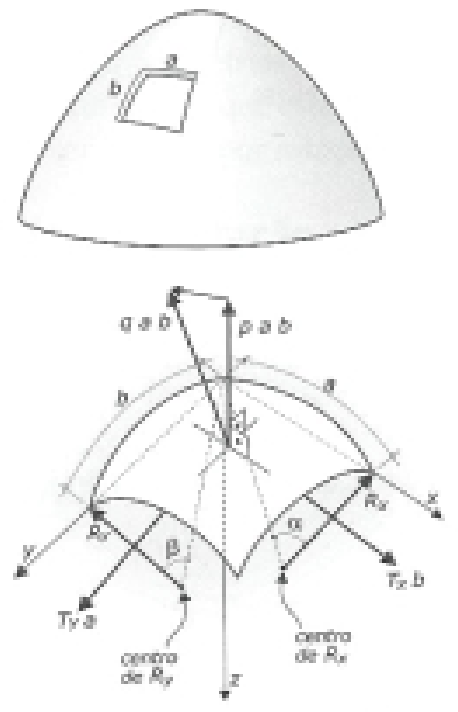

Figura 2.9 - Elemento de casca (Fonte: MARGARIDO (2003))
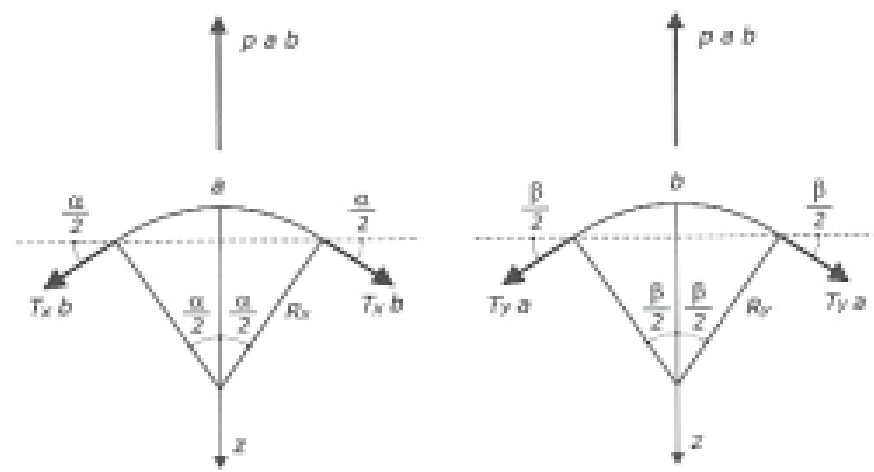

Figura 2.10 - Vistas do elemento de casca em estudo (Fonte: MARGARIDO (2003))

Estabelecendo o equilíbrio:

$2 \cdot T_{x} \cdot b \cdot \operatorname{sen}\left(\frac{\alpha}{2}\right)+2 \cdot T_{y} \cdot a \cdot \operatorname{sen}\left(\frac{\beta}{2}\right)=p \cdot a \cdot b$

Como os ângulos $\alpha$ e $\beta$ são pequenos pode-se fazer $\operatorname{sen} \alpha=\alpha$ e $\operatorname{sen} \beta=\beta$, e, pela definição de comprimento de arco:

$$
\alpha=\frac{a}{R_{x}} \text { e } \beta=\frac{b}{R_{y}}
$$
permitem visualizar melhor o elemento de casca em estudo. para demonstrar matematicamente porque as coberturas em cúpula são tão apropriadas para cobrirem grandes áreas, seja um elemento de casca para o qual será feito 0 equilíbrio de forças (Figura 2.9).

Para o elemento indicado, $q$ é a carga na área e $p$ a componente dessa carga segundo a direção normal à superfície. $R_{x}$ e $R_{y}$ são, respectivamente, os raios de curvatura nas direções x e y, e $T_{x}$ e $T_{y}$ as componentes de força por unidade de comprimento que equilibram a carga aplicada no elemento.

A Figura 2.10 fornece vistas laterais que casca em estudo.

Apenas para ilustrar a teoria de membranas, e 
Com isso encontra-se a Eq. 2.2, que é a equação básica da teoria de membranas, por meio do seguinte desenvolvimento:

$$
\begin{aligned}
& 2 \cdot T_{x} \cdot b \cdot \frac{\alpha}{2}+2 \cdot T_{y} \cdot a \cdot \frac{\beta}{2}=p \cdot a \cdot b \\
& 2 \cdot T_{x} \cdot b \cdot \frac{a}{2 \cdot R_{x}}+2 \cdot T_{y} \cdot a \cdot \frac{b}{2 \cdot R_{y}}=p \cdot a \cdot b \\
& \frac{T_{x}}{R_{x}}+\frac{T_{y}}{R_{y}}=p
\end{aligned}
$$

Com o auxílio da Eq. 2.2 pode-se observar que se a curvatura gaussiana é nula, o que ocorre quando uma das curvaturas $\left(\frac{1}{R_{x}}\right.$ ou $\left.\frac{1}{R_{y}}\right)$ é igual a zero, a distribuição da força radial externa fica restrita a apenas uma curvatura e torna-se menos eficiente. Por esse motivo as cascas com dupla curvatura são mais resistentes que as de curvatura simples, e por isso são tão propícias para cobertura de grandes áreas.

Para que a casca se comporte como uma membrana o projeto estrutural deve atender os seguintes requisitos:

a) A casca deve ser delgada, de espessura constante ou com variação suave e gradativa (sem variações bruscas).

b) A superfície deve ser contínua e a curvatura deve variar de forma gradativa e suave.

c) Os carregamentos devem ser distribuídos e não devem apresentar variações bruscas de intensidade.

d) Os apoios da casca devem ser adequados, de modo a desenvolverem apenas reações de membrana, ou seja, que se desenvolvem no plano tangente à casca.

Se essas condições não forem atendidas surgirão tensões de flexão na borda ou em toda a extensão da casca, e aí a teoria de membranas não será suficiente para realização do cálculo.

Seja agora uma casca esférica sujeita ao seu próprio peso, para a qual deseja-se conhecer a influência das condições de apoio e a distribuição de tensões nos meridianos e paralelos. Sob a ação do carregamento a casca deforma-se e alguns paralelos tendem a diminuir de tamanho enquanto outros tendem a aumentar (Figura 2.11). Isso significa que os paralelos da parte superior (que tendem a diminuir) estão comprimidos, enquanto os paralelos da parte inferior (que tendem a aumentar) estão tracionados. 


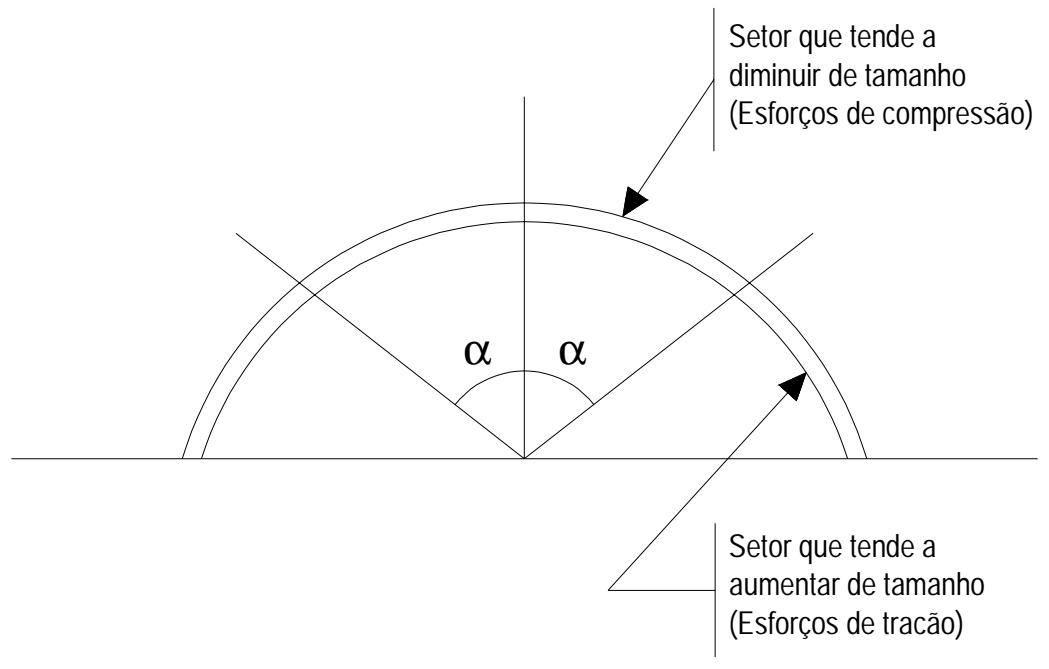

Figura 2.11 - Casca esférica sujeita ao peso próprio

Fazendo o equilíbrio e utilizando a equação básica da teoria de membranas é possível demonstrar que as forças nos meridianos e paralelos de largura unitária são dadas pelas Eqs. 2.3 e 2.4 , respectivamente. As tensões são obtidas dividindo as forças distribuídas nesses elementos pela espessura da casca.

$T_{m}=-R q \frac{1}{1+\cos \alpha}$

$T_{p}=R q\left(\frac{1}{1+\cos \alpha}-\cos \alpha\right)$

Analisando a Eq. 2.3 observa-se que a tensão meridiana (calculada a partir de $T_{m}$ ) cresce de cima para baixo, variando de $-\frac{R q}{2}$, quando $\alpha=0$ (no topo da casca), até o valor máximo localizado na base, dado por $-R q \frac{1}{1+\cos \alpha}$.

Se a casca for uma meia esfera as tangentes extremas (na base) serão verticais e, com isso, as tensões meridianas também o serão. Se, contudo, essas tangentes não forem verticais e os apoios não acompanharem a inclinação da casca, haverá uma componente horizontal de $T_{m}$ uniformemente distribuída ao longo do paralelo de borda, tornando necessária a existência de um anel enrijecedor para absorver esse esforço.

As Figuras 2.12 e 2.13 ilustram duas situações diferentes de apoio de cascas não hemisféricas, uma com apoios inclinados e outra com anel de borda. 


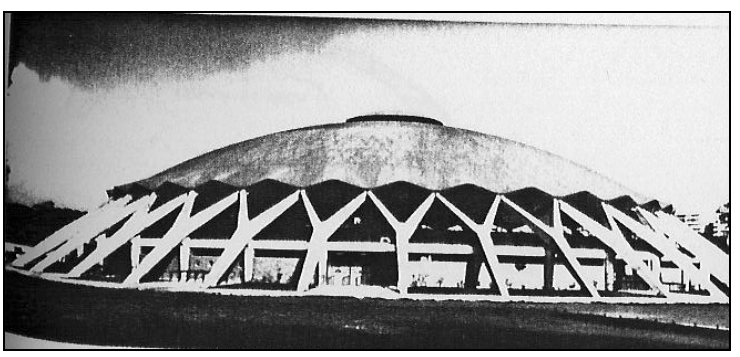

Figura 2.12 - Apoios inclinados (Fonte: LIN \& STOTESBURY(1981))

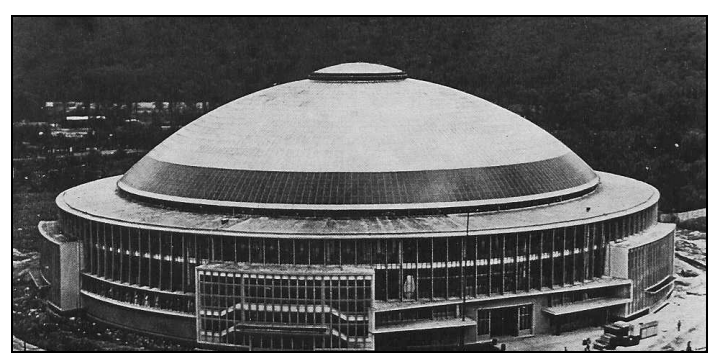

Figura 2.13 - Apoios com anel de borda (Fonte: MAKOWISKY(1980))

Analisando agora as tensões nos paralelos, convém calcular a raiz da Eq. 2.4, pois ele representa 0 ponto onde ocorre a inversão da solicitação. Fazendo, então:

$T_{p}=R q\left(\frac{1}{1+\cos \alpha}-\cos \alpha\right)=0$

obtém-se $\alpha=51^{\circ} 50^{\prime}$, que funciona com uma linha neutra dos paralelos da casca. Assim, para que toda a casca esteja sujeita a tensões de compressão, tanto nos meridianos quanto nos paralelos, a abertura angular máxima deve ser de 103040', como mostra a Figura 2.14. É bom lembrar que, como essa situação não corresponde a de uma meia esfera, haverá sempre a necessidade do anel de borda para absorver a componente horizontal de $T_{m}$, isso se os apoios não forem inclinados.

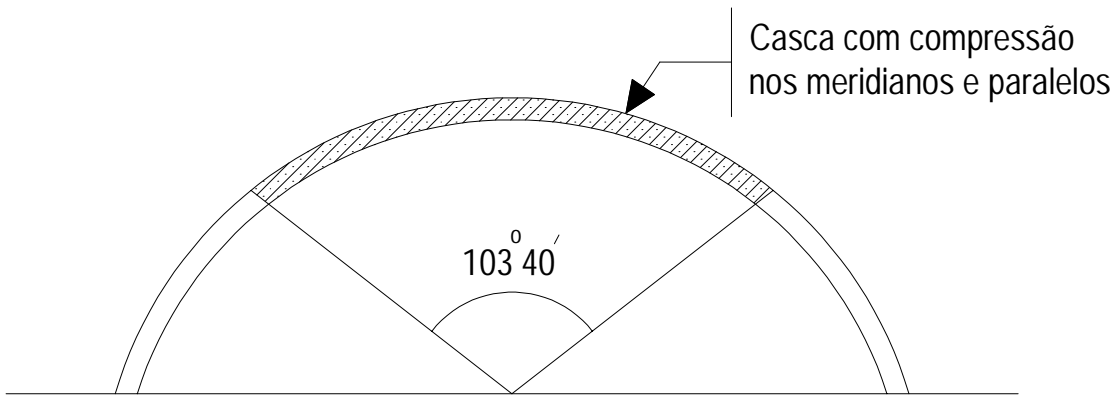

Figura 2.14 - Casca com compressão nos meridianos e nos paralelos

Quando os apoios não são inclinados ocorre um fenômeno conhecido como perturbação de borda, que é caracterizado pelo surgimento de tensões de flexão na região dos apoios, decorrentes do impedimento do deslocamento radial, como mostra a Figura 2.15.
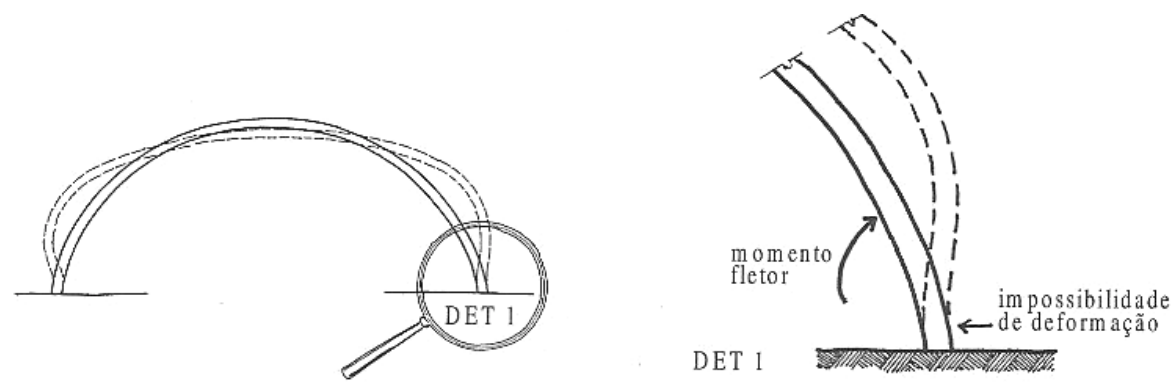

Figura 2.15 - Perturbação de borda (Fonte: REBELLO(2003)) 
Esse impedimento gera uma reação horizontal $H$, que por não ser tangente à casca desperta um momento fletor nas proximidades dos apoios, o que pode ser facilmente observado pela mudança de curvatura da deformada nessa região (Figura 2.15). Essa perturbação, no entanto, ocorre apenas nas proximidades dos apoios e não se propaga para o restante da estrutura, onde predomina 0 estado de membrana. Segundo REBELLO (2003) vários fatores podem provocar perturbação de borda, um deles é o aumento da temperatura, cujo efeito pode ser até três vezes superior ao efeito do carregamento vertical.

Se a estrutura não atender plenamente as condições necessárias para o estado de membrana terse-á o caso de casca resistente à flexão, situação esta que é caracterizada pela existência de momentos fletores e forças cortantes que perturbam o estado de membrana. Essas perturbações ocorrem principalmente nos locais onde existe variação brusca da espessura ou do plano tangente da casca, e, tal qual se verifica para a perturbação de borda, também apresentam caráter localizado e se dissipam à medida que se afastam do ponto causador da perturbação. Por esse motivo, VASCONCELOS (1991) afirma que "é possível imaginar o estado total de tensões como constituído pela superposição do estado de tensões de membrana com o estado de tensões produzido pelos momentos e forças que atuam no contorno da zona perturbada".

Obviamente que o estudo das cascas é muito mais amplo do que o que apresentado nesta seção, contudo, não há necessidade de maiores informações por enquanto. O leitor interessado em se aprofundar no assunto pode recorrer a TIMOSHENKO \& KRIEGER (1959), DARKOV (1960), BILLINGTON (1982) e VIEIRA (2003). Na próxima seção serão estudadas as cúpulas metálicas, que são chamadas por muitos autores de cascas treliçadas.

\section{4 - Sobre as Cúpulas Treliçadas}

Uma casca treliçada (ou reticulada) é definida pela forma resultante da aproximação de uma casca contínua por uma malha composta por elementos lineares de pequeno comprimento, como mostrado na Figura 2.6 (b). Esse tipo de estrutura resiste aos esforços atuantes de maneira similar a das cascas monolíticas delgadas, ou seja, por forças normais e por flexão, conforme discutido anteriormente.

A forma como os elementos lineares são dispostos ao longo da superfície da casca dá origem a vários sistemas estruturais que apresentam comportamentos diferentes e muitas particularidades, sendo necessário estudar cada um deles isoladamente. $O$ item a seguir descreve os principais tipos de cascas metálicas reticuladas ou treliçadas, que serão chamadas daqui por diante simplesmente de cúpulas metálicas.

\subsection{1 - Tipos de Coberturas em Cúpula}

Durante os séculos XVIII e XIX várias configurações estruturais para construção de cúpulas foram desenvolvidas na Alemanha, França e Suíça. As primeiras a serem construídas apresentavam forma hemisférica, o que simplificava muito a construção, pois introduziam apenas reações verticais. A necessidade de reduzir a altura dessas estruturas forçou os profissionais da época a aperfeiçoarem os sistemas, o que culminou na melhoria de alguns e no abandono de outros.

Segundo MAKOWSKI (1984), de todos os tipos de cúpulas de planta circular desenvolvidos até hoje apenas seis continuam sendo utilizados, são eles: 
a) Cúpulas Nervuradas;

b) Cúpulas Schwedler;

c) Cúpulas "three-way";

d) Cúpulas de nós rígidos;

e) Cúpulas Lamelares;

f) Cúpulas Geodésicas.

Aos tipos citados anteriormente pode-se acrescentar também as cúpulas em reticulado tridimensional, mais conhecido como estrutura espacial, solução esta bastante comum no Brasil. Cada um desses sistemas está sucintamente descrito a seguir.

\subsubsection{1 - Cúpulas Nervuradas}

As cúpulas nervuradas são constituídas por vários elementos radiais de área e inércia bastante elevadas, chamados nervuras, sobre os quais apóiam-se anéis horizontais de área e inércia bastante inferiores, que servem de suporte para as placas de cobertura, como mostram as Figuras 2.16 e 2.17. Essa acentuada diferença nas propriedades geométricas entre nervuras e anéis é uma das características que diferencia o sistema nervurado de outros sistemas estruturais, como 0 Schewedler, por exemplo, que será discutido mais adiante.

É um dos sistemas estruturais mais antigos e que continua sendo utilizado até os dias atuais, o que se justifica principalmente pela facilidade de fabricação e montagem das nervuras, que apresentam, em geral, as mesmas dimensões.

Esse sistema funciona como se houvessem vários arcos de elevada resistência unidos no topo por um ponto em comum ou por um anel central, que normalmente serve de elemento de iluminação para a cobertura, conforme já explicado.

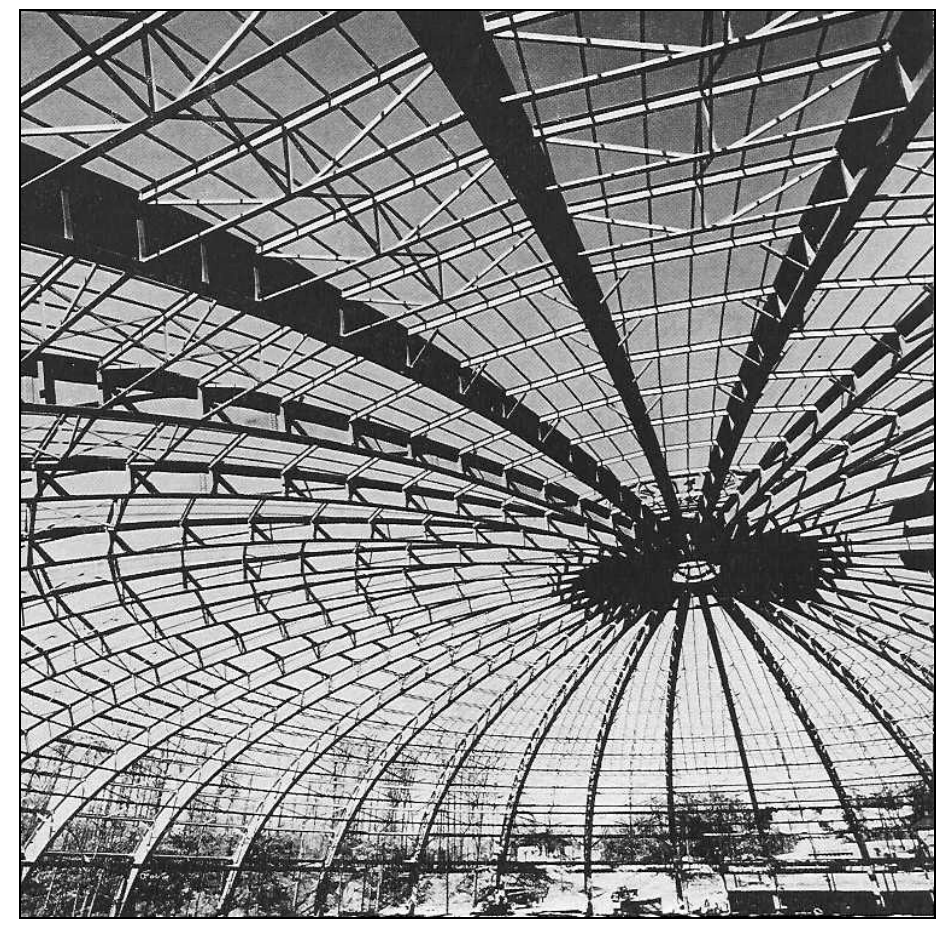

Figura 2.16 - Cúpula nervurada com anéis treliçados (Fonte: MAKOWSKI (1989)) 


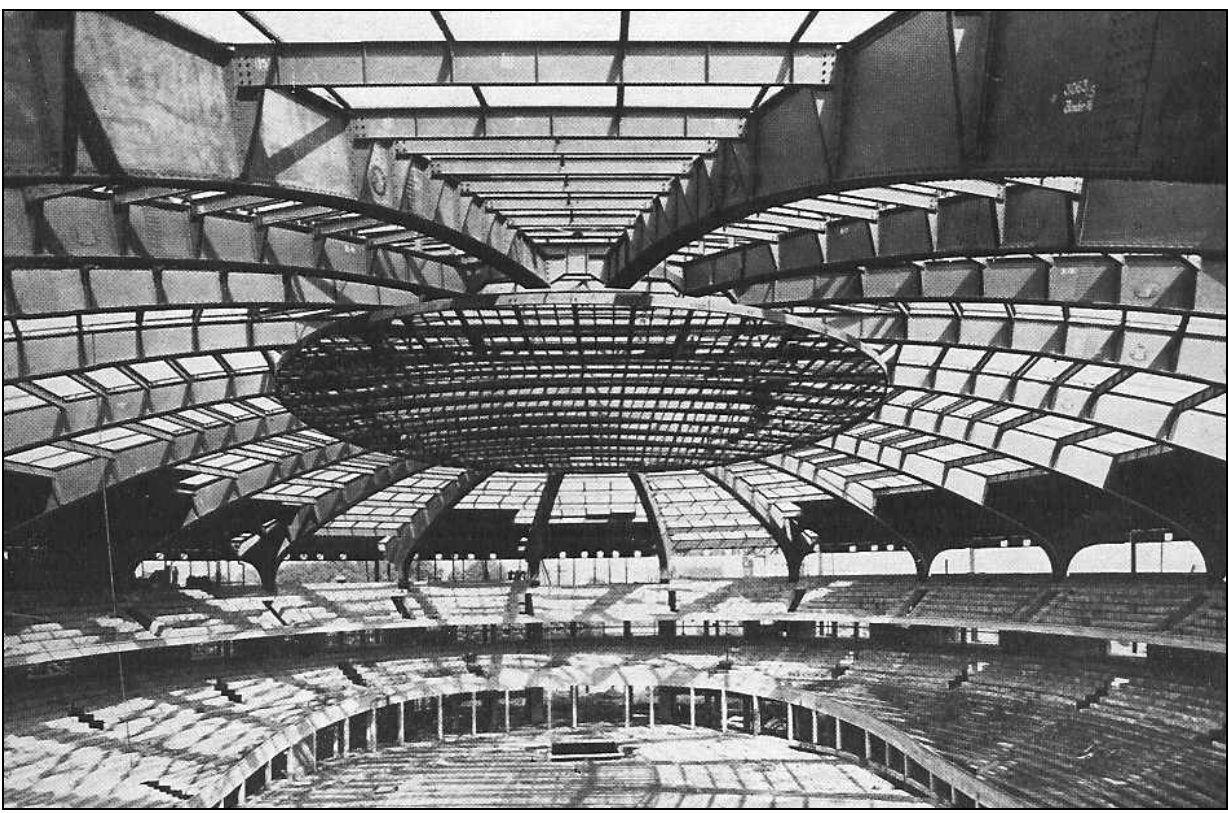

Figura 2.17 - Cúpula nervurada com anéis em alma cheia (Fonte: MAKOWSKI (1989))

Como a resistência dos anéis é bastante inferior a das nervuras, toda a estrutura comporta-se como um conjunto de arcos trabalhando independentemente, não apresentando, portanto, 0 comportamento de casca que se verifica em outros sistemas.

Para esclarecer esse comportamento é necessário estabelecer o conceito de funicular das forças, que é definido como a forma da estrutura para a qual, sob a atuação de um determinado carregamento, só atuam forças axiais de tração ou de compressão. Em outras palavras, a forma funicular define a geometria da estrutura para a qual o diagrama de momentos fletores resulta nulo.

A forma mais fácil de visualizar o funicular das forças é observando o comportamento de um cabo biapoiado, que por não possuir resistência à compressão ou à flexão é obrigado a mudar de forma de acordo com o carregamento que lhe é aplicado. Essa mudança de geometria faz com que o cabo resista ao carregamento desenvolvendo apenas tensões de tração, que é o único tipo de esforço que é capaz de suportar. Devido a essa característica os cabos são chamados de elementos flexíveis. A Figura 2.18 ilustra essa situação.
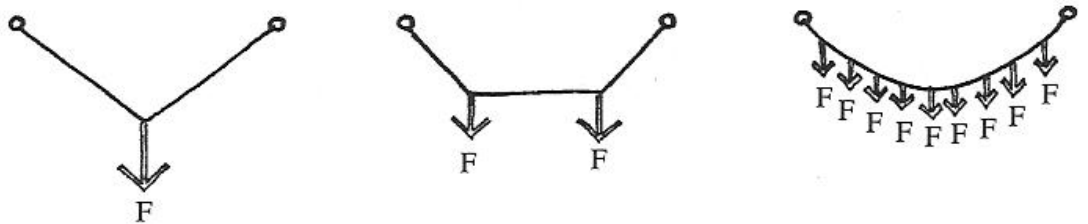

Figura 2.18 - Comportamento de um cabo biapoiado (Fonte: REBELLO (2003))

Aumentando a quantidade de cargas o cabo tende a assumir uma forma curva, o que dá origem a uma parábola, se as cargas forem igualmente espaçadas em relação ao eixo horizontal que liga os apoios, ou a uma catenária, se as cargas forem igualmente espaçadas em relação ao próprio eixo do cabo, como é o caso, por exemplo, da ação exercida pelo peso próprio. 
Adotando agora um elemento rígido, ou seja, capaz de absorver esforços de compressão, e invertendo a posição do cabo e das cargas em relação ao eixo horizontal que liga os apoios (Figura 2.19), obtém-se uma forma funicular correspondente onde só atuam tensões de compressão.
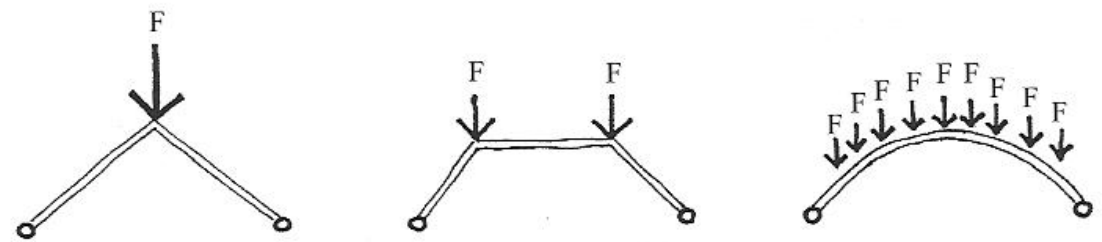

Figura 2.19 - Comportamento de um arco biapoiado (Fonte: REBELLO (2003))

Pode-se afirmar, então, que arcos e cabos possuem uma única forma funicular para um determinado carregamento, de modo que se a forma de aplicação desse carregamento for alterada, surgirão momentos fletores a menos que a estrutura possa se rearranjar geometricamente, como acontece com os elementos flexíveis (os cabos, por exemplo).

Voltando a tratar agora das cúpulas nervuradas que, como foi dito anteriormente, funcionam como um conjunto de arcos trabalhando independentemente um do outro, pode-se afirmar que haverá flexão nesses arcos a menos que os funiculares de todos eles coincidam entre si, o que é extremamente difícil de ocorrer dada a aleatoriedade das cargas que podem solicitar uma estrutura.

Quando os paralelos possuem resistência diminuta, como ocorre no sistema estrutural em discussão, os meridianos ficam sobrecarregados e acabam desenvolvendo tensões de flexão para resistirem aos esforços atuantes, o que dá origem a elementos de seção transversal avantajada.

Vê-se que, no caso das cúpulas nervuradas, os esforços de flexão surgem em decorrência de características funcionais da própria estrutura, e não apenas de fatores como perturbação de borda e variação brusca da inclinação da superfície como ocorre nas cascas delgadas.

\subsubsection{2 - Cúpulas Schwedler}

As cúpulas Schwedler foram introduzidas pelo engenheiro alemão J. W. Schwedler em 1863 e também continuam sendo bastante utilizadas até os dias atuais. Esse sistema surgiu como uma alternativa para redução da inércia dos arcos das cúpulas nervuradas, cujo dimensionamento sempre exigia seções transversais de grandes dimensões. Isso foi conseguido aumentando a resistência dos anéis e inserindo barras diagonais em cada setor da malha quadrangular resultante da união das nervuras com os anéis horizontais, como ilustrado na Figura 2.20.

Nesse sistema os anéis horizontais possuem dimensões compatíveis com as nervuras meridionais, o que permite que desenvolvam forças circunferenciais capazes de minimizar (ou mesmo eliminar) os momentos fletores na superfície da estrutura.

Ao contrário do sistema nervurado, o sistema Schwedler tem um comportamento semelhante ao de uma casca, sendo este o motivo pelo qual torna-se possível o uso de peças meridionais de seção mais reduzida. 


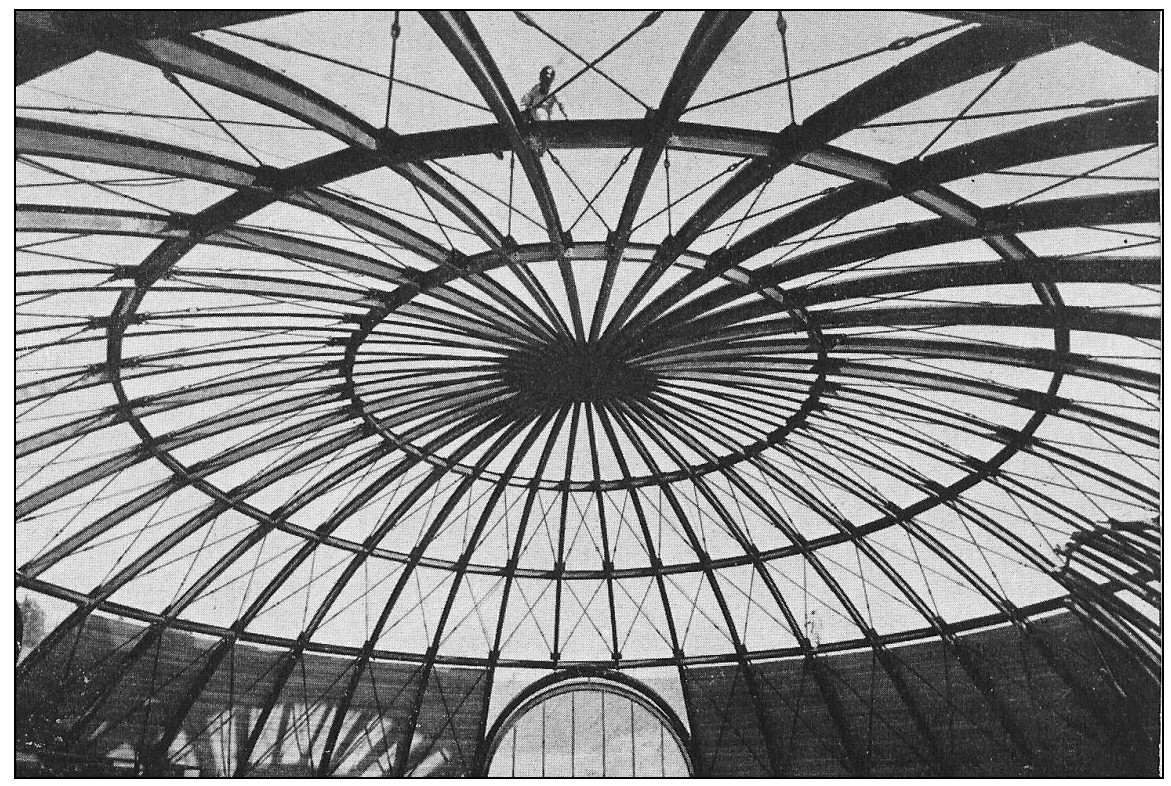

Figura 2.20 - Exemplo de cúpula Schwedler (Fonte: MAKOWSKI (1989))

No sistema Schwedler as diagonais trabalham apenas a tração, o que é conseguido utilizando barras de esbeltez bastante reduzida nesses elementos, de modo a fazer a barra comprimida perder estabilidade em regime elástico e sob baixo nível de carregamento, deixando, assim, que apenas a barra tracionada resista ao esforço aplicado. A Figura 2.21 ilustra essa situação.

Uma vez cessado o carregamento, a barra que perdeu estabilidade volta à sua posição original apta a flambar novamente caso 0 esforço volte a atuar, e apta a trabalhar à tração caso a solicitação se inverta.

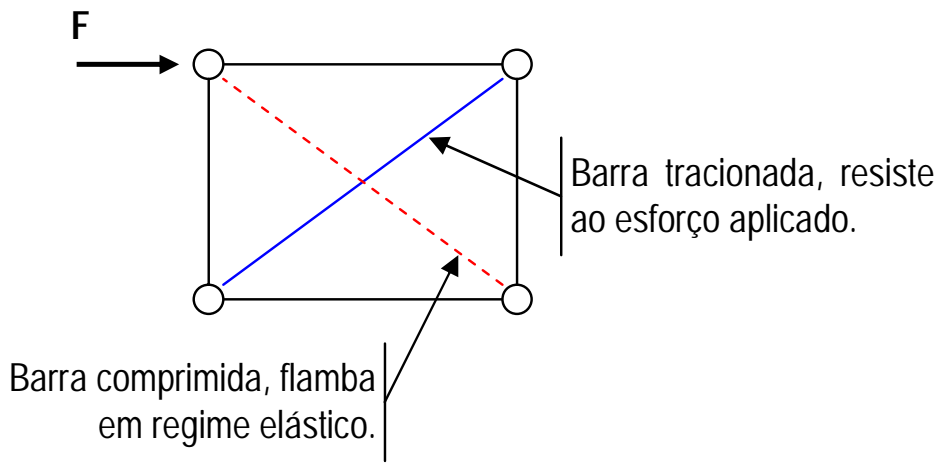

Figura 2.21 - Funcionamento dos elementos em diagonal do sistema Schwedler

Segundo MAKOWSKI (1984) esse sistema já foi utilizado na construção de cúpulas com diâmetros acima de $100 \mathrm{~m}$. No Brasil existe uma obra bastante interessante cuja disposição das barras lembra o sistema Schwedler, trata-se da cobertura do Ginásio Poliesportivo de São Carlos construído em 1998. A diferença nesse caso está nas diagonais (barras de contraventamento), que na obra nacional supracitada foram executadas com barras rígidas (que trabalham a compressão), de modo a propiciarem um maior enrijecimento da estrutura. 


\subsubsection{3 - Cúpulas com Malha em Três Direções (Three-Way)}

As cúpulas com malha triangular, ou em três direções, são constituídas por tubos curvos unidos em grupos de três elementos cuja união produz uma malha triangular tridimensional, como mostrado na Figura 2.22. A união desses grupos de elementos pode ser feita de várias formas, em geral utilizando dispositivos especiais que permitem o encaixe e a soldagem dos elementos.

Esse tipo de cúpula pode ter malha simples, como indicado na Figura 2.23, ou dupla, como indicado na Figura 2.24.

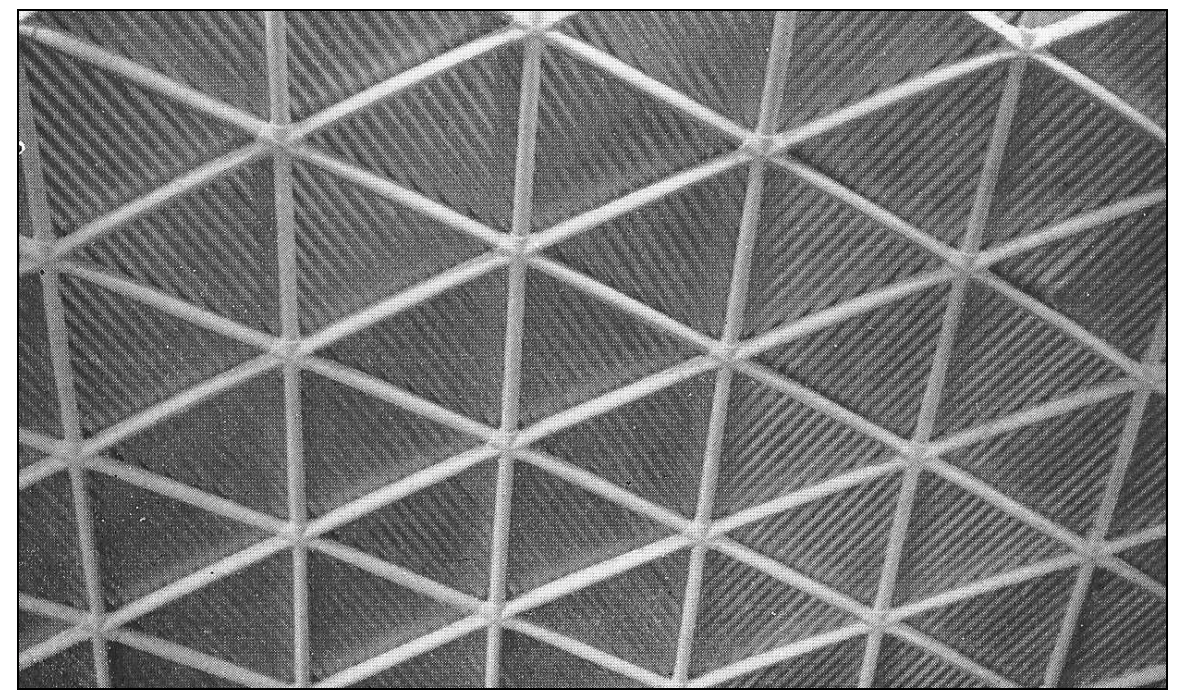

Figura 2.22 - Cúpula com malha em três direções (three-way) (Fonte: MAKOWSKI (1989))

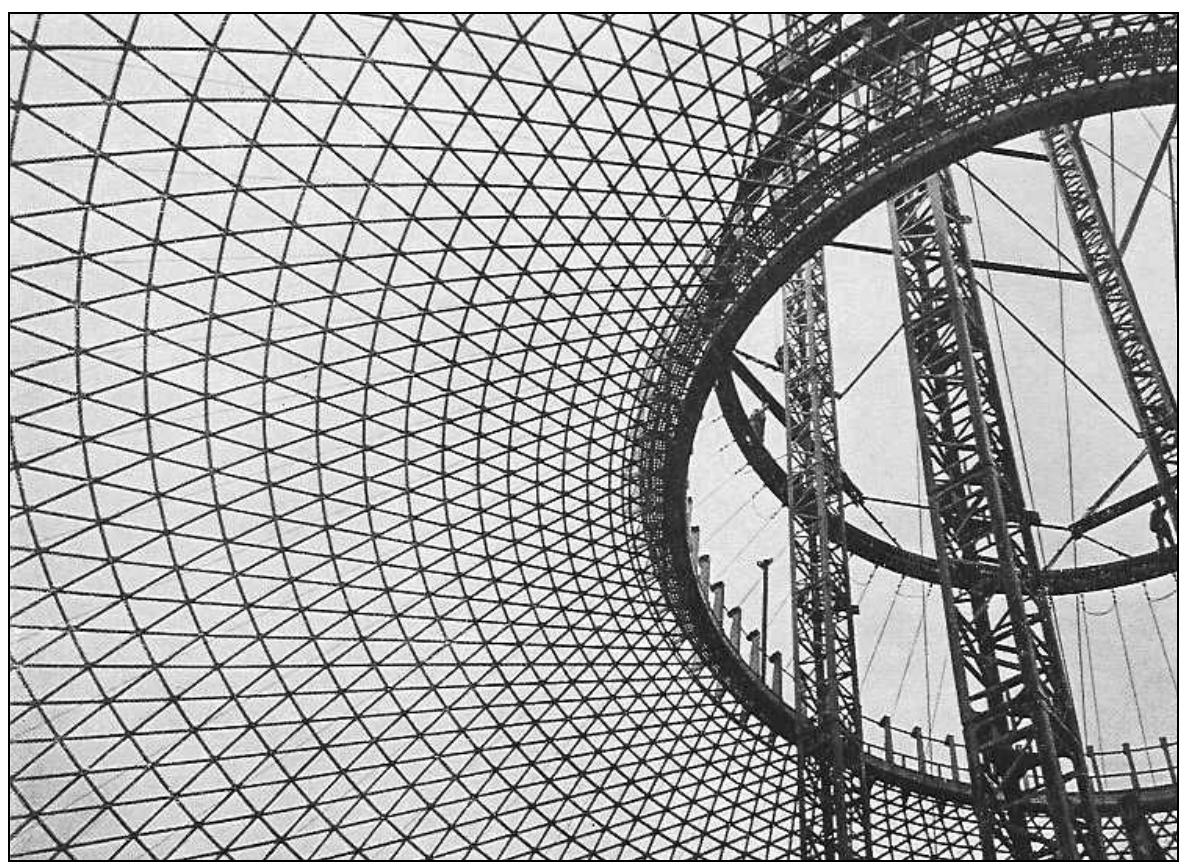

Figura 2.23 - Cúpula com malha simples em três direções (Fonte: MAKOWSKI (1989)) 


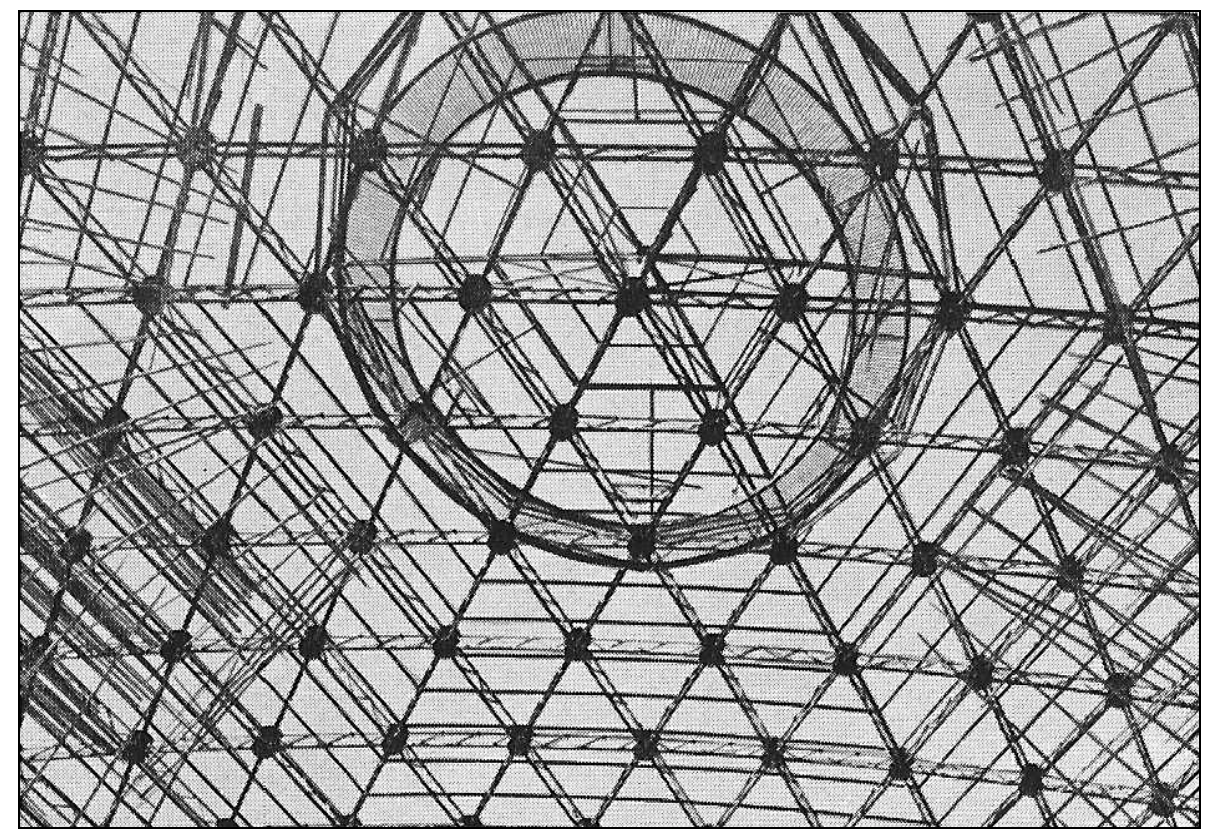

Figura 2.24 - Cúpula com malha dupla em três direções (Fonte: MAKOWSKI (1989))

\subsubsection{4 - Cúpulas de Nós Rígidos}

As cúpulas de nós rígidos são compostas por nervuras e anéis horizontais ligados rigidamente entre si, e não apresentam elementos diagonais nos setores quadrangulares da malha, como indicado na Figura 2.25.

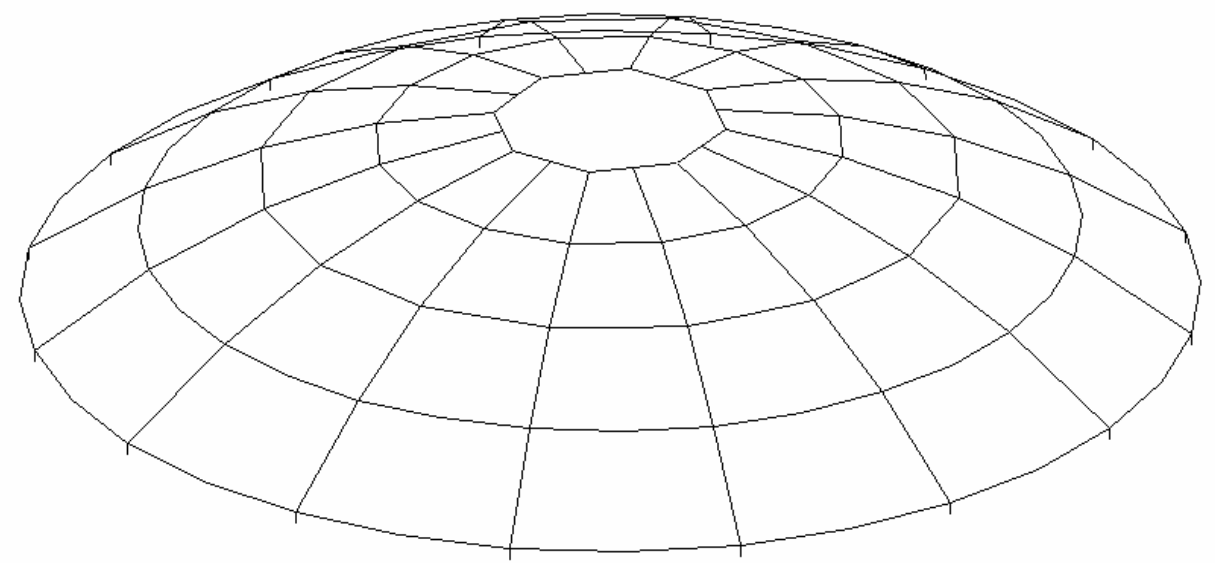

Figura 2.25 - Cúpula de nós rígidos

Trata-se de um sistema estrutural pesado e de difícil execução, o que aumenta consideravelmente 0 custo da obra. Por esses motivos sua utilização está praticamente restrita a pequenas coberturas e aos casos onde elementos em diagonal são indesejáveis, como nos observatórios. Exatamente por não possuírem diagonais esse tipo de cúpula é considerado, muitas vezes, como a versão espacial da viga Vierendeel. 


\subsubsection{5 - Cúpulas Lamelares}

Lamelas são elementos longos e esbeltos, unidos entre si de modo a formarem uma malha triangular estável e bastante resistente. Cada lamela tem comprimento igual ao dobro do módulo que irá compor e são ligadas, normalmente, no ponto central umas das outras. As Figuras 2.26 e 2.27 fornecem exemplos de cúpulas metálicas lamelares.

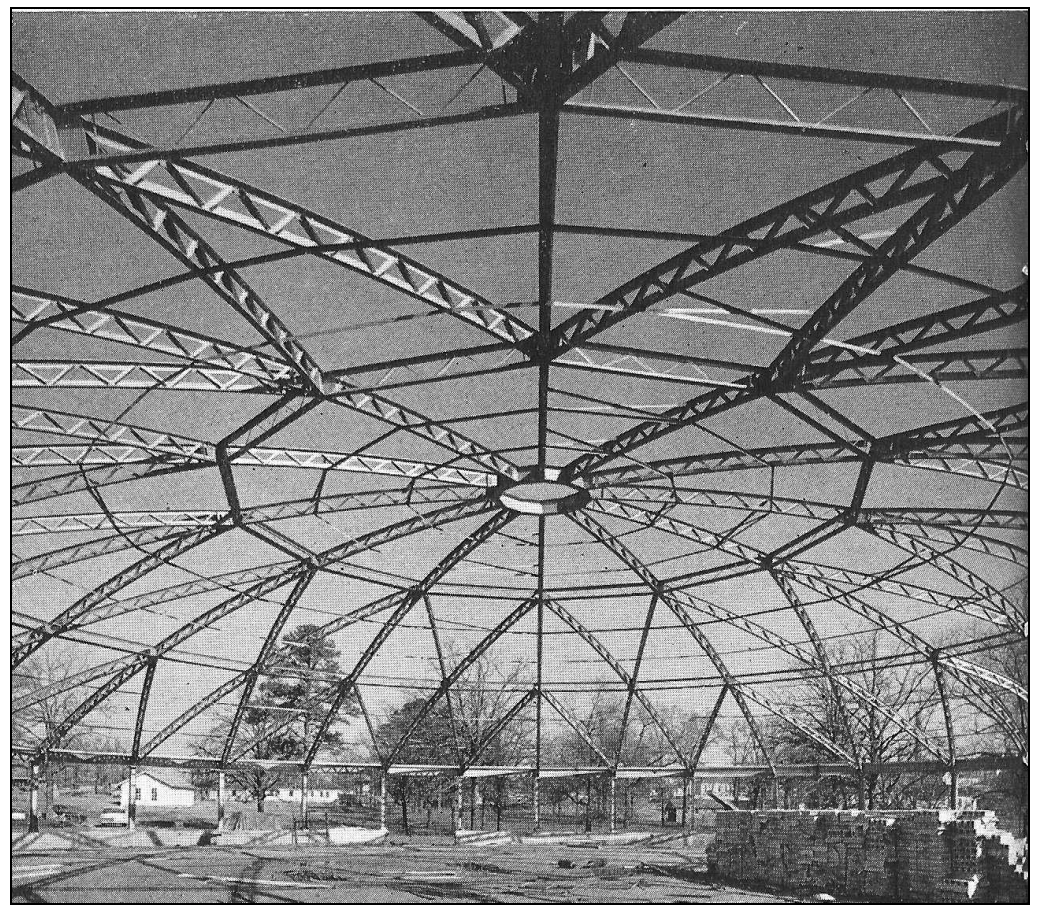

Figura 2.26 - Exemplo de cúpula lamelar (Fonte: MAKOWSKI (1989))

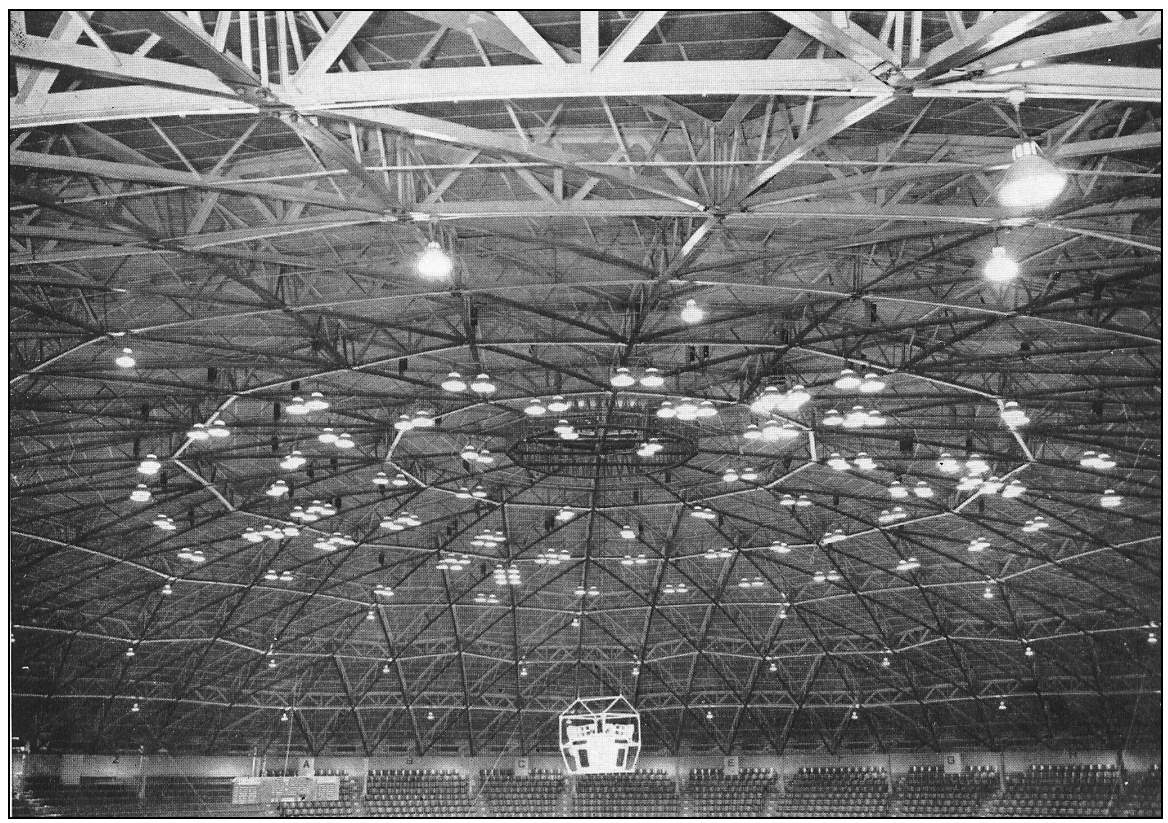

Figura 2.27 - Exemplo de cúpula lamelar (Fonte: MAKOWSKI (1989)) 
As cúpulas lamelares foram desenvolvidas em 1906 pelo arquiteto alemão M. Zollinger e se tornaram muito populares por permitir a fabricação em série das lamelas. Em 19250 engenheiro americano G. R. Kiewitt desenvolveu um sistema estrutural lamelar que leva seu nome, no qual as lamelas são dispostas de forma paralela, como mostra a Figura 2.27.
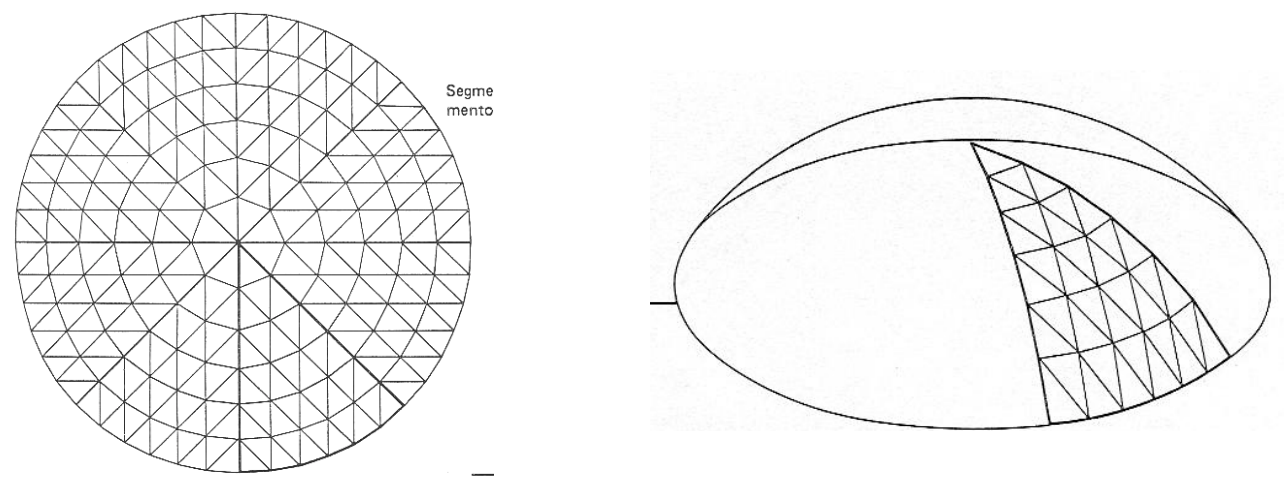

Figura 2.28 - Cúpula lamelar/Kiewitt (Fonte: ENGEL (1981))

"O sistema estrutural do tipo lamelar gera uma forma tridimensional leve e visualmente agradável, conjugada ao eficiente comportamento estático, com a vantagem de uma composição harmônica de distribuição de elementos, e conseqüentemente de esforços, descaracterizando planos específicos de rigidez" (FERREIRA \& CALIL JÚNIOR (2000)).

Um exemplo notável de cúpula lamelar é o superdome de Louisiana, nos Estados Unidos (Figura 2.29). Trata-se de um ginásio poliesportivo com capacidade para 75.000 espectadores sentados, mas que pode acolher muito mais em eventos como shows de rock, congressos políticos e demais tipos de eventos.

A cúpula tem um diâmetro de $207 \mathrm{~m}$ e alcança no centro uma altura de $83 \mathrm{~m}$. A cobertura está assentada em 2.100 pilares de concreto e em um anel de borda que tem, como se sabe, a função de resistir à reação horizontal.

Um fato curioso da construção dessa estrutura foi que 0 primeiro empreiteiro desistiu no início da obra alegando que ela "não se sustentaria de pé". Um novo empreiteiro foi contratado e quatro anos depois a construção foi concluída, transformando-se, então, em um grande triunfo da engenharia mundial.

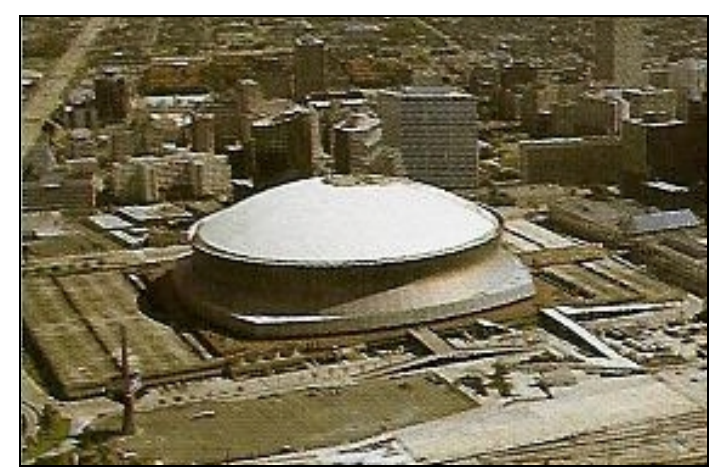

Figura 2.29 - O superdome de Louisiana - E.U.A. (Fonte: ATLAS DO EXTRAORDINÁRIO (1996))

\subsubsection{6 - Cúpulas Geodésicas}

As cúpulas geodésicas foram desenvolvidas por Richard Buckminster Fuller, um controverso inventor, que mesmo sem possuir instrução formal em engenharia ou arquitetura causou grande impacto com suas propostas durante as décadas de 50 e 60 , muitas das quais foram desacreditadas e ridicularizadas na época. Uma de suas idéias mais famosas foi a de cobrir parte da cidade de Nova York com uma cúpula geodésica de 3,22km de diâmetro, a qual permitiria uma 
economia tão grande em itens como limpeza de ruas, remoção de neve e horas de trabalho durante o frio que seria capaz de repor rapidamente o investimento feito para construí-la.

A verdade é que mesmo sendo muito criticado, Fuller conseguiu chamar a atenção para as coberturas em cúpula e inspirou muitos profissionais e estudantes, chegando a ser descrito muitas vezes como um grande gênio da época.

Fuller afirmava que as cúpulas geodésicas estavam embasadas em princípios matemáticos de distribuição de forças semelhantes àqueles encontrados em átomos e moléculas, e que com isso era possível construir estruturas mais leves e mais baratas. Estudos numéricos realizados mais tarde indicaram que a "matemática" geodésica avocada por Fuller se referia apenas a geometria da cúpula, e que este tipo de estrutura estava, obviamente, sujeito aos mesmos tipos de problemas dos demais sistemas estruturais.

Para explicar melhor o princípio que fundamenta as cúpulas geodésicas convém citar REBELLO (2003), que diz: "A associação geodésica parte da disposição dos arcos segundo curvas geodésicas. Denomina-se curva geodésica a curva de menor comprimento sobre a esfera. Assim, os arcos segundo geodésicas encontram-se dispostos no menor caminho das forças e, portanto, menos solicitados do que em outra posição qualquer, resultando em estruturas muito leves."

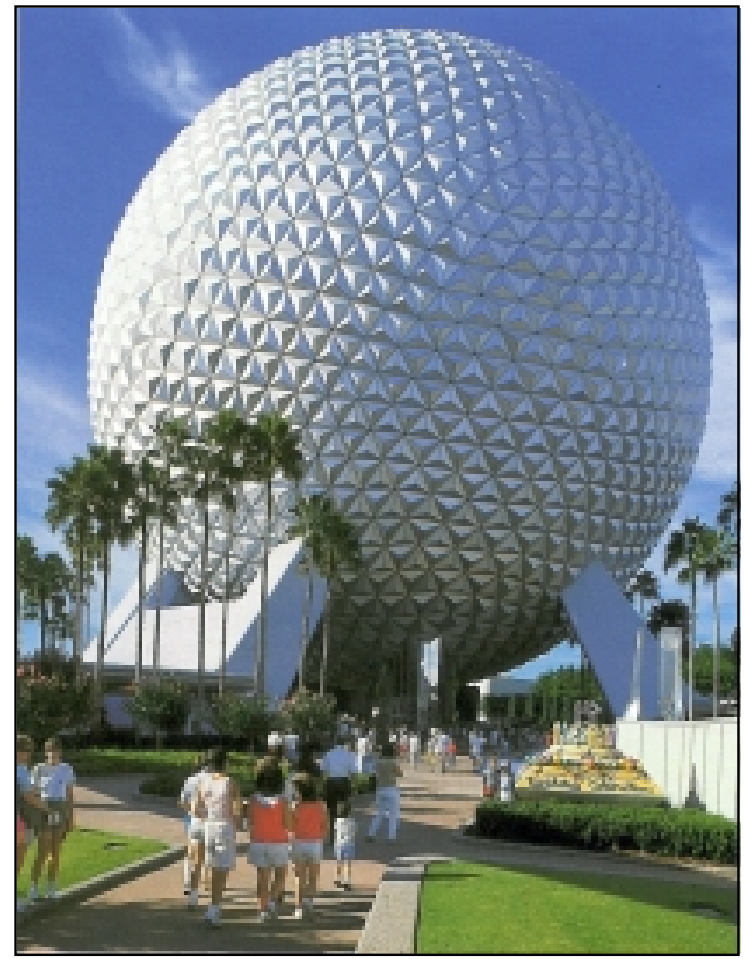

Figura 2.30 - Bola geodésica na Flórida - EUA (Fonte: ATLAS DO EXTRAORDINÁRIO (1996))
Um exemplo pitoresco de aplicação desse sistema estrutural é a gigantesca bola geodésica conhecida como "Nave Espacial Terra" (Figura 2.30), construída pelo "Walt Disney World" no período de 1966 a 1982 em Orlando, na Flórida.

Trata-se de uma estrutura completamente esférica com 50m de diâmetro, o equivalente a altura de um edifício de 18 andares, apoiada sobre três pares de pilares metálicos. A estrutura possui cerca de 1.450 barras de aço e foi projetada para resistir a ventos de $87,5 \mathrm{~m} / \mathrm{s}$.

As primeiras cúpulas executadas por Fuller seguiam a triangulação de um icosaedro regular projetado sobre a esfera, mas com 0 tempo outros poliedros foram utilizados para definir a configuração da cúpula, uma vez que o princípio básico é criar superfícies por meio de poliedros que possam ser inscritos ou circunscritos em uma esfera.

O icosaedro é, de fato, um poliedro que se aproxima bastante da geometria da esfera. Esse sólido tem ainda a vantagem de permitir que cada face seja sucessivamente subdivida em 4 triângulos eqüiláteros, cuja projeção dos vértices o torna ainda mais próximo do contorno curvo que se deseja aproximar (Figura 2.31). 


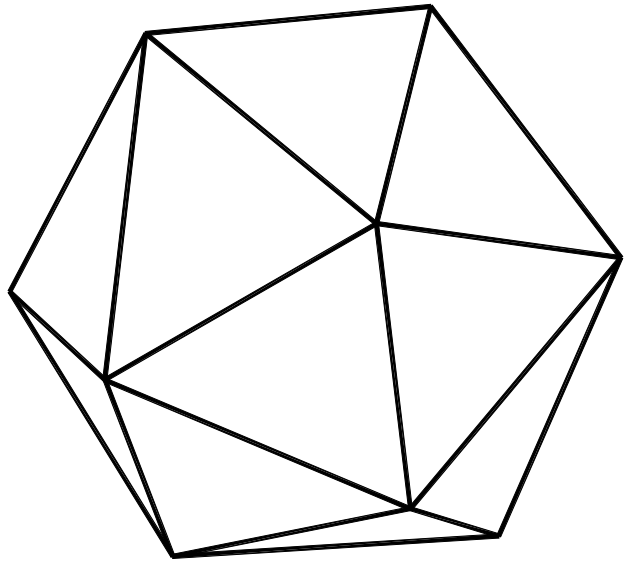

(a) Icosaedro regular (poliedro de vinte faces)

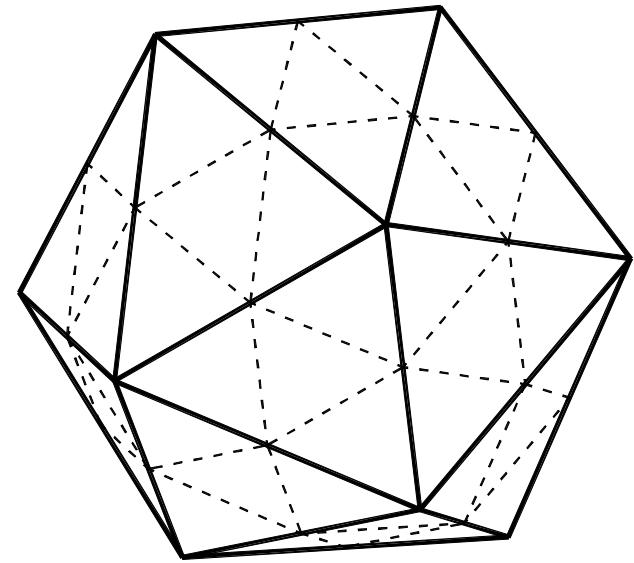

(b) Subdivisão das faces do icosaedro

Figura 2.31 - Poliedro utilizado em cúpulas geodésicas

\subsubsection{7 - Cúpulas em Reticulado Tridimensional}

As estruturas em reticulado tridimensional, ou estruturas espaciais como são mais conhecidas no Brasil, são constituídas por barras não coplanares conectadas umas as outras em módulos piramidais, de modo a formarem uma malha leve e extremamente resistente.

Segundo SOUZA \& GONÇALVES (2002) os registros mais antigos do emprego desse tipo de estrutura datam dos séculos XVIII e XIX, quando foram utilizadas na França e na Alemanha, respectivamente. No Brasil esse tipo de estrutura começou a receber grande atenção dos pesquisadores em meados da década de 90, quando ocorreu o colapso da estrutura do Centro de Convenções de Manaus, no estado do Amazonas.

As estruturas em reticulado tridimensional apresentam muitos atrativos de ordem técnica e estética, o que as torna muito apreciadas pelos diversos profissionais da construção metálica. Como principais características pode-se citar, por exemplo, a aparência leve e harmoniosa que a malha apresenta, e a simplicidade e similaridade das barras, que facilitam sobremaneira o projeto e a execução desse tipo de estrutura.

O principal campo de aplicação das estruturas espaciais é em coberturas de faces planas, mas elas se prestam muito bem para coberturas curvas, como é o caso das cúpulas. A Figuras 2.32 mostra uma cúpula com estrutura em reticulado tridimensional. 


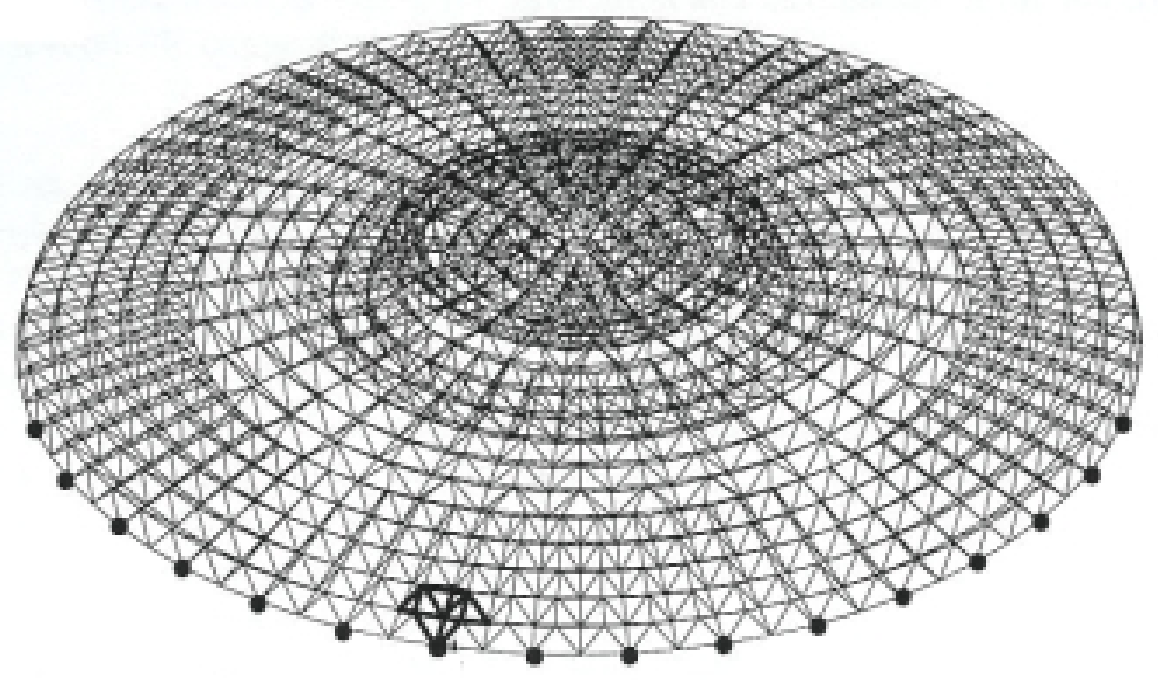

Figura 2.32 - Cúpula em reticulado tridimensional (plano da cobertura) Fonte: BATISTA et al. (2001)

São vários os motivos que incentivam o emprego de estruturas metálicas espaciais em grandes coberturas, alguns deles são:

a) Os elementos possuem peso próprio reduzido e alto índice de repetição, o que facilita sobremaneira as operações de fabricação, transporte e montagem. Nas coberturas em cúpula 0 índice de repetição é bem menor que nas coberturas planas, mas, mesmo assim, ainda se constitui em uma vantagem desse sistema estrutural.

b) A malha tridimensional propicia alto grau de hiperestacidade e rigidez, além de uma boa redistribuição de esforços.

As estruturas espaciais executadas no Brasil muitas vezes utilizam um sistema de ligação para o qual não existe similar no restante do mundo. É um sistema no qual as extremidades das barras são estampadas e ligadas por um único parafuso, como indica a Figura 2.33.

Esse sistema de ligação é conhecido em algumas regiões do país como nó "Sarton", mas no SET/EESC/USP recebe o nome de "nó típico", devido sua grande difusão na construção metálica brasileira. Pesquisas recentes apontam para a existência de problemas devido às excentricidades e variação da inércia decorrentes da estampagem nas extremidades das barras, motivo pelo qual sua utilização vem sendo regularmente desaconselhada por muitos pesquisadores.

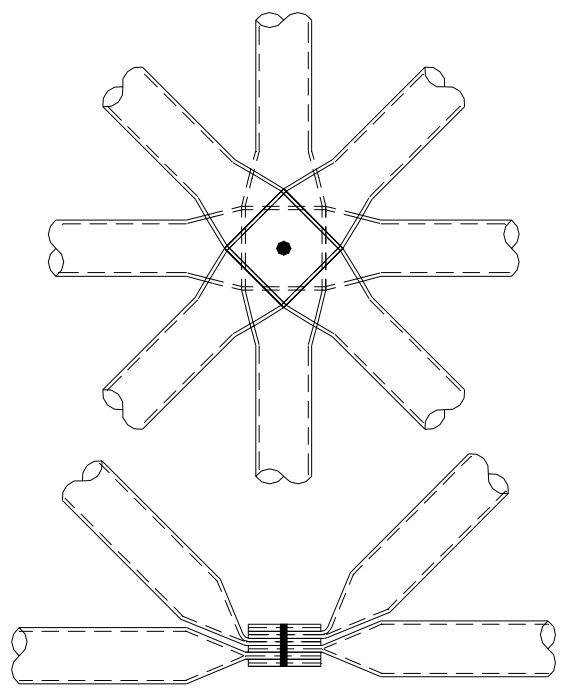

Figura 2.33 - Ligação em estrutura metálica espacial: "nó típico" 


\section{5 - Histórico e Evolução das Pesquisas Realizadas no Brasil e no Mundo}

Como 0 trabalho aqui apresentado aborda as coberturas em cúpula e suas ligações, e o estudo foi feito com o auxílio de análises lineares e não-lineares via elementos finitos, a revisão bibliográfica foi dividida em três partes, cada uma delas abordando um desses tópicos.

\subsection{1 - Pesquisas sobre Coberturas em Cúpula}

Os primeiros trabalhos sobre cúpulas metálicas foram desenvolvidos por SMITH ${ }^{1}$ e ROBERTS 2 no início dos anos 50, mas foi o professor Z.S. MAKOWSKI, também nos anos 50, o primeiro a se aprofundar no assunto.

O primeiro brasileiro a publicar algo sobre coberturas em cúpula parece ter sido o professor $\mathrm{J}$. BLESSMAN ${ }^{3}$, da Universidade Federal do Rio Grande do Sul, que em 1971 publicou um artigo sobre as pressões devidas ao vento nesse tipo de estrutura. Esse trabalho tornou-se uma referência no assunto, vindo a ser citado em vários trabalhos científicos posteriores.

Em 1984 MAKOWSKI fez uma compilação sobre as pesquisas desenvolvidas até então sobre as coberturas em cúpula, e essa compilação tornou-se uma referência em grande parte das pesquisas mundiais sobre esse tipo de estrutura.

Os trabalhos de caráter mais prático e que fornecem alguma orientação sobre o comportamento estrutural e a construção das cúpulas metálicas são: MULLORD (1984), que discutiu as idealizações normalmente adotadas e os aspectos gerais do comportamento da estrutura, e WALKER (1984), que apresentou várias tipologias construtivas e fez alguns comentários sobre 0 projeto e a construção desse tipo de cobertura.

Esses dois trabalhos são o ponto de partida para quem deseja estudar as coberturas reticuladas em forma de cúpula, sejam elas metálicas ou não.

Em seguida vêm mais dois trabalhos que merecem destaque, são eles: SUPPLE (1984), que discutiu alguns aspectos do colapso desse tipo desse estrutura, e SOARE (1984), que estudou 0 colapso ocorrido com um domus em 1963 na cidade de Bucharerst.

A década de 90 também trouxe contribuições importantes ao tema, principalmente sobre o estudo dos mecanismos de instabilidade e suas formas de propagação na estrutura. Como exemplos de pesquisas nessa área pode-se citar os trabalhos de GIONCU (1993), MATSUSHITA et al. (1993), MUTOH \& KATO (1993), ERIKSSON \& PACOSTE (1993), SUMEC (1993) e QIAN et al. (1993).

Um trabalho muito interessante foi desenvolvido por PAKANDAN \& SARSHAR (1993), que compararam o desempenho de três tipos de domus metálicos. Este trabalho, no entanto, aborda alguns sistemas estruturais pouco usuais no Brasil e não apresenta uma informação de grande interesse para os profissionais, que é o consumo de material em cada sistema analisado.

\footnotetext{
${ }^{1}$ SMITH, E.B. (1950). The dome - a study in the history of ideas. Princeton Monographs in Art and Archaeology, no. 25, Princeton University Press. Apud MAKOWSKI (1984).

2 ROBERTS, G. (1951). The structural design of the domes of Discovery. Festival of Britain. Proc. Inst. Civ. Eng. pp. 377-417. Apud MAKOWSKI (1984).

3 BLESSMAN, J. (1971). Pressures on domes with several winds profiles. Proc.. 3rd. Int. Conf. Wind Effect on Buildings and Structures. Tokyo. pp. 317-326. Apud MAKOWSKI (1984).
} 
Um trabalho particularmente interessante e que guarda certa semelhança com o que será discutido mais adiante nesta tese foi desenvolvido por KATO et al. (1998), que estudaram o colapso de cúpulas reticuladas com nós semi-rígidos e imperfeições geométricas iniciais. A principal diferença entre esses dois trabalhos está nos sistemas estruturais estudados, e isso, por si só, caracteriza a relevância, e, sob certos aspectos, a originalidade de cada trabalho.

Faz menos de dez anos que o Brasil voltou a apresentar algumas contribuições ao tema com os seguintes trabalhos: BATISTA et al. (1997), PIMENTA \& FRUCHTENGARTEN (1997) e VENDRAME (1999).

BATISTA et al. (1997) desenvolveram um intenso e criterioso estudo teórico e experimental com vistas à habilitação $0^{4}$ de uma cobertura metálica em cúpula, a qual chamaram de "Grande Calota Esférica de Cobertura". O sistema estrutural da cobertura em questão era do tipo reticulado tridimensional, com dimensões aproximadas de 100m de diâmetro e 10m de altura.

O estudo teve o objetivo de verificar a segurança e determinar os mecanismos de colapso da estrutura. Para tanto foram desenvolvidos análises estruturais estáticas e dinâmicas, lineares e nãolineares, e ensaios experimentais das juntas de ligação. Os resultados obtidos conduziram ao reforço de várias juntas, como requisito imprescindível para garantia da segurança e à habilitação da estrutura.

BATISTA \& BATISTA (1997) estudaram os mecanismos de colapso de juntas típicas de cúpulas metálicas em reticulado tridimensional, e, por meio de estudos experimentais, observaram que a carga de colapso da estrutura estava associada à ocorrência de instabilidade elástica de uma barra esbelta, ou de uma junta, ou do elemento de conexão barra-junta.

PIMENTA \& FRUCHTENGARTEN (1997) formularam um modelo não-linear para análise via elementos finitos de pórticos espaciais. O modelo foi aplicado ao estudo de uma cúpula com $28 \mathrm{~m}$ de diâmetro e 3,8m de altura, convenientemente dimensionada em regime linear, para a qual foi calculada a carga correspondente à instabilidade global, situação na qual não é encontrada configuração estável para a estrutura.

VENDRAME (1999) também estudou as cúpulas em reticulado espacial. Embora tenha enfatizado os sistemas de ligações, em especial, aquele conhecido como nó típico ${ }^{5}$, VENDRAME (1999) fez um estudo da ruína progressiva de uma estrutura reticulada com $81 \mathrm{~m}$ de diâmetro e 10m de altura.

A publicação mais recente desenvolvida por pesquisadores brasileiros sobre cúpulas metálicas é encontrada em BATISTA et al. (2001), que retomaram neste trabalho a discussão iniciada em 1997.

Em estruturas de madeira também existem publicações relevantes sobre coberturas em cúpula, podendo-se citar: FERREIRA (1999), FERREIRA \& CALIL JUNIOR (2000) e FERREIRA \& GESUALDO (2002).

\footnotetext{
${ }^{4} \mathrm{O}$ termo "habilitação" é utilizado por BATISTA et al. (1997) no sentido de obtenção das medidas corretivas necessárias para tornar uma estrutura segura para utilização plena.

${ }^{5}$ Nó cujas barras têm suas extremidades amassadas, sobrepostas umas sobre as outras, e ligadas por um único parafuso (ver item 3.1.6).
} 
O trabalho mais recente sobre domus metálicos treliçados foi publicado por KATO et al. (2003), que desenvolveram um estudo dessas estruturas considerando o comportamento elastoplástico e a instabilidade dos elementos e da estrutura como um todo.

\subsection{2 - Pesquisas sobre Ligações}

Fazer uma revisão bibliográfica a respeito das pesquisas sobre ligações não é uma tarefa fácil, tanto pela complexidade do assunto quanto pela variedade e quantidade de trabalhos publicados.

Como o tema central desta tese não é especificamente sobre ligações, será apresentado apenas aquilo que é de interesse imediato. O leitor interessado em mais detalhes pode recorrer a outros trabalhos, alguns deles desenvolvidos no SET/EESC/USP, como PRELORENTZOU (1991), SANTOS (1998), RIBEIRO (1998), LIMA (2003) e MAGGI (2004).

De uma maneira geral, as pesquisas sobre ligações seguem duas linhas básicas de trabalho, uma de natureza experimental e outra de natureza teórica, sendo que a primeira destas é, muitas vezes, desenvolvida para averiguar, calibrar ou ajustar a segunda.

Os estudos teóricos podem ser feitos analiticamente ou com o auxílio de métodos numéricos, entre os quais o método dos elementos finitos (MEF) tem tido um desempenho espantoso, uma vez que permite simular com relativa facilidade o comportamento dos mais diversos tipos de ligações e determinar, entre outros fatores, as regiões mais solicitadas, os mecanismos de colapso e as relações força-deslocamento.

A parte deste trabalho que aborda as ligações contemplou apenas a elaboração de estudos analíticos e numéricos. No entanto, convém registrar que, como consta em SANTOS (2002), que a proposta inicial de desenvolvimento deste trabalho contemplava a elaboração de um programa experimental que não foi levado a termo por diversos motivos, inclusive por falta de financiamento.

O estudo das ligações está descrito em detalhes no capítulo 4. Por enquanto basta citar as referências que serviram de base nessa fase do trabalho.

As simulações numéricas das ligações entre barras seguiram os critérios apresentados por YANG et al. (2000), que fez simulações numéricas com elementos finitos tridimensionais de ligações vigapilar com dupla cantoneira de alma, por LIMA (2003) e MAGGI (2004), que simularam ligações vigapilar com chapa de topo estendida.

No estudo dos aparelhos de apoio foram consultados os seguintes trabalhos:

a) ERMOPOULOS \& STAMATOPOULOS (1995) e ERMOPOULOS \& STAMATOPOULOS (1996), que desenvolveram um sistema de classificação para bases de pilares e estabeleceram um modelo teórico para previsão do comportamento momento-rotação desse tipo de ligação.

b) ERMOPOULOS \& STAMATOPOULOS (1997), que estudaram o comportamento último de placas de base e obtiveram curvas momento $x$ força axial.

c) KONTOLEON et al. (1999), que desenvolveram um estudo paramétrico da resposta de placas de base.

d) MARTINS et al. (2001), que simularam numericamente bases de apoio em pilares de aço e fizeram uma comparação entre os processos de dimensionamento estabelecidos por BLODGET (1966) e DeWOLF (1990). 
Os modelos analíticos foram desenvolvidos seguindo o raciocínio de SANTOS (1998) e SANTOS \& SÁLES (1999), que apresentaram um modelo teórico para descrição do comportamento momentorotação de ligações viga-pilar com chapa de topo, e por TIMOSHENKO \& KRIEGER (1959), cuja metodologia de análise de placas delgadas inspirou o desenvolvimento de um modelo para dimensionamento de placas em bases nervuradas.

\subsection{3 - Pesquisas Sobre a Análise Não-Linear das Estruturas}

A análise não-linear de estruturas também é uma área onde as pesquisas são intensas. Essa intensidade se justifica, em parte, pela crescente sofisticação da informática e pelo surgimento dos métodos numéricos; mas se fundamenta, sobretudo, no interesse que muitos pesquisadores têm em conhecer melhor o comportamento das estruturas e de aperfeiçoar os métodos de cálculo e análise existentes.

Sobre a análise não-linear de estruturas metálicas o ponto de partida pode ser a compilação realizada por CHEN \& TOMA (1994), na qual pode se encontrada, além da teoria e de exemplos de aplicação, alguns programas computacionais para análise não-linear de pórticos planos.

Outros trabalhos de interesse são: LAVALL (1996), que apresentou uma formulação para análise não-linear de pórticos planos de aço considerando imperfeições iniciais e tensões residuais; PAULA (1997) e PAULA \& PROENÇA (2001), que estudaram a análise não-linear em estruturas reticuladas planas; SÁLES et al. (1997), que investigaram a influência dos efeitos de segunda ordem em estruturas de aço; CHAN (2001), que revisou os critérios utilizados nas últimas décadas para análise não-linear de pórticos de aço; JUSTINO FILHO (2001), que estudou a análise estática nãolinear última aplicada às estruturas de aço; LANDESMANN et al. (2001), que implementou um modelo para análise estrutural com ligações semi-rígidas; e SANTOS et al. (2002), que discutiram a influência da não-linearidade geométrica em arcos metálicos.

Os trabalhos mais recentes nessa área são LAZANHA (2003), que desenvolveu uma análise dinâmica elastoplástica de estruturas metálicas sob excitação do vento, PASQUETTI (2003), que estudou a estabilldade estática e dinâmica de torres estaidas, MORAIS (2003), que analisou pórticos semi-rígidos em perfis formados a frio, PINHEIRO (2003), que realizou análises nãolineares de sistemas rotulados e semi-rígidos, e PINHEIRO \& SILVEIRA (2004) que comparou diferentes formulações em elementos finitos semi-rígidos na modelagem de pórticos planos metálicos.

A não-linearidade considerada neste trabalho está relacionada com a influência do comportamento momento-rotação das ligações, que, como se sabe, apresenta aspecto fortemente não-linear. Nessa área, além de CHEN \& TOMA (1994) convém citar CHAN \& CHUI (2000), que também compilaram os estudos sobre estruturas metálicas semi-rígidas, e SANTOS \& SÁLES (1999), que investigaram essa influência em pórticos planos de múltiplos andares.

\section{6 - Considerações Finais sobre a Revisão Bibliográfica}

Nos últimos cinqüenta anos várias pesquisas sobre coberturas em cúpula foram desenvolvidas no exterior, no Brasil, porém, essas pesquisas praticamente começaram há menos de dez anos.

Enquanto os pesquisadores estrangeiros abordaram essencialmente as cúpulas geodésicas e as do tipo "three way", os pesquisadores brasileiros abordaram quase que exclusivamente as cúpulas com 
reticulado tridimensional. Percebe-se, então, a existência de uma lacuna que precisa ser preenchida, que é o estudo dos demais sistemas utilizados no Brasil e no mundo.

Sobre a influência das ligações no comportamento global das cúpulas foram encontrados dois trabalhos, KATO et al. (1998), que abordou um sistema estrutural diferente dos que se pretende estudar neste trabalho, e um mais antigo, TOADER et al. (1984), que abordou coberturas curvas cilíndricas. Percebe-se, então, que há aqui também uma lacuna a ser preenchida com estudos e pesquisas.

A respeito do estudo sobre ligações há apenas que se observar que a maioria das simulações numéricas realizadas até 0 momento trata principalmente das ligações com chapa de topo, como cita YANG et al. (2000), e como pode ser visto em duas teses de doutorado defendidas recentemente no Brasil, que são LIMA (2003) e MAGGI (2004), ambas sobre ligações com chapa de topo. Vê-se, com isso, que um estudo criterioso sobre outros detalhes de ligações pode se transformar em uma considerável contribuição às pesquisas sobre ligações.

Resumindo, viu-se da revisão bibliográfica aqui apresentada, que o estudo sobre as cúpulas metálicas apresentas vários tópicos ainda pouco investigados, e é exatamente em alguns deles onde 0 trabalho aqui apresentado se encaixa. 


\section{Sobre o Sistema Estrutural Estudado}

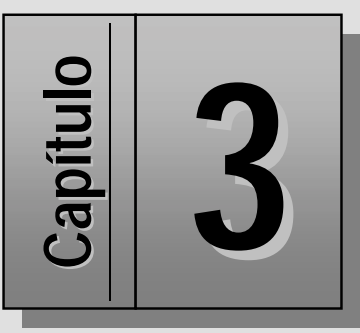

\section{1 - Introdução}

Como mostrado no capítulo anterior, existem várias tipologias construtivas disponíveis para construção de coberturas em cúpula; algumas delas já bastante discutidas na literatura técnica e outras não.

Este trabalho apresenta um sistema estrutural derivado do tipo Schwedler, desenvolvido no SET/EESC/USP para a cobertura do Ginásio Poliesportivo de São Carlos, cujo projeto foi desenvolvido por alguns docentes do departamento supracitado. Posteriormente, esse mesmo sistema foi empregado no projeto da cobertura de um templo evangélico para a cidade de Ribeirão Preto, no interior do estado de São Paulo.

A diferença entre o sistema Schwedler original e aquele desenvolvido no SET/EESC/USP é a existência de barras rígidas no contraventamento deste último, uma vez que, no sistema original, esses elementos são compostos por barras flexíveis, conforme mostrado anteriormente. As Figuras 3.1 e 3.2 ilustram melhor essa situação. 


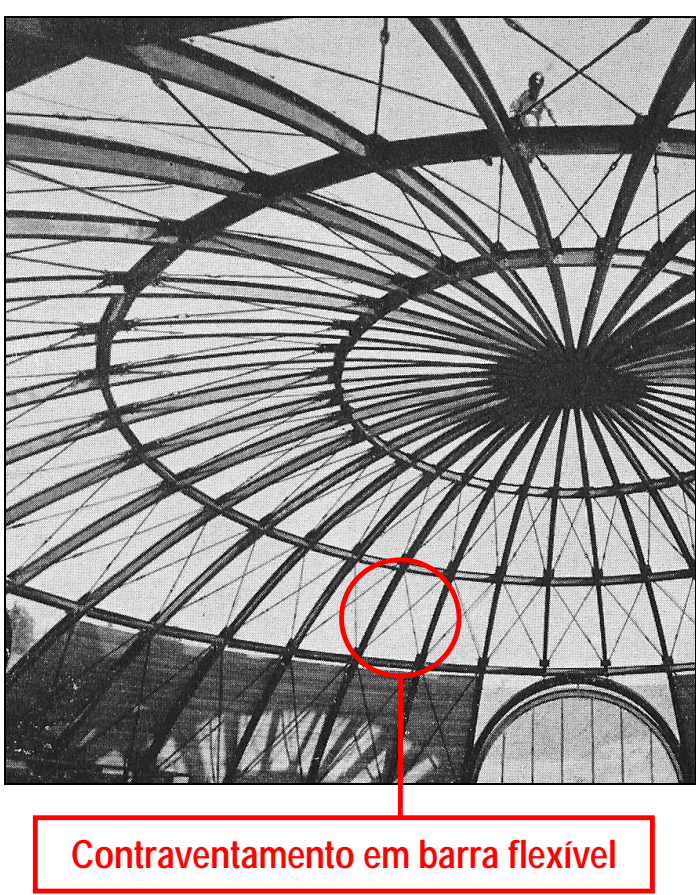

Figura 3.1 - Exemplo de cúpula Schwedler com contraventamento flexível (Fonte: MAKOWSKI (1984))

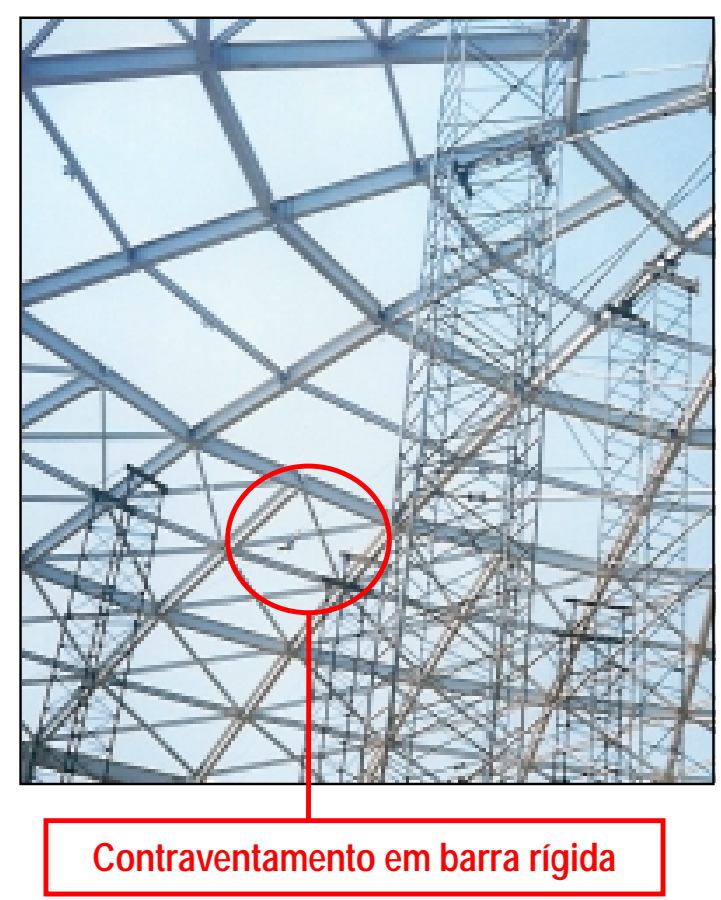

Figura 3.2 - Exemplo de cúpula Schwedler com contraventamento rígido (Fonte: Arquivo do autor)

Dada esta significativa diferença, o sistema proposto pelo SET/EESC/USP pode ser chamado de sistema Schwedler enrijecido. As Figuras 3.3 (a), (b) e (c) fornecem algumas vistas de uma estrutura que foi projetada com esse último sistema.

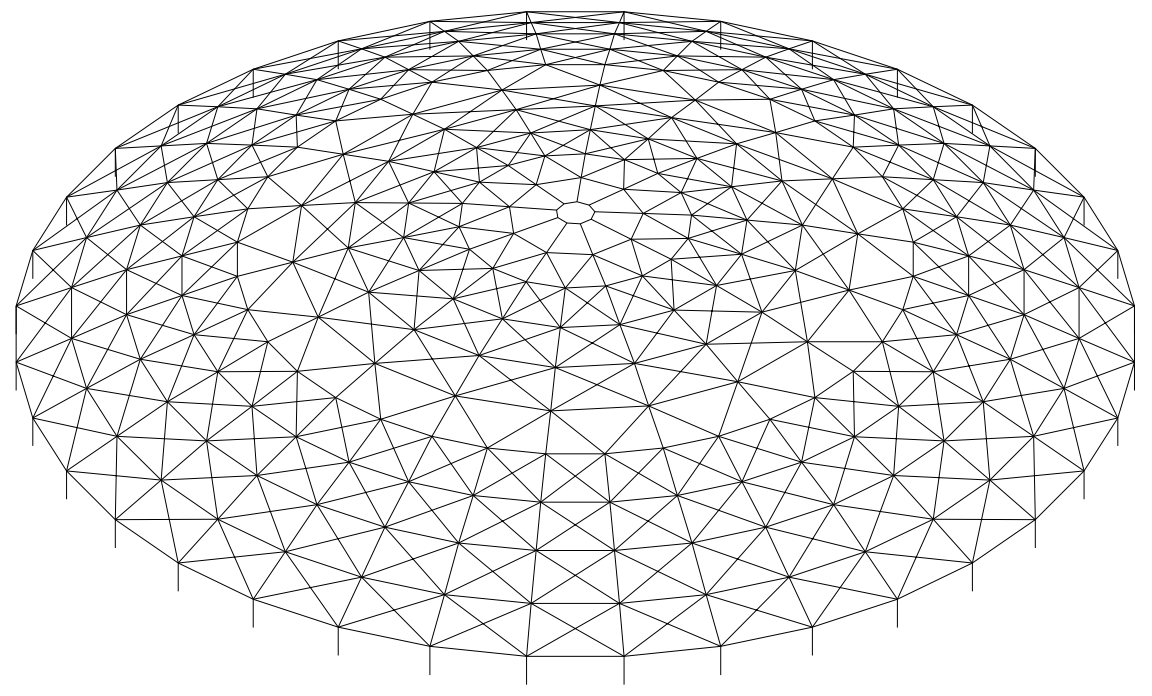

(a) Perspectiva da cobertura 


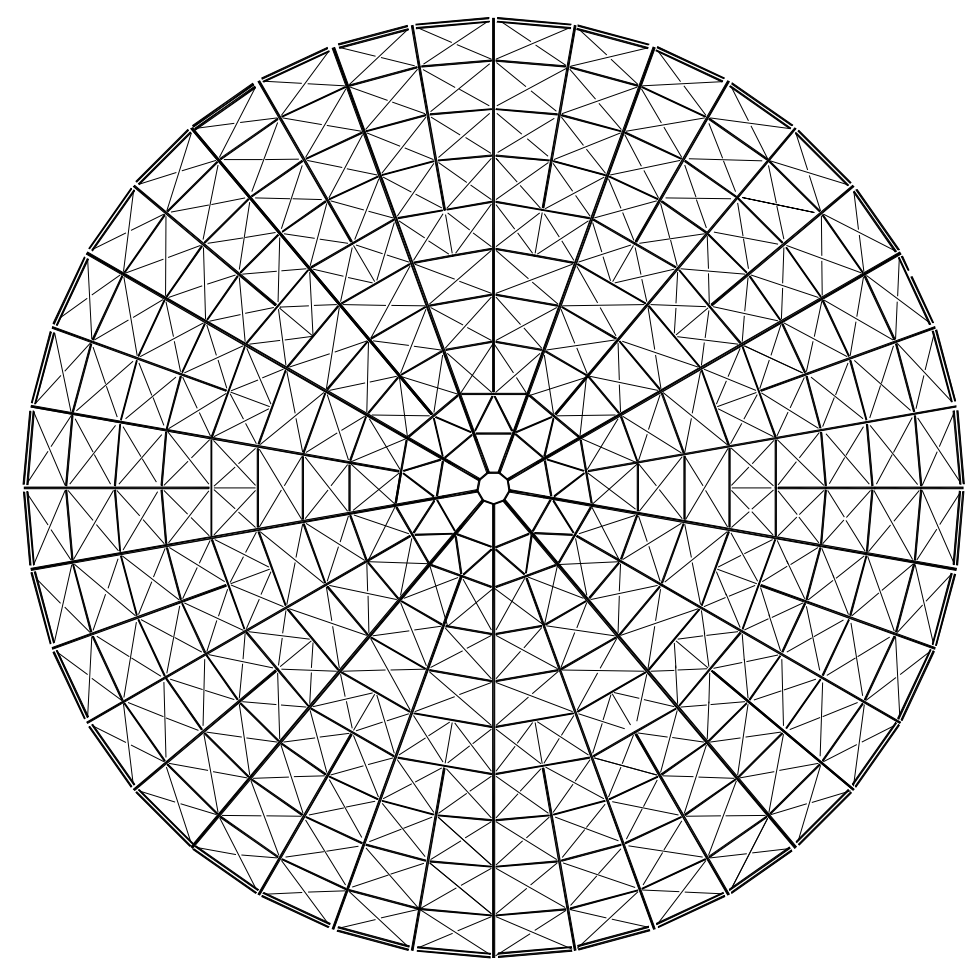

(b) Plano da cobertura

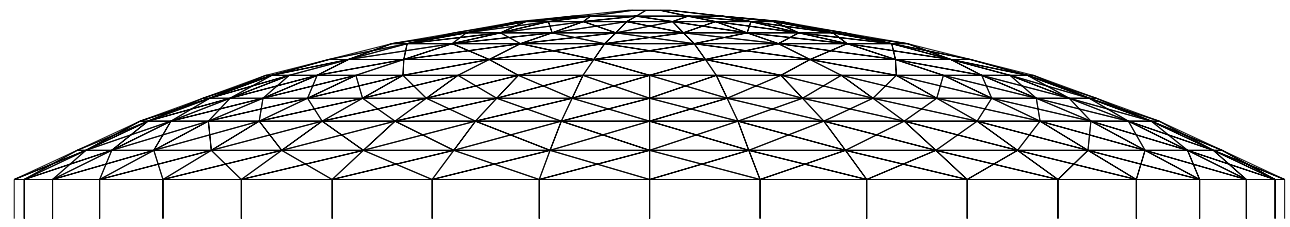

(c) Vista lateral

Figura 3.3 - Sistema Schwedler enrijecido

Tanto o sistema original quanto o enrijecido podem ser executados com elementos treliçados, como mostra a Figura 3.4. Neste trabalho, porém, foi estudado apenas o sistema em alma cheia, que por si só já constituiu um amplo campo de investigação. 


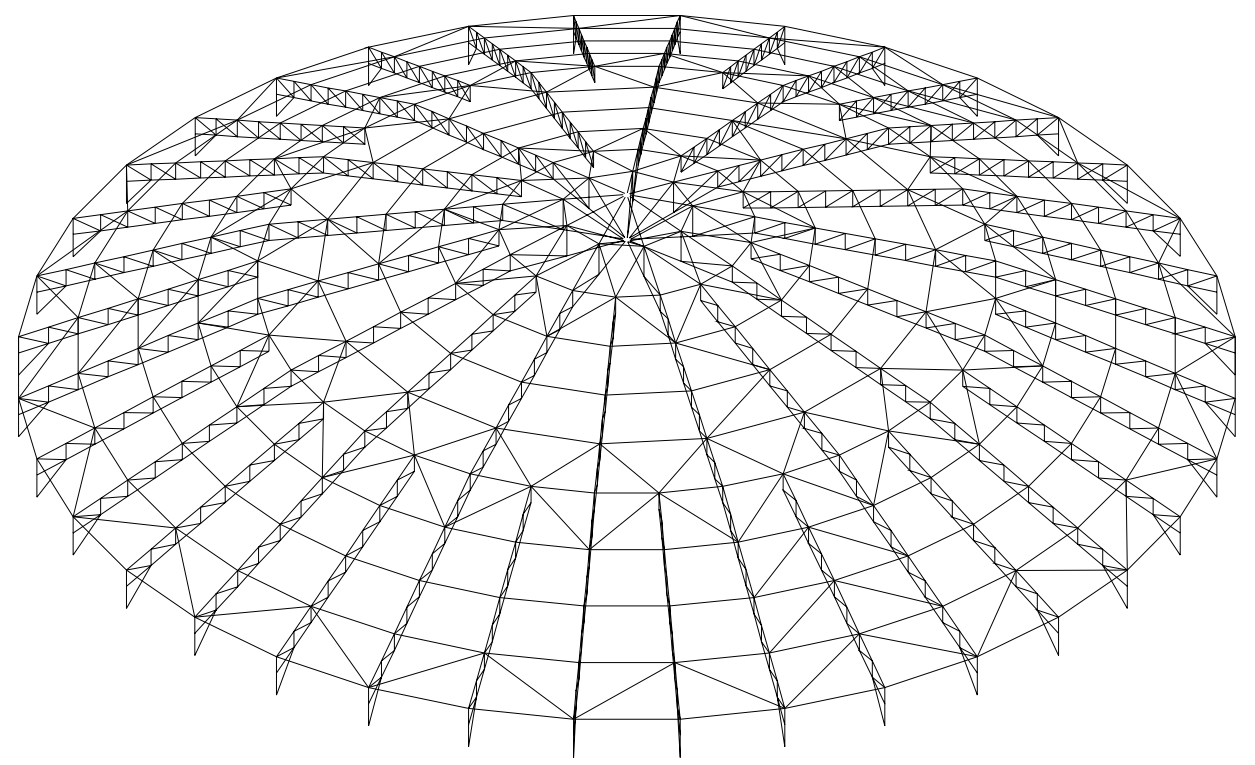

Figura 3.4 - Sistema Schwedler com elementos treliçadas (Perspectiva da cobertura)

\section{2 - Ligações Típicas do Sistema Estrutural Estudado}

A Figura 3.5 apresenta a nomenclatura adotada para designar os elementos que compõem a estrutura. Com base nessa nomenclatura são ilustradas as ligações entre as barras desse tipo de cobertura.

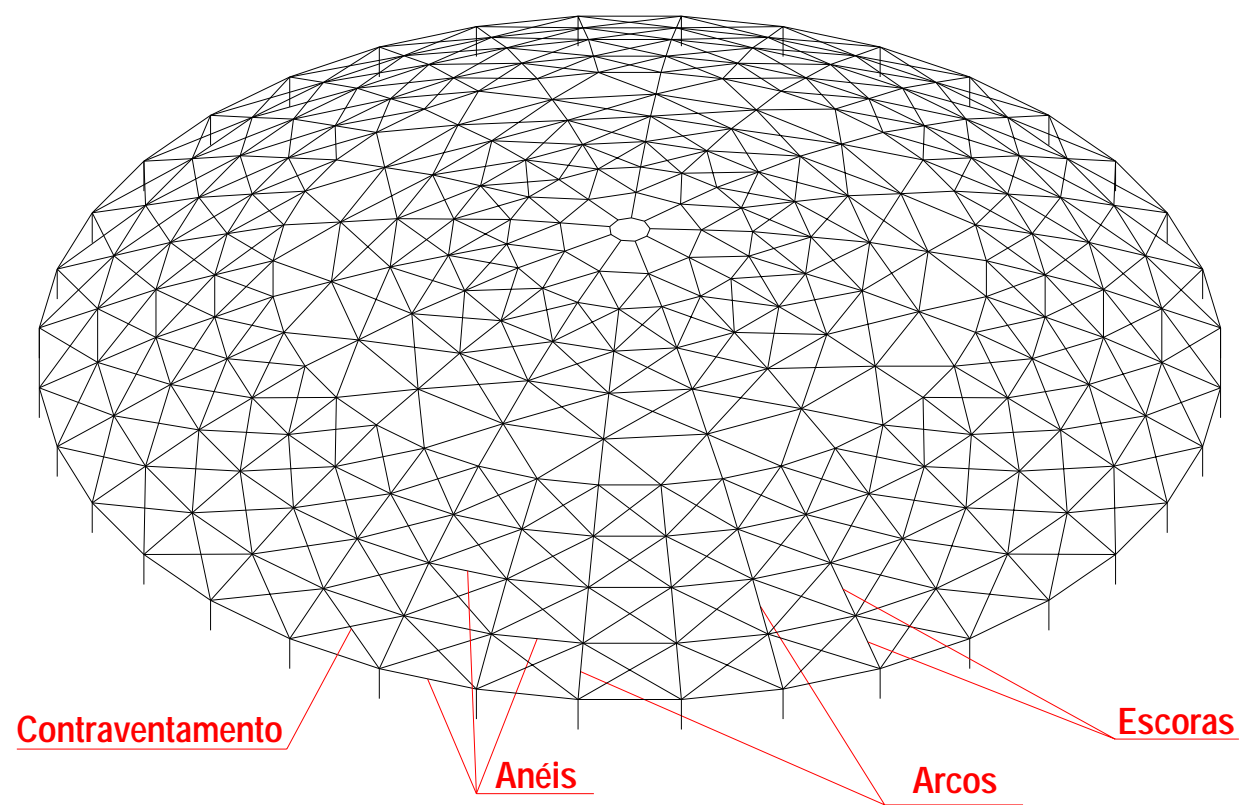

Figura 3.5 - Nomenclatura dos elementos componentes do sistema estrutural estudado 


\subsection{1 - Emendas dos Arcos}

Os arcos são os elementos responsáveis pela inclinação da cobertura. São compostos por trechos retos unidos em vários pontos por ligações soldadas e/ou parafusadas.

Por serem os componentes mais longos da estrutura, os arcos precisam de emendas em vários locais, algumas delas executadas em fábrica e outras a serem executados no campo. As ligações feitas em fábrica normalmente usam solda de penetração total, e algumas delas ainda recebem um filete de reforço na raiz. Já as ligações feitas na obra utilizam talas e parafusos.

Em ambos os casos essas ligações garantem a continuidade da barra e, se estiverem devidamente dimensionadas, não influenciam o comportamento da estrutura. As Figuras 3.6 e 3.7 mostram alguns detalhes usuais na ligação desses elementos.

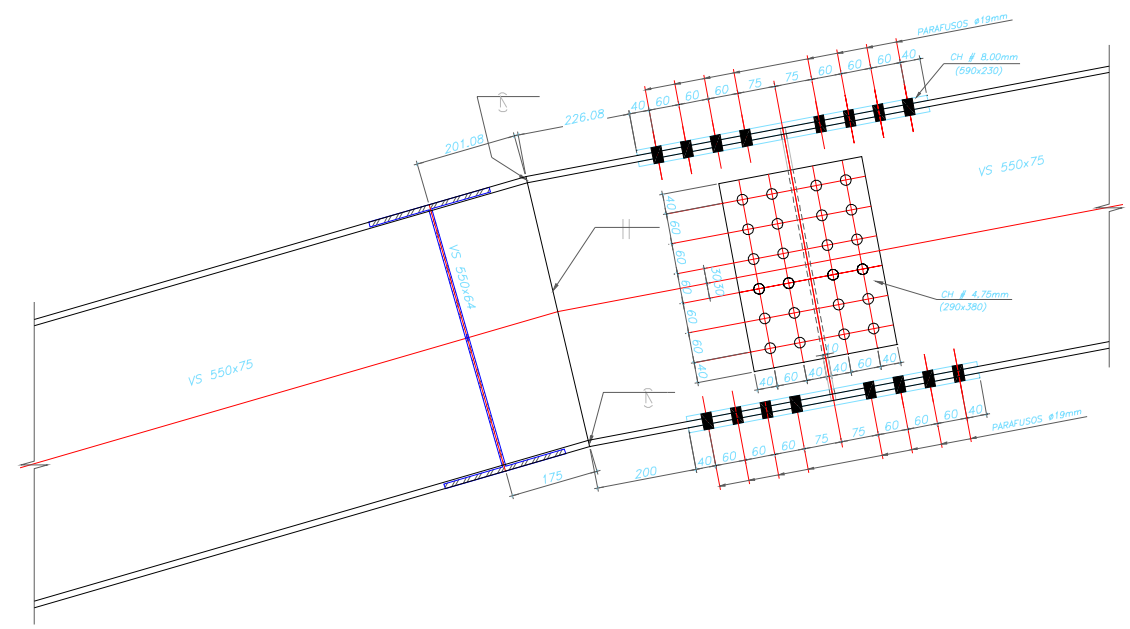

Figura 3.6 - Emenda dos arcos sem variação da seção

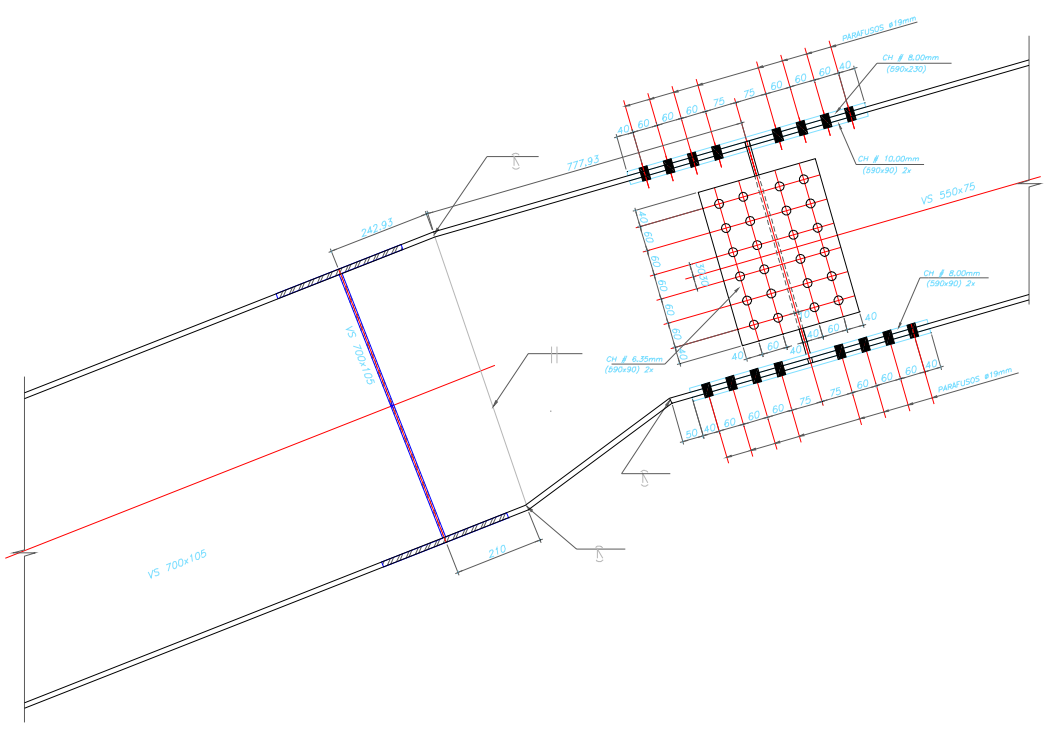

Figura 3.7 - Emenda dos arcos com variação de seção 


\subsection{2 - Ligações dos Anéis nos Arcos}

Os anéis têm a função de travar os arcos e de garantir, juntamente com os travamentos em $X, a$ estabilidade da estrutura. Sobre os anéis também atuam cargas decorrentes das chapas de cobertura e sobrecargas diversas, de forma que esses elementos também precisam resistir adequadamente os esforços internos que surgem em decorrência dessas cargas. A Figura 3.8 apresenta um detalhe de ligação dos anéis com dupla tala de alma.

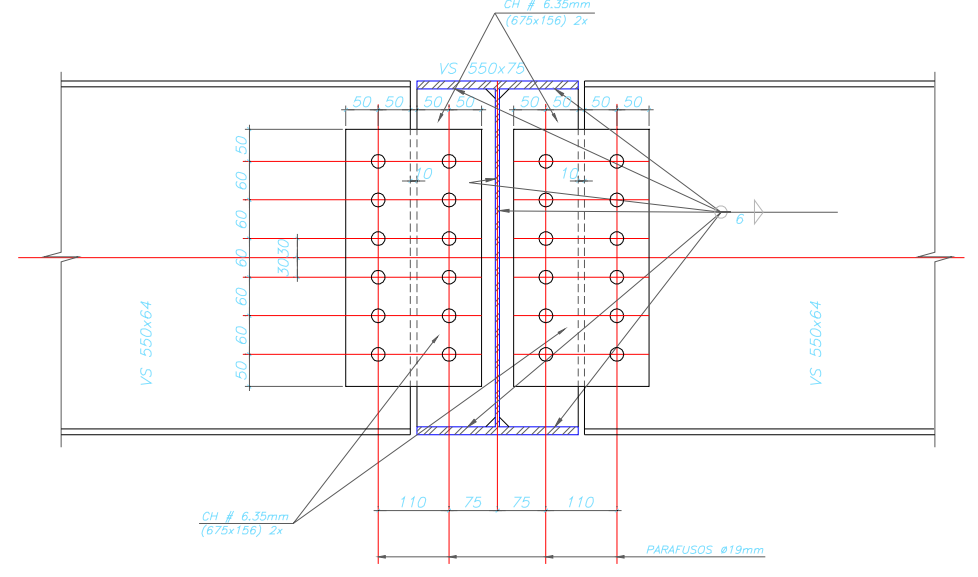

Figura 3.8 - Ligação dos anéis com os arcos

Embora a Figura 3.8 não mostre, os anéis não são perpendiculares aos arcos, pois, como a cobertura apresenta planta circular, os anéis precisam estar inclinados em relação ao arco, como mostra a Figura 3.9.

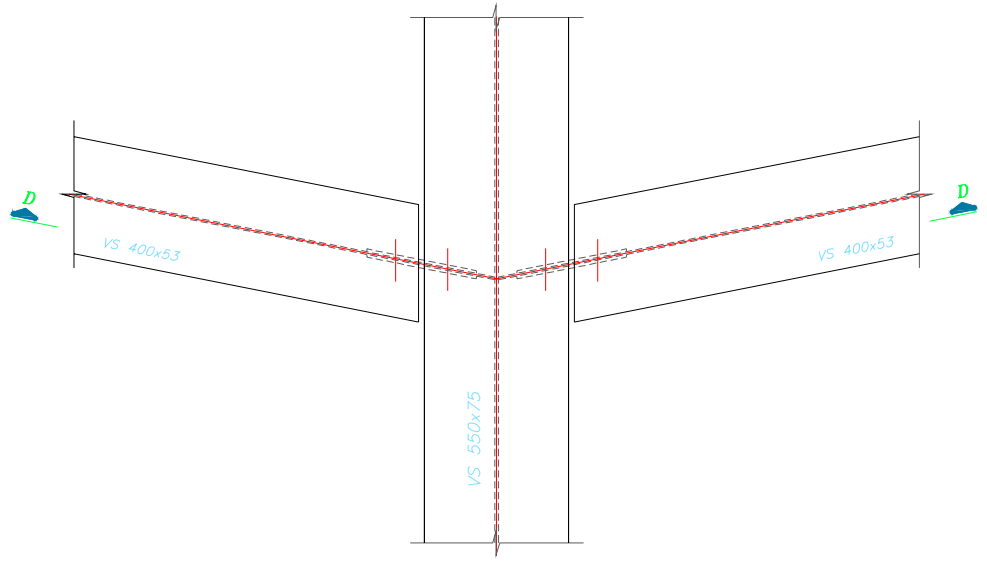

Figura 3.9 - Ligação dos anéis com os arcos (vista superior)

Sabe-se, da literatura técnica, que nas ligações em perfis I os momentos fletores são transmitidos predominantemente pelas mesas, enquanto 0 esforço cortante é transmitido predominantemente pela alma, sendo assim, o detalhe mostrado nas Figuras 3.8 e 3.9 é normalmente simulado como uma rótula perfeita, muito embora seja possível enrijecer essa ligação unindo as mesas dos perfis com chapas de cobrejunta ou soldando os flanges dos perfis, situação esta que é de execução bem mais fácil. 
Esses recursos, no entanto, oneram excessivamente 0 custo das ligações, pois implicam em maior consumo de material e em aumento da mão-de-obra.

Por outro lado, mesmo no detalhe articulado, ou seja, naquele onde as mesas dos perfis não participam da ligação, a grande quantidade de parafusos e a utilização de talas de dimensões elevadas pode introduzir uma rigidez considerável na ligação, a qual pode chegar ao ponto de distanciá-la consideravelmente do comportamento de rótula perfeita, mas sem aproximá-la 0 suficiente do comportamento de ligação rígida, uma vez que isso só se consegue ligando as mesas do perfil. Tem-se, então, uma ligação dita semi-rígida, cujo comportamento pode afetar 0 comportamento global da estrutura e a resistência de cálculo dos seus elementos.

A avaliação do comportamento de qualquer ligação requer o emprego de algum modelo constitutivo que pode ser desenvolvido analiticamente, ou, como é muito comum, desenvolvido a partir de, ou calibrado por, resultados experimentais e simulações numéricas em elementos finitos.

Para a ligação com dupla tala de alma que caracteriza a ligação dos anéis com os arcos não foi encontrado, até o momento da conclusão deste trabalho, nenhum modelo constitutivo que permitisse a caracterização do seu comportamento momento-rotação e a investigação da sua influência no comportamento global da estrutura. Diante disso, para que o trabalho pudesse ser realizado, foi desenvolvido um modelo constitutivo que permitiu caracterizar a curva momentorotação desse tipo de ligação, e que viabilizou a investigação da influência da rigidez no comportamento global da estrutura.

\subsection{3 - Ligações dos Arcos com as Bases de Concreto (Aparelhos de Apoio)}

Os suportes das cúpulas, assim como em muitos outros tipos de estruturas metálicas, são normalmente em concreto armado. Sendo assim, grande parte do cálculo dos aparelhos de apoio recai na determinação das espessuras de placas de base e de enrijecedores, e na determinação dos diâmetros e comprimentos dos chumbadores.

Alguns tipos de aparelhos de apoio das cúpulas metálicas são, na verdade, compostos por duas ligações, a primeira delas é semelhante à ligação de pilares metálicos com fundações em concreto, e a segunda é semelhante às ligações de extremidade de pórticos planos com traves inclinadas, que em inglês são conhecidas como rigid-frame knee. A Figura 3.10 ilustra esse tipo de ligação.

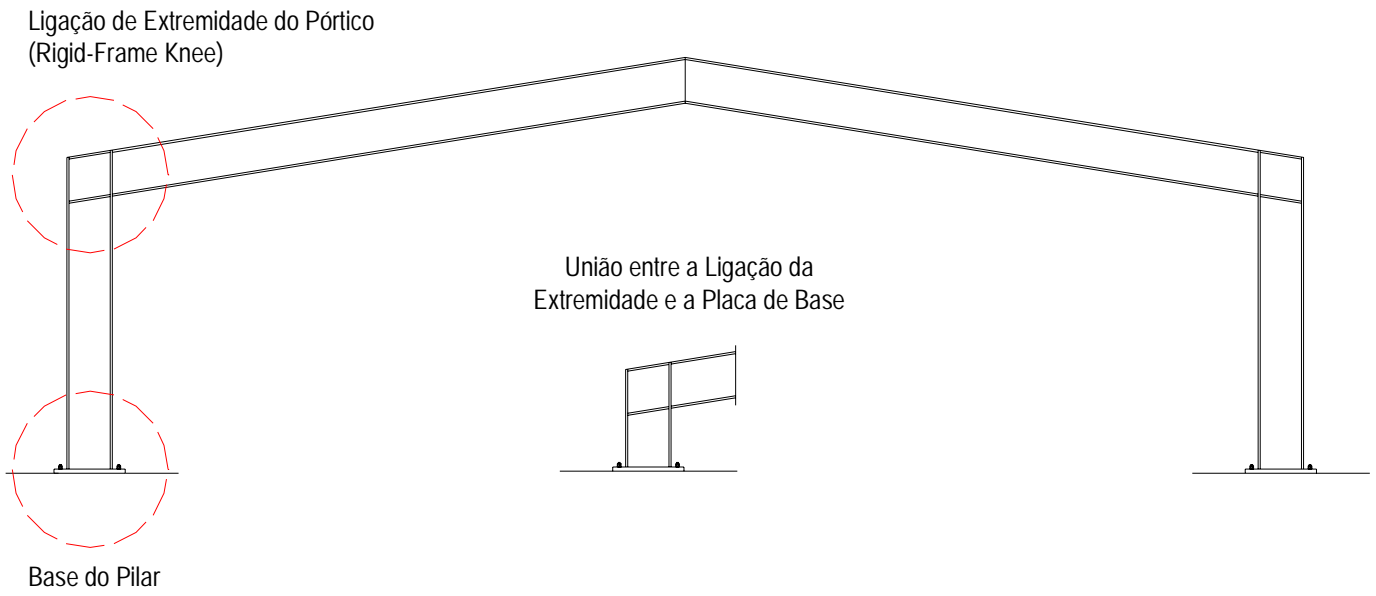

Figura 3.10 - Esquema da união entre a ligação de extremidade e a base do pilar 
As Figuras 3.11 a 3.13 apresentam alguns detalhes que podem ser utilizados em aparelhos de apoio de cúpulas metálicas, sendo que a grande maioria deles é muito pouco discutida na literatura técnica.
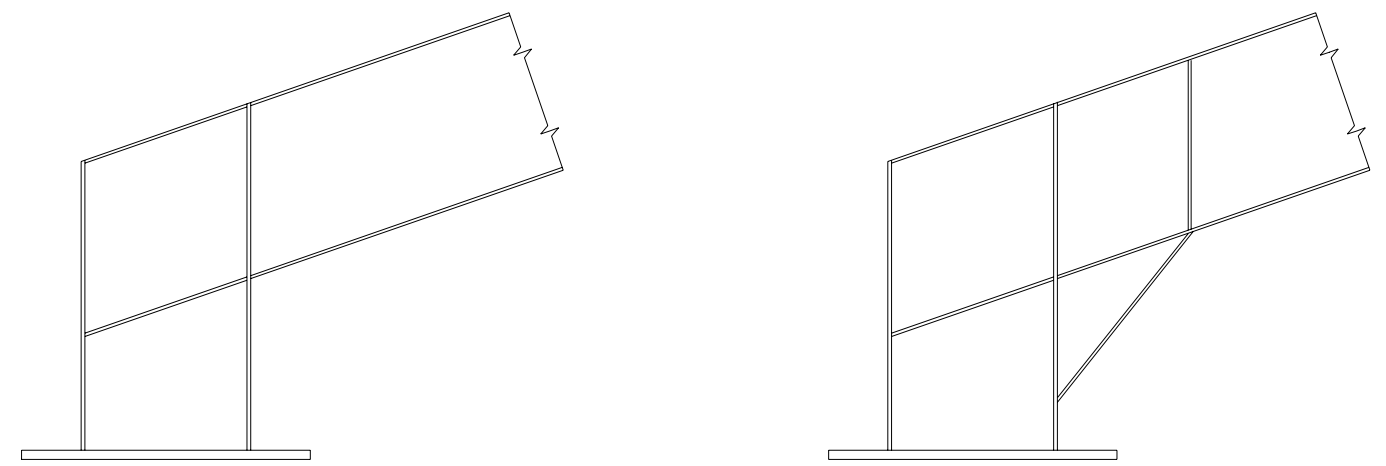

Figura 3.11 - Aparelho de apoio para cúpula metálica com e sem mísula
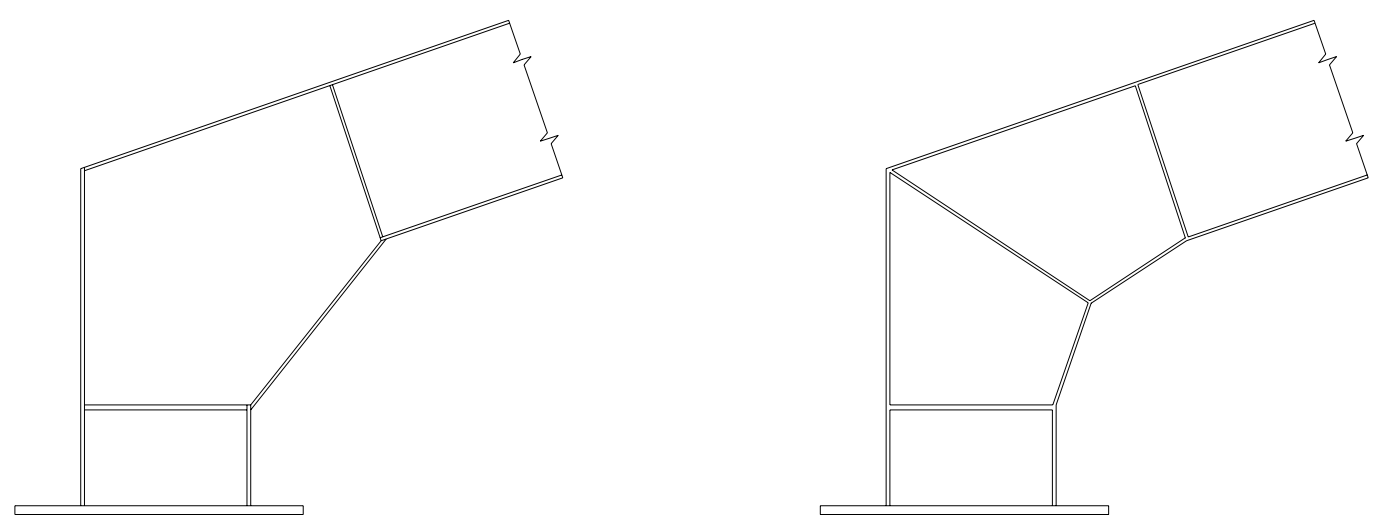

Figura 3.12 - Aparelho de apoio com variação da seção (Tapered haunch, em inglês)
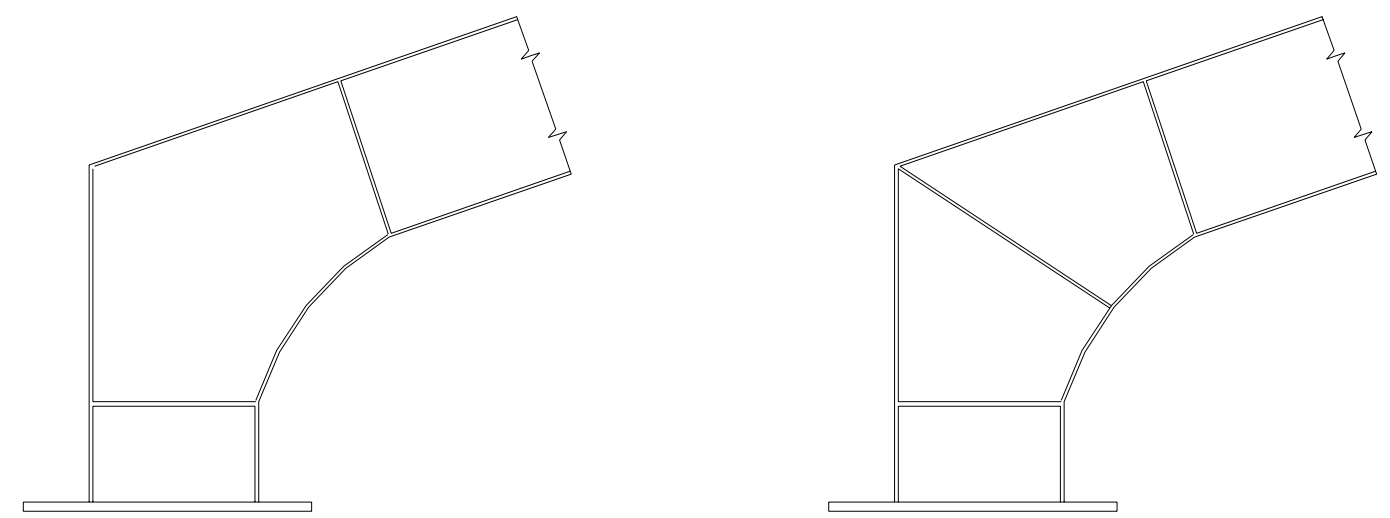

Figura 3.13 - Aparelho de Apoio com trechos curvos (Curved haunch, em inglês)

BLODGETT (1966) apresenta um gráfico, extraído de BEEDLE et al. (1951), que compara as curvas momento-rotação de algumas das ligações de extremidade apresentados nas figuras anteriores. 
O gráfico indica que a ligação com elementos retangulares e sem mísula de enrijecimento (square corner) é a mais flexível de todas, enquanto que o detalhe com mísula enrijecedora apresenta maior rigidez, maior momento resistente, e conseqüentemente menor capacidade de rotação. Comportamento semelhante tem o detalhe que apresenta variação da seção (tapered haunch knee - Figura 6.12), mas cuja curva momento-rotação não é mostrada no gráfico.

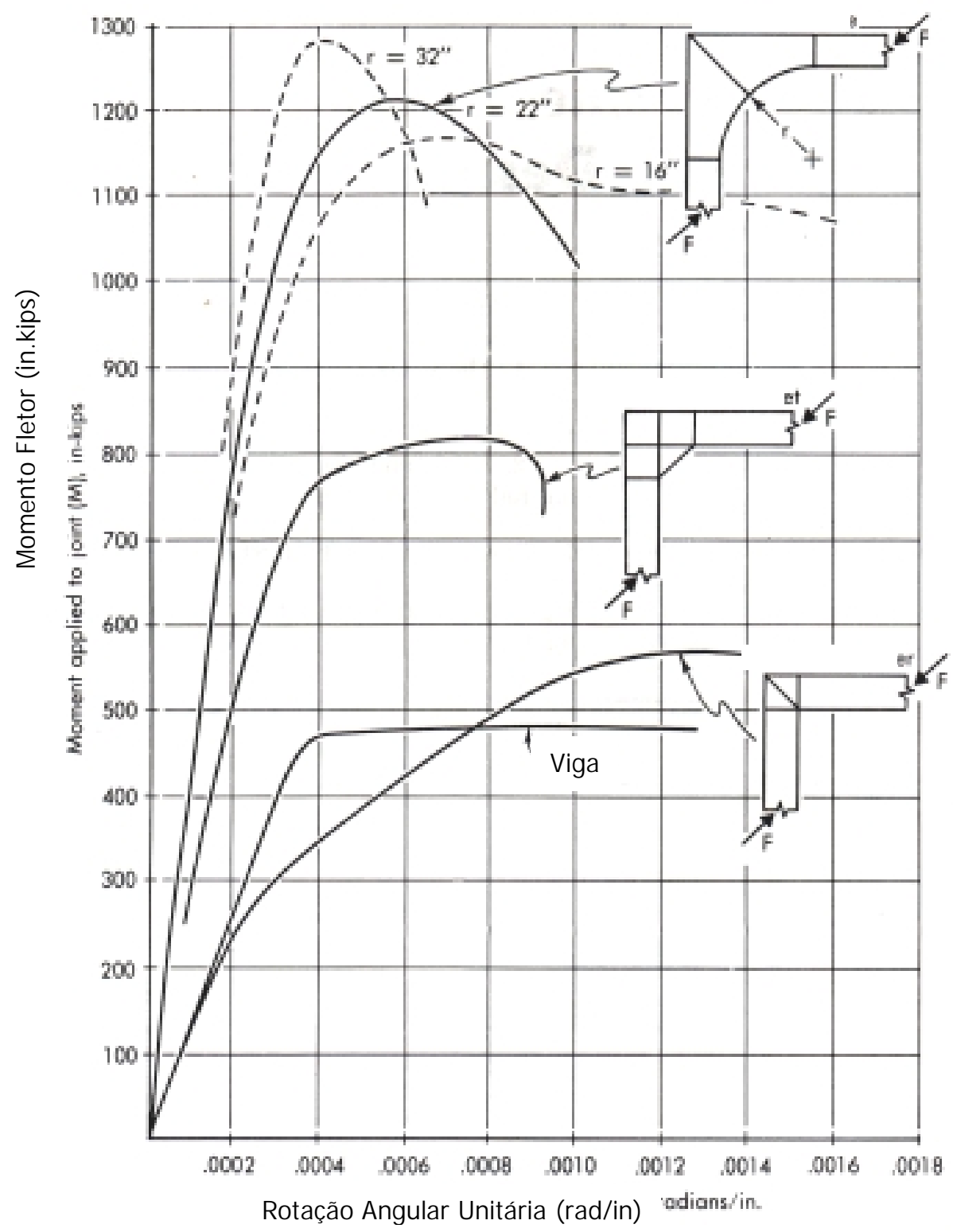

Figura 3.14 - Curvas momento x rotação de ligações de extremidades de pórticos planos (Fonte: BLODGETT (1966))

As ligações curvas (curved haunch knee) são as mais rígidas e as que apresentam o maior momento resistente. Esse tipo de ligação é influenciado pelo raio de curvatura da mesa inferior que, a medida em que é incrementado, provoca um leve ganho de rigidez e do momento resistente, levando a uma leve redução na capacidade de rotação. 
O dimensionamento dessas ligações é feito com base em estudos realizados já há algum tempo, e isso é percebido observando-se que GAYLORD et al. (1992) e SALMON \& JOHNSON (1996), que são obras muito conceituadas e amplamente utilizadas pelos projetistas atuais, remetem os interessados nessas ligações a BLEICH (1943), GRIFFITHS (1948), BEEDLE (1951), FICHER (1962) e BLODGETT (1966). Parece não haver, portanto, estudos recentes sobre essas ligações, 0 que também é percebido realizando pesquisas nas bases de dados da Elsevier of Sciece, que entre outras fontes inclui as publicações do AISC, do ASCE e de outras revistas na área de engenharia de estruturas.

Tendo em vista o considerável avanço da informática e dos métodos numéricos nos dias atuais, a sofisticação dos processos e equipamentos de ensaios experimentais, e as diversas limitações que haviam na época em que essas ligações foram inicialmente estudadas, seria extremamente interessante abordá-las novamente e revisar os critérios propostos para projetá-las.

No caso específico dos aparelhos de apoio para cúpulas metálicas existe ainda um outro fator que justifica a realização de estudos mais detalhados. É o fato dos critérios de dimensionamento das ligações de extremidade terem sido propostos supondo essas ligações afastadas da base do pilar, ou seja, sem a interferência de concentração de tensões que caracterizam os apoios das estruturas. O estudo da união de dois tipos de ligações em uma única região, e ainda mais em um local onde os esforços internos costumam ser de ordem bastante elevada, pode revelar aspectos ainda desconhecidos.

No trabalho aqui apresentado os aparelhos de apoio foram estudados inicialmente no que se referia ao dimensionado da placa de base, que no caso das coberturas em cúpula costumam apresentar grande espessura. Em seguida foi investigado o comportamento momento-rotação dessas bases. Os demais itens aventados nesta seção constituem um amplo campo de investigação e foram deixados para estudo em trabalhos futuros. 


\section{SOBRE O ESTUDO DAS LIGAÇÕES}

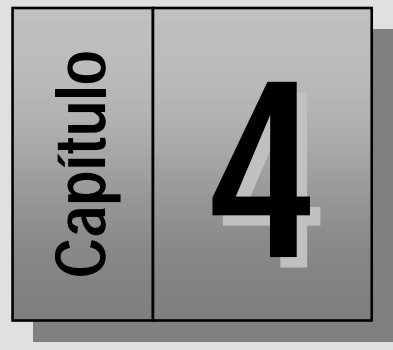

\section{1 - Introdução}

Este capítulo apresenta o estudo desenvolvido sobre as principais ligações existentes no sistema estrutural abordado neste trabalho. $O$ enfoque dado a cada uma delas variou de acordo com as contribuições que poderiam ser apresentadas, de forma que algumas ligações foram estudadas sob o ponto de vista do comportamento momento-rotação, outras sob o ponto de vista dos métodos ou critérios de dimensionamento, e outras sob ambos os aspectos.

\section{2 - Estudo das Ligações dos Anéis com os Arcos}

De uma forma geral, o comportamento das ligações em estruturas de aço costuma ser abordado de uma maneira bastante simplificada, o que facilita consideravelmente a análise estrutural e reduz 0 tempo de elaboração dos projetos.

O estudo pormenorizado dessas ligações, no entanto, vêm demonstrando que o comportamento real que elas apresentam é bem diferente daquele normalmente admitido nos projetos, e isso vem conduzindo, nos últimos tempos, à revisão dos procedimentos de cálculo empregados em certos casos.

$\mathrm{Na}$ prática usual é comum o projetista admitir que as ligações apresentam um comportamento idealizado que pode ser, dependendo do detalhe construtivo adotado, de rótula perfeita ou de engaste perfeito. 
Sabe-se, porém, de estudos experimentais realizados desde o início do século XX, que toda e qualquer ligação apresenta um comportamento intermediário situado entre os casos idealizados, aproximando-se de um ou outro tipo de acordo com o detalhe construtivo adotado. Desses estudos surgiu o conceito de ligação semi-rígida, o que permitiu ao AISC/ASD, já na edição de 1978, propor o sistema de classificação de ligações em estruturas de aço mais difundido no meio técnico, que consiste em:

a) Ligações rígidas: teoricamente é o tipo de conexão que impede completamente a rotação relativa entre as peças. Em termos práticos uma ligação pode ser considerada rígida se restringir no mínimo $90 \%$ da rotação entre as partes conectadas.

b) Ligações flexíveis: teoricamente é o tipo de conexão que não oferece nenhuma restrição ao giro. Na prática, porém, uma ligação é considerada flexível se após a aplicação do carregamento for atingido pelo menos $80 \%$ da rotação esperada teoricamente.

c) Ligações semi-rígidas: abrange as conexões onde a rotação relativa entre as partes varia entre 20 e $90 \%$ daquela que poderia ser atingida se a ligação fosse perfeitamente flexível. 0 emprego desse tipo de conexão requer que o projetista conheça a relação momento-rotação e que a incorpore na análise e no projeto da estrutura.

Em 1986 o AISC/LRFD introduziu uma modificação nesse sistema de classificação, o qual passou a contemplar apenas duas categorias classificadas como:

a) Ligações completamente restringidas (Fully restrained - FR): abrangendo as ligações classificadas como rígidas no sistema anterior.

b) Ligações parcialmente restringidas (Partially restrained - PR): abrangendo as ligações classificadas como semi-rígidas e flexíveis do sistema anterior.

No Eurocode 3 (1992) as ligações são classificadas quanto à rigidez e quanto à resistência, esta última caracterizada em função da capacidade de transferência de momento fletor apresentada pela ligação.

Com relação à rigidez, O EUROCODE 3 (1992) divide as ligações nos mesmos tipos definidos pelo AISC/ASD (1978), sendo que a rigidez da ligação deve ser comparada à rigidez do elemento conectado. Com relação à resistência as ligações são classificadas como:

a) Completamente resistentes.

b) Parcialmente resistentes.

c) Rotuladas.

Outros sistemas de classificação foram introduzidos por BJORHOVDE et al. (1990) e por NETHERCOT et al. (1998), mas estes sistemas não serão aqui discutidos, uma vez que neste trabalho as ligações foram tratadas apenas no que se referia à rigidez que elas apresentavam, seguindo, então, a classificação introduzida pelo AISC/ASD (1978) e mantida, em parte, ou sob outro formato, pelo EUROCODE 3 (1992). 
A descrição do comportamento das ligações costuma ser feito por meio de curvas momento-rotação $(M-\phi)$, obtidas normalmente por meios experimentais, por simulação numérica em elementos finitos e por modelos teóricos, empíricos ou semi-empíricos.

A incorporação das curvas momento-rotação na análise estrutural fornece resultados mais precisos que aqueles obtidos com as análises convencionais, motivo pelo qual muitas pesquisas nesse sentido vêm sendo desenvolvidas nos últimos tempos.

$\mathrm{Na}$ literatura técnica que trata do comportamento momento-rotação das ligações é muito usual o emprego dos termos "rigidez" e "flexibilidade". O primeiro desses termos é definido como a intensidade da restrição ao giro imposto pelo detalhe construtivo da ligação, enquanto o segundo é definido como a facilidade ao giro permitido por esse detalhe. Em termos práticos pode-se dizer que a rigidez é o oposto da flexibilidade e vice-versa.

\subsection{1 - Aspectos Gerais das Curvas Momento-Rotação}

Embora o trabalho aqui apresentado discuta apenas o comportamento das ligações mostradas no capítulo anterior, as Figura 4.1 e 4.2 mostram, a título de ilustração e para servir de base para início de discussão, alguns detalhes típicos de ligações viga-pilar em estruturas de aço e o aspecto geral das curvas momento-rotação que elas apresentam.

As curvas mostradas na Figura 4.2 demonstram que as ligações desenvolvem comportamento fortemente não-linear quando submetidas ao momento fletor. No entanto, o aspecto geral que essas curvas apresentam indicam a existência de um certo padrão de comportamento, o que permite postular duas grandezas de grande importância, que são a rigidez inicial e o momento último.

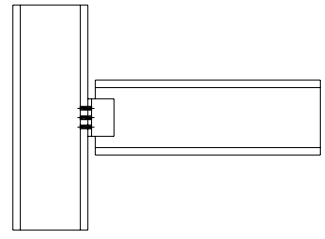

(a) Ligação com uma cantoneira de alma

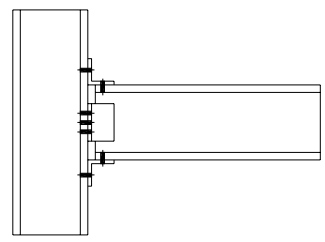

(d) Ligação com cantoneiras de topo e assento e dupla cantoneira de alma
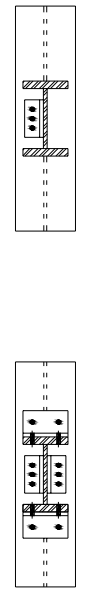

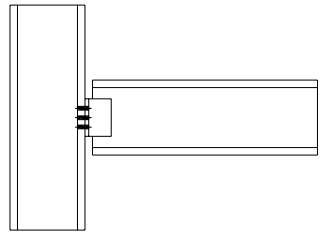

(b) Ligação com dupla cantoneira de alma

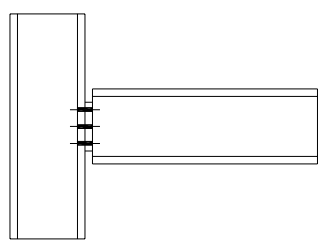

(e) Ligação com chapa de topo reduzida ("flush end plate")
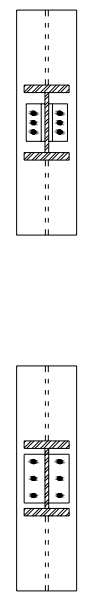$$
\text { end }
$$

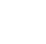

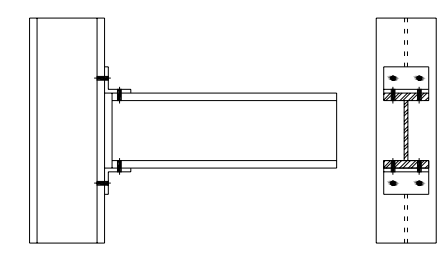

(c) Ligação com cantoneiras de topo e assento

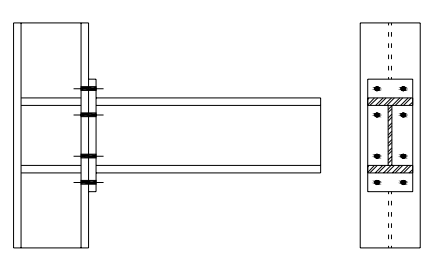

(f) Ligação com chapa de topo estendida

Figura 4.1 - Exemplos de ligações viga-pilar 


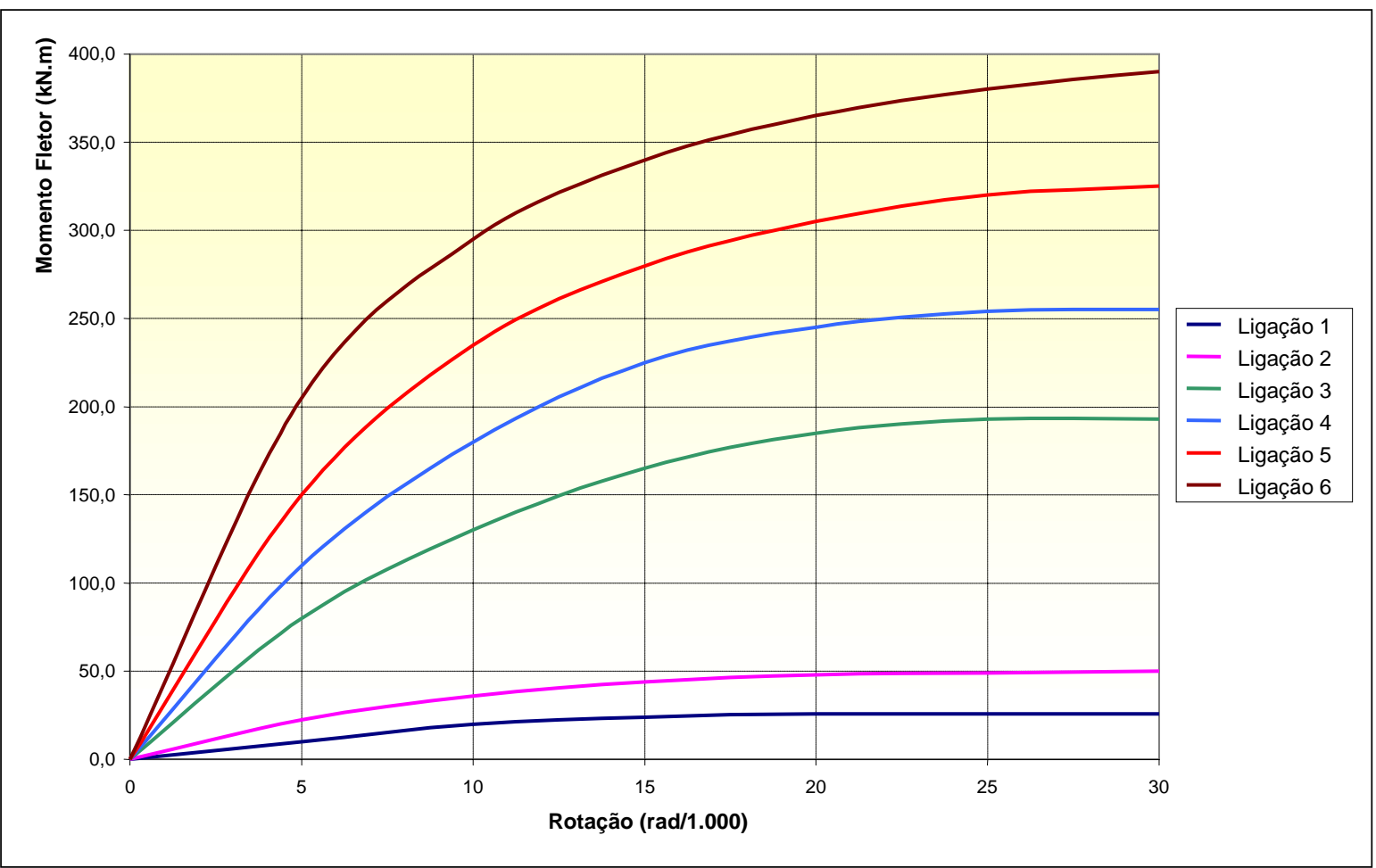

\begin{tabular}{|c|l|}
\hline \multicolumn{2}{|c|}{ Legenda das Ligações } \\
\hline 1 & Ligação com uma cantoneira de alma (single web angle conection) \\
\hline 2 & Ligação com dupla cantoneira de alma (double web angle conection) \\
\hline 3 & Ligação com cantoneiras de topo e assento (top and seat angle conection) \\
\hline 4 & $\begin{array}{l}\text { Ligação com cantoneiras de topo e assento e dupla cantoneira de alma (top and seat } \\
\text { angle with double web conection) }\end{array}$ \\
\hline 5 & Ligação com chapa de topo soldada à alma (flush end plate conection) \\
\hline 6 & Ligação com chapa de topo estendida (extended end plate conection) \\
\hline
\end{tabular}

Figura 4.2 - Exemplos de curvas momento-rotação de alguns tipos de ligações

(Fonte: KISHI \& CHEN (1996))

A rigidez inicial $\left(S_{i}\right)$ descreve o desempenho da ligação no início do carregamento. 0 aspecto linear que a curva momento-rotação assume nessa etapa sugere a existência de uma fase elástica, a qual vai deixando de existir a medida em que o carregamento vai assumindo valores mais elevados. Essa mudança de comportamento é provocada pela existência de concentração de tensões, de imperfeições geométricas e de descontinuidades nos elementos que compõem a ligação, fatores estes que, a partir de certo estágio do carregamento, passam a interferir na capacidade de rotação.

Na fase final do carregamento a curva momento-rotação tende para um valor assintótico conhecido como momento último $\left(M_{u}\right)$, a partir do qual a ligação entra na fase de colapso.

Como ilustração, a Figura 4.3 mostra uma curva momento-rotação de natureza experimental e a sua representação simplificada por meio da rigidez inicial e do momento último. 


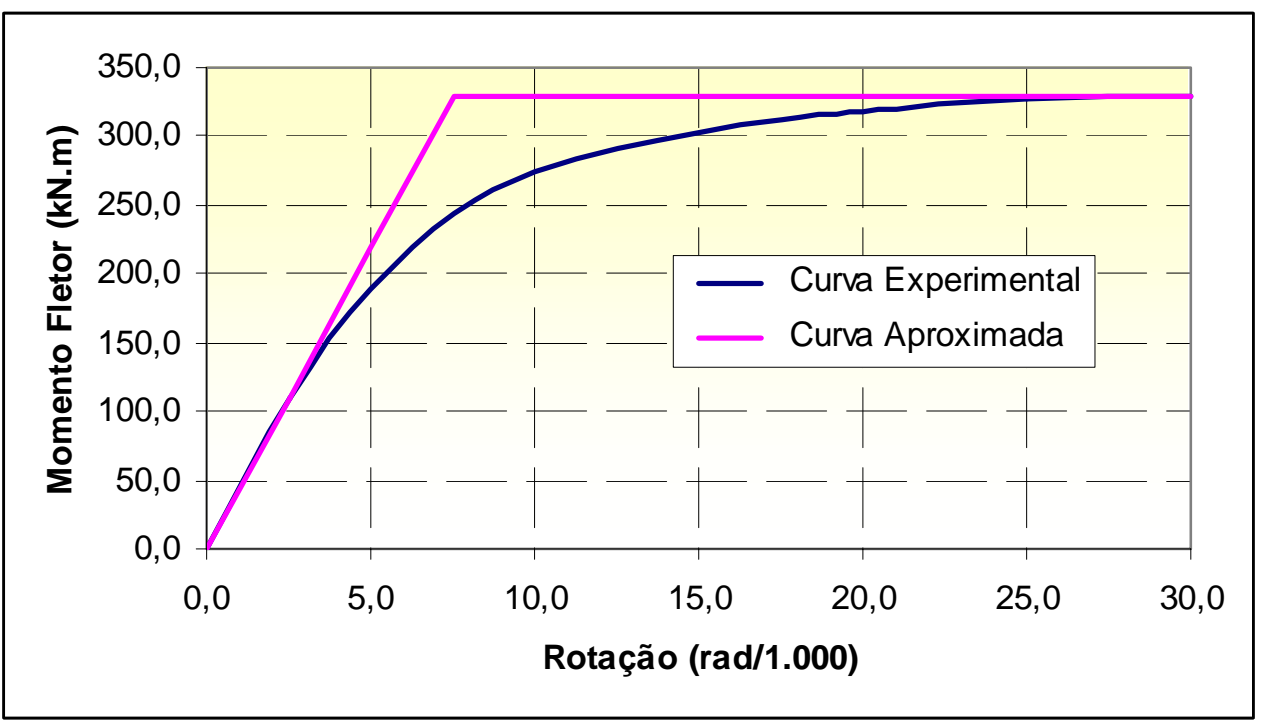

Figura 4.3 - Curva momento-rotação experimental e sua representação simplificada (Fonte: SANTOS \& SÁLES (1999))

COLSON (1990) afirma que a grande vantagem de se trabalhar com esses dois parâmetros é que eles podem ser avaliados a partir das propriedades geométricas e mecânicas dos componentes da ligação, e isso está comprovado em SÁLES (1995), SANTOS (1998) e foi comprovado novamente neste trabalho (ver capítulo 4).

Conhecidos a rigidez inicial e o momento último da ligação, a curva momento-rotação pode ser representada pela forma simplificada mostrada na Figura 4.3, ou descrita em uma forma mais precisa com o auxílio dos modelos de KISHI \& CHEN (1990) e de COLSON (1991).

O modelo de KISHI \& CHEN (1990), que também é conhecido como modelo dos três parâmetros (do inglês "Three parameter power model"), descreve o comportamento das ligações por meio da rigidez inicial $\left(S_{i}\right)$, do momento último $\left(M_{u}\right)$ e de um fator de forma $(n)$, que pode ser obtido pela aplicação de técnicas de ajuste de curva a resultados obtidos de forma numérica e/ou experimental.

A equação que descreve esse modelo é dada por:

$$
M=\frac{S_{i} \phi}{\left[1+\left(\frac{\phi}{\phi_{o}}\right)^{n}\right]^{1 / n}}
$$

onde $\phi_{o}$ é chamado de rotação plástica de referência e é definido por: $\phi_{o}=\frac{M_{u}}{S_{i}}$. 
O modelo de COLSON (1991) parte de um esquema que considera a ligação como um sistema termodinâmico submetido a lentos efeitos mecânicos, efeitos estes decorrentes apenas do momento fletor aplicado.

Fazendo o equilíbrio de energia do sistema, COLSON (1991) monta equações que analisadas sob as leis da termodinâmica conduzem à expressão dada a seguir:

$$
\phi=\frac{M}{S_{i}} \times \frac{1}{1-\left(\frac{M}{M_{u}}\right)^{a}}
$$

onde $a$ é um parâmetro de natureza experimental que, para as ligações por ele estudadas, é definido como:

a) $a=1,5$ para ligações completamente soldadas.

b) $a=2,5$ ou $a=3,0$ para ligações parafusadas sem controle de fabricação.

c) $a=4,0$ ou $a=5,0$ para ligações parafusadas com controle de fabricação.

Existem outros modelos disponíveis na literatura técnica para determinação de curvas momentorotação, vários deles descritos em SANTOS (1998). Um dos mais antigos e, por conseguinte, um dos mais difundidos, é o modelo polinomial de FRYE \& MORRIS (1975). A idéia básica desse modelo consiste em aproximar a curva experimental por meio de uma função polinomial que apresenta a seguinte forma:

$$
\phi=C_{1}(k M)+C_{2}(k M)^{3}+C_{3}(k M)^{5}
$$

onde $k$ é um parâmetro de padronização que depende do tipo e das características geométricas da ligação, e os coeficientes $C_{1}, C_{2}$ e $C_{3}$ são constantes obtidas por técnicas de ajuste de curva.

FRYE \& MORRIS (1975) fornecem os valores das constantes $C_{1}, C_{2}, C_{3}$ e $k$ para diversos tipos de ligações, o que transforma o modelo polinomial em uma ferramenta bastante útil para comparação com resultados fornecidos por outros modelos.

\subsection{2 - Sobre as Ligações com Dupla Tala de Alma Parafusada}

A conexão com dupla tala de alma abordada neste trabalho é, na verdade, composta por duas partes distintas. A primeira delas é responsável pela ligação das talas à alma da viga, e a segunda pela ligação das talas ao pilar ou a uma outra viga. A Figura 4.4 mostra alguns arranjos típicos desse tipo de ligação.

Tendo em vista que o estudo dessas ligações tem um objetivo específico, que é o de simular 0 comportamento da conexão entre arcos e anéis do sistema estrutural descrito no capítulo anterior, foi admitido o esquema de transferência de esforço mostrado na Figura 4.5, no qual a reação do anel passa para as talas por meio da primeira parte da conexão, que é composta pela ligação das talas com a alma do anel, e em seguida passa desta para a segunda parte da conexão, que é 
composta pela ligação das talas com a nervura dos arcos. Daí as reações introduzidas por ambos os perfis do anel chegam à alma do arco.

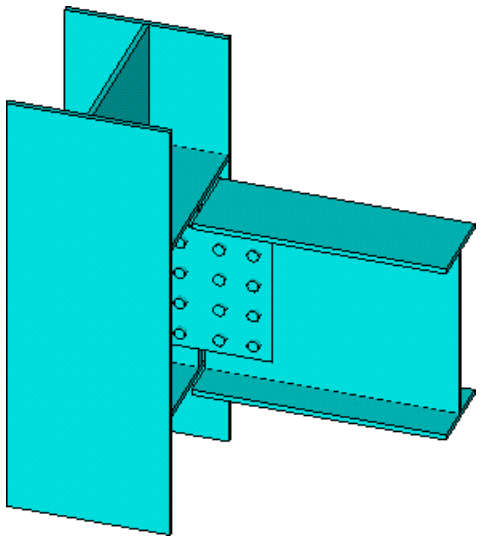

(a) Ligação viga-pilar

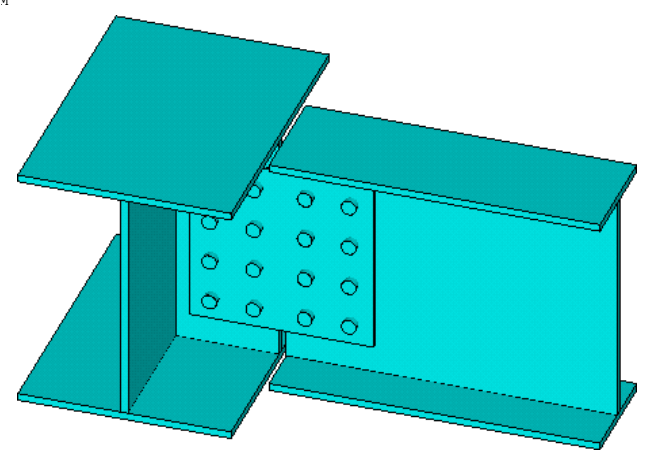

(b) Ligação viga-viga

Figura 4.4 - Ligação com dupla tala de alma parafusada

Sabe-se da literatura técnica que as ligações feitas exclusivamente pela alma do perfil são tipicamente flexíveis, pois a ausência de elementos ligando as mesas facilita o giro da ligação e dificulta a transferência de momento fletor.

O dimensionamento desse tipo de conexão costuma ser feito considerando apenas a existência da força cortante e, dependendo da estrutura em projeto, da força normal. A ligação em si, no entanto, está sempre submetida a um momento fletor decorrente da excentricidade de atuação da força cortante em relação ao centróide da ligação, como mostrado na Figura 4.5. Esse momento é dado por:

$$
M_{d}=V_{d} \times e
$$

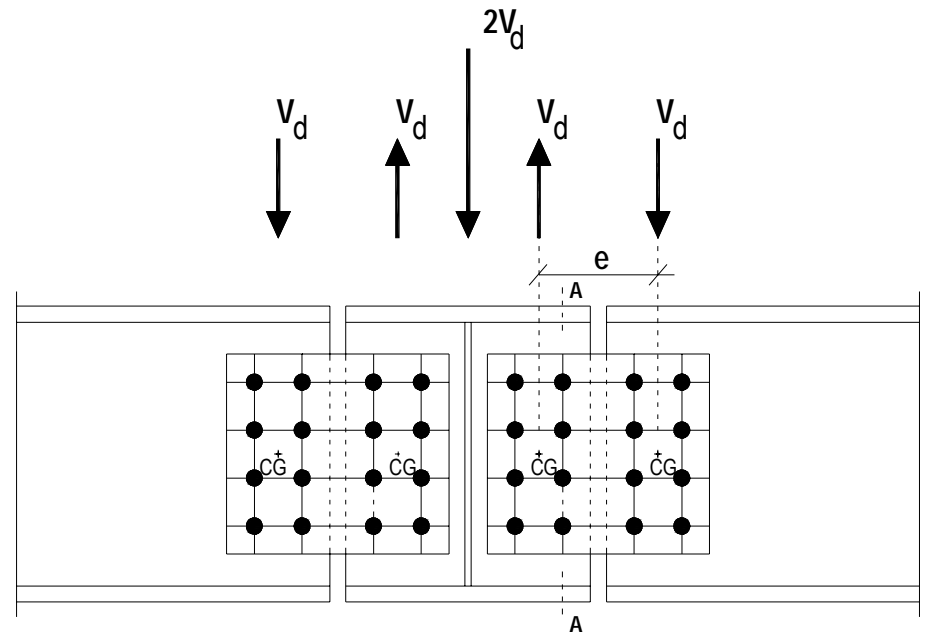

Figura 4.5 - Transferência de esforços na ligação com dupla tala de alma parafusada dos anéis com os $\operatorname{arcos}$ 
Para esse tipo de ligação não foi encontrado na literatura técnica nenhum modelo que permitisse a caracterização do comportamento momento-rotação, de forma que a proposição de um modelo que exerça tal função constitui uma contribuição ao assunto.

Nos próximos itens serão propostas expressões para determinação da rigidez inicial e do momento último desse tipo de ligação, expressões estas que, acopladas às equações de KISHI \& CHEN (1990) e COLSON (1991), permitem a obtenção de curvas momento-rotação.

\subsection{3 - Avaliação da Rigidez Inicial}

$\mathrm{Na}$ análise estrutural é bastante comum a representação dos elementos que compõem a estrutura por meio dos seus eixos, o que implica em admitir que as ligações são elementos discretos situados nas interseções desses eixos. Assim, quando um determinado nó da estrutura sofre uma rotação, admite-se que ela ocorre em torno desse ponto de interseção (JONES et al. (1983); FIELDING (1994))

Nas estruturas onde as ligações apresentam um comportamento ideal, quer seja rígido ou flexível, o giro do nó é composto pelo somatório dos giros introduzidos pelos elementos conectados. Nas estruturas reais, porém, sabe-se que as ligações também introduzem uma parcela de giro cuja intensidade depende, principalmente, do detalhe construtivo adotado. Supondo um sistema vigapilar, o giro total é dado por:

$\phi_{\text {total }}=\phi_{\text {viga }}+\phi_{\text {pilar }}+\phi_{\text {ligação }}$

Se for um sistema viga-viga:

$\phi_{\text {total }}=\phi_{\text {viga } 1}+\phi_{\text {viga } 2}+\phi_{\text {ligação }}$

Analisando as Eqs. 4.5(a) e 4.5(b) do ponto de vista prático, pode-se afirmar que o giro total do sistema deve ser pequeno, caso contrário a estrutura terá atingido um estado limite de utilização. Se o giro total do sistema é pequeno, a parcela correspondente ao giro da ligação é menor ainda, e isso se verifica até mesmo nas ligações ditas flexíveis, que supostamente possuem capacidade infinita de rotação.

A avaliação da rigidez inicial de uma ligação requer a determinação da parcela de giro introduzida apenas pela ligação (RADMZIMINSKI \& AZIZINAMINI (1988), FIELDING (1994), SÁLES (1995), SANTOS (1998)), o que implica em desprezar a influência das flexibilidades dos elementos conectados. Tratando a conexão como um apoio com rotação elástica, pode-se escrever:

$$
M=S_{i} \times \phi_{\text {ligação }}
$$

onde $M$ é o momento fletor aplicado e $S_{i}$ é a rigidez inicial da ligação. Explicitando $S_{i}$ na expressão anterior, encontra-se: 


$$
S_{i}=\frac{M}{\phi_{\text {ligação }}}
$$

O giro total nas conexões com dupla tala de alma é composto por duas parcelas, que são: a) o giro introduzido pela ligação das talas com a alma da viga (ou do anel, no caso em estudo), e b) o giro introduzido pela ligação das talas com o pilar ou com a viga de apoio, que no caso das cúpulas metálicas em estudo é representada pelo arco.

Para determinação do giro da ligação foi admitido o esquema estático mostrado na Figura 4.6(b), que consiste em abordar as talas como um elemento engastado elasticamente em uma extremidade e livre na outra, em cuja formulação foram consideradas as deformações por momento fletor e por força cortante. $O$ apoio elástico representa a influência da ligação das talas com a nervura soldada aos arcos.

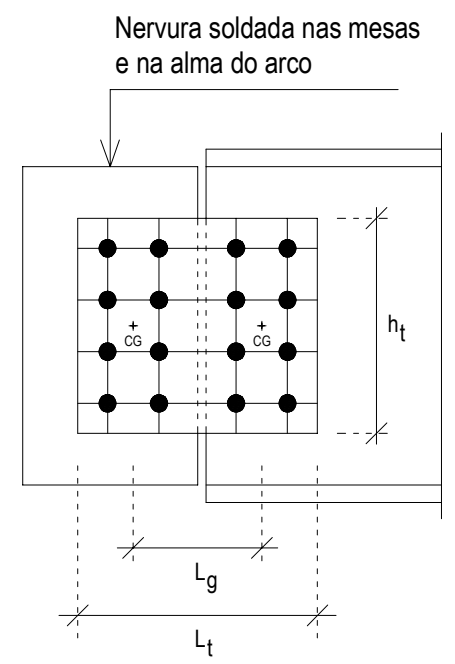

(a)

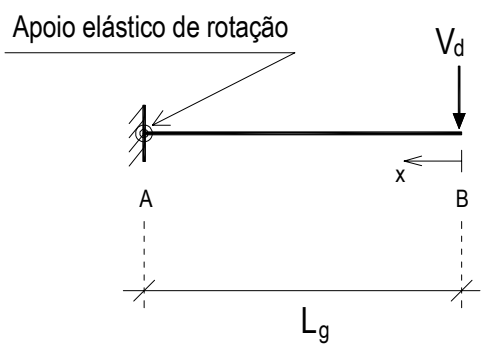

(b)

Figura 4.6 - Esquema estático para determinação do giro da ligação

Calculando inicialmente a flecha máxima sem a deformação por cortante, pode-se escrever, recordando a equação aproximada da curvatura:

$$
E I \frac{d^{2} v}{d x^{2}}=-V_{d} x
$$

Integrando duas vezes encontra-se:

$$
\begin{aligned}
& E I \frac{d v}{d x}=-\frac{V_{d} x^{2}}{2}+C_{1} \\
& E I v=-\frac{V_{d} x^{3}}{6}+C_{1} x+C_{2}
\end{aligned}
$$

A constante $C_{l}$ pode ser obtida impondo a seguinte condição de contorno: 
Se $x=L_{g} \quad \rightarrow \quad \frac{d v}{d x}=\phi_{A}=\frac{M_{A}}{k_{r}}=\frac{V_{d} L_{g}}{k_{r}}$

onde $k_{r}$ é a rigidez à rotação do apoio elástico, e $\phi_{A}$ e $M_{A}$ são, respectivamente, o giro e o momento fletor no ponto $A$.

Dessa condição de contorno resulta:

$C_{1}=\frac{V_{d} L_{g}}{2}\left(1+\frac{2 E I_{t}}{k_{r} L_{g}}\right)$

Fazendo:

$\beta=1+\frac{2 E I_{t}}{k_{r} L_{g}}$

Pode-se escrever:

$C_{1}=\frac{V_{d} L_{g}}{2} \beta$

A constante $C_{2}$ pode ser determinada impondo a seguinte condição de contorno:

Se $x=L_{g} \quad \rightarrow \quad v=0$

daí:

$0=-\frac{V_{d} L_{g}^{3}}{6}+\frac{V_{d} L_{g}^{2}}{2} \beta+C_{2}$

e com isso obtém-se $C_{2}$ que é dado por:

$C_{2}=-\frac{V_{d} L_{g}^{3}}{3}\left(\frac{3 \beta-1}{2}\right)$

Substituindo a Eq. 4.15 na Eq. 4.10, e lembrando que a flecha máxima ocorre quando $x=0$, encontra-se:

$\delta_{\operatorname{máx} 1}=\frac{V_{d} L_{g}^{3}}{3 E I}\left(\frac{3 \beta-1}{2}\right)$

Substituindo a Eq. 4.12 na Eq. 4.16 encontra-se: 


$$
\delta_{\text {máx } 1}=\frac{V_{d} L_{g}^{3}}{3 E I}\left(1+\frac{3 E I}{k_{r} L_{g}}\right)
$$

Fazendo:

$$
\alpha=\frac{1}{1+\frac{3 E I}{k_{r} L_{g}}}
$$

Pode-se escrever:

$$
\delta_{\text {máx } 1}=\frac{V_{d} L_{g}^{3}}{3 E I \alpha}
$$

Vê-se que a rigidez do apoio elástico é considerado no cálculo por meio do parâmetro $\alpha$, denominado aqui como fator de rigidez. Esse parâmetro varia de 0 , quando a rigidez à rotação $\left(k_{r}\right)$ do apoio elástico é nula (situação de articulação perfeita), à 1 , quando a rigidez à rotação é infinita (situação de engaste perfeito).

O deslocamento máximo provocado pelas deformações por cortante no esquema estático em questão é, segundo GERE \& WEAVER (1987), dado por:

$$
\delta_{\text {máx } 2}=\frac{6 V_{d} L_{g}}{5 G A}
$$

Somando os deslocamentos máximos das Eqs. 4.19 e 4.20 encontra-se o deslocamento máximo total, que é dado por:

$$
\delta_{\text {máx }}=\frac{V_{d} L_{g}^{3}}{3 E I \alpha}+\frac{6 V_{d} L_{g}}{5 G A}
$$

Rearranjando:

$$
\delta_{\text {máx }}=V_{d} L_{g}\left(\frac{5 G A L_{g}^{2}+18 E I}{15 E I G A \alpha}\right)
$$

Admitindo que o giro da ligação é pequeno, a rotação máxima pode ser determinada fazendo:

$$
\phi_{\max }=\frac{\delta_{\text {max }}}{L_{g}}
$$


Daí resulta:

$$
\phi_{\text {máx }}=V_{d}\left(\frac{15 E I G A \alpha}{5 G A L_{g}^{2}+18 E I}\right)
$$

O momento máximo nas talas é dado por (ver Figura 4.5):

$$
M=V_{d} L_{g}
$$

Substituindo as Eqs. 4.24 e 4.25 na Eq. 4.7 encontra-se a rigidez inicial da ligação, que é dada por:

$$
S_{i}=\frac{15 E I G A L_{g} \alpha}{5 G A L_{g}^{2}+18 E I}
$$

Lembrando que $A=t_{t t} h_{t}$ e $I=\frac{t_{t t} h_{t}^{3}}{12}$, onde $t_{t t}$ é a espessura total das talas de alma (somatório da espessura das duas chapas) e $h_{t}$ é a altura dessas talas, encontra-se:

$$
S_{i}=\frac{t_{t t} h_{t}^{3} E G L_{g} \alpha}{4 G L_{g}^{2}+1,20 E h_{t}^{2}}
$$

O uso da equação aproximada da curvatura (Eq. 4.8) na formulação do modelo pode parecer estranho e até mesmo inconsistente por conta das dimensões da tala, cuja altura pode ser maior que a largura. No entanto, tal equação foi utilizada por possibilitar a obtenção de uma expressão bastante simples para a rigidez inicial, a qual depende de um parâmetro adimensional $\alpha$ que pode ser facilmente ajustado com base em resultados numéricos e/ou experimentais. Dessa forma, o erro introduzido pela equação aproximada da curvatura pode ser eliminado, ou minimizado, por ocasião do ajuste do parâmetro $\alpha$.

\subsubsection{1 - Ajuste do Fator de Rigidez $\alpha$}

Observa-se que a aferição do modelo pode ser feita tanto em função do fator de rigidez $\alpha$ quanto em função da rigidez do apoio elástico $k_{r}$, a partir da qual o parâmetro $\alpha$ pode ser determinado (Eq 4.17). Este último procedimento, no entanto, tem o inconveniente de exigir o manuseio de números extremamente elevados, uma vez que a rigidez do apoio elástico apresenta, dependendo das dimensões da ligação, valores da ordem de $1 \times 10^{8} \mathrm{kNcm} / \mathrm{rad}$. Sendo assim, o ajuste direto do fator $\alpha$, cujos valores variam de 0 a 1 , mostrou-se muito mais simples, e por isso foi adotado neste trabalho.

O fator de rigidez foi ajustado em função de 28 simulações numéricas em elementos finitos nas quais foram adotados diferentes valores para os diversos parâmetros que compunham a ligação. A Tabela 4.1 e a Figura 4.7 fornecem os dados e 0 aspecto geral dos casos simulados. 
Tabela 4.1 - Dados dos modelos simulados numericamente para determinação do fator de rigidez

\begin{tabular}{|c|c|c|c|c|c|c|c|c|c|}
\hline \multirow{2}{*}{ Modelo } & \multicolumn{2}{|c|}{ Parafusos } & \multicolumn{4}{|c|}{ Dados das Talas } & \multicolumn{3}{|c|}{ Dados da Nervura } \\
\hline & $\mathrm{nL}$ & $\mathrm{n}_{\mathrm{p}}$ & $h_{t}(\mathrm{~mm})$ & $L_{t}(\mathrm{~mm})$ & $t_{t t}(\mathrm{~mm})$ & $\mathrm{L}_{g}(\mathrm{~mm})$ & $h_{\text {nerv }}(\mathrm{mm})$ & $L_{\text {nerv }}(m m)$ & $t_{\text {nerv }}(\mathrm{mm})$ \\
\hline 1 & 4 & 5 & 300 & 310 & 16 & 160 & 400 & 175 & 10 \\
\hline 2 & 4 & 5 & 300 & 310 & 20 & 160 & 400 & 175 & 10 \\
\hline 3 & 4 & 5 & 300 & 310 & 24 & 160 & 400 & 175 & 10 \\
\hline 4 & 4 & 5 & 300 & 310 & 16 & 160 & 500 & 175 & 10 \\
\hline 5 & 4 & 5 & 300 & 310 & 20 & 160 & 500 & 175 & 10 \\
\hline 6 & 4 & 5 & 300 & 310 & 24 & 160 & 500 & 175 & 10 \\
\hline 7 & 4 & 6 & 400 & 310 & 20 & 160 & 700 & 175 & 10 \\
\hline 8 & 4 & 5 & 300 & 310 & 20 & 160 & 700 & 175 & 10 \\
\hline 9 & 4 & 3 & 200 & 310 & 20 & 160 & 700 & 175 & 10 \\
\hline 10 & 4 & 5 & 300 & 310 & 16 & 160 & 400 & 175 & 15 \\
\hline 11 & 4 & 5 & 300 & 310 & 20 & 160 & 400 & 175 & 15 \\
\hline 12 & 4 & 5 & 300 & 310 & 24 & 160 & 400 & 175 & 15 \\
\hline 13 & 4 & 5 & 300 & 310 & 16 & 160 & 400 & 225 & 15 \\
\hline 14 & 4 & 5 & 300 & 310 & 20 & 160 & 400 & 225 & 15 \\
\hline 15 & 4 & 5 & 300 & 310 & 24 & 160 & 400 & 225 & 15 \\
\hline 16 & 2 & 5 & 300 & 210 & 16 & 110 & 400 & 175 & 10 \\
\hline 17 & 2 & 5 & 300 & 210 & 20 & 110 & 400 & 175 & 10 \\
\hline 18 & 2 & 5 & 300 & 210 & 24 & 110 & 400 & 175 & 10 \\
\hline 19 & 2 & 5 & 300 & 210 & 16 & 110 & 500 & 175 & 10 \\
\hline 20 & 2 & 5 & 300 & 210 & 20 & 110 & 500 & 175 & 10 \\
\hline 21 & 2 & 5 & 300 & 210 & 24 & 110 & 500 & 175 & 10 \\
\hline 22 & 2 & 3 & 200 & 210 & 20 & 110 & 700 & 175 & 10 \\
\hline 23 & 2 & 5 & 300 & 210 & 16 & 110 & 400 & 175 & 15 \\
\hline 24 & 2 & 5 & 300 & 210 & 20 & 110 & 400 & 175 & 15 \\
\hline 25 & 2 & 5 & 300 & 210 & 24 & 110 & 400 & 175 & 15 \\
\hline 26 & 2 & 5 & 300 & 210 & 16 & 110 & 400 & 225 & 15 \\
\hline 27 & 2 & 5 & 300 & 210 & 20 & 110 & 400 & 225 & 15 \\
\hline 28 & 2 & 5 & 300 & 210 & 24 & 110 & 400 & 225 & 15 \\
\hline
\end{tabular}

Nervura soldada ao pilar

ou a uma outra viga

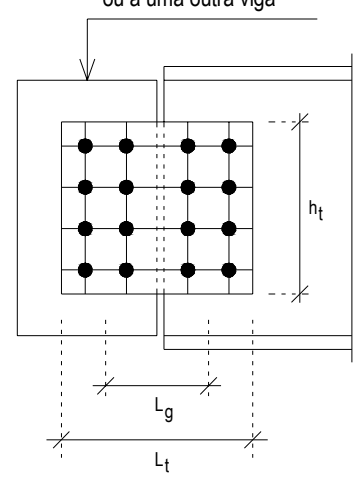

(a) Ligação com quatro linhas de parafusos (duas em cada elemento)
Nervura soldada ao pilar

ou a uma outra viga

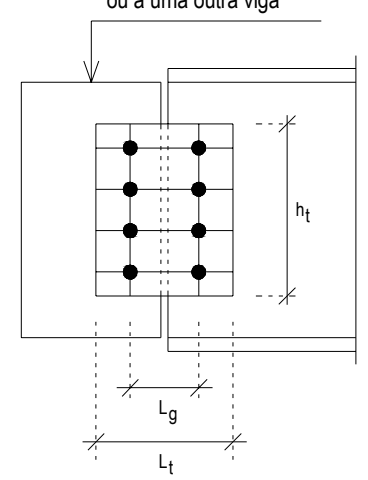

(b) Ligação com duas linhas de parafusos (uma em cada elemento)

Figura 4.7 - Esquema dos modelos simulados numericamente 
0 estudo numérico foi realizado utilizando o programa computacional ANSYS 7.1 (2000) e 0 elemento finito hexaédrico SOLID45, que permite gerar malhas bastante regulares e fáceis de trabalhar, o que se mostrou bastante conveniente por conta da necessidade de sobrepor as malhas dos sólidos que compunham o perfil e a nervura com o conjunto das talas. Tal elemento, representado esquematicamente na Figura 4.8, possui oito nós com três graus de liberdade de translação cada um, e permite a utilização de leis constitutivas não-lineares para o material.

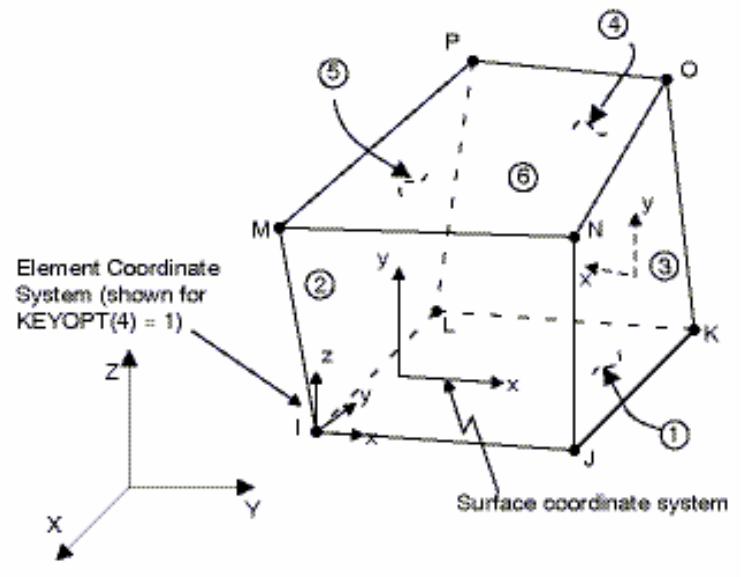

Figura 4.8 - Elemento Finito SOLID 45 (Fonte: ANSYS 7.1 (2000))

A ligação entre as chapas do perfil foi simulada com o auxílio de um recurso do ANSYS 7.1 (2000) conhecido como "nós coincidentes". Já a existência dos parafusos foi considerada por meio da acoplagem dos deslocamentos de vários nós localizados no perfil e nas talas, o que permitiu gerar um modelo simples e fácil de trabalhar. A Figura 4.9 mostra um dos modelos analisados.

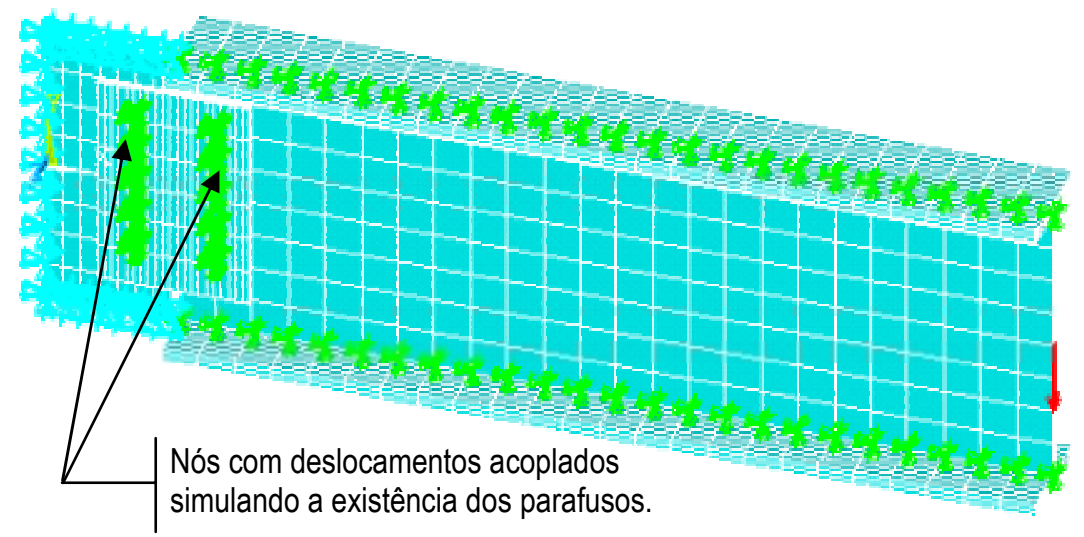

Figura 4.9 - Modelo em elementos finitos analisado no ANSYS 7.1 (2000)

O acoplamento dos deslocamentos na região dos parafusos permitiu que os esforços atuantes na parte do perfil onde estava aplicado o carregamento fossem transmitidos para as talas, e destas para a nervura, como ocorre no modelo real. 
A Tabela 4.2 apresenta os resultados obtidos numericamente via elementos finitos e aqueles encontrados fazendo $\alpha=1,0$ na Eq. 4.26. Dividindo um valor pelo outro foram encontrados os valores que o fator de rigidez deveria apresentar para que os resultados coincidissem.

Tabela 4.2 - Resultados dos exemplos simulados numericamente

\begin{tabular}{|c|c|c|c|c|}
\hline Modelo & $S_{i}(M E F)$ & $S_{i}(M P)$ & $\eta$ & $\alpha\left(\mathrm{S}_{\mathrm{i}(\mathrm{MP})} / \mathrm{S}_{\mathrm{i}(\mathrm{MEF})}\right)$ \\
\hline 1 & 2.012 .119 & 3.737 .202 & 0,830 & 0,538 \\
\hline 2 & 2.207 .048 & 4.671 .502 & 0,664 & 0,472 \\
\hline 3 & 2.362 .403 & 5.605 .802 & 0,554 & 0,421 \\
\hline 4 & 1.899 .770 & 3.737 .202 & 0,664 & 0,508 \\
\hline 5 & 2.073 .567 & 4.671 .502 & 0,531 & 0,444 \\
\hline 6 & 1.949 .933 & 5.605 .802 & 0,443 & 0,348 \\
\hline 7 & 3.721 .342 & 7.063 .257 & 0,506 & 0,527 \\
\hline 8 & 1.670 .902 & 4.671 .502 & 0,380 & 0,358 \\
\hline 9 & 551.192 & 2.328 .305 & 0,253 & 0,237 \\
\hline 10 & 2.600 .969 & 3.737 .202 & 1,246 & 0,696 \\
\hline 11 & 2.922 .936 & 4.671 .502 & 0,996 & 0,626 \\
\hline 12 & 3.190 .896 & 5.605 .802 & 0,830 & 0,569 \\
\hline 13 & 2.497 .051 & 3.737 .202 & 0,969 & 0,668 \\
\hline 14 & 2.791 .448 & 4.671 .502 & 0,775 & 0,598 \\
\hline 15 & 3.033 .946 & 5.605 .802 & 0,646 & 0,541 \\
\hline 16 & 1.309 .955 & 2.996 .033 & 0,563 & 0,437 \\
\hline 17 & 1.487 .965 & 3.745 .041 & 0,450 & 0,397 \\
\hline 18 & 1.559 .054 & 4.494 .049 & 0,375 & 0,347 \\
\hline 19 & 1.327 .158 & 2.996 .033 & 0,450 & 0,443 \\
\hline 20 & 1.413 .138 & 3.745 .041 & 0,360 & 0,377 \\
\hline 21 & 1.477 .103 & 4.494 .049 & 0,300 & 0,329 \\
\hline 22 & 320.726 & 2.105 .018 & 0,171 & 0,152 \\
\hline 23 & 1.862 .592 & 2.996 .033 & 0,844 & 0,622 \\
\hline 24 & 2.036 .011 & 3.745 .041 & 0,675 & 0,544 \\
\hline 25 & 2.171 .093 & 4.494 .049 & 0,563 & 0,483 \\
\hline 26 & 1.813 .098 & 2.996 .033 & 0,656 & 0,605 \\
\hline 27 & 1.977 .089 & 3.745 .041 & 0,525 & 0,528 \\
\hline 28 & 2.104 .410 & 4.494 .049 & 0,438 & 0,468 \\
\hline
\end{tabular}

Comparando os resultados obtidos com os dados dos exemplos analisados (ver Tabelas 4.1 e 4.2 ) observou-se que o fator de rigidez apresenta o seguinte comportamento:

a) Aumenta com a espessura da nervura e com a altura e largura das talas.

b) Diminui com a espessura das talas e com a altura e largura das nervuras.

Criando o fator $\eta=\frac{h_{t} t_{n e r v} L_{t}}{t_{t t} h_{n e r v} L_{n e r v}}$, que leva em consideração os parâmetros que afetam 0 comportamento de $\alpha$, foi possível plotar o gráfico $\eta x \alpha$ mostrado na Figura 4.10. 


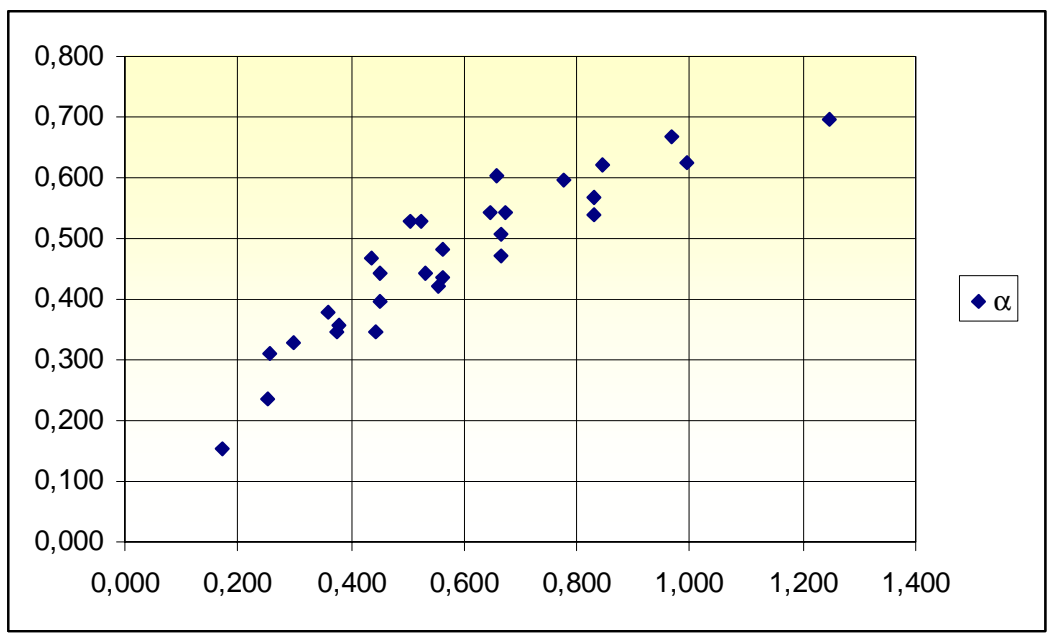

Figura 4.10 - Comportamento $\eta x \alpha$

Este gráfico (Figura 4.10) mostra a existência de uma regularidade no comportamento $\eta x \alpha$, o que torna viável a interpolação de uma curva para determinação de $\alpha$ em função de $\eta$. Utilizando 0 "software" Mathcad 2000 Professional foram encontradas as Eq. 4.28 e 4.29, dadas a seguir. 0 desempenho dessas expressões está mostrado na Figura 4.11.

$$
\begin{aligned}
& \alpha=\frac{0,596}{1+9,627 e^{-7,074 \eta}} \\
& \alpha=0,675 \eta^{0,608}-0,005
\end{aligned}
$$

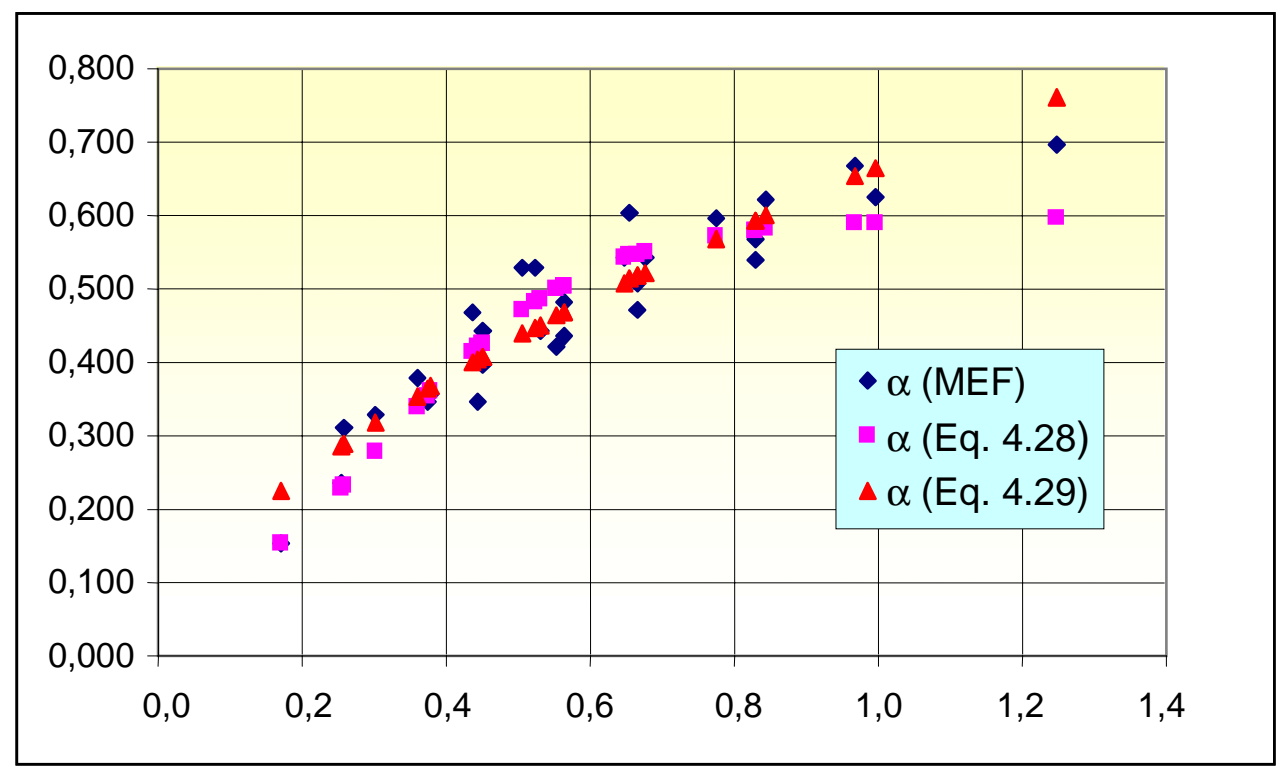

Figura 4.11 - Comportamento $\eta x \alpha$ (Eqs. 4.27 e 4.28)

Aplicando a técnica dos mínimos quadrados conseguiu-se ajustar uma expressão na qual 0 parâmetro $\eta$ foi separado em três partes, cada uma delas submetida a um coeficiente diferente, 0 
que permitiu avaliar mais precisamente a influência de cada parâmetro no comportamento da ligação. A equação obtida está mostrada a seguir, e seu desempenho ilustrado na Figura 4.12.

$\alpha=1,8167\left(\frac{h_{t}}{t_{t t}}\right)^{0,1914}\left(\frac{t_{\text {nerv }}}{h_{\text {nerv }}}\right)^{0,1572}\left(\frac{L_{t}}{L_{\text {nerv }}}\right)^{0,0923}+0,0923$

(Eq. 4.30)

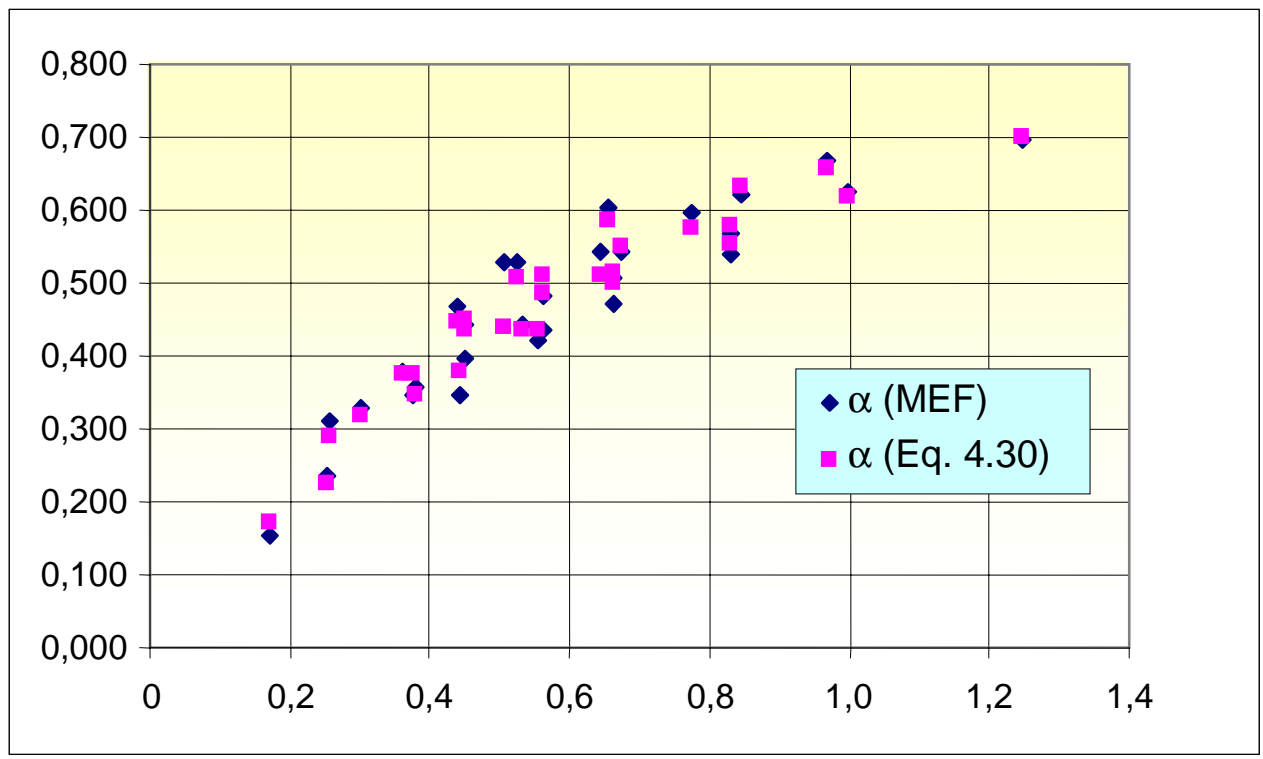

Figura 4.12 - Comportamento $\eta x \alpha$ (Eq. 4.29)

A Tabela 4.3 compara os valores da rigidez inicial nos 28 casos analisados via elementos finitos com aqueles fornecidos pelo modelo proposto ( $S_{i}$ avaliado pelas Eqs. 4.27 e 4.30). Os resultados mostram uma diferença de aproximadamente $\pm 15 \%$, o que pode ser considerado uma aproximação bastante razoável para a variável em questão.

Tabela 4.3 - Comparação de resultados para a rigidez inicial $\left(\mathrm{S}_{\mathrm{i}}\right)(\mathrm{MP}=$ Modelo proposto / Eqs. 4.27 e 4.30)

\begin{tabular}{c|c|c|c|c|c|c|c}
\hline Modelo & $\mathbf{S}_{\mathbf{i}}$ (MEF) & $\mathbf{S}_{\mathbf{i}}(\mathbf{M P})$ & Diferença & Modelo & $\mathbf{S}_{\mathbf{i}}$ (MEF) & $\mathbf{S}_{\mathbf{i}}(\mathbf{M P})$ & Diferença \\
\hline $\mathbf{1}$ & 2.012 .119 & 2.159 .240 & $\mathbf{7} \%$ & $\mathbf{1 5}$ & 3.033 .946 & 2.855 .533 & $-6 \%$ \\
\hline $\mathbf{2}$ & 2.207 .048 & 2.331 .976 & $6 \%$ & $\mathbf{1 6}$ & 1.309 .955 & 1.532 .202 & $17 \%$ \\
\hline $\mathbf{3}$ & 2.362 .403 & 2.452 .172 & $4 \%$ & $\mathbf{1 7}$ & 1.487 .965 & 1.631 .368 & $10 \%$ \\
\hline $\mathbf{4}$ & 1.899 .770 & 1.917 .137 & $1 \%$ & $\mathbf{1 8}$ & 1.559 .054 & 1.689 .901 & $8 \%$ \\
\hline $\mathbf{5}$ & 2.073 .567 & 2.042 .000 & $-2 \%$ & $\mathbf{1 9}$ & 1.327 .158 & 1.344 .966 & $1 \%$ \\
\hline $\mathbf{6}$ & 1.949 .933 & 2.116 .134 & $9 \%$ & $\mathbf{2 0}$ & 1.413 .138 & 1.407 .108 & $0 \%$ \\
\hline $\mathbf{7}$ & 3.534 .363 & 3.114 .146 & $-13 \%$ & $\mathbf{2 1}$ & 1.477 .103 & 1.430 .019 & $-3 \%$ \\
\hline $\mathbf{8}$ & 1.670 .902 & 1.623 .541 & $-3 \%$ & $\mathbf{2 2}$ & 320.726 & 358.941 & $12 \%$ \\
\hline $\mathbf{9}$ & 551.192 & 522.468 & $-5 \%$ & $\mathbf{2 3}$ & 1.862 .592 & 1.889 .694 & $1 \%$ \\
\hline $\mathbf{1 0}$ & 2.600 .969 & 2.621 .492 & $1 \%$ & $\mathbf{2 4}$ & 2.036 .011 & 2.059 .550 & $1 \%$ \\
\hline $\mathbf{1 1}$ & 2.922 .936 & 2.885 .632 & $-1 \%$ & $\mathbf{2 5}$ & 2.171 .093 & 2.186 .098 & $1 \%$ \\
\hline $\mathbf{1 2}$ & 3.190 .896 & 3.093 .775 & $-3 \%$ & $\mathbf{2 6}$ & 1.813 .098 & 1.756 .949 & $-3 \%$ \\
\hline $\mathbf{1 3}$ & 2.497 .051 & 2.449 .847 & $-2 \%$ & $\mathbf{2 7}$ & 1.977 .089 & 1.900 .555 & $-4 \%$ \\
\hline $\mathbf{1 4}$ & 2.791 .448 & 2.680 .046 & $-4 \%$ & $\mathbf{2 8}$ & 2.104 .410 & 2.001 .848 & $-5 \%$ \\
\hline
\end{tabular}




\subsection{4 - Avaliação do Momento Último}

O momento último de uma ligação pode ser avaliado considerando os critérios utilizados para dimensioná-la (SANTOS (1998)).

O momento fletor que solicita as ligações com dupla tala de alma parafusada é provocado pela atuação excêntrica da força cortante em relação ao centróide dos grupos de parafusos, como mostrado na Figura 4.5, sendo dado por:

$$
M_{d}=V_{d} \times e=V_{d} \times L_{g}
$$

Para a ligação em estudo, o momento último pode ser avaliado em função da resistência das talas e dos parafusos, o que é conseguido determinando a força cortante que provoca um estado limite último nesses elementos.

\subsubsection{1 - Determinação do momento último em funcão da resistência das talas}

Segundo ANDRADE (1994) a região mais solicitada das talas é a seção A-A, indicada na Figura 4.5. Os esforços que atuam nessa seção são a força cortante $V_{d}$ e um momento fletor dado por:

$$
M=V_{d} \times(e-x)
$$

onde $x$ é a distância do centróide do grupo de parafusos à seção A-A.

\section{a) Momento último em função do colapso das talas por tensões normais}

O colapso por tensões normais ocorre quando a tensão na seção A-A atinge o limite de escoamento, o que permite escrever:

$$
\frac{M_{u 1}}{W_{x t}}=f_{y}
$$

lembrando que $W_{x t}=\frac{t_{t t} h_{t}^{2}}{6}$, encontra-se:

$$
M_{u 1}=\frac{t_{t t} h_{t}^{2} f_{y}}{6}
$$

\section{b) Momento último em função do colapso das talas por tensões cisalhantes}

O Colapso por cisalhamento das talas ocorre quando: 
$\frac{V_{d}}{A_{t}}=0,6 f_{y}$

Como $A_{t}=t_{t t} h_{t}$, o esforço cortante máximo resulta em:

$$
V_{d}=0,6 t_{t t} h_{t} f_{y}
$$

Multiplicando ambos os lados da Eq. 36 pela excentricidade $e$, e lembrando que $e=L_{g}$, encontra-se o momento que provoca o colapso das talas por cisalhamento:

$$
M_{u 2}=0,6 t_{t t} h_{t} L_{g} f_{y}
$$

\subsubsection{2 - Determinação do momento último em função da resistência dos parafusos}

Nos parafusos sob cisalhamento excêntrico, que é o caso das ligações com dupla tala de alma em estudo, o colapso ocorre com a ruptura do conector mais solicitado, o que permite escrever, admitindo parafusos com a rosca inclusa no plano de corte e utilizando o método vetorial para determinação do esforço no parafuso mais solicitado, a seguinte expressão:

$$
F_{d}=\sqrt{\left(F_{m x}\right)^{2}+\left(F_{v y}+F_{m y}\right)^{2}}=0,42 A_{p} f_{u p}
$$

onde:

$$
\begin{aligned}
& A_{p}=\text { Área do parafuso } \\
& f_{u}=\text { tensão de ruptura do parafuso } \\
& F_{v y}=\frac{V_{d}}{n_{p}} \\
& F_{m x}=\frac{M}{\sum R_{v p}^{2}} \times y \\
& F_{m x}=\frac{M}{\sum R_{v p}^{2}} \times x \\
& M=V_{d} \times e
\end{aligned}
$$

Substituindo as expressões anteriores na Eq. 4.38 obtém-se:

$$
\frac{1}{\left(\sum R_{v}^{2}\right)^{2}}\left(x^{2}+y^{2}+\frac{\sum R_{v}^{2}}{n_{p}^{2} e^{2}}\right) M_{u 3}^{2}+\left(\frac{2 x}{n_{p}\left(\sum R_{v}^{2}\right)^{2}}\right) M_{u 3}-0,18 A_{p}^{2} f_{u}^{2}=0
$$

que é uma equação do segundo grau cuja raiz positiva fornece o valor de $M$ que provoca a ruptura do parafuso mais solicitado. Daí: 
$M_{u 3}=\frac{(-b+\sqrt{\Delta})}{2 a}$

onde:

$$
\begin{aligned}
& \Delta=b^{2}-4 a c \\
& a=\frac{1}{\left(\sum R_{v}^{2}\right)^{2}}\left(x^{2}+y^{2}+\frac{\sum R_{v}^{2}}{n_{p}^{2} e^{2}}\right) \\
& b=\left(\frac{2 x}{n_{p}\left(\sum R_{v}^{2}\right)^{2}}\right) \\
& c=-0,18 A_{p}^{2} f_{u}^{2}
\end{aligned}
$$

Obviamente que poderia ter sido utilizado um método mais preciso para determinação do esforço no parafuso mais solicitado, como o método do centro instantâneo de rotação, por exemplo. No entanto, como é suficiente obter apenas uma estimativa do momento último da ligação, o método vetorial mostrou-se adequado dado sua simplicidade e praticidade.

\subsubsection{3 - Considerações finais sobre a determinação do momento último}

O projeto de ligações com dupla tala de alma parafusada envolve, naturalmente, mais verificações do que aquelas relacionadas com as talas e os parafusos. Para a avaliação do momento último, no entanto, é suficiente considerar apenas a influência desses dois elementos, pois, se a ligação estiver devidamente dimensionada, os valores obtidos considerando as demais formas de colapso não serão muito diferentes daqueles fornecidos pelas Eqs. 4.34, 4.37 e 4.40.

\subsection{5 - Curvas Momento-Rotação}

A fim de obter informações mais completas para avaliação do modelo proposto, foram desenvolvidas algumas simulações em elementos finitos considerando a não linearidade física dos materiais empregados, e o contato existente entre os parafusos e as chapas que compunham a ligação. Os benefícios desse estudo foram os seguintes:

a) Avaliação da perda de rigidez que a ligação sofre com o acréscimo do carregamento, e a obtenção de curvas momento-rotação que serviram de base para comparação com 0 modelo proposto.

b) Determinação das constantes $n$ e $a$, que constam nos modelos de KISHI \& CHEN (1990) e COLSON (1991), respectivamente, com as quais pôde-se acoplar esses modelos com o que foi proposto neste trabalho.

Nos exemplos simulados numericamente nesta parte do trabalho o comportamento do material foi representado por um diagrama bi-linear, o qual, segundo MAGGI (2000), reproduz consistentemente 
o comportamento do aço. A Figura 4.13 ilustra esse diagrama, que no programa computacional ANSYS recebe o nome de "Bilinear isotropic hardening plasticity", ou simplesmente BISO.

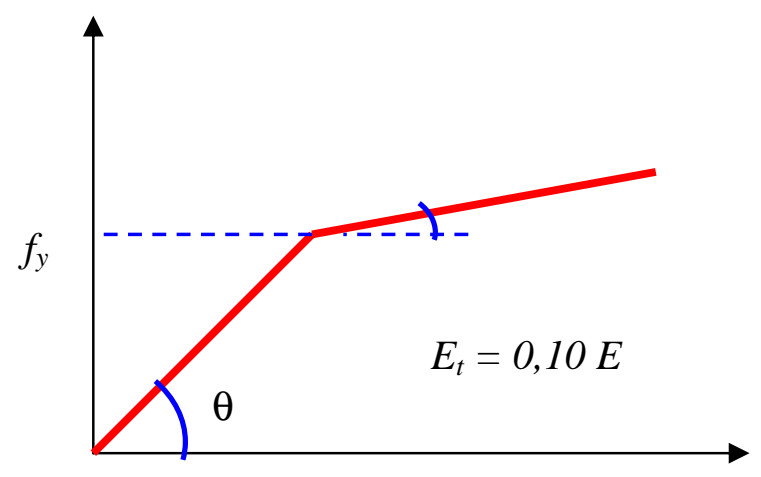

Figura 4.13 - Modelo elastoplástico bilinear

Na figura anterior $f_{y}$ é a tensão de escoamento do aço, $E$ é o módulo de elasticidade longitudinal e $E_{t}$ o módulo de elasticidade tangente, que, segundo o modelo em questão, passa a governar 0 comportamento do material quando este atinge o limite de escoamento.

Para chapas e perfis foram adotadas as propriedades do aço ASTM A-36, cuja tensão de escoamento é de $250 \mathrm{MPa}$ e o módulo de elasticidade longitudinal é de $205.000 \mathrm{MPa}$. Para 0 módulo plástico $\left(E_{t}\right)$ foi adotado o valor clássico de $10 \%$ do valor do módulo de elasticidade longitudinal, assim: $E_{t}=0,10 \times 205000 \mathrm{MPa} \therefore E_{t}=20500 \mathrm{MPa}$.

Os parafusos adotados nas simulações foram do tipo A-325, com tensão de escoamento de 635 MPa e módulos de elasticidade iguais aos do aço ASTM A-36.

A interação entre os parafusos e as chapas que compunham a ligação foi simulada por meio de elementos de contato do tipo superfície-superfície. Entre os elementos disponíveis na biblioteca do ANSYS 7.1 (2000) foram escolhidos os elementos TARGE169 e CONTA173.

Os elementos finitos de contato informam ao programa computacional que determinados grupos de elementos não estão interligados, mas apenas em contato, e que, dependendo do sentido da solicitação, poderão ser pressionados uns contra os outros ou afastados uns dos outros.

Os elementos TARGE169 e CONTA173 estabelecem a interação entre os sólidos que compõem o modelo definindo pares de contato compostos por superfícies "alvo" e superfícies de contato propriamente ditas. Os elementos TARGE169, cujo nome se origina na palavra inglesa "target", representam as superfícies deformáveis no par de contato, e são o alvo sobre o qual um outro sólido poderá ser pressionado. 0 contato se estabelece quando os elementos CONTA173, cujo nome se origina na palavra inglesa "contact", penetram na superfície alvo.

Os elementos finitos de contato acrescentam novos termos na matriz de rigidez do modelo, fornecendo informações sobre os locais onde surgirão pressões ou afastamentos entre os 
elementos. "Assim, o elemento de contato possui a característica de apresentar rigidez na compressão e nenhuma rigidez na tração" (MAGGI (2000)).

A Figura 4.14 ilustra um dos modelos analisados, e as Figuras 4.15 e 4.16 os resultados obtidos nos dois casos simulados com os critérios descritos anteriormente.

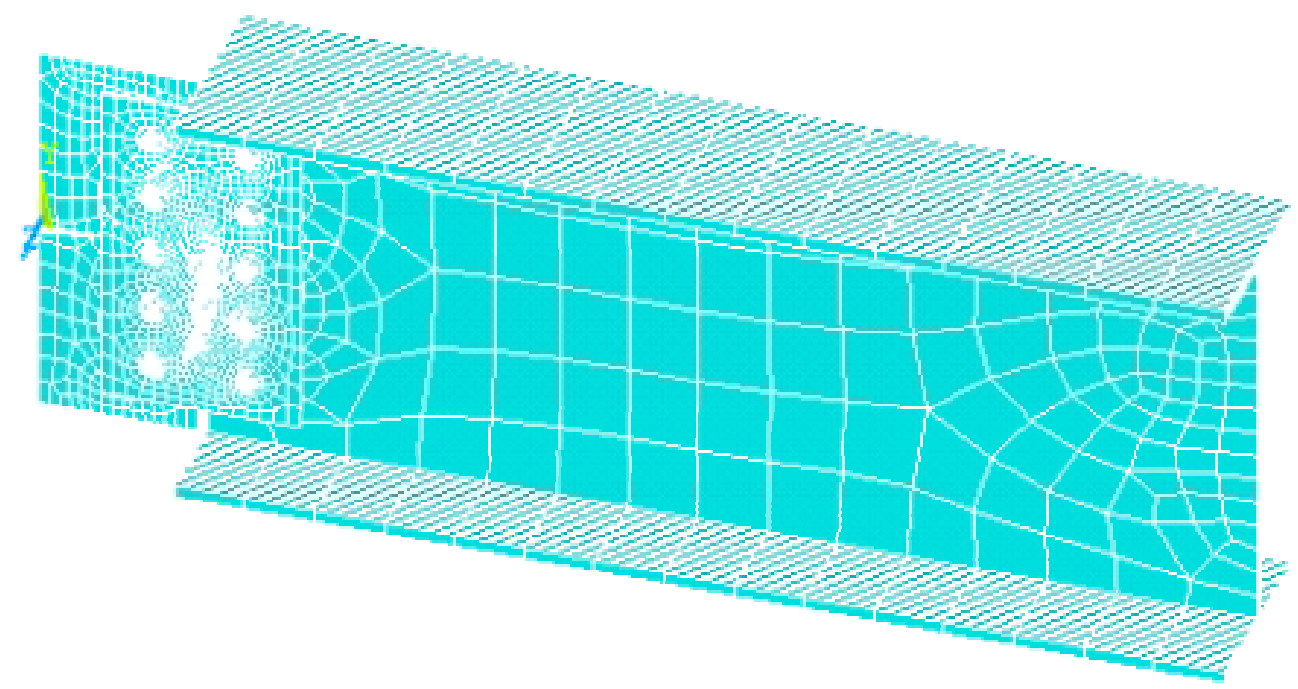

Figura 4.14 - Modelo em elementos finitos no qual foi considerado o comportamento não-linear do material e o contato entre os parafusos e as chapas do perfil, das talas e da nervura

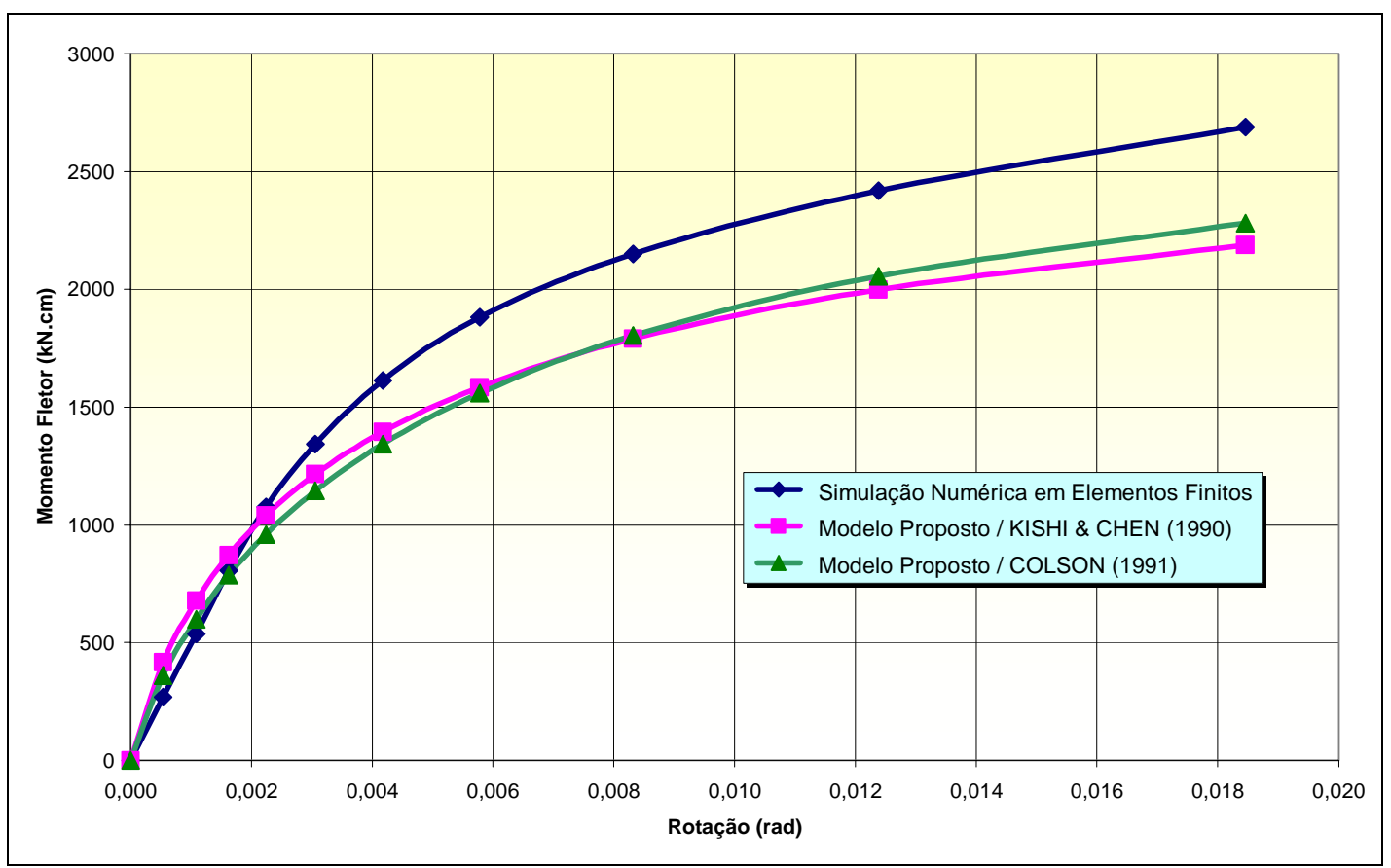

Figura 4.15 - Curva momento - rotação (Caso 1) 


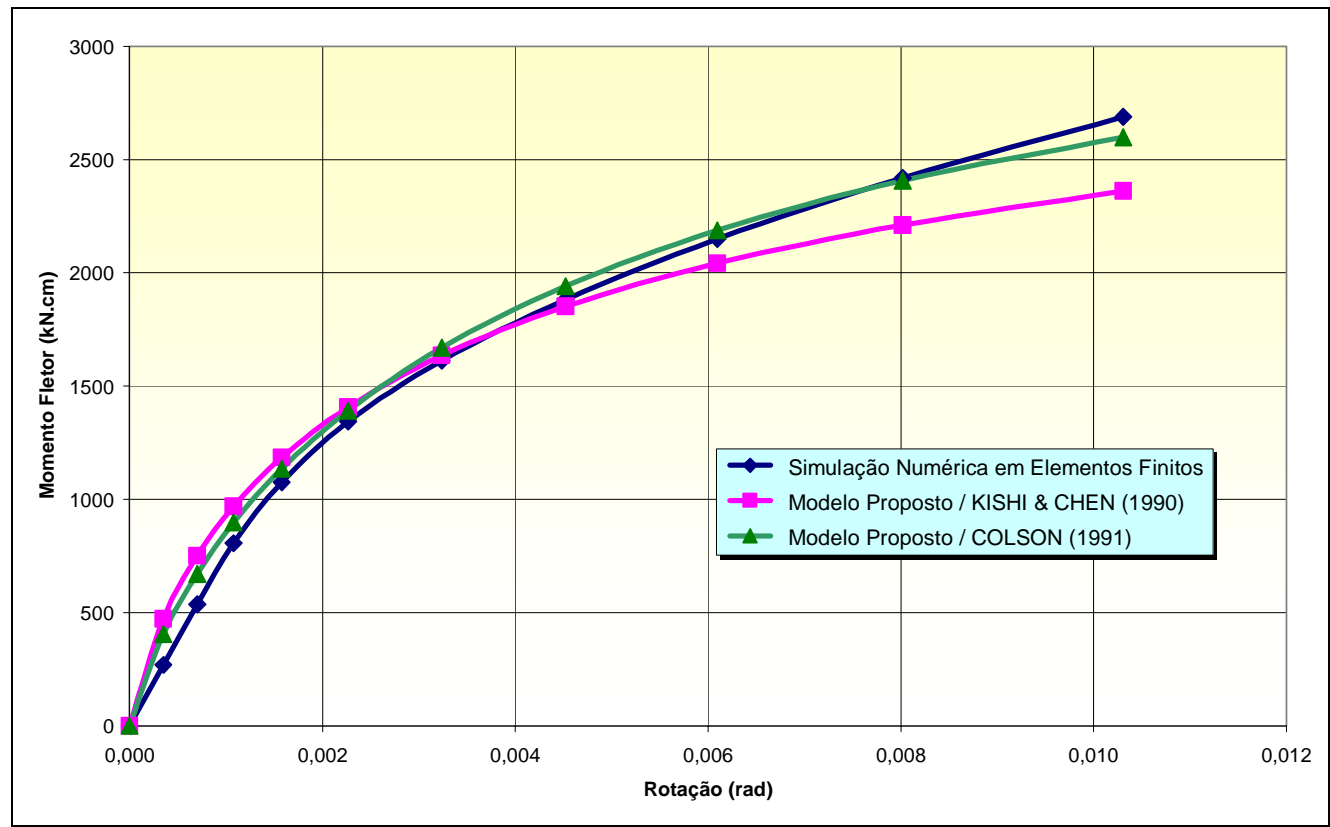

Figura 4.16 - Curva momento-rotação (Caso 2)

Vê-se que, em comparação com as simulações em elementos finitos, o modelo proposto apresenta uma leve tendência de superestimar a rigidez inicial da ligação e de subestimar o momento último. Isso, no entanto, pode não se verificar quando forem feitas comparações com resultados experimentais, uma vez que os resultados numéricos também representam aproximações do fenômeno em estudo.

Enquanto não existirem dados experimentais que validem por completo o modelo proposto, ou que indiquem quais ajustes devem ser feitos, recomenda-se adotar $n=0,50$ e $a=0,25$ nos modelos de KISHI \& CHEN (1990) e COLSON (1991), respectivamente, pois, tendo em vista os resultados obtidos nas simulações realizadas neste trabalho, esses valores não superestimam 0 comportamento momento-rotação da ligação.

Tal recomendação fundamenta-se em LIMA (2003), que diz: "A curva momento versus rotação de uma ligação, usada na análise global de uma estrutura, pode ser simplificada adotando-se uma curva aproximada adequada, incluindo as aproximações lineares (por exemplo bi-linear ou tri-linear), desde que esteja abaixo da curva real da ligação".

$\mathrm{Na}$ ausência de dados experimentais para comparação de resultados, a realização de um estudo numérico é o melhor que se pode fazer para averiguação da ordem de grandeza dos valores fornecidos por modelos teóricos. Na ausência dessas informações, todo e qualquer modelo proposto, mesmo aqueles oriundos das mais sofisticadas analises em elementos finitos não podem ser devidamente validados, e estarão sempre propensos à necessidade de ajustes, correções e calibrações.

Aqui se encerra, por absoluta falta de informações experimentais que permitam o enriquecimento ou a continuidade da discussão, o estudo sobre as ligações com dupla tala de alma parafusada. 


\section{3 - Estudo das Emendas dos Arcos}

\subsubsection{Introdução}

Os perfis metálicos são encontrados no mercado com dimensões limitadas, de forma que muitas vezes é necessário emendar diversas partes para compor uma peça com a dimensão desejada. Outra situação bastante comum decorre das limitações de fabricação e transporte, que freqüentemente fazem com que uma peça seja dividida em duas ou mais partes, sendo necessário, portanto, emendá-las durante a montagem. Ambas as situações são encontradas na execução dos arcos do sistema estrutural em estudo neste trabalho.

As emendas podem ser executadas de diversas formas, cabendo ao engenheiro a escolha do detalhe mais apropriado para a situação que pretende atender. Nas ligações de fábrica é comum a utilização de detalhes soldados, que podem ou não utilizar chapas de cobrejunta; já nas ligações de campo as emendas costumam ser parafusadas, o que torna indispensável o uso de tais chapas.

Embora existam vários detalhes para realização de emendas em perfis I, este trabalho discute apenas o tipo indicado na Figura 4.17, que é composto por duas partes bastante distintas, que são: a ligação das mesas do perfil e a ligação da alma; ambas utilizando talas ou chapas de cobrejunta.

Essas emendas são verificadas para as solicitações atuante nas linhas de centro das talas, e normalmente são posicionadas em seções da barra onde os esforços são reduzidos, ou pelo menos onde o momento fletor não apresenta valor elevado. É comum a inserção dessas ligações nos quartos de vão, como citam SÁLES et al. (1994) e PFEIL \& PFEIL (2000).
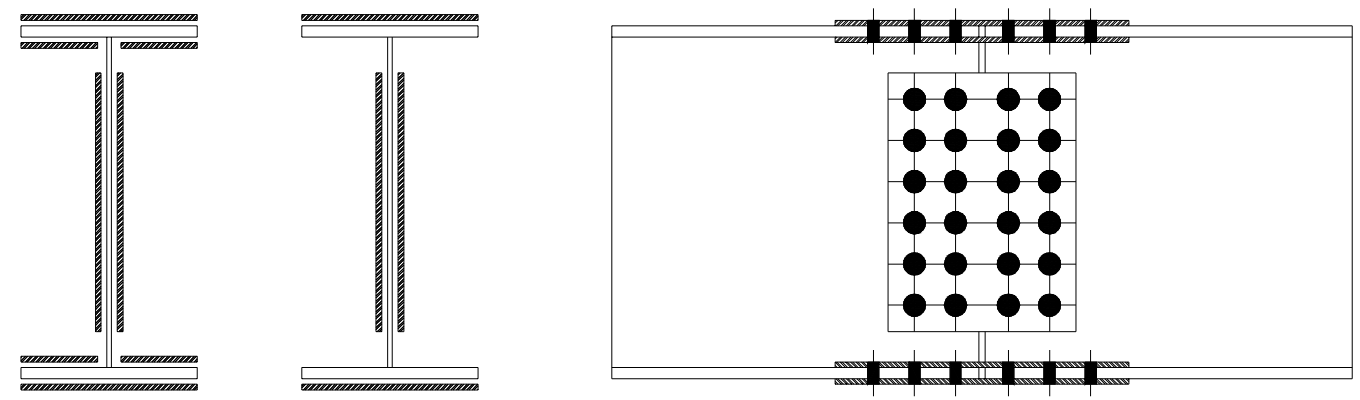

Figura 4.17 - Detalhe típico de emenda parafusa em perfis I de aço

Dependendo da intensidade do momento fletor pode ser suficiente a utilização de apenas uma tala em cada ligação das mesas, mas nos casos de maior solicitação costumam ser necessárias talas em ambos os lados das mesas.

\subsubsection{Métodos para Avaliação dos Esforços nos Parafusos}

Em emendas com talas parafusadas é necessário verificar os componentes dos perfis (mesas e alma), suas respectivas talas, e o cisalhamento nos parafusos, sendo este último item um motivo de grande divergência entre os diversos autores que abordam 0 assunto. 
Em se tratando de peça fletida, ocorre solicitação por momento fletor $\left(M_{d}\right)$ e força cortante $\left(V_{d}\right)$ na região da emenda, esforços estes que solicitam os diversos componentes da ligação.

Em geral, supõe-se que a conexão da alma é solicitada pela totalidade da força cortante e por uma pequena parcela de momento fletor, parte dele decorrente da atuação excêntrica da força cortante, e outra parte decorrente do momento fletor absorvido pela alma da viga. Isso significa que o grupo de parafusos da alma está submetido a cisalhamento excêntrico, cujo cálculo não representa nenhum mistério para os projetistas.

Dentro desse contexto a conexão das mesas fica responsável pela transmissão da maior parte do momento fletor atuante na emenda, que decomposto em um binário provoca cisalhamento centrado nos parafusos, sendo sua verificação ainda mais simples que a situação encontrada na conexão da alma.

A dificuldade está justamente na avaliação do momento fletor que solicita cada uma das conexões da emenda, pois são encontrados na literatura técnica recomendações bastante diferentes umas das outras, que conduzem, inevitavelmente, a resultados bastante diferentes também.

PICARD \& BEAULIEU (sem data) 1 , sugerem que todo o momento fletor é equilibrado apenas pelas mesas, enquanto a conexão da alma responde apenas pela força cortante $V_{d}$ e pelo momento $M_{w}=V_{d} \times e$, decorrente da atuação excêntrica da força cortante em relação ao centróide da ligação, como mostra a Figura 4.18.

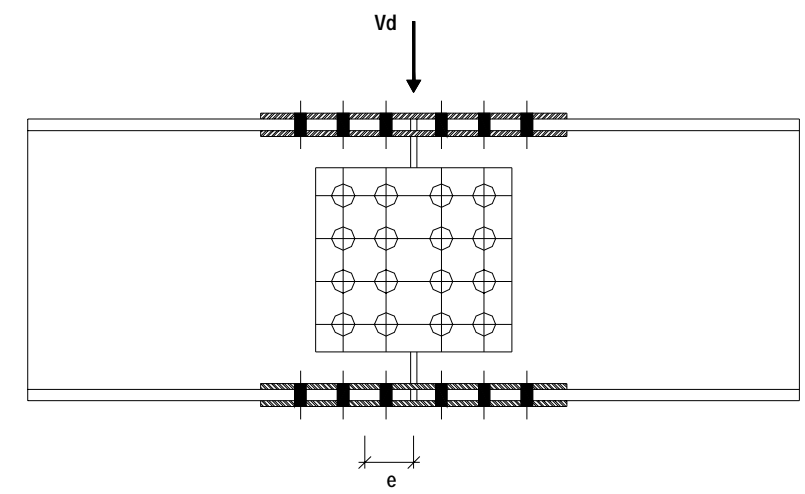

Figura 4.18 - Excentricidade da força cortante em relação ao centróide da ligação da alma

Já ANDRADE (1994) e PFEIL \& PFEIL (2000) indicam que além do momento $M_{w}=V_{d} \times e$ a conexão da alma é solicitada também por uma parcela do momento fletor atuante na emenda proporcional à inércia da alma. Já SÁLES et al. (1994) e SALMON \& JOHNSON (1996) indicam que essa parcela de momento é proporcional à inércia das talas empregadas na ligação.

Essas diferentes abordagens do problema conduzem a resultados consideravelmente discrepantes no que se refere ao cisalhamento máximo que pode solicitar os parafusos da alma, carecendo, portanto, de um estudo mais detalhado para dirimir algumas dúvidas.

1 PICARD \& BEAULIEU (sem data) apud USIMINAS (1988). 


\subsubsection{Avaliação dos Esforços nos Parafusos da Alma}

Nesta seção são apresentados sumariamente os métodos empregados para avaliação dos esforços no grupo de parafusos da conexão da alma. A próxima seção apresenta um estudo comparativo entre esses métodos.

\subsubsection{Método 1: a conexão da alma absorve uma parcela de $M_{d}$ proporcional a inércia da alma do perfil}

Nesse método, que é recomendado por PFEIL \& PFEIL (2000) e ANDRADE (1994), o momento fletor absorvido pela conexão da alma é determinado por:

$$
M_{w}=M_{1}+V_{d} \times e
$$

sendo $M_{l}$ definido como:

$$
M_{1}=\frac{I_{w}}{I_{x}} \times M_{d}
$$

onde $I_{x}$ e $I_{w}$ são, respectivamente, as inércias do perfil e da alma deste.

Conseqüentemente, a parcela de momento fletor absorvida pelas mesas será dada por:

$$
M_{m}=\frac{I_{m}}{I_{x}} \times M_{d}
$$

onde $I_{m}$ é a inércia das mesas do perfil. 0 momento $M_{m}$ também pode ser calculado fazendo:

$$
M_{m}=M_{d}-M_{w}
$$

A justificativa para esta forma de distribuição dos esforços está no fato de que a alma também contribui com a resistência à flexão do perfil, e que por isso absorve uma parcela do momento fletor proporcional à sua contribuição. Essa contribuição, no entanto, é modesta, de forma que a maior parcela do momento é, de fato, equilibrada pelas mesas.

\subsubsection{Método 2: a conexão da alma absorve uma parcela de $M_{d}$ proporcional a inércia das talas que ligam a alma do perfil}

Nesse método, que é recomendado por SÁLES et al.(1994), o momento fletor absorvido pela conexão da alma depende da inércia das talas utilizadas e é dado novamente pela Eq. 4.41, porém com $M_{l}$ definido como:

$$
M_{1}=\frac{I_{t w}}{I_{t x}} \times M_{d}
$$


onde $I_{t x}$ e $I_{t w}$ são, respectivamente, as inércias de todas as talas que compõem a emenda, e a inércia das talas que compõem apenas a emenda da alma.

Conseqüentemente, a parcela de momento fletor absorvida pelas mesas passa a ser dada por:

$$
M_{m}=\frac{I_{t m}}{I_{t x}} \times M_{d}
$$

onde $I_{t m}$ é a inércia das talas das mesas do perfil. Alternativamente o momento $M_{m}$ pode ser obtido em função do valor de $M_{w}$, o que pode ser feito com a Eq. 4.47 dada a seguir:

$$
M_{m}=M_{d}-M_{w}
$$

No método 1, a avaliação das parcelas de momento em função das inércias das chapas que compõem o perfil fundamenta-se no raciocínio de que, na região da emenda, as talas simplesmente transmitem a cargas que atuam em uma peça para a outra, não exercendo nenhuma outra função a não ser essa. Isso significa que, se os esforços "nascem" no perfil, os quinhões transmitidos pelas talas são aqueles devidos apenas aos elementos que compõem o próprio perfil.

No método 2 parte-se do pressuposto de que na exata região da emenda não existe perfil, e que a inércia ali existente decorre exclusivamente das talas, devendo, portanto, as parcelas de momento serem avaliadas em função de suas inércias.

\subsubsection{3 - Método 3: todo o momento fletor $M_{d}$ é absorvido pela conexão das mesas}

No método 3, que foi proposto por PICARD \& BEAULIEU (sem data) e que também é recomendado por USIMINAS (1988), não existe momento $M_{1}$, pois se supõe que todo o momento fletor é absorvido pelas mesas do perfil. Com isso, o momento fletor na ligação da alma é calculado simplesmente como:

$$
M_{w}=V_{d} \times e
$$

que é decorrente apenas da atuação excêntrica da força cortante em relação ao centróide da ligação, como mostra a Figura 4.18.

\subsubsection{4 - Método 4: recomendações de SALMON \& JOHNSON (1996)}

Contrariamente a PICARD \& BEAULIEU (sem data), SALMON \& JOHNSON (1996) afirmam que não há necessidade de se considerar a parcela de momento devida a excentricidade entre a força cortante e o centróide da ligação, pois, como essa excentricidade apresenta um valor reduzido, sua consideração só se justifica se a força cortante apresentar um valor muito elevado na região da emenda, o que não é muito usual na prática.

Para SALMON \& JOHNSON (1996) basta considerar que a conexão da alma é solicitada por um momento fletor proporcional a inércia das talas das alma, sendo esse momento calculado admitindo o escoamento na fibra mais afastada das talas das mesas, o que resulta na seguinte expressão: 


$$
M_{w}=\frac{I_{t w}}{I_{t x}} \times W_{t x} \times f_{y}
$$

onde $W_{t x}$ é o módulo elástico do conjunto de todas as talas que compõem a ligação, e $f_{y}$ é a tensão de escoamento do aço.

Conhecidos os métodos existentes, resta agora analisar os resultados fornecidos por todos eles quando aplicados às mesmas situações.

\subsubsection{Estudo Comparativo}

Com o objetivo de comparar todos esses métodos foram analisadas três emendas diferentes encontradas na literatura técnica brasileira, que em suas respectivas publicações de origem são utilizadas como exemplo de aplicação do método defendido por seu autor. A Tabela 4.4 apresenta todos os dados de interesse desses exemplos.

Tabela 4.4 - Dados dos exemplos de aplicação

\begin{tabular}{c|c|c|c}
\hline Dados & Exemplo 1 & Exemplo 2 & Exemplo 3 \\
\hline Fonte / Referência & ANDRADE (1994) & SÁLES et al. (1994) & USIMINAS (1988) \\
\hline Perfil da Viga & $\mathrm{IP} 600$ & $\mathrm{VS} 600 \times 125$ & $\begin{array}{c}2 \mathrm{CH} 300 \times 16 \\
1 \mathrm{CH} 568 \times 6,3\end{array}$ \\
\hline Momento Fletor & $\mathrm{M}_{\mathrm{d}}=515 \mathrm{kNm}$ & $\mathrm{M}_{\mathrm{d}}=640 \mathrm{kNm}$ & $\mathrm{M}_{\mathrm{d}}=373 \mathrm{kNm}$ \\
\hline Força Cortante & $\mathrm{V}_{\mathrm{d}}=345 \mathrm{kN}$ & $\mathrm{V}_{\mathrm{d}}=160 \mathrm{kN}$ & $\mathrm{V}_{\mathrm{d}}=371 \mathrm{kN}$ \\
\hline Dupla Tala nas Mesas & $\mathrm{Não}$ & $\mathrm{Sim}$ & $\mathrm{Não}$ \\
\hline Talas das Mesas - Externa & $\mathrm{CH} 19 \times 220 \times 750$ & $\mathrm{CH} 9.5 \times 300 \times 410$ & $\mathrm{CH} 9,5 \times 300 \times 800$ \\
\hline Talas das Mesas - Interna & - & $\mathrm{CH} 9.5 \times 130 \times 410$ & - \\
\hline Talas da Alma & $\mathrm{CH} 9,5 \times 270 \times 490$ & $\mathrm{CH} 6.3 \times 410 \times 420$ & $\mathrm{CH} 6,3 \times 380 \times 360$ \\
\hline $\begin{array}{c}\text { Parafusos nas Mesas } \\
\text { Parafusos na Alma }\end{array}$ & $2 \mathrm{Linhas} / 6 \phi 19$ & $4 \mathrm{Linhas} / 2 \phi 19$ & 2 Linhas $/ 5 \phi 19$ \\
\hline $\begin{array}{c}\text { Espaçamento Horizontal entre } \\
\text { Furos da Alma }\end{array}$ & $\mathrm{g}=60 \mathrm{~mm}$ & $\mathrm{~g}=100 \mathrm{~mm}$ & $\mathrm{~g}=70 \mathrm{~mm}$ \\
\hline $\begin{array}{c}\text { Espaçamento Vertical entre } \\
\text { Furos da Alma }\end{array}$ & $\mathrm{s}=60 \mathrm{~mm}$ & $\mathrm{~s}=100 \mathrm{~mm}$ & $\mathrm{~s}=90 \mathrm{~mm}$ \\
\hline
\end{tabular}


A Tabela 4.5 apresenta os resultados obtidos para o exemplo 1, em seguida, na Tabela 4.6, esses resultados são comparados.

Tabela 4.5 - Forças nos parafusos do exemplo 1 (Exemplo extraído de ANDRADE (1996))

\begin{tabular}{c|c|c}
\hline Método & Parafusos da Alma & Parafusos das Mesas \\
\hline $\mathbf{1}$ & $97,3 \mathrm{kN}$ & $59,0 \mathrm{kN}$ \\
$\mathbf{2}$ & $93,3 \mathrm{kN}$ & $59,9 \mathrm{kN}$ \\
$\mathbf{3}$ & $36,2 \mathrm{kN}$ & $73,9 \mathrm{kN}$ \\
$\mathbf{4}$ & $111,1 \mathrm{kN}$ & $51,6 \mathrm{kN}$ \\
\hline
\end{tabular}

Tabela 4.6 - Comparação dos resultados obtidos no exemplo 1

\begin{tabular}{c|c|c}
\hline \multirow{2}{*}{ Comparação } & \multicolumn{2}{|c}{ Diferença Percentual nos Esforços } \\
\cline { 2 - 3 } & Parafusos da Alma & Parafusos das Mesas \\
\hline Método 1 x Método 2 & $4 \%$ & $2 \%$ \\
Método 1 x Método 3 & $169 \%$ & $25 \%$ \\
Método 3 x Método 4 & $207 \%$ & $43 \%$ \\
\hline
\end{tabular}

Os resultados obtidos indicaram que, pelos métodos 1, 2 e 4, a emenda está adequadamente dimensionada, enquanto que pelo método 3 há excesso de parafusos na ligação da alma e escassez na ligação das mesas.

As Tabelas 4.7 e 4.8 apresentam os resultados obtidos para o exemplo 2, e as Tabelas 4.9 e 4.10 os resultados obtidos para o exemplo 3.

Tabela 4.7 - Forças nos parafusos do exemplo 2 (Exemplo extraído de SÁLES et al.(1994))

\begin{tabular}{c|c|c}
\hline Método & Parafusos da Alma & Parafusos das Mesas \\
\hline $\mathbf{1}$ & $122,3 \mathrm{kN}$ & $122,6 \mathrm{kN}$ \\
$\mathbf{2}$ & $97,0 \mathrm{kN}$ & $126,8 \mathrm{kN}$ \\
$\mathbf{3}$ & $34,2 \mathrm{kN}$ & $137,7 \mathrm{kN}$ \\
$\mathbf{4}$ & $93,7 \mathrm{kN}$ & $123,8 \mathrm{kN}$ \\
\hline
\end{tabular}

Tabela 4.8 - Comparação dos resultados obtidos no exemplo 2

\begin{tabular}{c|c|c}
\hline \multirow{2}{*}{ Comparação } & \multicolumn{2}{|c}{ Diferença Obtida para os Esforços } \\
\cline { 2 - 3 } & Parafusos da Alma & Parafusos das Mesas \\
\hline Método 1 x Método 2 & $26 \%$ & $3 \%$ \\
Método 1 x Método 3 & $257 \%$ & $12 \%$ \\
Método 3 x Método 4 & $174 \%$ & $11 \%$ \\
\hline
\end{tabular}


Tabela 4.9 - Forças nos parafusos do exemplo 3 (Exemplo extraído de USIMINAS(1988))

\begin{tabular}{c|c|c}
\hline Método & Parafusos da Alma & Parafusos das Mesas \\
\hline $\mathbf{1}$ & $128,4 \mathrm{kN}$ & $57,2 \mathrm{kN}$ \\
$\mathbf{2}$ & $107,2 \mathrm{kN}$ & $59,7 \mathrm{kN}$ \\
$\mathbf{3}$ & $75,0 \mathrm{kN}$ & $63,9 \mathrm{kN}$ \\
$\mathbf{4}$ & $86,8 \mathrm{kN}$ & $56,9 \mathrm{kN}$ \\
\hline
\end{tabular}

Tabela 4.10 - Comparação dos resultados obtidos no exemplo 3

\begin{tabular}{c|c|c}
\hline \multirow{2}{*}{ Comparação } & \multicolumn{2}{|c}{ Diferença Obtida para os Esforços } \\
\cline { 2 - 3 } & Parafusos da Alma & Parafusos das Mesas \\
\hline Método 1 x Método 2 & $20 \%$ & $4 \%$ \\
Método 1 x Método 3 & $71 \%$ & $12 \%$ \\
Método 3 x Método 4 & $16 \%$ & $12 \%$ \\
\hline
\end{tabular}

Nos exemplos 2 e 3 o método 1 mostrou-se o mais conservador em relação à ligação da alma, enquanto o método 3 continuou a fornecer resultados bastante diferentes dos demais.

Os resultados fornecidos pelos métodos 1 e 2 indicaram diferenças inferiores a $5 \%$ nos esforços dos parafusos das mesas, e diferenças entre 4 e $26 \%$ nos esforços dos parafusos da alma.

As comparações entre os métodos 1 e 3 indicaram diferenças entre 12 e $25 \%$ para os esforços nos parafusos das mesas, e entre 71 e $257 \%$ para os esforços nos parafusos da alma. Entre os modelos 3 e 4 observou-se diferenças com essa mesma ordem de grandeza. Diante de tamanha discrepância pode-se afirmar que, ou os métodos 1, 2 e 4 superdimensionam a ligação da alma, ou o método 3 fornece resultados seriamente contrários a segurança. Observa-se também que, mesmo entre os métodos 1, 2 e 4, não há grande proximidade entre os resultados, havendo, inclusive, revezamento entre qual modelo é mais ou menos rigoroso.

Aparentemente essas diferenças dependem essencialmente da relação entre o momento fletor $M_{d} \mathrm{e}$ o esforço cortante $V_{d}$ que solicitam a emenda, e que tendem a diminuir a medida em que os esforços diminuem. Isso pode induzir à idéia de que executando a emenda em um local de baixa solicitação da barra a segurança dos parafusos da alma estaria garantida independentemente do método empregado.

Como tentativa de reproduzir o que aconteceria em uma situação usual, considere-se uma viga biapoiada com $12 m$ de vão, contida lateralmente, composta por um perfil VS $450 \times 51$ e submetida a uma carga uniformemente distribuída $q$, para a qual pretende-se dimensionar emendas para os quartos de vão.

Dimensionando a emenda para uma carga de $14 \mathrm{kN} / \mathrm{m}$ atuante na viga, que é a maior que pode ser aplicada sem que algum estado limite ocorra, é necessário empregar 2 linhas com 4 parafusos de $19 \mathrm{~mm}$ cada para atender todos os métodos estudados. 
Fazendo a carga variar de 0 a $14 \mathrm{kN} / \mathrm{m}$ obtém-se o gráfico mostrado na Figura 4.19 , que indica que as diferenças nos resultados fornecidos por cada modelo são bastante acentuadas mesmo para baixos valores de carregamento.

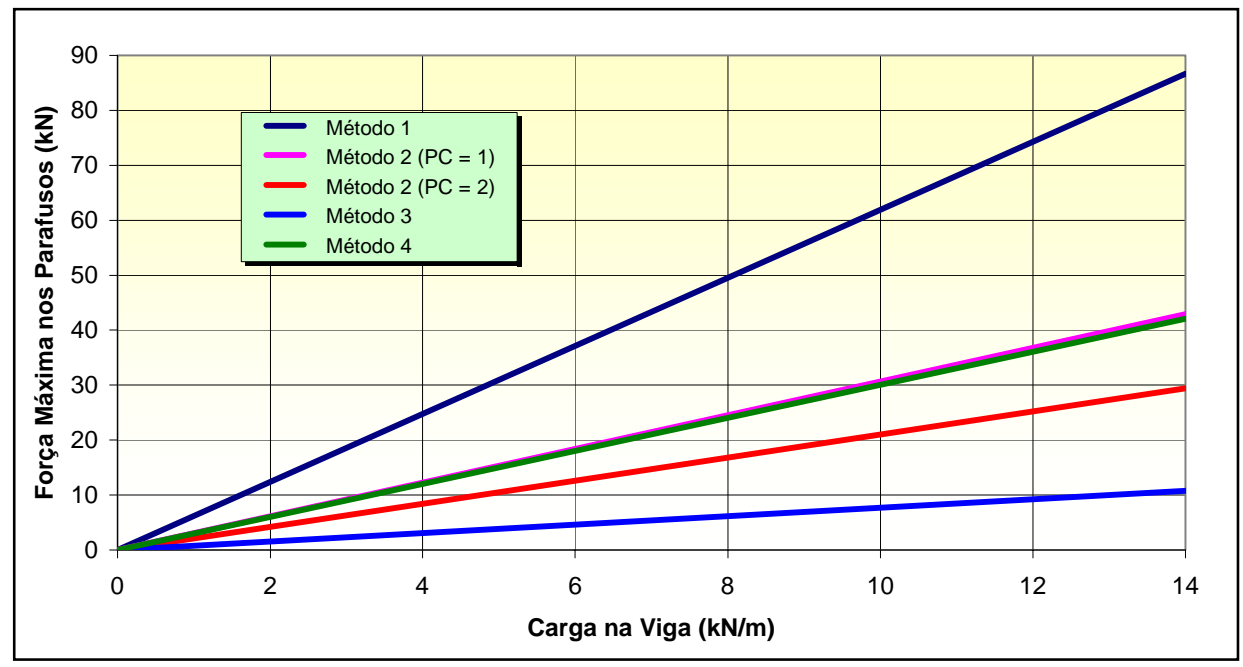

Figura 4.19 - Variação do esforço no parafuso mais solicitado do exemplo 4

Para construção desse gráfico o método 2 foi analisado sob duas situações diferentes, a primeira delas considerando parafusos das mesas trabalhando a corte duplo $(P C=2)$, situação que requer talas nas regiões superior e inferior das mesas, e a segunda considerando parafusos trabalhando a corte simples $(P C=1)$, situação que ocorre quando existem talas de mesas apenas nas regiões externas ao perfil.

Tal simulação mostrou-se importante, pois, como os resultados fornecidos por esse método dependem diretamente da inércia das talas, pode-se obter resultados muito diferentes simplesmente acrescentando ou suprimindo talas nas ligações das mesas.

Embora também dependa da rigidez das talas, o mesmo não corre com o método 4, pois, como

$$
W_{t x}=I_{t x} \times \frac{2}{H v+2 \times t_{t m}}
$$

onde $H_{v}$ é a altura da viga e $t_{t m}$ a espessura das talas das mesas, a revisão da Eq. 4.49 fornece:

$$
M_{w}=I_{t w} \times \frac{2}{H v+2 \times t_{t m}} \times f_{y}
$$

que independe do fato de existirem talas em ambos ou em apenas um dos lados das mesas.

Essa dependência da inércia das talas pode conduzir a resultados inesperados, por exemplo, analisando a ligação em questão com 4, 5 e 6 parafusos em cada linha de conectores da alma pelos métodos 2 e 4, obtém-se os resultados apresentados na Tabela 4.11. Esses resultados mostram que 
aumentando a quantidade de parafusos na ligação o esforço no parafuso mais solicitado aumenta em vez de diminuir, como seria de se esperar.

Tabela 4.11 - Influência da variação da quantidade de parafusos nos métodos 2 e 4

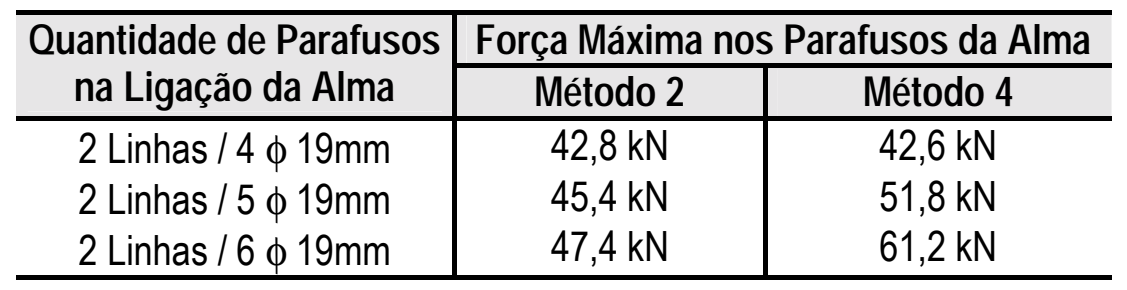

Diante disso, em um caso extremo, pode ocorrer do profissional se deparar com a situação em que, ao aumentar o número de parafusos em uma ligação cujo cisalhamento nos conectores já estava verificado, quer seja com o objetivo de melhorar o detalhe ou mesmo de aumentar a reserva de resistência da conexão, obter uma nova ligação que já não atende essa verificação. Poderia se deparar também, com a situação não menos incomum, de ter que reduzir o número de conectores para conseguir verificar o cisalhamento no parafuso mais solicitado.

Isso ocorre porque para aumentar o número de parafusos na ligação da alma é necessário aumentar também a altura das talas, o que provoca um aumento da inércia desses elementos e faz com que a conexão passe a absorver uma parcela maior do momento fletor que solicita a emenda. Situação semelhante, porém não tão grave, pode ser obtida ao se aumentar a espessura das talas, o que é comum quando se quer elevar a resistência da seção líquida desses elementos, ou quando se quer melhorar a resistência à pressão de contato entre furos e entre furo e borda.

Esse comportamento é ainda mais acentuado no método 4, proposto por SALMON \& JOHNSON (1996), no qual $M_{w}$ também depende do momento que provoca o inicio do escoamento na fibra mais afastada das talas das mesas, momento este que também varia a medida em que se altera a altura das talas da alma.

Outro aspecto a ser investigado está relacionado com a assertiva de SALMON \& JOHNSON (1996) de que não há necessidade de considerar a parcela $V_{d} \times e$ no cômputo do momento absorvido pela conexão da alma. No sentido de verificar a veracidade dessa afirmação os exemplos 1 e 2 foram reavaliados sem a consideração dessa parcela, e os resultados obtidos foram comparados com aqueles no qual a referida parcela foi considerada. Os resultados obtidos em ambos os casos estão indicados na Tabela 4.12.

Tabela 4.12 - Contribuição da parcela $V_{d} \times e$ nos exemplo 1 e 2

\begin{tabular}{c|cc}
\hline Parâmetro Analisado & Exemplo 1 & Exemplo 2 \\
\hline Momento Total $M_{w}$ & $13.394,7 \mathrm{kNcm}$ & $12.763,8 \mathrm{kNcm}$ \\
Parcela $M_{1}$ & $10.349,7 \mathrm{kNcm}$ & $9.718,8 \mathrm{kNcm}$ \\
Parcela $V d \times e$ & $3.045,0 \mathrm{kNcm}$ & $3.045,0 \mathrm{kNcm}$ \\
Força no Parafuso com $V d \times e$ & $97,3 \mathrm{kN}$ & $93,3 \mathrm{kN}$ \\
Força no Parafuso sem $V d \times e$ & $77,9 \mathrm{kN}$ & $74,0 \mathrm{kN}$ \\
\hline
\end{tabular}


Vê-se que nos exemplos analisados a contribuição de $V d \times e$ foi de aproximadamente $1 / 3$ do momento $M_{l}$, e de aproximadamente $1 / 4$ do momento $M_{w}$.

Com relação ao esforço máximo nos parafuso houve uma redução de $20 \%$ com a desconsideração dessa parcela, que não é tão pequena como citam SALMON \& JOHNSON (1996), indicando que talvez não seja prudente sua dispensa do cálculo.

Estando apresentadas as características e discordâncias dos métodos estudados, é necessário investigar qual deles mais se aproxima do comportamento real da ligação. Para tanto foi desenvolvido um estudo numérico via elementos finitos cujos resultados estão apresentados no próximo item. Esse estudo numérico também permitiu a proposição de um novo método de cálculo para avaliação do esforço nos parafusos de emendas em vigas de aço, como mostra o item 4.3.6 deste trabalho.

\subsubsection{Simulação Numérica via Elementos Finitos}

O estudo numérico foi desenvolvido tendo como referência o exemplo analisado por SÁLES et al. (1994) (exemplo 2, na Tabela 4.4), pois entre os três que foram estudados anteriormente este era 0 único a apresentar informações sobre o vão e o carregamento da viga. A Figura 4.20 fornece os detalhes desse exemplo.

\section{Dados da estrutura}

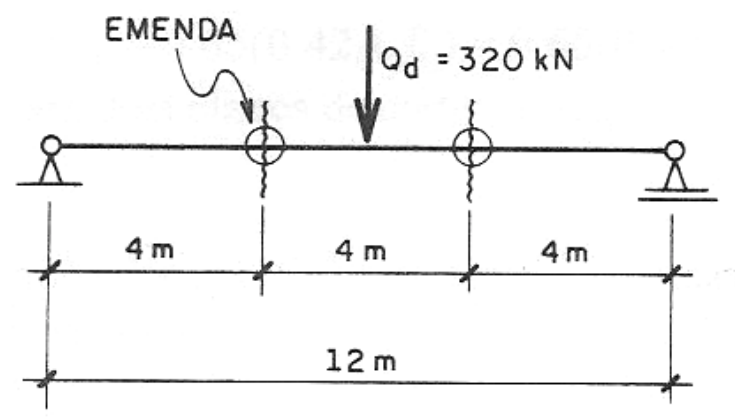

Detalhe da emenda

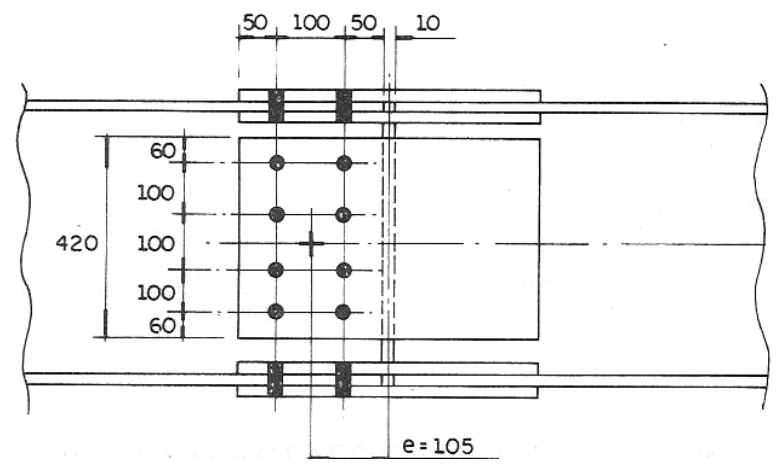

$\underline{\text { Dimensões das talas }}$

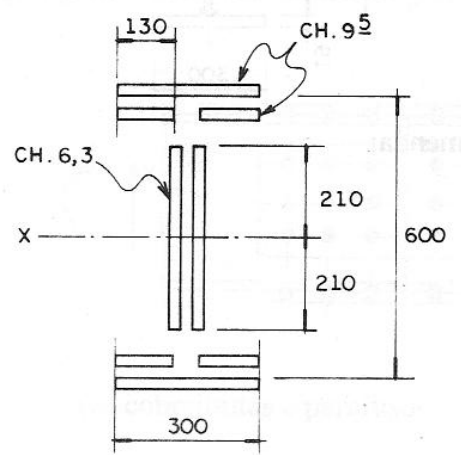

Figura 4.20 - Exemplo extraído de SÁLES et al. (1994) 
Como a estrutura e seu carregamento eram simétricos, pôde-se analisar um modelo com apenas metade da geometria, como mostrado na Figura 4.21.

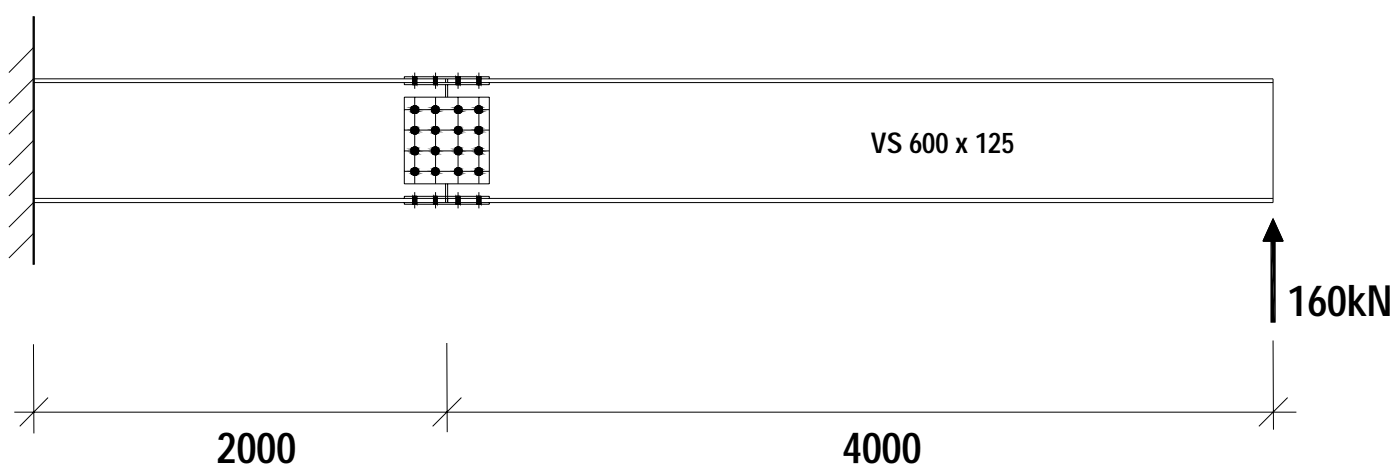

Figura 4.21 - Modelo analisado numericamente

A fim de determinar quais fatores afetam o comportamento desse tipo de ligação foram desenvolvidos oito modelos diferentes a partir do exemplo proposto por SÁLES et al. (1994), cada um deles contendo uma pequena modificação nas espessuras dos elementos do perfil ou das talas de cobrejunta, como mostra a Tabela 4.13.

Tabela 4.13 - Dados dos modelos simulados numericamente

\begin{tabular}{c|cc|c|c|c|c}
\hline \multirow{2}{*}{ Modelo } & \multicolumn{2}{|c|}{ Característica } & \multicolumn{2}{c|}{ Dados do Perfil } & \multicolumn{2}{c}{ Dados das Talas } \\
\cline { 3 - 6 } & & $\mathbf{t}_{\mathrm{f}}$ & $\mathbf{t}_{\mathrm{w}}$ & $\mathbf{t}_{\mathrm{tf}}$ & $\mathbf{t}_{\mathrm{tw}}$ \\
\hline $\mathbf{1}$ & \multicolumn{2}{|c|}{ Referência (modelo original) } & $19,0 \mathrm{~mm}$ & $8,0 \mathrm{~mm}$ & $9,5 \mathrm{~mm}$ & $6,3 \mathrm{~mm}$ \\
\hline $\mathbf{2}$ & Aumento do Parâmetro & $\mathrm{t}_{\mathrm{f}}$ & $25,4 \mathrm{~mm}$ & $8,0 \mathrm{~mm}$ & $9,5 \mathrm{~mm}$ & $6,3 \mathrm{~mm}$ \\
\hline $\mathbf{3}$ & Diminuição do Parâmetro & $\mathrm{t}_{\mathrm{f}}$ & $16,0 \mathrm{~mm}$ & $8,0 \mathrm{~mm}$ & $9,5 \mathrm{~mm}$ & $6,3 \mathrm{~mm}$ \\
\hline $\mathbf{4}$ & Aumento do Parâmetro & $\mathrm{t}_{\mathrm{w}}$ & $19,0 \mathrm{~mm}$ & $9,5 \mathrm{~mm}$ & $9,5 \mathrm{~mm}$ & $6,3 \mathrm{~mm}$ \\
\hline $\mathbf{5}$ & Diminuição do Parâmetro & $\mathrm{t}_{\mathrm{w}}$ & $19,0 \mathrm{~mm}$ & $6,3 \mathrm{~mm}$ & $9,5 \mathrm{~mm}$ & $6,3 \mathrm{~mm}$ \\
\hline $\mathbf{6}$ & Aumento do Parâmetro & $\mathrm{t}_{\mathrm{tf}}$ & $19,0 \mathrm{~mm}$ & $8,0 \mathrm{~mm}$ & $12,7 \mathrm{~mm}$ & $6,3 \mathrm{~mm}$ \\
\hline $\mathbf{7}$ & Diminuição do Parâmetro & $\mathrm{t}_{\mathrm{tf}}$ & $19,0 \mathrm{~mm}$ & $8,0 \mathrm{~mm}$ & $8,0 \mathrm{~mm}$ & $6,3 \mathrm{~mm}$ \\
\hline $\mathbf{8}$ & Aumento do Parâmetro & $\mathrm{t}_{\mathrm{tw}}$ & $19,0 \mathrm{~mm}$ & $8,0 \mathrm{~mm}$ & $9,5 \mathrm{~mm}$ & $8,0 \mathrm{~mm}$ \\
\hline $\mathbf{9}$ & Diminuição do Parâmetro & $\mathrm{t}_{\mathrm{tw}}$ & $19,0 \mathrm{~mm}$ & $8,0 \mathrm{~mm}$ & $9,5 \mathrm{~mm}$ & $4,8 \mathrm{~mm}$ \\
\hline
\end{tabular}

(Nota: Parâmetro que foi modificado em relação ao modelo original)

Vê-se que os modelos descritos na Tabela 4.13 abrangeram as diversas situações necessárias para a caracterização do comportamento desse tipo de ligação, no que se refere à distribuição do momento fletor entre as conexões das mesas e da alma. Por exemplo, com os modelos 1 e 2 pôdese determinar a influência da variação da inércia das mesas, enquanto que com os modelos 7 e 8 pôde-se determinar a influência das talas que conectam essas mesas. Os demais modelos fazem 0 mesmo com a alma do perfil e suas talas.

O estudo numérico foi realizado utilizando o programa computacional ANSYS 7.1 (2000) e 0 elemento finito hexaédrico SOLID45, que permite gerar malhas bastante regulares e fáceis de 
trabalhar, o que se mostrou bastante conveniente por conta da necessidade de sobrepor as malhas dos sólidos que compunham o perfil e o conjunto das talas.

A ligação entre as chapas do perfil foi simulada com o auxílio de um recurso do ANSYS 7.1 (2000) conhecido como "nós coincidentes". Já a existência dos parafusos foi considerada por meio da acoplagem dos deslocamentos de vários nós localizados no perfil e nas talas, o que permitiu gerar um modelo simples e fácil de trabalhar. A Figura 4.22 mostra um dos modelos analisados.

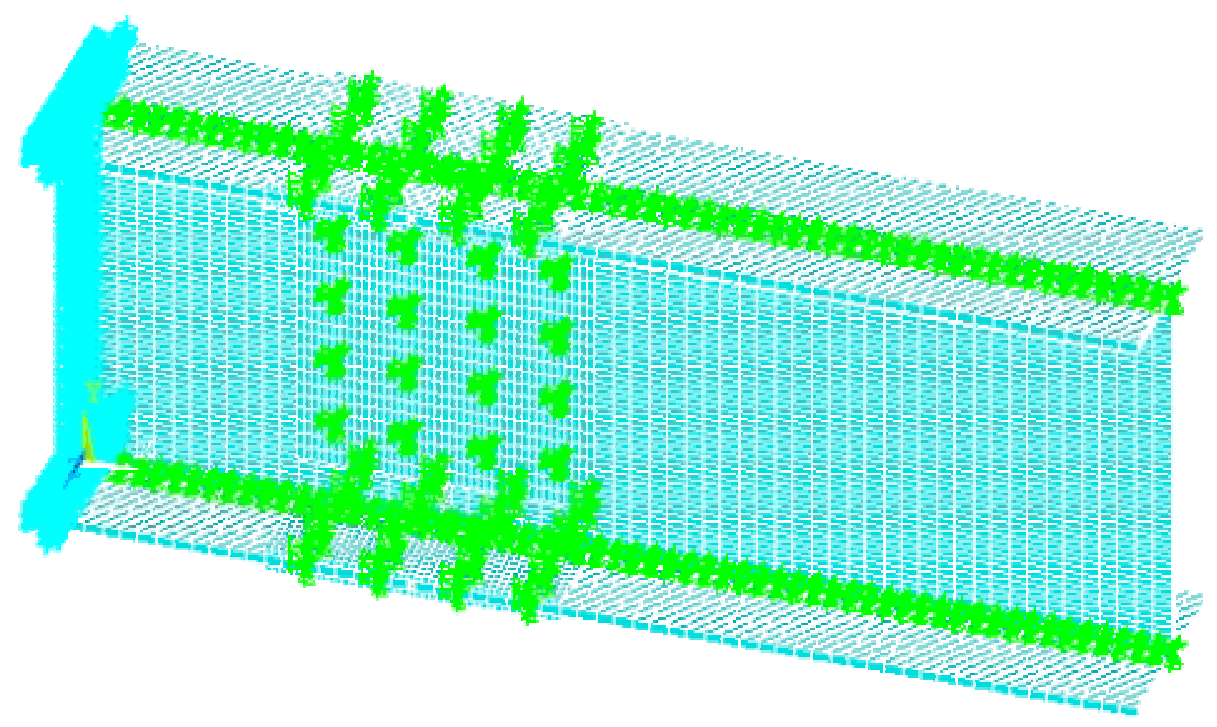

Figura 4.22 - Modelo em elementos finitos analisado no ANSYS 7.1 (2000)

A acoplagem dos deslocamentos na região dos parafusos permitiu que os esforços atuantes na parte do perfil onde estava aplicado o carregamento fossem transmitidos para as talas, e destas para a outra parte do perfil, como ocorre no modelo real. Os resultados obtidos estão nas Tabelas 4.14 e 4.15, juntamente com aqueles fornecidos pelos modelos de cálculo encontrados na literatura.

Tabela 4.14 - Influência da variação da inércia do perfil

\begin{tabular}{|c|c|c|c|c|c|c|c|c|c|c|}
\hline \multirow[t]{2}{*}{$\begin{array}{l}\text { Parâmetro } \\
\text { Modificado }\end{array}$} & \multicolumn{2}{|c|}{$\begin{array}{c}\text { MEF - } \\
\text { ANSYS (2000) }\end{array}$} & \multicolumn{2}{|c|}{$\begin{array}{c}\text { ANDRADE } \\
(1994)\end{array}$} & \multicolumn{2}{|c|}{$\begin{array}{c}\text { SÁLES et al. } \\
\text { (1994) }\end{array}$} & \multicolumn{2}{|c|}{$\begin{array}{l}\text { PICARD \& } \\
\text { BEAULIEU } \\
\text { (sem data) }\end{array}$} & \multicolumn{2}{|c|}{$\begin{array}{c}\text { SALMON \& } \\
\text { JOHNSON } \\
(1996)\end{array}$} \\
\hline & $\mathrm{F}_{\mathrm{pw}}$ & $F_{p m}$ & $F_{p w}$ & $F_{p m}$ & $F_{p w}$ & $\mathrm{~F}_{\mathrm{pm}}$ & $F_{p w}$ & $F_{p m}$ & $\mathrm{~F}_{\mathrm{pw}}$ & $F_{p m}$ \\
\hline+ & 64,53 & 134,23 & 99,15 & 127,86 & 100,64 & 127,61 & 34,21 & 139,23 & 93,68 & 125,12 \\
\hline$t_{w}$ & 72,58 & 130,25 & 138,43 & 120,16 & 99,66 & 126,58 & 34,21 & 137,93 & 93,68 & 123,96 \\
\hline Referência & 67,54 & 130,50 & 118,67 & 123,42 & 99,66 & 126,58 & 34,21 & 137,93 & 93,68 & 123,96 \\
\hline$-\quad t_{f}$ & 71,83 & 126,47 & 140,52 & 118,99 & 98,94 & 125,84 & 34,21 & 136,99 & 93,68 & 123,11 \\
\hline$t_{w}$ & 59,06 & 130,64 & 99,03 & 126,69 & 99,66 & 126,58 & 34,21 & 137,93 & 93,68 & 123,96 \\
\hline
\end{tabular}

(Nota:

Resultados de referência, obtidos com o modelo original) 
Tabela 4.15 - Influência da variação da inércia das talas

\begin{tabular}{|c|c|c|c|c|c|c|c|c|c|c|}
\hline \multirow[t]{2}{*}{$\begin{array}{l}\text { Parâmetro } \\
\text { Modificado }\end{array}$} & \multicolumn{2}{|c|}{$\begin{array}{l}\text { MEF - } \\
\text { ANSYS } \\
(2000)\end{array}$} & \multicolumn{2}{|c|}{$\begin{array}{c}\text { ANDRADE } \\
(1994)\end{array}$} & \multicolumn{2}{|c|}{$\begin{array}{l}\text { SÁLES et al. } \\
\text { (1994) }\end{array}$} & \multicolumn{2}{|c|}{$\begin{array}{l}\text { PICARD \& } \\
\text { BEAULIEU } \\
\text { (sem data) }\end{array}$} & \multicolumn{2}{|c|}{$\begin{array}{c}\text { SALMON \& } \\
\text { JOHNSON } \\
(1996)\end{array}$} \\
\hline & $F_{p w}$ & $F_{p m}$ & $\mathrm{~F}_{\mathrm{pw}}$ & $\mathrm{F}_{\mathrm{pm}}$ & $F_{p w}$ & $\mathrm{~F}_{\mathrm{pm}}$ & $\mathrm{F}_{\mathrm{pw}}$ & $F_{p m}$ & $\overline{F_{p w}}$ & $F_{p m}$ \\
\hline$t_{t f}$ & 49,84 & 134,41 & 118,67 & 123,42 & 83,55 & 129,28 & 34,21 & 137,93 & 93,68 & 123,96 \\
\hline$t_{t w}$ & 0,1 & 129,99 & 118,67 & 123, & 116,20 & 123,83 & 34,21 & 137,93 & 116,35 & 120,19 \\
\hline Referência & 67,54 & 130,50 & 118,67 & 123,42 & 99,66 & 126,58 & 34,21 & & 93,68 & 123,96 \\
\hline$-\quad t_{t f}$ & 76,61 & 126,78 & 118,67 & 123,42 & 111,28 & 124,65 & 34,21 & 137,93 & 93,68 & 123,96 \\
\hline$t_{t w}$ & 64,05 & 131,15 & 118,67 & 123,42 & 84,53 & 129,11 & 34,21 & 137,93 & 73,88 & 127,29 \\
\hline
\end{tabular}

(Nota:

Resultados de referência, obtidos com o modelo original)

Analisando os resultados obtidos numericamente observa-se que quaisquer alterações nas inércias do perfil e/ou das talas de cobrejunta afetam a distribuição de esforços nos parafusos, o que por si só já indica que todos os modelos estudados até aqui incorrem em erro, pois eles ou só consideram a influência do perfil, ou só consideram a influência das talas, ou não consideram nenhuma dessas influências, como é o caso do método de PICARD \& BEAULIEU (sem data). Além disso, os resultados obtidos demonstram claramente que:

a) Aumentando a inércia das mesas do perfil e/ou de suas talas, os esforços nos parafusos que conectam esses elementos são aumentados, enquanto que os esforços nos parafusos da alma sofrem redução. O inverso ocorre quando a inércia das mesas ou de suas talas é diminuída.

b) Aumentando a inércia da alma do perfil e/ou de suas talas, os esforços nos parafusos que conectam esses elementos são aumentados, enquanto que os esforços nos parafusos das conexões das mesas são reduzidos. $O$ inverso ocorre quando a inércia da alma ou de suas talas é diminuída.

Pode-se afirmar que, em resumo, o aumento da inércia de um determinado elemento que compõe 0 perfil (mesas ou alma) ou de suas talas, faz com que essa parte da ligação absorva uma parcela maior do momento fletor que solicita toda a ligação. Por outro lado, a redução da inércia faz com que uma parcela maior de momento seja transmitida para outra parte da ligação. Conclui-se, então, que um modelo consistente para dimensionamento desse tipo de ligação deve levar em consideração tal comportamento.

Comparando agora os resultados fornecidos pelos processos de dimensionamento estudados, com aqueles fornecidos pelo método dos elementos finitos, observa-se que, exceto pelo processo de PICARD \& BEAULIEU (sem data), todos os outros subdimensionaram os esforços nos parafusos das mesas e superdimensionaram os esforços nos parafusos da alma, indicando que, na verdade, a ligação das mesas absorve mais momento fletor do que o que foi previsto teoricamente, enquanto a ligação da alma, conseqüentemente, não absorve tanto momento como suposto inicialmente. 
Com relação ao superdimensionamento dos esforços nos parafusos da conexão da alma, é necessário observar que parte desse conservadorismo se deve ao método de cálculo utilizado na avaliação do esforço no parafuso mais solicitado. Tradicionalmente, ligações sob carregamento excêntrico são avaliadas pelo método vetorial, cujos resultados costumam ser, conforme consta na literatura técnica e como comprovado neste trabalho, muito conservadores. Para contornar esse inconveniente existem outros métodos de cálculo, como o do centro instantâneo de rotação e 0 método vetorial com excentricidade reduzida, proposto pelo AISC com base em resultados experimentais.

As observações feitas até o momento permitem postular alguns requisitos básicos que precisam ser atendidos em um modelo de cálculo para dimensionamento de emendas em vigas de aço, são eles:

a) Deve considerar a influência da variação de inércia dos elementos do perfil e das talas utilizadas na conexão.

b) Deve transferir uma parcela maior do momento fletor para a conexão das mesas do que aquela normalmente prevista pelos modelos existentes.

c) Deve utilizar um método mais preciso que o método vetorial para avaliação do esforço máximo em parafusos de ligações solicitadas excentricamente.

Com base nesses requisitos, e utilizando os dados apresentados nas Tabelas 4.14 e 4.15 para aferição e comparação de resultados, pôde-se propor o método apresentado no próximo item, que, como será visto, representa razoavelmente bem o comportamento de emendas em perfis I de aço.

\subsubsection{Proposta de Modelo de Cálculo}

Descreve-se a seguir o modelo de cálculo proposto neste trabalho, que depende tanto da rigidez do perfil quanto da rigidez das talas. Apresenta também um estudo comparativo dos resultados fornecidos por esse modelo em relação aos fornecidos pelos métodos 1 e 2, e pelas simulações numéricas descritas anteriormente.

Chamando de $\alpha$ o coeficiente para cálculo do quinhão de momento fletor absorvido pela conexão da alma, e de $\beta$ o quinhão de momento absorvido pela conexão das mesas, pode-se escrever:

Para o método 1: $\quad \alpha=\frac{I_{w}}{I_{x}}$ e $\beta=\frac{I_{m}}{I_{x}}$

Para o método 2: $\quad \alpha=\frac{I_{t w}}{I_{t x}}$ e $\beta=\frac{I_{t m}}{I_{t x}}$

Como $I_{w}+I_{m}=I_{x}$ e $I_{t w}+I_{t m}=I_{t x}$, pode-se escrever, tanto para 0 modelo 1 quanto para 0 modelo 2, as seguintes expressões:

$$
\begin{aligned}
& \alpha=1-\beta \\
& \beta=1-\alpha
\end{aligned}
$$

o que permite calcular facilmente um parâmetro em função do outro. 
Se tanto a inércia do perfil quanto a inércia das talas afetam a distribuição dos esforços nos parafusos, então é mais coerente fazer a divisão do momento fletor em função do somatório dessas inércias, e assim os parâmetros $\alpha$ e $\beta$ assumem a seguinte forma:

$$
\begin{gathered}
\alpha=\frac{I_{w}+I_{t w}}{I_{x}+I_{t x}} \\
\beta=\frac{I_{m}+I_{t m}}{I_{x}+I_{t x}}
\end{gathered}
$$

No entanto, refazendo os cálculos considerando os fatores apresentados nas Eqs. 4.54 e 4.55, os esforços nos parafusos nas mesas resultaram novamente subdimensionados, enquanto os esforços nos parafusos da alma resultaram, mais uma vez, superdimensionados. Isso revela que a parcela absorvida pela conexão das mesas é ainda maior que aquela correspondente ao somatório da inércia das mesas e das talas, e que a parcela absorvida pela conexão da alma é menor que aquela prevista pelo somatório das inércias de seus elementos, o que exige mais uma correção nos parâmetros $\alpha$ e $\beta$.

Como as parcelas referentes às inércias das talas já foram totalmente consideradas, sendo cada uma delas utilizada em seu parâmetro correspondente, $\alpha$ ou $\beta$, conforme o caso, a única forma de redefinir esses parâmetros é redistribuindo a inércia dos elementos do perfil, o que se justifica pelo fato de que, se parcela de momento absorvida pela conexão das mesas é maior que aquela que pode ser atribuída ao somatório $I_{m}+I_{t m}$, então mais uma parcela deve ser incorporada a ela. Por outro lado, se os esforços nos parafusos da alma estão superdimensionados, então algo do somatório $I_{w}+I_{t w}$ deve ser suprimido.

Propõe-se, então, que o trecho da alma do perfil compreendido entre as mesas e as talas da alma seja acrescentado ao parâmetro $\alpha$ e suprimido do parâmetro $\beta$, como mostra a Figura 4.23.

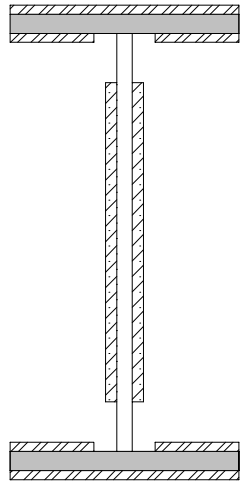

(a) Sem Redistribuição

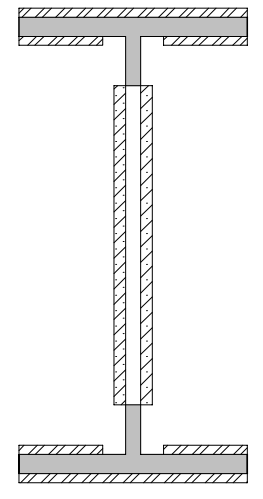

(b) Com Redistribuição

\section{LEGENDA}

Parte do perfil utilizada no cálculo de $\beta$

Parte do perfil utilizada no cálculo de $\alpha$

Parte das talas utilizada no cálculo de $\beta$

Parte das talas utilizada no cálculo de $\alpha$

Figura 4.23 - Redistribuição dos setores da seção transversal do perfil para cálculo de $\alpha$ e $\beta$ 
Reescrevendo, então, as expressões de $\alpha$ e $\beta$, obtém-se:

$$
\begin{aligned}
& \alpha=\frac{I_{w_{r e d}}+I_{t w}}{I_{x}+I_{t x}} \\
& \beta=\frac{I_{m}+I_{t m}+I_{c o m p}}{I_{x}+I_{t x}}
\end{aligned}
$$

onde:

$$
\begin{aligned}
I_{w \text { red }} & =\frac{t_{w} h_{t w}^{3}}{12} \\
I_{\text {comp }} & =\frac{t_{w}\left(\frac{h_{w}-h_{t w}}{2}\right)^{3}}{6}+2 \times t_{w}\left(h_{w}-h_{t w}\right) \times\left(\frac{h_{w}+h_{t w}}{4}\right)^{2}
\end{aligned}
$$

Para que o cálculo não fique demasiadamente laborioso, pode-se determinar primeiramente 0 parâmetro $\alpha$, que requer um esforço algébrico menor, e em seguida determinar o parâmetro $\beta$ por meio da Eq. 4.53.

Como agora a parcela do perfil a ser considerada no cômputo do momento absorvido pela conexão das mesas é dada por duas seções em $T$, que surge devido à junção das mesas com o trecho redistribuído da alma, torna-se necessário calcular a distância entre o centróide dessas duas seções para então decompor o momento em um binário e determinar a força que solicitará os parafusos. Recorrendo às equações da mecânica determina-se que o braço do binário é dado por:

$$
d_{b}=\frac{\left[b_{f} t_{f}^{2}+t_{w} h_{\text {comp }}\left(2 t_{f}+h_{\text {comp }}\right)\right]}{2\left(b_{f} t_{f}+t_{w} h_{\text {comp }}\right)}
$$

onde

$$
h_{\text {comp }}=\frac{h_{w}-h_{t w}}{2}
$$

Aplicando esse método, que será chamado daqui por diante de SIAC (Somatório das Inércias e Áreas Corrigidas), aos casos apresentados nas Tabelas 4.14 e 4.15, foram obtidos os resultados mostrados na Tabela 4.16, que revelam um desempenho bastante razoável para o modelo proposto. 
Tabela 4.16 - Comparação de resultados SIAC x MEF

\begin{tabular}{|c|c|c|c|c|c|c|c|c|}
\hline \multirow{2}{*}{\multicolumn{3}{|c|}{$\begin{array}{l}\text { Modelos Analisados I } \\
\text { Características }\end{array}$}} & \multirow{2}{*}{\multicolumn{2}{|c|}{$\begin{array}{l}\text { MEF - ANSYS } \\
(2000)\end{array}$}} & \multirow{2}{*}{\multicolumn{2}{|c|}{ SIAC }} & \multirow{2}{*}{\multicolumn{2}{|c|}{$\begin{array}{l}\text { Diferença } \\
\text { SIAC/MEF }\end{array}$}} \\
\hline & & & & & & & & \\
\hline 1 & & ainal & \multirow{2}{*}{$\frac{F_{p w}}{67,54}$} & \multirow{2}{*}{$\frac{F_{p m}}{130,50}$} & \multirow{2}{*}{$\begin{array}{c}\mathrm{F}_{\mathrm{pw}} \\
69,80\end{array}$} & \multirow{2}{*}{$\frac{F_{p m}}{131,17}$} & \multirow{2}{*}{$\begin{array}{c}\mathrm{F}_{\mathrm{pw}} \\
3,3 \%\end{array}$} & \multirow{2}{*}{$\begin{array}{l}F_{p m} \\
0,5 \% \\
\end{array}$} \\
\hline & & & & & & & & \\
\hline 2 & + & $t_{f}$ & 49,84 & 134,41 & 63,55 & 132,25 & $27,5 \%$ & \\
\hline 3 & - & $t_{f}$ & 76,61 & 126,78 & 73,39 & 130,55 & $-4,2 \%$ & $3,0 \%$ \\
\hline 4 & + & $t_{w}$ & 70,14 & 129,99 & 77,51 & 129,85 & $10,5 \%$ & $-0,1 \%$ \\
\hline 5 & - & $t_{w}$ & 64,05 & 131,15 & 62,91 & 132,36 & $-1,8 \%$ & $0,9 \%$ \\
\hline 6 & + & $t_{t f}$ & 64,53 & 134,23 & 64,86 & 132,81 & $0,5 \%$ & $-1,1 \%$ \\
\hline 7 & - & $t_{t f}$ & 71,83 & 126,47 & 74,41 & 129,97 & $3,6 \%$ & $2,8 \%$ \\
\hline 8 & + & $t_{\mathrm{tw}}$ & 72,58 & 130,25 & 74,08 & 130,84 & $2,1 \%$ & $0,5 \%$ \\
\hline 9 & - & $t_{\mathrm{tw}}$ & 59,06 & 130,64 & 65,74 & 131,46 & $11,3 \%$ & $0,6 \%$ \\
\hline
\end{tabular}

(Nota:

Resultados de referência, obtidos com o modelo original)

Além das emendas citadas na Tabela 4.16 foram simuladas outras de variadas dimensões, inclusive os sete tipos diferentes que compunham o projeto da cobertura em cúpula estudada no capítulo 5 . A comparação dos resultados desses exemplos apresentou a mesma ordem de grandeza daqueles que constam na Tabela 4.16, não sendo necessário, portanto, inseri-los no texto, embora tenham sido utilizados na validação do modelo.

\subsubsection{Emendas em Barras Solicitadas Axialmente}

Nas barras solicitadas axialmente os esforços nos parafusos das emendas costumam ser determinados de modo semelhante ao das barras fletidas, ou seja, calculam-se os quinhões de força normal absorvidos por cada parte da ligação em função das áreas dos elementos do perfil (mesas e alma), ou em função da área das talas de cobrejunta.

Um estudo numérico semelhante ao realizado para as emendas fletidas conduziu a um modelo de cálculo semelhante ao apresentado no item anterior, pois novamente observou-se que as conexões das mesas tendiam a absorver mais esforço do que aquele indicado pelos modelos apresentados na literatura.

Simulando as mesmas emendas estudadas anteriormente sob a ação de uma carga axial uniformemente distribuída em toda a seção transversal da barra, foram obtidos os resultados dispostos na Tabela 4.17.

Percebe-se que 0 modelo proposto para emendas solicitadas axialmente ainda apresenta uma tendência de superdimensionar o esforço nos parafusos da alma, chegando a fornecer valores que são cerca de 5 a $25 \%$ maiores que os fornecidos pelo MEF. Já para os esforços nos parafusos das mesas a tendência é de subdimensionamento, fornecendo valores da ordem de 2 a $7 \%$ menores que os obtidos numericamente. 
Tabela 4.17 - Comparação de resultados SIAC x MEF (emendas com força axial)

\begin{tabular}{|c|c|c|c|c|c|c|c|c|c|c|}
\hline \multirow{2}{*}{\multicolumn{3}{|c|}{$\begin{array}{c}\text { Modelos Analisados } \\
\text { / Características }\end{array}$}} & \multicolumn{2}{|c|}{ MEF - ANSYS } & \multicolumn{2}{|c|}{ Modelo 1} & \multicolumn{2}{|c|}{ Modelo 2} & \multicolumn{2}{|c|}{ SIAC } \\
\hline & & & \multirow{2}{*}{$\begin{array}{c}F_{p w} \\
48,67\end{array}$} & \multirow{2}{*}{$\frac{F_{p m}}{77,67}$} & \multirow{2}{*}{$\frac{F_{p w}}{56,00}$} & \multirow{2}{*}{$\frac{F_{p m}}{74,00}$} & \multirow{2}{*}{$\frac{F_{p w}}{69,76}$} & \multirow{2}{*}{$\frac{F_{p m}}{67,12}$} & \multirow{2}{*}{$\frac{F_{p w}}{55,51}$} & \multirow{2}{*}{$\frac{F_{p m}}{74,24}$} \\
\hline 1 & Mod & iginal & & & & & & & & \\
\hline 2 & + & $t_{f}$ & 45,54 & 79,23 & 56,00 & 74,00 & 57,10 & 73,45 & 50,10 & 76,95 \\
\hline 3 & - & $t_{f}$ & 50,86 & 76,57 & 56,00 & 74,00 & 77,85 & 63,08 & 58,47 & 72,77 \\
\hline 4 & + & $t_{w}$ & 50,49 & 76,76 & 56,00 & 74,00 & 81,10 & 61,45 & 61,89 & 71,05 \\
\hline 5 & - & $t_{w}$ & 46,18 & 78,91 & 56,00 & 74,00 & 56,99 & 73,50 & 48,96 & 77,52 \\
\hline 6 & + & $t_{t f}$ & 43,40 & 80,30 & 46,83 & 78,59 & 69,76 & 67,12 & 50,44 & 76,78 \\
\hline 7 & - & $t_{t f}$ & 54,28 & 74,86 & 65,50 & 69,25 & 69,76 & 67,12 & 59,98 & 72,01 \\
\hline 8 & + & $\mathrm{t}_{\mathrm{tw}}$ & 54,70 & 74,65 & 65,81 & 69,10 & 69,93 & 67,04 & 59,04 & 72,48 \\
\hline 9 & - & $t_{t w}$ & 41,45 & 81,28 & 45,27 & 79,36 & 69,89 & 67,06 & 52,10 & 75,95 \\
\hline
\end{tabular}

(Nota:

Resultados de referência, obtidos com o modelo original)

\subsubsection{Considerações Finais e Conclusões}

Foi revisado, neste item, os métodos de cálculo existentes para dimensionamento de emendas parafusadas em perfis I de aço, e discutiu-se diversos aspectos relacionados com o desempenho de cada um deles. Em virtude das observações realizadas, foi desenvolvido um processo de cálculo que se mostrou mais apropriado para o dimensionamento desse tipo de ligação. 0 processo proposto apresentou bons resultados em todos os casos analisados, embora tenha sido observada uma leve tendência de superdimensionamento da conexão da alma e de subdimensionamento da conexão das mesas.

\section{4 - Estudo dos Aparelhos de Apoio - Dimensionamento}

\subsubsection{Introdução}

$\mathrm{Na}$ grande maioria das estruturas metálicas a extremidade inferior dos pilares precisa ser fixada em fundações de concreto armado. Normalmente a transferência dos esforços existentes no pilar para a fundação é feita por meio de elementos metálicos que devem desempenhar duas funções:

a) Conectar o pilar metálico à fundação para que não ocorram deslocamentos que separem essas partes, o que em geral é conseguido com o uso de chumbadores e barras de cisalhamento, como indicado na Figura 4.24.

b) Suavizar a transferência dos esforços do pilar para a fundação de concreto, cuja resistência à compressão é bastante inferior a do aço. Isso normalmente é conseguido com o uso de placas de base, como mostra a Figura 4.24, ou de grelhas metálicas e vigas travessa, conforme ilustrado nas Figuras 4.25 e 4.26, respectivamente. Esses elementos permitem distribuir os esforços do pilar em uma superfície de concreto com dimensões apropriadas. 

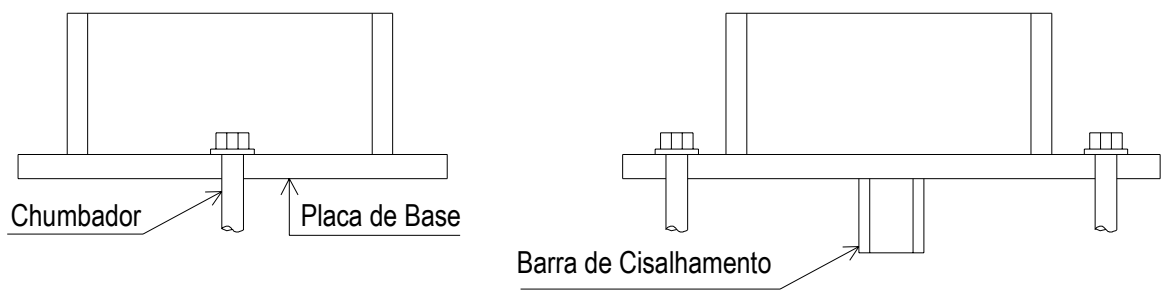

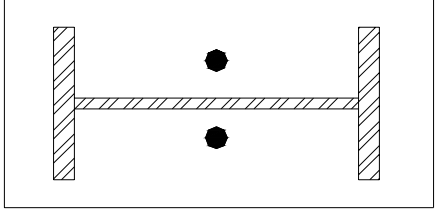

(a) Base Articulada

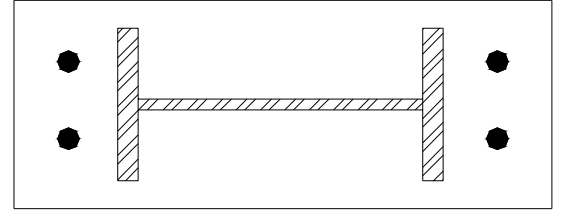

(b) Base Engastada

Figura 4.24 - Bases típicas para pilares metálicos

O cálculo das bases típicas (Figura 4.24) consiste, basicamente, no dimensionamento dos chumbadores (diâmetro e comprimento de ancoragem), da espessura da placa de base e de sua solda com o pilar. Na literatura técnica são encontrados muitos exemplos resolvidos e explanações detalhadas sobre o comportamento dessas bases, de forma que o projetista encontra informações suficientes para desenvolver seus projetos com segurança e praticidade.
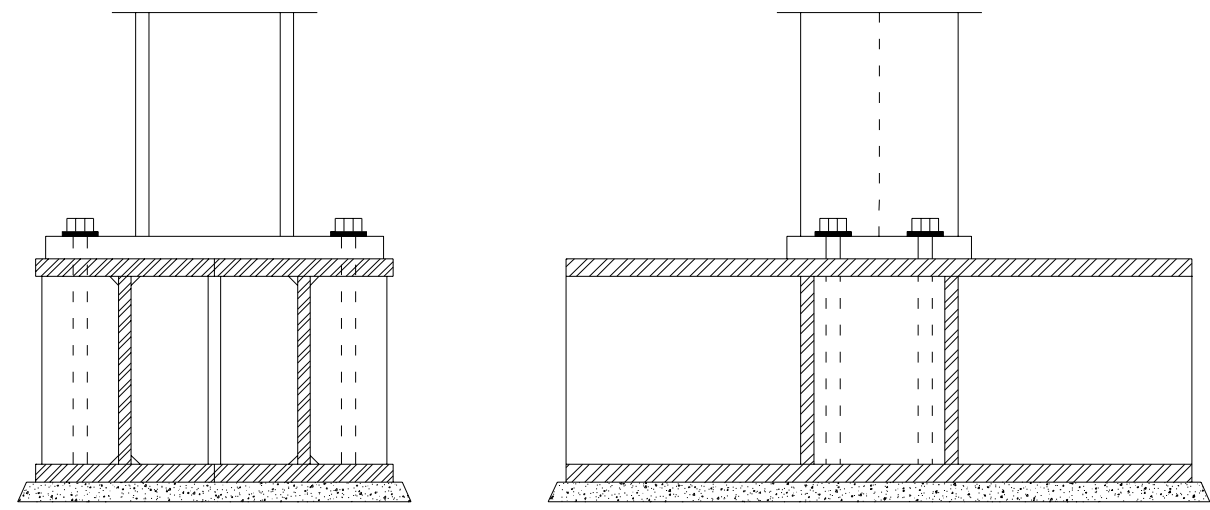

Figura 4.25 - Pilar apoiado em grelha metálica

As placas de base nervuradas, que são o objeto de estudo desta parte do trabalho, assim como as grelhas metálicas (Figura 4.25) e as vigas travessa (Figura 4.26), são utilizadas quando os esforços atuantes na base são elevados, situação na qual o projeto de uma base típica normalmente conduz a placas de elevada espessura. A Figura 4.27 apresenta um detalhe típico de base nervurada (ou enrijecida). 


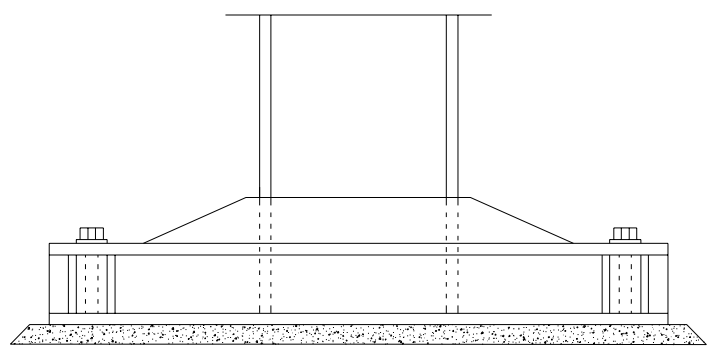

Figura 4.26 -Pilar apoiado sobre viga travessa

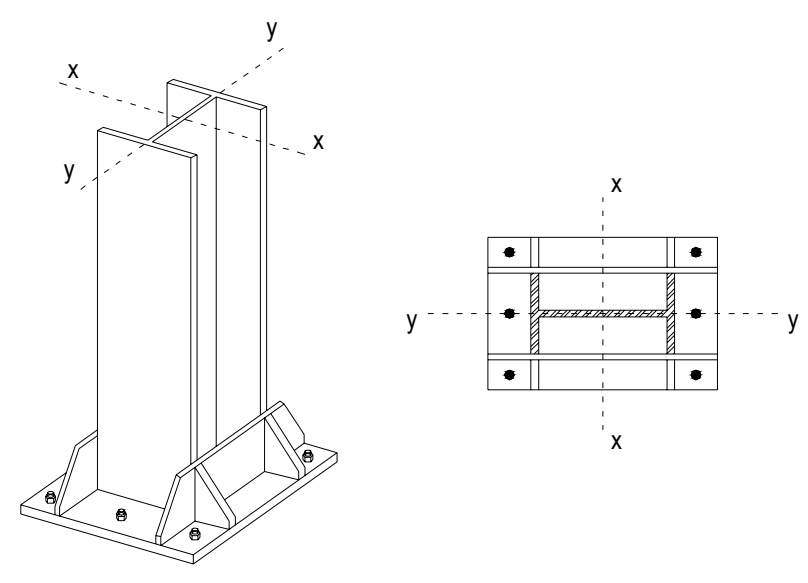

Figura 4.27 - Esquema de base de pilar nervurada

Ao contrário do que se observa para as bases típicas, é difícil encontrar na literatura técnica explanações sobre essas outras formas de ligar os pilares metálicos às fundações; de forma que 0 projetista pode se deparar com a incômoda situação de não ter material para consulta caso precise projetar um aparelho de apoio diferente dos tipos habituais.

A solução para muitos casos têm sido a simulação numérica em elementos finitos do aparelho de apoio, para assim obter as informações necessárias para dimensioná-lo. 0 problema é que essa solução requer programas especiais e profissionais devidamente treinados para utilizá-los, o que nem sempre é fácil de encontrar nos escritórios de cálculo. A verdade é que a situação mais cômoda em um escritório de engenharia ocorre quando se dispõem de um método prático, que possa ser manipulado manualmente ou facilmente implementado para uso em calculadoras e computadores.

Descreve-se a seguir um procedimento prático que foi desenvolvido para o dimensionamento de bases nervuradas, com 0 qual se poderá determinar com considerável facilidade a espessura a ser adotada para a placa. Tal procedimento foi desenvolvido a partir de uma considerável série de simulações numéricas em elementos finitos e de técnicas de ajuste de curva, como será descrito mais adiante.

\subsubsection{Alguns Aspectos do Dimensionamento de Bases de Pilares}

As bases de pilares podem ser divididas em articuladas (ou flexíveis), que são projetadas para resistirem apenas a força normal e a força cortante, e em rígidas (ou engastadas), projetadas para resistirem também ao momento fletor. Para esses tipos de apoios alguns trabalhos interessantes são: DeWOLF \& SARISLEY (1980), THAMBIRATNAN \& PARAMAISVAM (1986) e DeWOLF \& RICKER (1990).

Não havendo nervuras de enrijecimento, as placas de base são dimensionadas em função da flexão em balanços fictícios de largura unitária, externos e internos à seção transversal do pilar, conforme recomendações do AISC (1986). Como ilustração, considere-se a base flexível de pilar indicada na Figura 4.28, onde os balaços fictícios externos são designados por $m$ e $n$. 

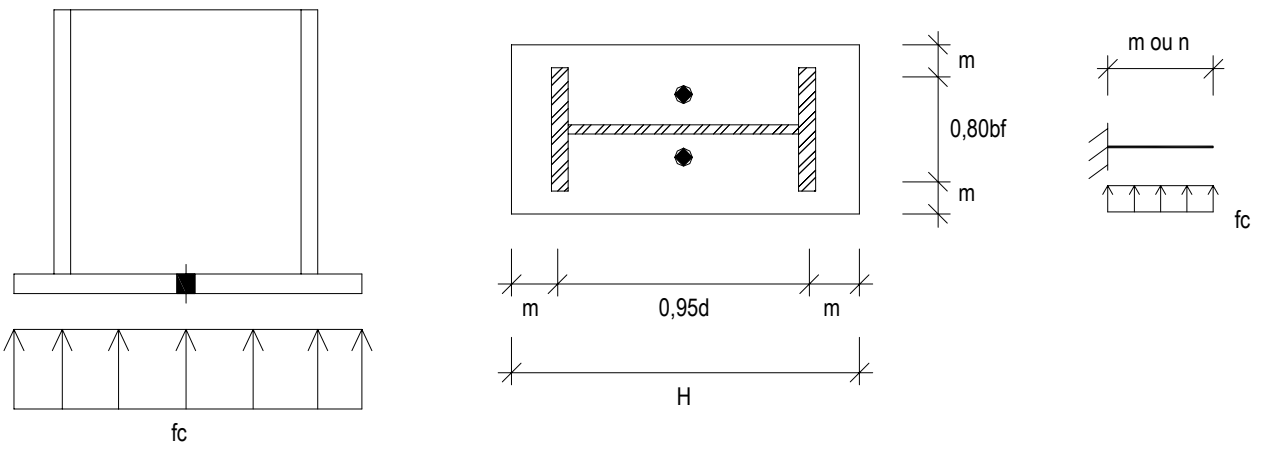

Figura 4.28 - Balanços externos (Método do AISC (1986))

O momento fletor $\left(M_{p}\right)$ a ser considerado no dimensionamento da placa será o maior valor obtido entre:

$$
M_{p 1}=\frac{f_{c} m^{2}}{2} \text { e } M_{p 2}=\frac{f_{c} n^{2}}{2}
$$

Conhecido o momento máximo determina-se a espessura da placa de base por meio da condição de segurança indicada na Eq. 4.63, também estabelecida em termos de largura unitária:

$$
\phi_{b} M_{n}=0,9 Z f_{y} \geq M_{p}
$$

onde $Z=\frac{b t^{2}}{4}=\frac{t^{2}}{4}$, pois a largura $b$ é tomada como igual a unidade.

Desenvolvendo a Eq. 4.63 obtém-se que a espessura da placa será determinada pela Eq. 4.64, dada a seguir:

$$
t_{p} \geq \sqrt{\frac{4 M_{p}}{0,9 f_{y}}}
$$

O AISC (1986) fala ainda em um balanço interno que não precisa ser aqui discutido, uma vez que a citação tem como único objetivo mostrar a dedução da equação anterior, que é aplicável tanto para os balanços externos quanto para o balanço interno.

A inserção de nervuras no aparelho de apoio altera o comportamento da placa, que passa a apresentar diferentes formas de flexão em sua extensão, pois as nervuras funcionam como apoios nos locais onde são inseridos.

Definem-se como setores da placa as diversas regiões compreendidas entre as nervuras e as chapas componentes do pilar, e entre as nervuras e as extremidades livres da placa. A verificação de uma base nervurada recai, então, na verificação desses setores, sendo necessário recorrer à teoria de placas para um estudo mais apurado. 
A Figura 4.29 ilustra alguns detalhes nervurados para bases engastadas. Os tipos (a), (b) e (c) são utilizados quando o objetivo é apenas o de reduzir a espessura da placa de base, já os tipos (d) e (e) são utilizados quando além da redução da espessura da placa necessita-se também de uma quantidade maior de chumbadores.

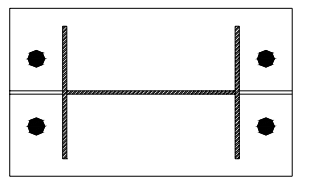

a) Base com nervuras alinhadas à alma do pilar

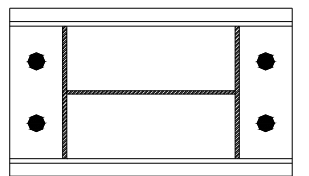

b) Base com nervuras parelelas à alma do pilar

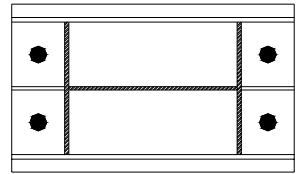

c) Base com nervuras parelelas e alinhadas à alma do pilar
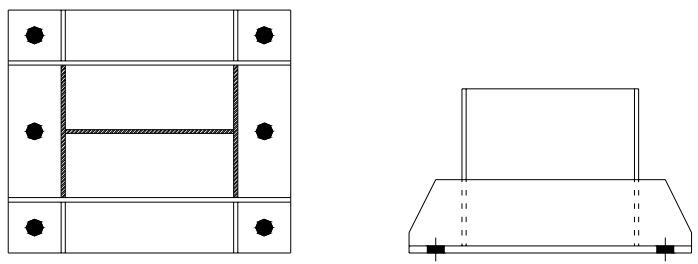

d) Base com nervuras paralelas à alma e alinhadas com as mesas do pilar
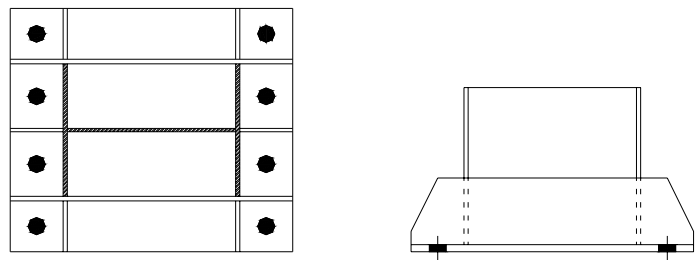

e) Base com nervuras paralelas à alma e alinhadas com a alma e as mesas do pilar

Figura 4.29 - Alguns tipos de bases nervuradas

Neste trabalho serão abordadas essencialmente as bases engastadas, no entanto, o procedimento que será aqui proposto pode ser facilmente adaptado para bases articuladas, como será indicado mais adiante. Convém lembrar, porém, que a colocação de nervuras aumenta a rigidez da ligação, e utilizá-las em bases articuladas, onde se prevê completa e irrestrita liberdade ao giro na análise estrutural, pode ser interpretado como um contra-senso.

Sabendo que as nervuras funcionam como vínculos ou apoios das placas de base, resta saber que tipo de restrição aos deslocamentos elas introduzem, pois, dependendo do local onde são inseridas elas podem funcionar como apoios simples ou engastes, o que tem considerável influência na distribuição dos esforços.

Embora os detalhes apresentados na Figura 4.29 sejam muitos, basta estudar os diferentes setores encontrados nos casos mostrados na Figura 4.30 para obter informações suficientes para dimensionar todos os detalhes mostrados na Figura 4.29. A Tabela 1 apresenta uma descrição resumida de cada um desses setores. 

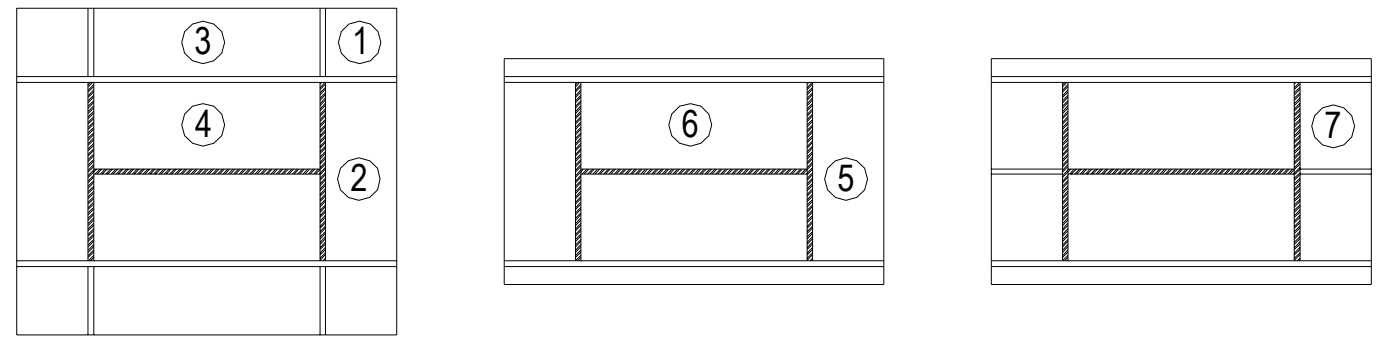

Figura 4.30 - Setores encontrados em bases nervuradas

Tabela 4.18 - Descrição dos Setores Encontrados em Bases Nervuradas

\begin{tabular}{c|l}
\hline Setor & Descrição \\
\hline $\mathbf{1}$ & Duas bordas engastadas e duas livres \\
$\mathbf{2}$ & Três bordas engastadas e uma livre \\
$\mathbf{3}$ & Três bordas engastadas e uma livre \\
$\mathbf{4}$ & Quatro bordas engastadas \\
$\mathbf{5}$ & Uma borda engastada, duas simplesmente apoiadas e uma livre \\
$\mathbf{6}$ & Três bordas engastadas e uma simplesmente apoiada \\
$\mathbf{7}$ & Duas bordas engastadas, uma borda simplesmente apoiada e uma livre \\
\hline
\end{tabular}

\subsubsection{DETERMINAÇÃO DOS MOMENTOS FLETORES MÁXIMOS}

\subsubsection{1 - Distribuição das tensões na placa de base}

Nas bases articuladas a pressão de compressão no concreto é considerada uniforme, o que resulta em uma distribuição também uniforme da pressão atuante na placa de base (Figura 4.31(a)). Nos apoios engastados a tensão varia linearmente, de forma que as placas podem resultar totalmente ou parcialmente comprimidas, como mostram as Figura 4.31(b) e 4.31(c).

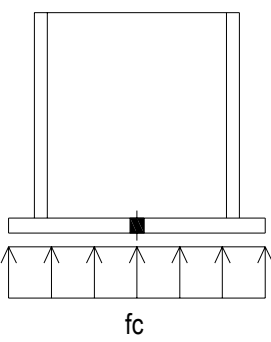

(a) Base Articulada

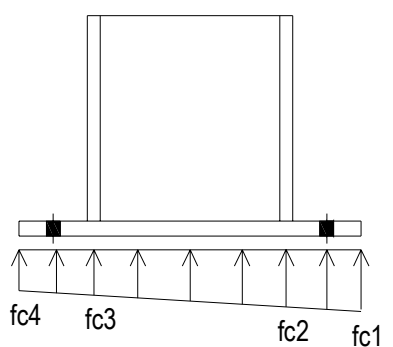

(b) Base Engastada / Placa Totalmente Comprimida

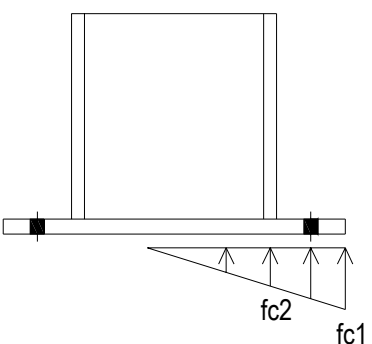

(b) Base Engastada / Placa Parcialmente Comprimida

Figura 4.31 - Distribuição das tensões em bases de pilares

Para maiores detalhes sobre as distribuições de pressão que podem atuar nas placas de bases, e para determinação da posição da linha neutra recomenda-se que o leitor consulte SÁLES et al. (1994) e ANDRADE (1994). 
Observando as distribuições de pressão para bases engastadas, percebe-se que os setores 1, 2, 5 e 7, localizados nas extremidades da placa, ficam submetidos a carregamentos trapezoidais, enquanto os setores 3, 4 e 6, localizados no centro da placa, também podem apresentar esse mesmo tipo de carregamento, no caso de toda a base estar comprimida (Figura 4.31(b)), ou poder estar submetidos a um carregamento triangular aplicado em parte de sua extensão, no caso da placa estar parcialmente comprimida (Figura 4.31(c)).

\subsubsection{2 - Critério adotado por TIMOSHENKO \& KRIEGER (1959)}

TIMOSHENKO \& KRIEGER (1959) analisaram várias placas com diferentes condições de contorno e sob diversos tipos de carregamentos pelo método das diferenças finitas. Parte dos resultados obtidos foram organizados na forma de tabelas que permitem calcular esforços e deslocamentos em alguns pontos específicos dos casos estudados. A Tabela 4.19, por exemplo, apresenta as expressões recomendadas para a determinação de deslocamentos e momentos fletores em uma placa com os quatro lados engastados, submetida a um carregamento uniformemente distribuído, como indicado na Figura 4.32.

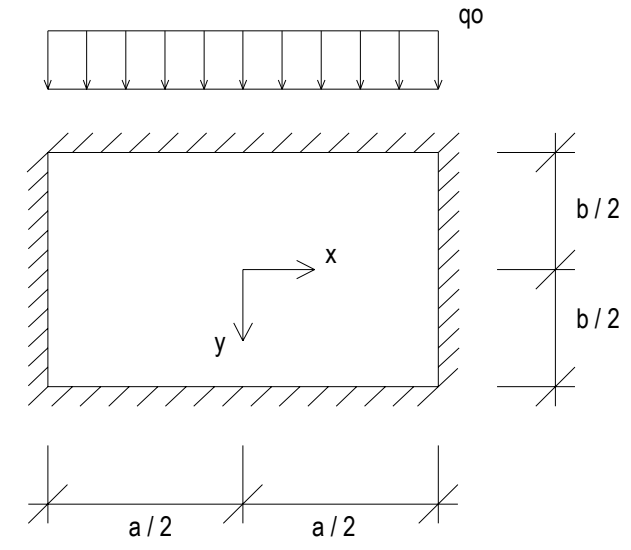

Figura 4.32 - Placa estudada por TIMOSHENKO \& KRIEGER (1959)

Tabela 4.19 - Deslocamentos e momentos fletores para placas com as bordas engastadas submetida a carga uniformemente distribuída (Fonte: TIMOSHENKO \& KRIEGER (1959)).

\begin{tabular}{|c|c|c|c|c|c|}
\hline b/a & $W_{(x=0 ; y=0)}$ & $M x_{(x=a / 2 ; y=0)}$ & $M y_{(x=0 ; y=b / 2)}$ & $M x_{(x=0 ; y=0)}$ & My $(x=0 ; y=0)$ \\
\hline 1,0 & $0,00126 q_{0} a^{4} / D$ & $-0,0513 q_{0} a^{2}$ & $-0,0513 q_{0} a^{2}$ & $0,0231 q_{0} a^{2}$ & $0,0231 q_{0} a^{2}$ \\
\hline 1,2 & $0,00172 q_{0} a^{4} / D$ & $-0,0639 q_{0} a^{2}$ & $-0,0554 q_{0} a^{2}$ & $0,0299 q_{0} a^{2}$ & $0,0228 q_{0} a^{2}$ \\
\hline 1,4 & $0,00207 q_{0} a^{4} / D$ & $-0,0726 q_{0} a^{2}$ & $-0,0568 q_{0} a^{2}$ & $0,0349 q_{0} a^{2}$ & $0,0212 q_{0} a^{2}$ \\
\hline 1,6 & $0,00230 q_{0} a^{4 / D}$ & $-0,0780 q_{0} a^{2}$ & $-0,0571 q_{0} a^{2}$ & $0,0381 q_{0} a^{2}$ & $0,0193 q_{0} a^{2}$ \\
\hline 1,8 & $0,00245 q_{0} a^{4 / D}$ & $-0,0812 q_{0} a^{2}$ & $-0,0571 q_{0} a^{2}$ & $0,0401 q_{0} a^{2}$ & $0,0174 q_{0} a^{2}$ \\
\hline 2,0 & $0,00254 q_{0} a^{4} / D$ & $-0,0829 q_{0} a^{2}$ & $-0,0571 q_{0} a^{2}$ & $0,0412 q_{0} a^{2}$ & $0,0158 q_{0} a^{2}$ \\
\hline$\infty$ & $0,00260 q_{0} a^{4} / D$ & $-0,0833 q_{0} a^{2}$ & $-0,0571 q_{0} a^{2}$ & $0,0417 q_{0} a^{2}$ & $0,0125 q_{0} a^{2}$ \\
\hline
\end{tabular}

O critério sugerido por TIMOSHENKO \& KRIEGER (1959) consiste, então, em calcular os deslocamentos e momentos fletores em função de uma constante que depende da relação entre as dimensões da placa, como mostrado na Tabela 4.19. Embora a obra supracitada seja um clássico da literatura técnica mundial e a principal referência no estudo das placas, ela apresenta duas características que dificultam o estudo das bases nervuradas, são elas: 
a) Não apresenta o estudo de placas com condições de contorno capazes de representar os diversos setores das bases de pilares enrijecidas encontradas na prática.

b) Os carregamentos estudados nessa referência são, em sua maioria, caracterizados por pressões uniformes e/ou triangulares, situações essas que não reproduzem os casos em estudo neste trabalho, como pôde ser observado anteriormente.

Tendo por base o estudo desenvolvido por TIMOSHENKO \& KRIEGER (1959), pôde-se propor um procedimento semelhante para avaliação dos esforços em placas nervuradas que será discutido no próximo item.

\subsubsection{3 - Critérios propostos neste trabalho}

Foram desenvolvidas aproximadamente duzentas simulações numéricas em elementos finitos que permitiram caracterizar o comportamento dos diversos setores das bases enrijecidas encontradas na prática. Os resultados obtidos nessas simulações foram organizados na forma de tabelas, e, a partir deles, algumas expressões foram obtidas por meio de técnicas de ajuste de curva. Essas expressões facilitam 0 processo de dimensionamento e permitem sua implementação em computadores e calculadoras.

O dimensionamento da espessura da placa de base, como já foi dito anteriormente, é feito em função do momento fletor máximo que nela atua. Para TIMOSHENKO \& KRIEGER (1959) os momentos fletores em uma placa submetida a um carregamento uniformemente distribuído podem ser calculados por:

$$
M=\beta q a^{2}
$$

onde $\beta$ depende da relação entre as dimensões da placa ( $a$ e $b$, ver Figura 4.32) e $q$ é a intensidade da carga uniformemente distribuída.

A mesma expressão pode ser utilizada se o carregamento for triangular, bastando, para isso, utilizar valores apropriados de $\beta$. Essa expressão, porém, deixa de ser válida no caso de carregamento trapezoidal, pois, devido as diversas variações de intensidade que esse carregamento pode assumir, fica extremamente complicado calcular os esforços em função apenas do parâmetro $\beta$, os quais iriam variar não apenas com as dimensões da placa, mas também com a intensidade do carregamento.

Propõem-se, então, substituir a Eq. 4.65 pela Eq. 4.66, dada a seguir, que calcula o momento fletor em função do carregamento médio uniformemente distribuído sobre toda a placa, corrigido por um fator $\gamma$ que depende da relação entre $q_{1}$ e $q_{2}$, que são os valores inicial e final do carregamento trapezoidal, respectivamente.

$$
M=\gamma \beta\left(\frac{q_{1}+q_{2}}{2}\right) a^{2}
$$


Tem-se, então, uma expressão geral, com a qual pode-se calcular:

a) os momentos provocados por carregamentos uniformes fazendo $q_{1}=q_{2}$;

b) os momentos provocados por carregamentos triangulares fazendo $q_{1}=0$ ou $q_{2}=0$;

c) os momentos provocados por carregamentos trapezoidais fazendo $q_{1} \neq q_{2} \neq 0$;

Todos esses casos são analisados com os valores de $\beta$ obtidos com carregamento uniformemente distribuído, corrigidos pelo fator $\gamma$, que encarrega-se de incluir o efeito da variação linear do carregamento.

A Eq. 4.66 pode ser aplicada aos setores 1, 2, 5 e 7, pois neles a distribuição de pressões é do tipo trapezoidal. Já nos setores 3,4 e 6 esse tipo de distribuição de pressões só ocorrerá se toda a placa de base estiver comprimida (Figura 4.33(a)), caso contrário a distribuição de pressões será triangular e só atuará em parte da superfície do setor. Nesse caso será necessário fazer uma simplificação que consiste no seguinte:

a) No caso de mais da metade da região entre as mesas estar comprimida, o que ocorre quando a posição da linha neutra é maior que $H / 2$, onde $H$ é o comprimento da placa, será admitido simplificadamente e a favor da segurança que o carregamento triangular atua em todo o setor, como mostrado na Figura 4.33(b).

b) No caso da região comprimida entre as mesas do pilar ser menor ou igual a metade da sua extensão, será admitido, simplificadamente e a favor da segurança, que o carregamento triangular atua em metade do setor, como mostrado na Figura 4.33(c).

Sendo assim, se o carregamento for triangular e estiver aplicado sobre apenas metade do setor deverá ser utilizada a Eq. 4.65 para determinação do momento máximo. Nos demais casos deverá ser empregada e Eq. 4.66 .

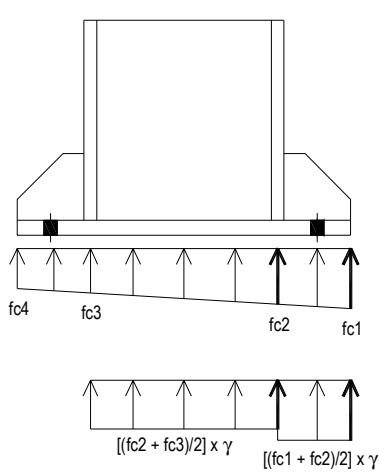

(a)

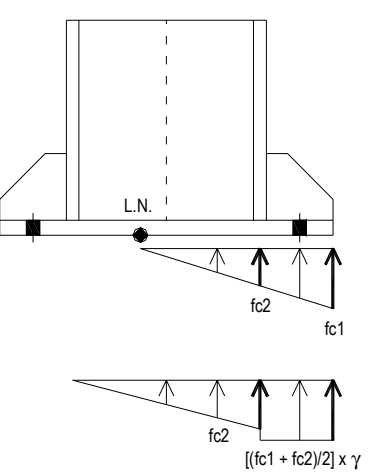

(b)

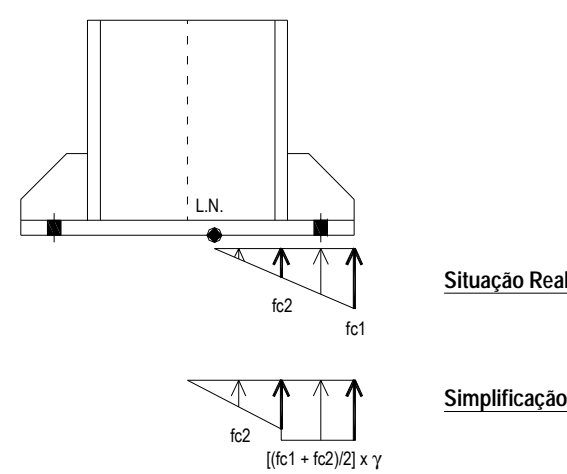

(c)

Figura 4.33 - Distribuição das tensões: situação real x simplificação 


\subsubsection{Proposta para Determinação dos Momentos Fletores Máximos}

Neste item são analisados os diversos setores que podem ser encontrados nas placas de base nervuradas usuais, conforme ilustrado na Figura 4.34.

São apresentadas tabelas e expressões que permitem fazer uma boa avaliação dos momentos fletores máximos nesses setores, que foram obtidas por simulações numéricas com elementos finitos de placa. Foi utilizado o programa computacional STRAP 8.0 (1997), e os elementos finitos empregados possuíam quatro nós cada, geometria quadrilateral e seis graus de liberdade em cada nó, sendo três rotações e três translações.

Foram simuladas placas retangulares com uma dimensão fixa de $10 \mathrm{~cm}$ e outra variando de $1 \mathrm{a}$ $20 \mathrm{~cm}$, de forma que a relação entre as dimensões variassem de 0,1 a 2,0, o que abrange a maioria das situações encontradas na prática. Para placas cuja relação entre as dimensões excede esse limite é aconselhável fazer um estudo específico em elementos finitos.

A Tabela 4.24 mostra a dimensão aproximada dos elementos finitos gerados automaticamente pelo programa para os vários casos analisados.

Tabela 4.20 - Discretização dos modelos

\begin{tabular}{cc}
\hline Dimensões da Placa & Rede \\
\hline $01 \times 10$ a $09 \times 10$ & $2,0 \mathrm{~mm} \times 2,0 \mathrm{~mm}$ \\
$10 \times 10$ a $15 \times 10$ & $2,5 \mathrm{~mm} \times 2,5 \mathrm{~mm}$ \\
$16 \times 10$ a $18 \times 10$ & $3,0 \mathrm{~mm} \times 3,0 \mathrm{~mm}$ \\
$19 \times 10$ a $20 \times 10$ & $3,5 \mathrm{~mm} \times 3,5 \mathrm{~mm}$ \\
\hline
\end{tabular}

\subsubsection{1 - Setor 1 (placa com dois lados engastados e dois lados livres)}

O momento fletor máximo no setor 1 é igual ao maior valor obtido com as seguintes expressões:

$$
\begin{aligned}
& M_{x}=\gamma_{x} \beta_{x}\left(\frac{q_{1}+q_{2}}{2}\right) b^{2} \\
& M_{y}=\gamma_{y} \beta_{y}\left(\frac{q_{1}+q_{2}}{2}\right) b^{2}
\end{aligned}
$$

onde $\beta_{x}$ e $\beta_{y}$ podem ser calculados pela Eq. 4.69, obtida por técnicas de ajuste de curva, ou com auxílio da Tabela 4.21. Esses dois parâmetros dependem das dimensões da placa, por isso precisam ser calculados em função do parâmetro $\alpha_{m}$ indicado na Eq. 4.70.

$$
\begin{gathered}
\beta=\frac{a}{1+b \times e^{-c \times \alpha_{m}}} \\
\alpha_{m}=\frac{a}{b}
\end{gathered}
$$




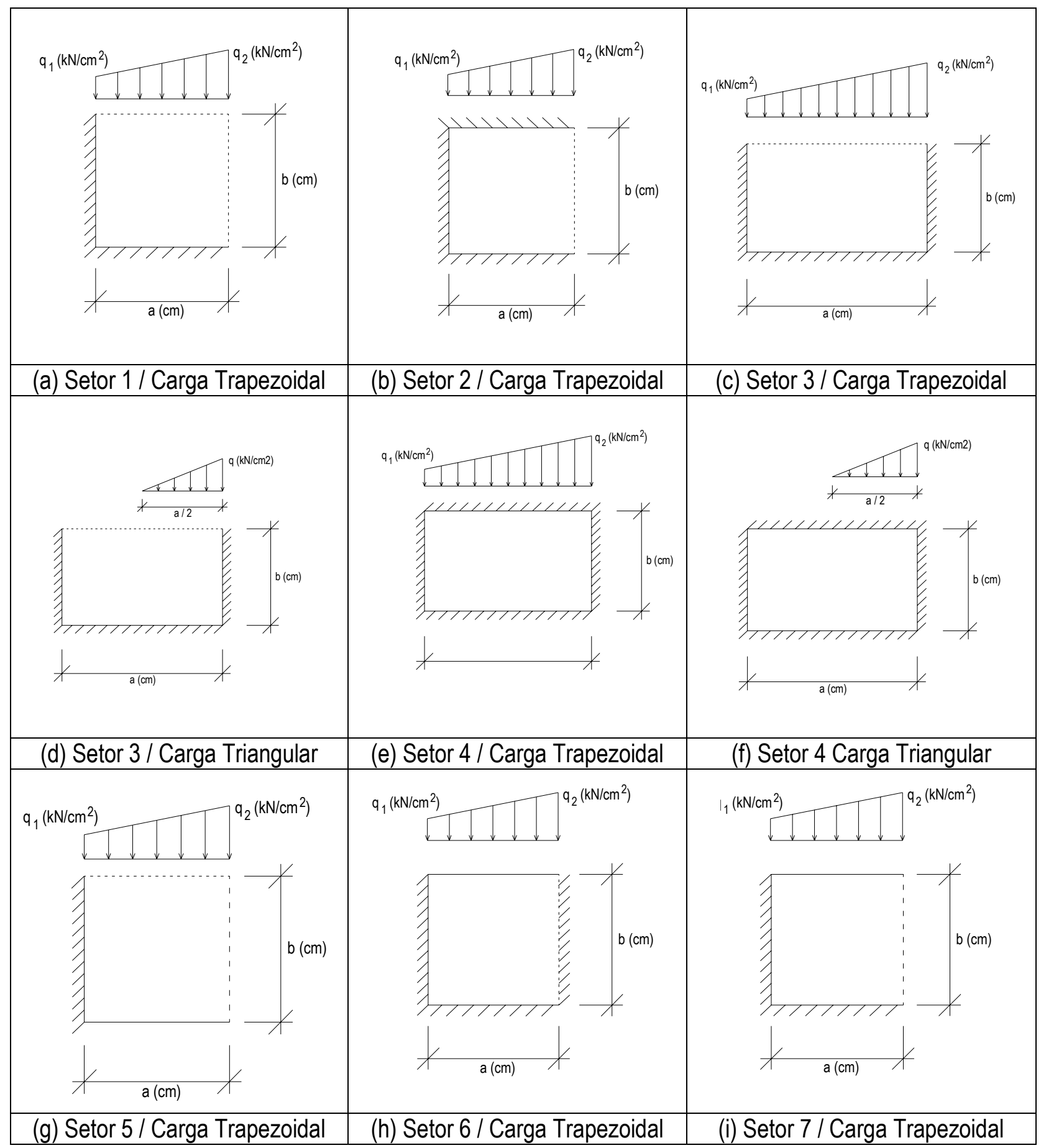

Figura 4.34 - Setores analisados e seus carregamentos 
Tabela 4.21 - Valores de $\beta_{x}$ e $\beta_{y}$ no Setor 1

\begin{tabular}{|c|c|c|c|c|c|c|c|c|c|c|}
\hline$\alpha_{m}$ & 0,1 & 0,2 & 0,3 & 0,4 & 0,5 & 0,6 & 0,7 & 0,8 & 0,9 & 1,0 \\
\hline$\beta_{x}$ & 0,0051 & 0,0205 & 0,0458 & 0,0789 & 0,1169 & 0,1574 & 0,1973 & 0,2353 & 0,2705 & 0,3011 \\
\hline$\beta_{y}$ & 0,0041 & 0,0160 & 0,0381 & 0,0691 & 0,1070 & 0,1480 & 0,1884 & 0,2298 & 0,2680 & 0,3011 \\
\hline$\alpha_{m}$ & 1,1 & 1,2 & 1,3 & 1,4 & 1,5 & 1,6 & 1,7 & 1,8 & 1,9 & 2,0 \\
\hline$\beta_{x}$ & 0,3272 & 0,3498 & 0,3680 & 0,3831 & 0,3949 & 0,4036 & 0,4113 & 0,4172 & 0,4243 & 0,4278 \\
\hline$\beta_{y}$ & 0,3312 & 0,3565 & 0,3784 & 0,3985 & 0,4149 & 0,4290 & 0,4407 & 0,4516 & 0,4601 & 0,4683 \\
\hline
\end{tabular}

Tabela 4.22 - Constantes para Cálculo de $\beta_{x}$ e $\beta_{y}$ para flexão no setor 1

\begin{tabular}{c|cc|c|c}
\hline \multirow{2}{*}{ Coeficientes } & \multicolumn{2}{|c|}{$\alpha=\frac{b}{a} \leq 1,0$} & \multicolumn{2}{c}{$1,0<\alpha=\frac{b}{a} \leq 2,0$} \\
\cline { 2 - 5 } & $\beta_{\mathrm{x}}$ & $\beta_{\mathrm{y}}$ & $\beta_{\mathrm{x}}$ & $\beta_{\mathrm{y}}$ \\
\hline $\mathbf{a}_{\mathrm{m}}$ & 0,36 & 0,36 & 0,45 & 0,50 \\
\hline $\mathbf{b}_{\mathrm{m}}$ & 33,12 & 40,53 & 8,00 & 7,05 \\
\hline $\mathbf{c}_{\mathrm{m}}$ & 5,62 & 5,69 & 2,86 & 2,42 \\
\hline
\end{tabular}

A Eq. 4.69 foi obtida, conforme dito anteriormente, com o auxílio de técnicas de ajuste de curva, e tem como objetivo não condicionar a determinação de $\beta$ ao uso de tabelas. No entanto, dado 0 caráter numérico dessa equação, os valores tabelados podem ser considerados mais precisos.

Já os parâmetros $\gamma_{x}$ e $\gamma_{y}$ dependem da relação entre os valores da carga trapezoidal, e seus valores podem ser determinados com auxílio das Tabelas 4.23 e 4.24, ou com as Eqs. 4.71 e 4.72, cujos coeficientes estão apresentados na Tabela 4.25.

$$
\begin{gathered}
\alpha_{q}=\frac{q_{1}}{q_{2}}, \text { onde } q_{1} \leq q_{2} \\
\gamma=a_{q} \times \alpha_{q}+b_{q}
\end{gathered}
$$

\begin{tabular}{|c|c|c|c|c|c|c|c|c|c|c|c|}
\hline$\alpha_{q}$ & 0,0 & 0,1 & 0,2 & 0,3 & 0,4 & 0,5 & 0,6 & 0,7 & 0,8 & 0,9 & 1,0 \\
\hline$\gamma_{x}$ & 1,333 & 1,248 & 1,209 & 1,176 & 1,148 & 1,098 & 1,078 & 1,061 & $\overline{1,046}$ & $\overline{1,011}$ & 1,000 \\
\hline$\gamma_{v}$ & 1,530 & 1,433 & 1,353 & 1,285 & 1,227 & 1,177 & 1,132 & 1,093 & 1,059 & 1,028 & 1,000 \\
\hline
\end{tabular}

Tabela 4.23 - Fator de Correção do Carregamento no Setor 1 quando $\alpha_{m} \leq 1,0$

\begin{tabular}{|c|c|c|c|c|c|c|c|c|c|c|c|}
\hline$\alpha_{q}$ & 0,0 & 0,1 & 0,2 & 0,3 & 0,4 & 0,5 & 0,6 & 0,7 & 0,8 & 0,9 & 1,0 \\
\hline$\gamma_{x}$ & 1,218 & 1,178 & 1,145 & 1,117 & 1,093 & 1,073 & 1,054 & 1,038 & 1,024 & 1,011 & 1,000 \\
\hline$\gamma_{y}$ & 1,590 & 1,482 & 1,391 & 1,315 & 1,250 & 1,185 & 1,143 & 1,101 & 1,064 & 1,030 & 1,000 \\
\hline
\end{tabular}

Tabela 4.24 - Fator de Correção do Carregamento no Setor 1 quando $\alpha_{m}>1,0$ 
Tabela 4.25 - Constantes para Cálculo de $\gamma_{x}$ e $\gamma_{y}$ para flexão no setor 1

\begin{tabular}{c|c|c|c|c}
\hline \multirow{2}{*}{ Coeficientes } & \multicolumn{2}{|c|}{$\alpha=\frac{b}{a} \leq 1,0$} & \multicolumn{2}{c}{$1,0<\alpha=\frac{b}{a} \leq 2,0$} \\
\cline { 2 - 5 } & $\gamma_{\mathrm{x}}$ & $\gamma_{\mathrm{y}}$ & $\gamma_{\mathrm{x}}$ & $\gamma_{\mathrm{y}}$ \\
\hline $\mathbf{a}_{\mathrm{q} 1}$ & $-0,33$ & $-0,53$ & $-0,22$ & $-0,59$ \\
\hline $\mathbf{b}_{\mathrm{q} 1}$ & 1,33 & 1,53 & 1,22 & 1,59 \\
\hline
\end{tabular}

Os valores de $\gamma_{x}$ e $\gamma_{y}$ foram encontrados dividindo os valores correspondentes às situações de carregamento trapezoidal onde $\frac{1}{10} \leq \alpha_{q} \leq 1$ (ver Eq. 4.71) por aqueles correspondentes ao carregamento uniformemente distribuído. A existência de um padrão de comportamento permitiu 0 ajuste da Eq. 4.72 e a construção das Tabelas 4.23 a 4.25. 0 mesmo processo foi empregado nos demais setores de placa estudados, não sendo necessários maiores explicações a respeito.

\subsubsection{2 - Setor 2 (placa com três lados engastados e um lado livre)}

No setor 2 o momento máximo é dado pela Eq. 4.73. As Tabelas 4.26 a 4.30 permitem a avaliação dos parâmetros envolvidos, tal qual foi feito para o Setor 1.

$$
M=\gamma \beta\left(\frac{q_{1}+q_{2}}{2}\right) b^{2}
$$

Tabela 4.26 - Constante $\beta$ para flexão no Setor 2

\begin{tabular}{c|c|c|c|c|c|c|c|c|c|c}
\hline$\alpha_{\mathrm{m}}$ & $\mathbf{0 , 1}$ & $\mathbf{0 , 2}$ & $\mathbf{0 , 3}$ & $\mathbf{0 , 4}$ & $\mathbf{0 , 5}$ & $\mathbf{0 , 6}$ & $\mathbf{0 , 7}$ & $\mathbf{0 , 8}$ & $\mathbf{0 , 9}$ & $\mathbf{1 , 0}$ \\
\hline $\boldsymbol{\beta}$ & 0,0050 & 0,0191 & 0,0365 & 0,0583 & 0,0746 & 0,0842 & 0,0895 & 0,0927 & 0,0938 & 0,0938 \\
\hline$\alpha_{\mathrm{m} 2}$ & $\mathbf{1 , 1}$ & $\mathbf{1 , 2}$ & $\mathbf{1 , 3}$ & $\mathbf{1 , 4}$ & $\mathbf{1 , 5}$ & $\mathbf{1 , 6}$ & $\mathbf{1 , 7}$ & $\mathbf{1 , 8}$ & $\mathbf{1 , 9}$ & $\mathbf{2 , 0}$ \\
\hline $\boldsymbol{\beta}$ & 0,0936 & 0,0933 & 0,0929 & 0,0925 & 0,0922 & 0,0913 & 0,0910 & 0,0910 & 0,0909 & 0,0909 \\
\hline
\end{tabular}

Tabela 4.27 - Fator de Correção do Carregamento $\gamma$ no Setor 2 quando $\alpha_{m} \leq 1,0$

\begin{tabular}{c|c|c|c|c|c|c|c|c|c|c|c}
\hline $\boldsymbol{\alpha}_{q}$ & $\mathbf{0 , 0}$ & $\mathbf{0 , 1}$ & $\mathbf{0 , 2}$ & $\mathbf{0 , 3}$ & $\mathbf{0 , 4}$ & $\mathbf{0 , 5}$ & $\mathbf{0 , 6}$ & $\mathbf{0 , 7}$ & $\mathbf{0 , 8}$ & $\mathbf{0 , 9}$ & $\mathbf{1 , 0}$ \\
\hline$\gamma_{y}$ & 1,663 & 1,537 & 1,436 & 1,353 & 1,281 & 1,218 & 1,163 & 1,115 & 1,073 & 1,035 & 1,000 \\
\hline
\end{tabular}

Tabela 4.28 - Fator de Correção do Carregamento $\gamma$ no Setor 2 quando $\alpha_{m}>1,0$

\begin{tabular}{c|c|c|c|c|c|c|c|c|c|c|c}
\hline $\boldsymbol{\alpha}_{\mathbf{q}}$ & $\mathbf{0 , 0}$ & $\mathbf{0 , 1}$ & $\mathbf{0 , 2}$ & $\mathbf{0 , 3}$ & $\mathbf{0 , 4}$ & $\mathbf{0 , 5}$ & $\mathbf{0 , 6}$ & $\mathbf{0 , 7}$ & $\mathbf{0 , 8}$ & $\mathbf{0 , 9}$ & $\mathbf{1 , 0}$ \\
\hline $\boldsymbol{\gamma}$ & 1,857 & 1,700 & 1,571 & 1,461 & 1,367 & 1,285 & 1,214 & 1,151 & 1,095 & 1,045 & 1,000 \\
\hline
\end{tabular}


Tabela 4.29 - Coeficientes para Cálculo de $\beta$ para flexão no setor 2

\begin{tabular}{ccc}
\hline Coeficientes & $\alpha=\frac{b}{a} \leq 1,0$ & $1,0<\alpha=\frac{b}{a} \leq 2,0$ \\
\hline $\mathbf{a}_{\mathrm{m}}$ & 0,10 & 0,10 \\
$\mathbf{b}_{\mathrm{m}}$ & 36,60 & 0,25 \\
$\mathbf{c}_{\mathrm{m}}$ & 10,22 & 2,06 \\
\hline
\end{tabular}

Tabela 4.30 - Coeficientes para Cálculo de y para flexão no setor 2 (com a Eq.4.72)

\begin{tabular}{ccc}
\hline Coeficientes & $\alpha=\frac{b}{a} \leq 1,0$ & $1,0<\alpha=\frac{b}{a} \leq 2,0$ \\
\hline $\mathbf{a}_{\mathrm{q}}$ & $-0,66$ & $-0,86$ \\
$\mathbf{b}_{\mathrm{q}}$ & 1,66 & 1,86 \\
\hline
\end{tabular}

\subsubsection{3 - Setor 3 (placa com três lados engastados e um livre)}

O setor 3 possui as mesmas condições de contorno do setor 2, o que permite que sejam utilizados os mesmos valores de $\beta$ quando o carregamento é do tipo trapezoidal. Mas como esse carregamento está aplicado de forma diferente do setor 2, é necessário determinar novos valores para $\gamma$.

Outro fator a considerar é que o setor 3 pode estar submetido a carregamentos triangulares em metade da sua extensão, o que ocorre quando a placa de base está parcialmente comprimida. Esta última situação exige valores apropriados de $\beta$ e o emprego da Eq. 4.65 para cálculo do momento máximo.

A avaliação do momento máximo requer também algumas modificações nas equações anteriores, a primeira delas está na avaliação do parâmetro $a_{m}$, e a segunda na própria avaliação do momento máximo, como mostram as Eqs. 4.74 e 4.75.

$$
\begin{gathered}
a_{m}=\frac{b}{a} \\
M=\gamma \beta\left(\frac{q_{1}+q_{2}}{2}\right) a^{2}
\end{gathered}
$$

Os itens 4.4.4.3.1 e 4.4.4.3.2 fornecem os meios necessários para determinação de $\gamma$ nas duas situações de carregamento indicadas.

\subsubsection{1 - Carregamento Trapezoidal (Figura 4.34(c))}

Tabela 4.31 - Fator de Correção do Carregamento no Setor 2 quando $\alpha_{m} \leq 1,0$

\begin{tabular}{c|c|c|c|c|c|c|c|c|c|c|c}
\hline $\boldsymbol{\alpha}_{q}$ & $\mathbf{0 , 0}$ & $\mathbf{0 , 1}$ & $\mathbf{0 , 2}$ & $\mathbf{0 , 3}$ & $\mathbf{0 , 4}$ & $\mathbf{0 , 5}$ & $\mathbf{0 , 6}$ & $\mathbf{0 , 7}$ & $\mathbf{0 , 8}$ & $\mathbf{0 , 9}$ & $\mathbf{1 , 0}$ \\
\hline $\boldsymbol{\gamma}$ & 1,480 & 1,382 & 1,300 & 1,231 & 1,171 & 1,147 & 1,100 & 1,059 & 1,022 & 1,011 & 1,000 \\
\hline
\end{tabular}

Tabela 4.32 - Fator de Correção do Carregamento no Setor 2 quando $\alpha_{m}>1,0$

\begin{tabular}{c|c|c|c|c|c|c|c|c|c|c|c}
\hline $\boldsymbol{\alpha}_{\mathbf{q}}$ & $\mathbf{0 , 0}$ & $\mathbf{0 , 1}$ & $\mathbf{0 , 2}$ & $\mathbf{0 , 3}$ & $\mathbf{0 , 4}$ & $\mathbf{0 , 5}$ & $\mathbf{0 , 6}$ & $\mathbf{0 , 7}$ & $\mathbf{0 , 8}$ & $\mathbf{0 , 9}$ & $\mathbf{1 , 0}$ \\
\hline $\boldsymbol{\gamma}$ & 1,192 & 1,158 & 1,129 & 1,104 & 1,082 & 1,064 & 1,048 & 1,034 & 1,022 & 1,010 & 1,000 \\
\hline
\end{tabular}


Tabela 4.33 - Coeficientes para Cálculo de $\gamma$ para flexão no setor 2 (com a Eq. (4.72))

\begin{tabular}{ccc}
\hline Coeficientes & $\alpha=\frac{b}{a} \leq 1,0$ & $1,0<\alpha=\frac{b}{a} \leq 2,0$ \\
\hline $\mathbf{a}_{\mathrm{q}}$ & $-0,48$ & $-0,192$ \\
$\mathrm{~b}_{\mathrm{q}}$ & 1,48 & 1,192 \\
\hline
\end{tabular}

\subsubsection{2 - Carregamento Triangular (Figura 4.34(d))}

Tabela 4.34 - Valores de $\beta$ para o setor 3 com carregamento triangular

\begin{tabular}{|c|c|c|c|c|c|c|c|c|c|c|}
\hline$\alpha_{m}$ & 0,1 & 0,2 & 0,3 & 0,4 & 0,5 & 0,6 & 0,7 & 0,8 & 0,9 & 1,0 \\
\hline $\bar{\beta}$ & 0,0032 & 0,0092 & 0,0157 & 0,0207 & 0,0237 & 0,0252 & 0,0260 & 0,0264 & 0,0266 & 0,0266 \\
\hline$\alpha_{\mathrm{m} 2}$ & 1,1 & 1,2 & 1,3 & 1,4 & 1,5 & 1,6 & 1,7 & 1,8 & 1,9 & 2,0 \\
\hline$\beta$ & 0,0264 & 0,0263 & 0,0263 & 0,0262 & 0,0262 & 0,0260 & 0,0260 & 0,0260 & 0,0260 & 0,0260 \\
\hline
\end{tabular}

Tabela 4.35 - Coeficientes para cálculo de $\beta$

\begin{tabular}{ccc}
\hline Coeficientes & $\alpha=\frac{b}{a} \leq 1,0$ & $1,0<\alpha=\frac{b}{a} \leq 2,0$ \\
\hline $\mathbf{a}_{\mathbf{m}}$ & 0,027 & 0,027 \\
$\mathbf{b}_{\mathbf{m}}$ & 5,320 & 5,320 \\
$\mathbf{c}_{\mathbf{m}}$ & 7,370 & 7,370 \\
\hline
\end{tabular}

\subsubsection{4 - Setor 4 (placa com os quatro lados engastados)}

No caso do setor 4 estar submetido a carregamento trapezoidal, como mostra a Figura 4.34(e), utiliza-se as Eqs. 4.68 e 4.69 para avaliação do momento máximo. No caso do setor estar submetido a carga triangular, como mostra a Figura 4.34(f), utiliza-se a Eq. 4.65. Os itens 4.4.4.4.1 e 4.4.4.4.2 fornece os meios para determinação dos parâmetros envolvidos no cálculo.

\subsubsection{1 - Carregamento Trapezoidal (Figura 4.34(e))}

Tabela 4.36 - Coeficientes para cálculo de $\beta$

\begin{tabular}{c|c|c|c|c|c|c|c|c|c|c}
\hline$\alpha_{m}$ & $\mathbf{0 , 1}$ & $\mathbf{0 , 2}$ & $\mathbf{0 , 3}$ & $\mathbf{0 , 4}$ & $\mathbf{0 , 5}$ & $\mathbf{0 , 6}$ & $\mathbf{0 , 7}$ & $\mathbf{0 , 8}$ & $\mathbf{0 , 9}$ & $\mathbf{1 , 0}$ \\
\hline$\beta_{\mathrm{x}}$ & 0,0005 & 0,0022 & 0,0051 & 0,0090 & 0,0142 & 0,0205 & 0,0278 & 0,0357 & 0,0438 & 0,0513 \\
\hline$\beta_{\mathrm{y}}$ & 0,0008 & 0,0033 & 0,0075 & 0,0134 & 0,0207 & 0,0285 & 0,0360 & 0,0425 & 0,0476 & 0,0513 \\
\hline$\alpha_{\mathrm{m}}$ & $\mathbf{1 , 1}$ & $\mathbf{1 , 2}$ & $\mathbf{1 , 3}$ & $\mathbf{1 , 4}$ & $\mathbf{1 , 5}$ & $\mathbf{1 , 6}$ & $\mathbf{1 , 7}$ & $\mathbf{1 , 8}$ & $\mathbf{1 , 9}$ & $\mathbf{2 , 0}$ \\
\hline$\beta_{\mathrm{x}}$ & 0,0580 & 0,0639 & 0,0687 & 0,0726 & 0,0757 & 0,0780 & 0,0799 & 0,0812 & 0,0822 & 0,0829 \\
\hline$\beta_{y}$ & 0,0538 & 0,0554 & 0,0563 & 0,0568 & 0,0569 & 0,0569 & 0,0569 & 0,0569 & 0,0569 & 0,0569 \\
\hline
\end{tabular}


Tabela 4.37 - Constantes para Cálculo de $\beta_{\mathrm{x}}$ e $\beta_{\mathrm{y}}$ para flexão no setor 4

\begin{tabular}{c|c|c|c|c}
\hline \multirow{2}{*}{ Coeficientes } & \multicolumn{2}{|c|}{$\alpha=\frac{2}{a} \leq 1,0$} & \multicolumn{2}{c}{$1,0<\alpha=\frac{b}{a} \leq 2,0$} \\
\cline { 2 - 5 } & $\beta_{\mathrm{x}}$ & $\beta_{\mathrm{y}}$ & $\beta_{\mathrm{x}}$ & $\beta_{\mathrm{y}}$ \\
\hline $\mathbf{a}_{\mathrm{m}}$ & 0,07 & 0,06 & 0,09 & 0,06 \\
\hline $\mathbf{b}_{\mathrm{m}}$ & 53,26 & 39,46 & 18,80 & 48,29 \\
\hline $\mathbf{c}_{\mathrm{m}}$ & 5,24 & 6,23 & 3,36 & 6,13 \\
\hline
\end{tabular}

Tabela 4.38 - Fator de Correção do Carregamento no Setor 4 quando $\alpha_{m} \leq 1,0$

\begin{tabular}{c|c|c|c|c|c|c|c|c|c|c|c}
\hline $\boldsymbol{\alpha}_{\mathrm{q}}$ & $\mathbf{0 , 0}$ & $\mathbf{0 , 1}$ & $\mathbf{0 , 2}$ & $\mathbf{0 , 3}$ & $\mathbf{0 , 4}$ & $\mathbf{0 , 5}$ & $\mathbf{0 , 6}$ & $\mathbf{0 , 7}$ & $\mathbf{0 , 8}$ & $\mathbf{0 , 9}$ & $\mathbf{1 , 0}$ \\
\hline $\boldsymbol{\gamma}_{\mathrm{x}}$ & 2,000 & 1,818 & 1,667 & 1,538 & 1,429 & 1,333 & 1,250 & 1,176 & 1,111 & 1,053 & 1,000 \\
\hline$\gamma_{\mathrm{y}}$ & 1,750 & 1,591 & 1,458 & 1,538 & 1,429 & 1,333 & 1,250 & 1,176 & 1,111 & 1,053 & 1,000 \\
\hline
\end{tabular}

Tabela 4.39 - Fator de Correção do Carregamento no Setor 4 quando $\alpha_{m}>1,0$

\begin{tabular}{c|c|c|c|c|c|c|c|c|c|c|c}
\hline $\boldsymbol{\alpha}_{q}$ & $\mathbf{0 , 0}$ & $\mathbf{0 , 1}$ & $\mathbf{0 , 2}$ & $\mathbf{0 , 3}$ & $\mathbf{0 , 4}$ & $\mathbf{0 , 5}$ & $\mathbf{0 , 6}$ & $\mathbf{0 , 7}$ & $\mathbf{0 , 8}$ & $\mathbf{0 , 9}$ & $\mathbf{1 , 0}$ \\
\hline$\gamma_{x}$ & 1,302 & 1,248 & 1,202 & 1,164 & 1,131 & 1,099 & 1,075 & 1,053 & 1,033 & 1,016 & 1,000 \\
\hline$\gamma_{y}$ & 1,045 & 1,028 & 1,020 & 1,014 & 1,008 & 1,006 & 1,004 & 1,003 & 1,002 & 1,001 & 1,000 \\
\hline
\end{tabular}

Tabela 4.40 - Constantes para Cálculo de $\gamma_{x}$ e $\gamma_{y}$ para flexão no setor 4

\begin{tabular}{|c|c|c|c|c|}
\hline \multirow[t]{2}{*}{ Coeficientes } & \multicolumn{2}{|c|}{$\alpha=\frac{b}{a} \leq 1,0$} & \multicolumn{2}{|c|}{$1,0<\alpha=\frac{b}{a} \leq 2,0$} \\
\hline & $\gamma_{x}$ & $\gamma_{y}$ & $\gamma_{x}$ & $\gamma_{y}$ \\
\hline$a_{q}$ & $-1,00$ & $-0,75$ & $-0,30$ & $-0,05$ \\
\hline$b_{q}$ & 2,00 & 1,75 & 1,30 & 1,05 \\
\hline
\end{tabular}

4.4.1 - Carregamento Triangular (Figura 4.34(f))

Tabela 4.41 - Coeficiente de Cálculo do Momento Fletor Máximo no Setor 4

\begin{tabular}{l|l|l|l|l|l|l|l|l|l|l}
\hline$\alpha_{m}$ & 0,1 & 0,2 & 0,3 & 0,4 & 0,5 & 0,6 & 0,7 & 0,8 & $\mathbf{0 , 9}$ & 1,0 \\
\hline$\beta$ & 0,0006 & 0,0022 & 0,0040 & 0,0069 & 0,0086 & 0,0110 & 0,0132 & 0,0152 & 0,0170 & 0,0185 \\
\hline$\alpha_{m 2}$ & 1,1 & 1,2 & 1,3 & 1,4 & 1,5 & 1,6 & 1,7 & 1,8 & 1,9 & 2,0 \\
\hline$\beta$ & 0,0198 & 0,0208 & 0,0216 & 0,0223 & 0,0228 & 0,0232 & 0,0235 & 0,0237 & 0,0238 & 0,0239 \\
\hline
\end{tabular}

Tabela 4.42 - Coeficientes para Cálculo de $\beta$ para flexão no setor 4 (com a Eq. (9))

\begin{tabular}{ccc}
\hline Coeficientes & $\alpha=\frac{b}{a} \leq 1,0$ & $1,0<\alpha=\frac{b}{a} \leq 2,0$ \\
\hline $\mathbf{a}_{\mathrm{m}}$ & 0,022 & 0,025 \\
$\mathbf{b}_{\mathrm{m}}$ & 22,40 & 7,27 \\
$\mathbf{C}_{\mathrm{m}}$ & 5,48 & 3,15 \\
\hline
\end{tabular}




\subsubsection{5 - Setor 5 ( placa com um lado engastado, dois simplesmente apoiados e um livre)}

Para o setor 5 utiliza-se as mesmas equações utilizadas no setor 2, porém com os valores de $\beta$ e $\gamma$ indicados nas Tabelas 4.43 a 4.47 .

Tabela 4.43 - Coeficientes para cálculo de $\beta$ - Flexão no Setor 5

\begin{tabular}{c|c|c|c|c|c|c|c|c|c|c}
\hline$\alpha_{m}$ & $\mathbf{0 , 1}$ & $\mathbf{0 , 2}$ & $\mathbf{0 , 3}$ & $\mathbf{0 , 4}$ & $\mathbf{0 , 5}$ & $\mathbf{0 , 6}$ & $\mathbf{0 , 7}$ & $\mathbf{0 , 8}$ & $\mathbf{0 , 9}$ & $\mathbf{1 , 0}$ \\
\hline$\beta_{\mathrm{x}}$ & 0,0050 & 0,0196 & 0,0403 & 0,0615 & 0,0797 & 0,0937 & 0,1038 & 0,1107 & 0,1153 & 0,1184 \\
\hline$\beta_{y}$ & 0,0015 & 0,0060 & 0,0123 & 0,0187 & 0,0290 & 0,0449 & 0,0605 & 0,0747 & 0,0868 & 0,0967 \\
\hline$\alpha_{m}$ & $\mathbf{1 , 1}$ & $\mathbf{1 , 2}$ & $\mathbf{1 , 3}$ & $\mathbf{1 , 4}$ & $\mathbf{1 , 5}$ & $\mathbf{1 , 6}$ & $\mathbf{1 , 7}$ & $\mathbf{1 , 8}$ & $\mathbf{1 , 9}$ & $\mathbf{2 , 0}$ \\
\hline$\beta_{\mathrm{x}}$ & 0,1204 & 0,1218 & 0,1226 & 0,1233 & 0,1237 & 0,1239 & 0,1241 & 0,1243 & 0,1245 & 0,1246 \\
\hline$\beta_{y}$ & 0,1046 & 0,1110 & 0,1159 & 0,1199 & 0,1229 & 0,1250 & 0,1268 & 0,1281 & 0,1292 & 0,1300 \\
\hline
\end{tabular}

Tabela 4.44 - Constantes para Cálculo de $\beta_{\mathrm{x}}$ e $\beta_{\mathrm{y}}$ para flexão no setor 5

\begin{tabular}{c|c|c|c|c}
\hline \multirow{2}{*}{ Coeficientes } & \multicolumn{2}{|c|}{$\alpha=\frac{b}{a} \leq 1,0$} & \multicolumn{2}{c}{$1,0<\alpha=\frac{b}{a} \leq 2,0$} \\
\cline { 2 - 5 } & $\beta_{\mathrm{x}}$ & $\beta_{\mathrm{y}}$ & $\beta_{\mathrm{x}}$ & $\beta_{\mathrm{y}}$ \\
\hline $\mathbf{a}_{\mathrm{m}}$ & 0,12 & 0,11 & 0,11 & 0,14 \\
\hline $\mathbf{b}_{\mathrm{m}}$ & 19,65 & 47,50 & 47,5 & 9,24 \\
\hline $\mathbf{c}_{\mathrm{m}}$ & 7,65 & 5,96 & 5,96 & 3,25 \\
\hline
\end{tabular}

Tabela 4.45 - Fator de Correção do Carregamento no Setor 5 quando $\alpha_{m} \leq 1,0$

\begin{tabular}{c|c|c|c|c|c|c|c|c|c|c|c}
\hline$\alpha_{q}$ & $\mathbf{0 , 0}$ & $\mathbf{0 , 1}$ & $\mathbf{0 , 2}$ & $\mathbf{0 , 3}$ & $\mathbf{0 , 4}$ & $\mathbf{0 , 5}$ & $\mathbf{0 , 6}$ & $\mathbf{0 , 7}$ & $\mathbf{0 , 8}$ & $\mathbf{0 , 9}$ & $\mathbf{1 , 0}$ \\
\hline$\gamma_{\mathrm{x}}$ & 1,320 & 1,273 & 1,200 & 1,169 & 1,143 & 1,093 & 1,075 & 1,059 & 1,022 & $\mathbf{1 , 0 1 1}$ & 1,000 \\
\hline$\gamma_{\mathrm{y}}$ & 1,475 & 1,389 & 1,317 & 1,255 & 1,204 & 1,158 & 1,118 & 1,084 & 1,053 & 1,024 & 1,000 \\
\hline
\end{tabular}

Tabela 4.46 - Fator de Correção do Carregamento no Setor 5 quando $\alpha_{m}>1,0$

\begin{tabular}{c|c|c|c|c|c|c|c|c|c|c|c}
\hline $\boldsymbol{\alpha}_{\mathbf{q}}$ & $\mathbf{0 , 0}$ & $\mathbf{0 , 1}$ & $\mathbf{0 , 2}$ & $\mathbf{0 , 3}$ & $\mathbf{0 , 4}$ & $\mathbf{0 , 5}$ & $\mathbf{0 , 6}$ & $\mathbf{0 , 7}$ & $\mathbf{0 , 8}$ & $\mathbf{0 , 9}$ & $\mathbf{1 , 0}$ \\
\hline$\gamma_{\mathrm{x}}$ & 1,034 & 1,029 & 1,023 & 1,019 & 1,015 & 1,011 & 1,008 & 1,007 & 1,004 & 1,002 & 1,000 \\
\hline$\gamma_{y}$ & 1,612 & 1,501 & 1,409 & 1,330 & 1,263 & 1,204 & 1,153 & 1,109 & 1,068 & 1,032 & 1,000 \\
\hline
\end{tabular}

Tabela 4.47 - Constantes para Cálculo de $\gamma_{x}$ e $\gamma_{y}$ para flexão no setor 5

\begin{tabular}{c|c|c|c|c}
\hline \multirow{2}{*}{ Coeficientes } & \multicolumn{2}{|c|}{$\alpha=\frac{b}{a} \leq 1,0$} & \multicolumn{2}{c}{$1,0<\alpha=\frac{b}{a} \leq 2,0$} \\
\cline { 2 - 5 } & $\gamma_{\mathrm{x}}$ & $\gamma_{\mathrm{y}}$ & $\gamma_{\mathrm{x}}$ & $\gamma_{\mathrm{y}}$ \\
\hline $\mathrm{a}_{\mathrm{q}}$ & $-0,320$ & $-0,475$ & $-0,034$ & $-0,612$ \\
\hline $\mathrm{b}_{\mathrm{q}}$ & 1,320 & 1,475 & 1,034 & 1,612 \\
\hline
\end{tabular}




\subsubsection{6 - Setor 6 (placa com três lados engastados e um simplesmente apoiado)}

Para o setor 6 utiliza-se as mesmas equações empregadas no setor 4, com os valores de $\beta$ e $\gamma$ indicados nas Tabelas 4.48 a 4.54.

\subsubsection{1 - Carregamento trapezoidal}

Tabela 4.48 - Coeficientes para cálculo de $\beta$

\begin{tabular}{c|c|c|c|c|c|c|c|c|c|c}
\hline$\alpha_{m}$ & $\mathbf{0 , 1}$ & $\mathbf{0 , 2}$ & $\mathbf{0 , 3}$ & $\mathbf{0 , 4}$ & $\mathbf{0 , 5}$ & $\mathbf{0 , 6}$ & $\mathbf{0 , 7}$ & $\mathbf{0 , 8}$ & $\mathbf{0 , 9}$ & $\mathbf{1 , 0}$ \\
\hline$\beta_{\mathrm{x}}$ & 0,0008 & 0,0032 & 0,0073 & 0,0130 & 0,0203 & 0,0287 & 0,0377 & 0,0465 & 0,0545 & 0,0612 \\
\hline$\beta_{y}$ & 0,0012 & 0,0050 & 0,0112 & 0,0195 & 0,0286 & 0,0372 & 0,0442 & 0,0494 & 0,0529 & 0,0550 \\
\hline$\alpha_{\mathrm{m}}$ & $\mathbf{1 , 1}$ & $\mathbf{1 , 2}$ & $\mathbf{1 , 3}$ & $\mathbf{1 , 4}$ & $\mathbf{1 , 5}$ & $\mathbf{1 , 6}$ & $\mathbf{1 , 7}$ & $\mathbf{1 , 8}$ & $\mathbf{1 , 9}$ & $\mathbf{2 , 0}$ \\
\hline$\beta_{\mathrm{x}}$ & 0,0669 & 0,0714 & 0,0749 & 0,0776 & 0,0796 & 0,0811 & 0,0822 & 0,0830 & 0,0835 & 0,0838 \\
\hline$\beta_{y}$ & 0,0562 & 0,0568 & 0,0571 & 0,0572 & 0,0572 & 0,0572 & 0,0572 & 0,0572 & 0,0572 & 0,0572 \\
\hline
\end{tabular}

Tabela 4.49 - Constantes para Cálculo de $\beta_{x}$ e $\beta_{y}$ para flexão no setor 6

\begin{tabular}{c|cc|c|c}
\hline \multirow{2}{*}{ Coeficientes } & \multicolumn{2}{|c|}{$\alpha=\frac{b}{a} \leq 1,0$} & \multicolumn{2}{c}{$1,0<\alpha=\frac{b}{a} \leq 2,0$} \\
\cline { 2 - 5 } & $\beta_{\mathrm{x}}$ & $\beta_{\mathrm{y}}$ & $\beta_{\mathrm{x}}$ & $\beta_{\mathrm{y}}$ \\
\hline $\mathbf{a}_{\mathrm{m}}$ & 0,075 & 0,059 & 0,085 & 0,058 \\
\hline $\mathbf{b}_{\mathrm{m}}$ & 45,74 & 34,82 & 13,08 & 2,45 \\
\hline $\mathbf{c}_{\mathrm{m}}$ & 5,75 & 7,12 & 3,54 & 3,96 \\
\hline
\end{tabular}

Tabela 4.50 - Fator de Correção do Carregamento no Setor 6 quando $\alpha_{m} \leq 1,0$

\begin{tabular}{c|c|c|c|c|c|c|c|c|c|c|c}
\hline $\boldsymbol{\alpha}_{q}$ & $\mathbf{0 , 0}$ & $\mathbf{0 , 1}$ & $\mathbf{0 , 2}$ & $\mathbf{0 , 3}$ & $\mathbf{0 , 4}$ & $\mathbf{0 , 5}$ & $\mathbf{0 , 6}$ & $\mathbf{0 , 7}$ & $\mathbf{0 , 8}$ & $\mathbf{0 , 9}$ & $\mathbf{1 , 0}$ \\
\hline$\gamma_{x}$ & 1,750 & 1,591 & 1,458 & 1,346 & 1,250 & 1,167 & 1,111 & 1,094 & 1,053 & 1,029 & 1,000 \\
\hline$\gamma_{y}$ & 1,833 & 1,667 & 1,528 & 1,410 & 1,310 & 1,222 & 1,250 & 1,176 & 1,111 & 1,053 & 1,000 \\
\hline
\end{tabular}

Tabela 4.51 - Fator de Correção do Carregamento no Setor 6 quando $\alpha_{m}>1,0$

\begin{tabular}{c|c|c|c|c|c|c|c|c|c|c|c}
\hline $\boldsymbol{\alpha}_{q}$ & $\mathbf{0 , 0}$ & $\mathbf{0 , 1}$ & $\mathbf{0 , 2}$ & $\mathbf{0 , 3}$ & $\mathbf{0 , 4}$ & $\mathbf{0 , 5}$ & $\mathbf{0 , 6}$ & $\mathbf{0 , 7}$ & $\mathbf{0 , 8}$ & $\mathbf{0 , 9}$ & $\mathbf{1 , 0}$ \\
\hline$\gamma_{x}$ & 1,261 & 1,212 & 1,174 & 1,141 & 1,111 & 1,087 & 1,066 & 1,046 & 1,029 & 1,015 & 1,000 \\
\hline$\gamma_{y}$ & 1,036 & 1,025 & 1,018 & 1,010 & 1,008 & 1,004 & 1,002 & 1,001 & 1,000 & 1,000 & 1,000 \\
\hline
\end{tabular}

Tabela 4.52 - Constantes para Cálculo de $\gamma_{x}$ e $\gamma_{y}$ para flexão no setor 5

\begin{tabular}{c|c|c|c|c}
\hline \multirow{2}{*}{ Coeficientes } & \multicolumn{2}{|c|}{$\alpha=\frac{b}{a} \leq 1,0$} & \multicolumn{2}{c}{$1,0<\alpha=\frac{b}{a} \leq 2,0$} \\
\cline { 2 - 5 } & $\gamma_{\mathrm{x}}$ & $\gamma_{\mathrm{y}}$ & $\gamma_{\mathrm{x}}$ & $\gamma_{\mathrm{y}}$ \\
\hline $\mathbf{a}_{\mathrm{q}}$ & $-0,750$ & $-0,833$ & $-0,261$ & $-0,036$ \\
\hline $\mathbf{b}_{\mathrm{q}}$ & 1,750 & 1,833 & 1,261 & 1,036 \\
\hline
\end{tabular}




\subsubsection{2 - Carregamento Triangular}

Tabela 4.53 - Coeficientes para cálculo de $\beta$

\begin{tabular}{c|c|c|c|c|c|c|c|c|c|c}
\hline$\alpha_{m}$ & $\mathbf{0 , 1}$ & $\mathbf{0 , 2}$ & $\mathbf{0 , 3}$ & $\mathbf{0 , 4}$ & $\mathbf{0 , 5}$ & $\mathbf{0 , 6}$ & $\mathbf{0 , 7}$ & $\mathbf{0 , 8}$ & $\mathbf{0 , 9}$ & $\mathbf{1 , 0}$ \\
\hline$\beta$ & 0,0007 & 0,0026 & 0,0051 & 0,0079 & 0,0104 & 0,0136 & 0,0155 & 0,0174 & 0,0190 & 0,0203 \\
\hline$\alpha_{m}$ & $\mathbf{1 , 1}$ & $\mathbf{1 , 2}$ & $\mathbf{1 , 3}$ & $\mathbf{1 , 4}$ & $\mathbf{1 , 5}$ & $\mathbf{1 , 6}$ & $\mathbf{1 , 7}$ & $\mathbf{1 , 8}$ & $\mathbf{1 , 9}$ & $\mathbf{2 , 0}$ \\
\hline$\beta$ & 0,0213 & 0,0221 & 0,0227 & 0,0231 & 0,0234 & 0,0237 & 0,0238 & 0,0239 & 0,0240 & 0,0241 \\
\hline
\end{tabular}

Tabela 4.54 - Constantes para Cálculo de $\beta_{\mathrm{x}}$ e $\beta_{\mathrm{y}}$ para flexão no setor 6 - triangular

\begin{tabular}{ccc}
\hline Coeficientes & $\alpha=\frac{b}{a} \leq 1,0$ & $1,0<\alpha=\frac{b}{a} \leq 2,0$ \\
\hline $\mathbf{a}_{\mathrm{m}}$ & 0,022 & 0,025 \\
$\mathbf{b}_{\mathrm{m}}$ & 20,43 & 6,298 \\
$\mathbf{c}_{\mathrm{m}}$ & 6,04 & 3,483 \\
\hline
\end{tabular}

\subsubsection{7 - Setor 7 (placa com dois lados engastados, um simplesmente apoiado e outro livre)}

No setor 7, a exemplo do setor 5 , utiliza-se as mesmas equações empregadas no setor 2, porém com os valores de $\beta$ e $\gamma$ indicados nas Tabelas 4.55 a 4.59 .

Tabela 4.55 - Coeficientes para cálculo de $\beta$ - Flexão no setor 7

\begin{tabular}{|c|c|c|c|c|c|c|c|c|c|c|}
\hline$\alpha_{m}$ & 0,1 & 0,2 & 0,3 & 0,4 & 0,5 & 0,6 & 0,7 & 0,8 & 0,9 & 1,0 \\
\hline$\beta_{x}$ & 0,0050 & 0,0194 & 0,0383 & 0,0547 & 0,0658 & 0,0724 & 0,0761 & 0,0781 & 0,0792 & 0,0798 \\
\hline$\beta_{y}$ & 0,0041 & 0,0160 & 0,0373 & 0,0628 & 0,0864 & 0,1043 & 0,1170 & 0,1265 & 0,1324 & 0,1356 \\
\hline$\alpha_{m}$ & 1,1 & 1,2 & 1,3 & 1,4 & 1,5 & 1,6 & 1,7 & 1,8 & 1,9 & 2,0 \\
\hline$\beta_{x}$ & 0,0803 & 0,0806 & 0,0808 & 0,0809 & 0,0811 & 0,0811 & 0,0812 & 0,0812 & 0,0812 & 0,0812 \\
\hline$\beta_{y}$ & 0,1378 & 0,1390 & 0,1395 & 0,1398 & 0,1398 & 0,1398 & 0,1398 & 0,1398 & 0,1398 & 0,1398 \\
\hline
\end{tabular}

Tabela 4.56 - Fator de Correção do Carregamento no Setor 7 quando $\alpha_{m} \leq 1,0$

\begin{tabular}{c|c|c|c|c|c|c|c|c|c|c|c}
\hline $\boldsymbol{\alpha}_{\mathrm{q}}$ & $\mathbf{0 , 0}$ & $\mathbf{0 , 1}$ & $\mathbf{0 , 2}$ & $\mathbf{0 , 3}$ & $\mathbf{0 , 4}$ & $\mathbf{0 , 5}$ & $\mathbf{0 , 6}$ & $\mathbf{0 , 7}$ & $\mathbf{0 , 8}$ & $\mathbf{0 , 9}$ & $\mathbf{1 , 0}$ \\
\hline$\gamma_{x}$ & 1,320 & 1,273 & 1,200 & 1,169 & 1,143 & 1,093 & 1,075 & 1,059 & 1,022 & 1,011 & 1,000 \\
\hline$\gamma_{y}$ & 1,594 & 1,486 & 1,396 & 1,319 & 1,255 & 1,198 & 1,149 & 1,104 & 1,066 & 1,031 & 1,000 \\
\hline
\end{tabular}

Tabela 4.57 - Fator de Correção do Carregamento no Setor 7 quando $\alpha_{m}>1,0$

\begin{tabular}{c|c|c|c|c|c|c|c|c|c|c|c}
\hline $\boldsymbol{\alpha}_{\mathbf{q}}$ & $\mathbf{0 , 0}$ & $\mathbf{0 , 1}$ & $\mathbf{0 , 2}$ & $\mathbf{0 , 3}$ & $\mathbf{0 , 4}$ & $\mathbf{0 , 5}$ & $\mathbf{0 , 6}$ & $\mathbf{0 , 7}$ & $\mathbf{0 , 8}$ & $\mathbf{0 , 9}$ & $\mathbf{1 , 0}$ \\
\hline$\gamma_{x}$ & 1,000 & 1,000 & 1,000 & 1,000 & 1,000 & 1,000 & 1,000 & 1,000 & 1,000 & 1,000 & 1,000 \\
\hline$\gamma_{y}$ & 1,760 & 1,619 & 1,503 & 1,406 & 1,322 & 1,249 & 1,186 & 1,129 & 1,079 & 1,035 & 1,000 \\
\hline
\end{tabular}


Tabela 4.58 - Constantes para Cálculo de $\beta_{x}$ e $\beta_{y}$ para flexão no setor 7

\begin{tabular}{c|c|c}
\hline Coeficientes & $\boldsymbol{\beta}_{\mathbf{x}}$ & $\beta_{\mathbf{y}}$ \\
\hline $\mathbf{a}_{\mathbf{m}}$ & 0,082 & 0,149 \\
\hline $\mathbf{b}_{\mathbf{m}}$ & 19,47 & 25,41 \\
\hline $\mathbf{c}_{\mathbf{m}}$ & 9,17 & 7,30 \\
\hline
\end{tabular}

Tabela 4.59 - Constantes para Cálculo de $\gamma_{x}$ e $\gamma_{y}$ para flexão no setor 7

\begin{tabular}{c|cccc}
\hline \multirow{2}{*}{ Coeficientes } & \multicolumn{2}{|c|}{$\alpha=\frac{b}{a} \leq 1,0$} & \multicolumn{2}{c}{$1,0<\alpha=\frac{b}{a} \leq 2,0$} \\
\cline { 2 - 5 } & $\gamma_{\mathrm{x}}$ & $\gamma_{\mathrm{y}}$ & $\gamma_{\mathrm{x}}$ & $\gamma_{\mathrm{y}}$ \\
\hline $\mathrm{a}_{\mathrm{q}}$ & $-0,320$ & $-0,594$ & 0,000 & $-0,760$ \\
\hline
\end{tabular}

\subsubsection{8 - Comparação de Resultados}

Para avaliação do equacionamento proposto, seja uma placa com $a=7 \mathrm{~cm}, b=14 \mathrm{~cm}, q_{1}=0,84$ $\mathrm{kN} / \mathrm{cm}^{2}$ e $q_{2}=1,40 \mathrm{kN} / \mathrm{cm}^{2}$ para a qual deseja-se calcular os momentos máximos. Admitir placa tipo setor 1 .

$$
\begin{array}{ll}
\alpha_{m}=\frac{a}{b}=\frac{7}{14}=0,5 & \text { da Tabela 4.21: } \beta_{x}=0,1169 \text { e } \beta_{y}=0,1070 . \\
\alpha_{q}=\frac{q_{1}}{q_{2}}=\frac{0,84}{1,40}=0,6 & \text { a Tabela 4.23 fornece: } \gamma_{x}=1,078 \text { e } \gamma_{y}=1,132 .
\end{array}
$$

Calculando os momentos máximos pelas Eqs. 4.67 e 4.68 obtém-se:

$$
\begin{aligned}
& M_{x}=\gamma_{x} \beta_{x}\left(\frac{q_{1}+q_{2}}{2}\right) b^{2}=1,078 \times 0,1169 \times\left(\frac{0,84+1,40}{2}\right) \times 14^{2} \therefore M_{x}=27,66 \frac{\mathrm{kNcm}}{\mathrm{cm}} \\
& M_{y}=\gamma_{y} \beta_{y x}\left(\frac{q_{1}+q_{2}}{2}\right) b^{2}=1,132 \times 0,1070 \times\left(\frac{0,84+1,40}{2}\right) \times 14^{2} \therefore M_{y}=26,59 \frac{\mathrm{kNcm}}{\mathrm{cm}}
\end{aligned}
$$

o momento máximo então é de $27,66 \frac{\mathrm{kNcm}}{\mathrm{cm}}$.

A simulação numérica dessa mesma placa em elementos finitos forneceu $M_{x}=27,71 \frac{\mathrm{kNcm}}{\mathrm{cm}} \mathrm{e}$ $M_{y}=26,49 \frac{\mathrm{kNcm}}{\mathrm{cm}}$, que mostram o bom desempenho do equacionamento proposto, pois o erro no momento máximo foi algo em torno de $0,2 \%$.

\subsubsection{Exemplo de Aplicação do Modelo Proposto}

Seja a base de pilar HPL 180 indicada na Figura 4.35, dimensionada por ANDRADE (1994) sem nervuras de enrijecimento, situação na qual foi obtido um momento máximo de $16,40 \mathrm{kNcm} / \mathrm{cm}$ e espessura mínima da placa de base de $18,7 \mathrm{~mm}$, tendo sido adotado $19 \mathrm{~mm}$. 
Determinar o momento máximo e a espessura mínima a ser adotada para essa placa admitindo a existência de nervuras conforme detalhe indicado na Figura 4.36.

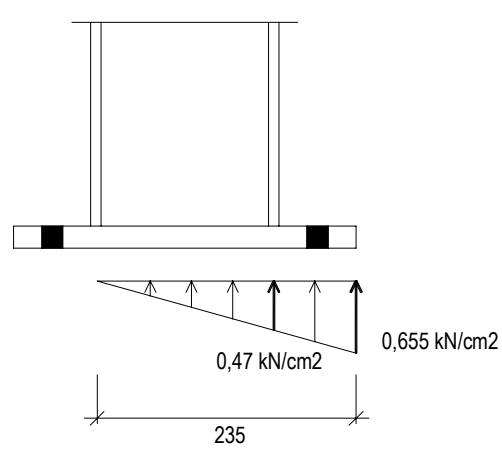

Figura 4.35 - Base de pilar estudada por ANDRADE (1997)

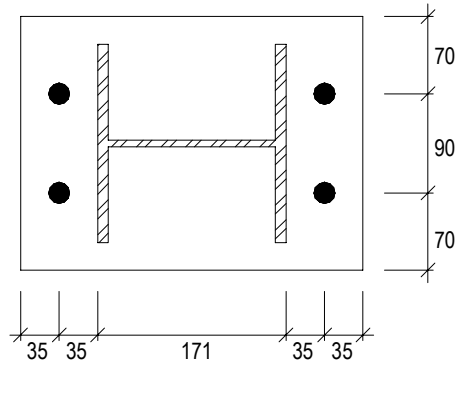

Figura 4.36 - Detalhe nervurado

\subsubsection{1 - Momento Máximo no Setor $A$}

O setor A é semelhante ao setor 7 discutido no item anterior, sendo assim:

$$
\begin{aligned}
& a=35 \mathrm{~mm}+35 \mathrm{~mm}=70 \mathrm{~mm} \\
& b=\frac{b_{f}-t_{s}}{2}=\frac{180-9,5}{2}=85,25 \mathrm{~mm} \\
& \alpha_{m}=\frac{a}{b}=\frac{70}{85,25}=0,82 \quad \rightarrow \quad \beta=0,1193 \\
& \alpha_{q}=\frac{f_{c 1}}{f_{c 2}}=\frac{0,47}{0,655}=0,72 \quad \rightarrow \quad \gamma=1,050 \\
& M_{p}=\gamma \beta\left(\frac{q_{1}+q_{2}}{2}\right) b^{2}=1,050 \times 0,1193 \times\left(\frac{0,47+0,655}{2}\right) \times 8,53^{2} \therefore M_{p}=5,13 \frac{\mathrm{kNcm}}{\mathrm{cm}}
\end{aligned}
$$

\subsubsection{2 - Momento Máximo no Setor B}

O setor B é semelhante ao setor 6 discutido no item anterior. Como a posição da LN indica que mais da metade desse setor está comprimido então deve-se trabalhar com a equação para carregamento trapezoidal.

$$
\begin{aligned}
& a=h_{w}=152 \mathrm{~mm} \\
& b=\frac{b_{f}-t_{w}}{2}=\frac{180-6}{2}=87 \mathrm{~mm} \\
& \alpha_{m}=\frac{b}{a}=\frac{87}{152}=0,57 \quad \rightarrow \quad \beta_{x}=0,0266 \text { e } \beta_{y}=0,0351 \\
& \alpha_{q}=\frac{f_{c 1}}{f_{c 2}}=\frac{0}{0,47}=0 \quad \rightarrow \quad \gamma_{x}=1,750 \text { e } \gamma_{y}=1,833
\end{aligned}
$$




$$
\begin{aligned}
& M_{p x}=\gamma_{x} \beta_{x}\left(\frac{q_{1}+q_{2}}{2}\right) a^{2}=1,750 \times 0,0266 \times\left(\frac{0+0,47}{2}\right) \times 15,2^{2} \therefore M_{p x}=2,53 \frac{\mathrm{kNcm}}{\mathrm{cm}} \\
& M_{p y}=\gamma_{y} \beta_{y x}\left(\frac{q_{1}+q_{2}}{2}\right) a^{2}=1,833 \times 0,0351 \times\left(\frac{0+0,47}{2}\right) \times 15,2^{2} \therefore M_{p x}=3,49 \frac{\mathrm{kNcm}}{\mathrm{cm}}
\end{aligned}
$$

\subsubsection{3 - Determinação da espessura mínima da placa}

O momento máximo na placa é de $5,13 \frac{\mathrm{kNcm}}{\mathrm{cm}}$, que é quase $70 \%$ menor que o momento obtido no detalhe sem nervuras. Com isso, a espessura mínima da placa de base é, adotando a mesma expressão empregada na referência supracitada, dada por:

$$
t_{p} \geq \sqrt{\frac{16 M_{p}}{3 f_{y}}}=\sqrt{\frac{16 \times 5,13}{3 \times 25}} \quad \rightarrow \quad t_{p} \geq 10,5 \mathrm{~mm}
$$

que é cerca de $40 \%$ menor que a espessura mínima obtida no detalhe sem nervuras. Devese adotar chapa de $12,7 \mathrm{~mm}$, ou seja, duas espessuras a menos que a situação de referência (base sem nervuras).

\subsubsection{4 - Simulação numérica em elementos finitos}

Para efeito de comparação de resultados a placa tomada como exemplo foi simulada em elementos finitos. A Figura 4.37 mostra a distribuição dos momentos fletores máximos no detalhe nervurado, e a Tabela 4.60 resume e compara os resultados obtidos nos casos com e sem as nervuras.

Observa-se mais uma vez que o procedimento proposto forneceu boas aproximações dos momentos máximos, sendo isso um indicativo de que após uma série criteriosa de testes ele pode vir a ser recomendado para o dimensionamento de bases nervuradas.
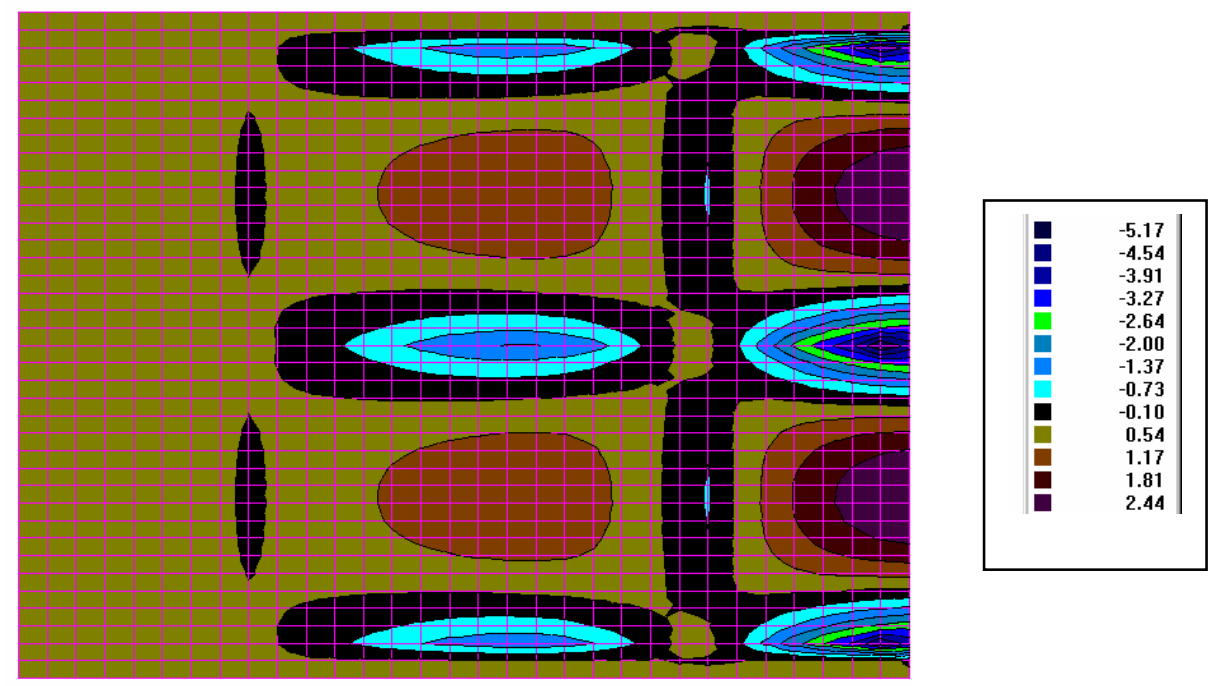

Figura 4.37 - Distribuição dos momentos fletores máximos no detalhe nervurado 
Tabela 4.60 - Comparação dos Momentos Fletores Máximos Obtidos $(\mathrm{kNcm} / \mathrm{cm})$

\begin{tabular}{cccc}
\hline Situação Analisada & Cálculo Manual & MEF & Diferença \\
\hline Detalhe Original (sem nervuras) & 16,40 (a) & 15,41 & $6 \%$ \\
Detalhe 1 (com nervuras) & 11,77 (b) & 11,07 & $6 \%$ \\
\hline
\end{tabular}

(a) Valor fornecido por ANDRADE (1994) / (b) Valor fornecido pelo modelo proposto neste trabalho

\subsubsection{Considerações Finais e Conclusões}

Esta seção apresentou um procedimento prático para dimensionamento de placas de base nervuradas desenvolvido por meio de simulações numéricas via elementos finitos, o qual apresentou resultados bastante satisfatórios nos casos onde foi aplicado.

Devido ao caráter numérico sobre o qual o procedimento está embasado, os resultados obtidos com sua utilização não são exatos, mas aparentemente constituem-se boas aproximações que podem ser utilizadas no projeto de bases de pilares sem prejuízo da segurança ou economia.

\section{5 - Estudo dos Aparelhos de Apoio - Avaliação da Rigidez}

\subsubsection{Generalidades}

Dependendo das ações atuantes, as bases de pilares podem estar sujeitas à força normal de tração ou de compressão. No caso de apoios engastados sob força normal de compressão a base pode resultar totalmente ou parcialmente comprimida, como mostram as Figuras 4.38(a) e 4.38(b), respectivamente.

No caso de força normal de tração, a base pode resultar parcialmente comprimida, o que ocorre quando as tensões provocadas pelo momento fletor são maiores que aquelas produzidas pela força axial, ou podem resultar sem nenhuma compressão no concreto, o que ocorre quando a situação oposta se verifica, ou seja, quando as tensões provocadas pela força axial são maiores que aquelas provadas pelo momento fletor.

Neste trabalho foram estudadas apenas as bases com força normal de compressão, que são as mais usuais na prática.

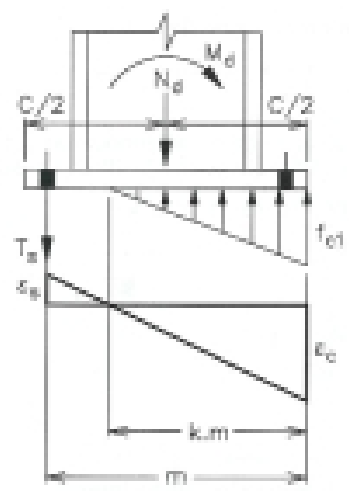

(a) Base parcialmente Comprimida

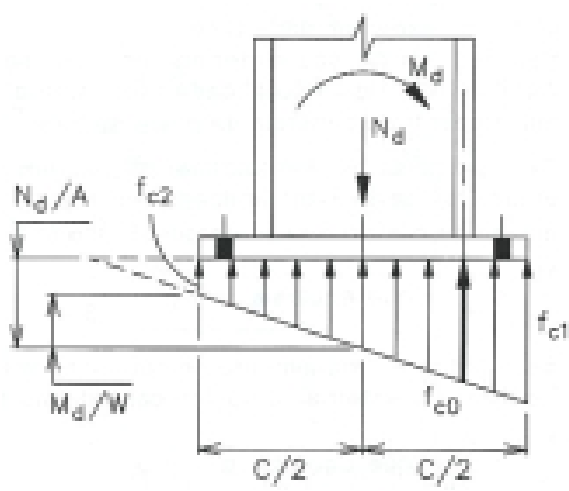

(b) Base totalmente comprimida

Figura 4.38 - Bases de pilares com força normal de compressão (Fonte: ANDRADE (1995)) 


\subsubsection{Avaliação da Rigidez em Bases Engastadas Submetidas a Força Axial de Compressão}

\subsubsection{Bases Parcialmente Comprimidas}

A fim de avaliar a rigidez ao giro desse tipo de ligação, foi considerado inicialmente o caso de base engastada com força normal de compressão, conforme mostrado na Figura 4.39, na qual o concreto resulta parcialmente comprimido, como mostra a distribuição de tensões da Figura 4.38(a).

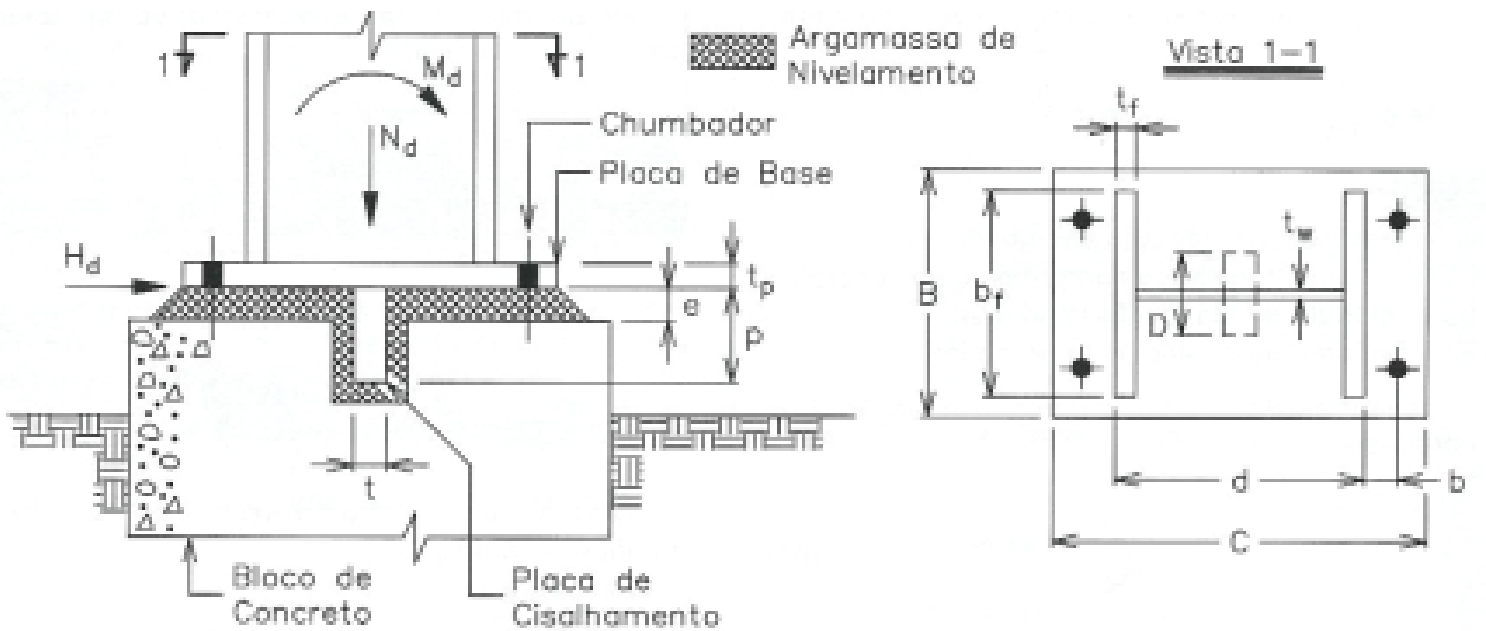

Figura 4.39 - Base engastada com força normal de compressão(Fonte: ANDRADE (1995))

Admitindo que aço e concreto estão em regime elástico (BLODGETT (1966), ANDRADE (1994), SÁLES et al. (1994), SALMON \& JOHNSON (1996)), pode-se obter, por meio de condições de equilibrio, os esforços que surgem nos chumbadores e no trecho onde o concreto fica submetido a tensões de compressão.

Fazendo o equilíbrio de forças e momentos:

$$
\begin{aligned}
& N_{d}=\frac{1}{2} k m f_{c 1} B-T_{s} \\
& M_{d}-\frac{C}{2} N_{d}=m T_{s}-\left(\frac{1}{2} k m f_{c 1} B\right) \frac{1}{3} k m
\end{aligned}
$$

onde:

$f_{c 1}$ : Tensão máxima de compressão no concreto.

$T_{s}$ : Força total nos chumbadores tracionados.

$k$ : Constante introduzida por ANDRADE (1995) para determinação da posição da linha neutra da seção. $O$ equacionamento, pode, naturalmente, ser desenvolvido sem essa constante, como 0 faz SÁLES et al. (1995), contudo, a introdução dessa constante facilita a resolução da equação que fornece a posição da linha neutra. 
As dimensões $B$ e $C$ são arbitradas pelo projetista, e disso resulta de imediato a dimensão $m$. Mesmo assim, ainda restam três variáveis a serem determinadas, que são: $f_{c l}, T_{s}$ e $k$. Esse problema é resolvido partindo da premissa de que os materiais estão em regime elástico, pois disso resulta:

$$
\begin{gathered}
\varepsilon_{s}=\frac{f_{s}}{E_{s}} \\
\varepsilon_{c}=\frac{f_{c 1}}{E_{c}}
\end{gathered}
$$

onde: $f_{s}=$ Tensão de tração nos chumbadores.

$E_{s}=$ Módulo de elasticidade do aço.

$E_{c}=$ Módulo de elasticidade do concreto.

$\varepsilon_{s}=$ Deformação elástica no aço.

$\varepsilon_{c}=$ Deformação elástica no concreto.

Fazendo a relação entre as deformações elásticas no aço e no concreto (BLODGETT (1966)), obtém-se:

$$
\frac{\varepsilon_{s}}{\varepsilon_{c}}=\frac{m-k m}{k m}=\frac{1-k}{k}
$$

Substituindo as Eqs 4.79 e 4.79 na Eq. 4.80 encontra-se:

$$
\frac{\frac{f_{s}}{E_{s}}}{\frac{f_{c 1}}{E_{c}}}=\frac{1-k}{k} \rightarrow \frac{f_{s}}{f_{c 1}}=\frac{E_{s}}{E_{c}} \frac{1-k}{k}
$$

Chamando de $A_{s}$ a área dos chumbadores tracionados e de $n$ a relação entre os módulos de elasticidade do aço e do concreto, obtém-se:

$$
\begin{aligned}
& f_{s}=\frac{T_{s}}{A_{s}} \\
& n=\frac{E_{s}}{E_{c}}
\end{aligned}
$$

E com isso a Eq. 4.81 pode ser reescrita como:

$$
\frac{T_{s}}{f_{c 1}}=A_{s} n \frac{1-k}{k}
$$


Dessa formulação resulta um sistema de três equações e três incógnitas formado pelas Eqs. 4.76, 4.77 e 4.84. Desse sistema obtém-se a equação cúbica dada a seguir, cuja raiz no intervalo $\{0,1\}$ fornece a posição da linha neutra.

$$
k^{3}+3 \rho k^{2}+6 n \mu(1+\rho) k-6 n \mu(1+\rho)=0
$$

onde:

$$
\begin{aligned}
& \rho=\frac{1}{m}\left(\frac{M_{d}}{N_{d}}-\frac{C}{2}\right) \\
& \mu=\frac{A_{s}}{B m}
\end{aligned}
$$

Conhecida a posição da linha neutra encontra-se:

$$
\begin{aligned}
& f_{c 1}=\frac{6 N_{d}}{k m B} \times \frac{1+\rho}{3-k} \\
& T_{s}=N_{d} \frac{3 \rho+k}{3-k}
\end{aligned}
$$

Se não houvesse força normal, o giro da ligação poderia ser tomado como ocorrendo em torno do ponto de encontro entre a linha de eixo da mesa comprimida e a placa de base, tal qual SANTOS (1998) e RIBEIRO (1998) fizeram para ligações viga-pilar com placa de extremidade estendida. Havendo força normal, porém, o giro precisa ser considerado na linha neutra, o que resulta na Eq. 4.90. A Figura 4.40 ilustra essas duas situações.

$$
\phi=\frac{\delta}{L}=\frac{\delta}{m(1-k)}
$$

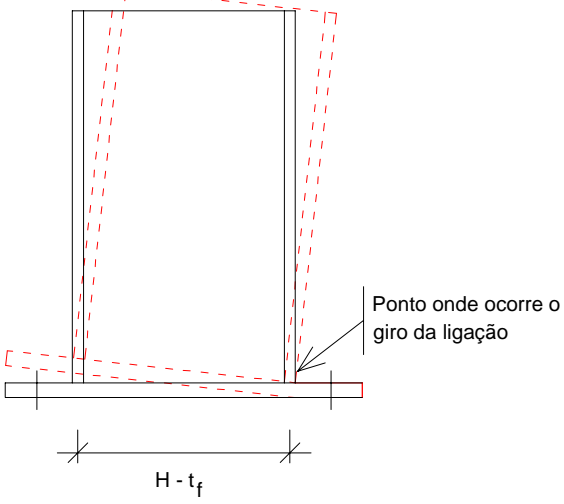

(a) Ligação sob momento fletor

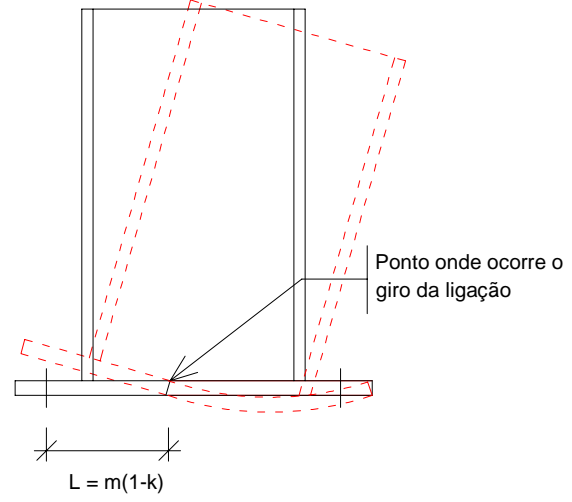

(b) Ligação sob momento fletor e força axial de compressão

Figura 4.40 - Giro em ligações com placa de extremidade 
Para cálculo do afastamento $\delta$ pode-se partir do esquema estático mostrado na Figura 4.41, que é composto por uma barra engastada em uma extremidade, onde 0 engaste representa a influência da parte comprimida da placa; e apoiada em um vínculo elástico que representa a influência dos chumbadores e da ancoragem destes no concreto da fundação. A força que mobiliza o esquema estático é a tração nos chumbadores.

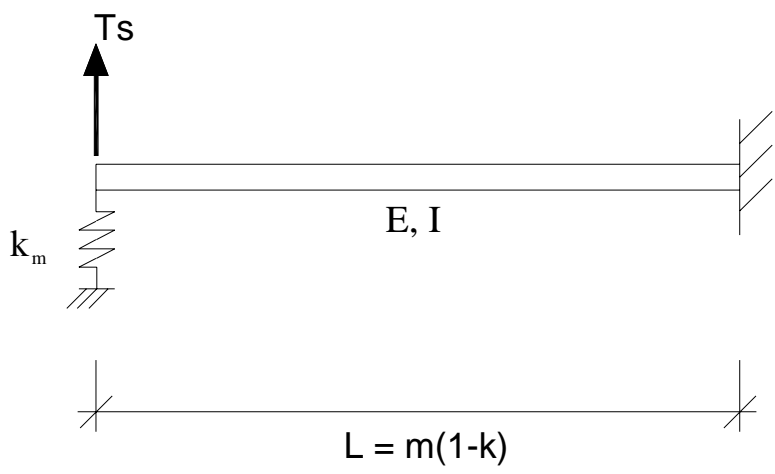

Figura 4.41 - Esquema estático para determinação do afastamento da placa de base

O afastamento da placa da base do concreto é dado por $\delta$, que depende da rigidez EI da placa e da constante de mola $k_{m}$. Deixando de lado, por enquanto, a influência da ancoragem dos chumbadores, a constante de mola passa a depender apenas da rigidez axial desses elementos (os chumbadores). Recorrendo-se à Mecânica dos Sólidos, encontra-se:

$$
\delta=\frac{T_{s}}{\frac{3 E I}{L^{3}}+\frac{E A_{s}}{L_{s}}}
$$

onde $L_{s}$ é o comprimento dos chumbadores.

Substituindo a Eq. 4.91 na Eq. 4.90, encontra-se o giro da ligação:

$$
\phi=\frac{T_{s}}{\left(\frac{3 E I}{L^{2}}+\frac{E A_{s} w}{L_{s}}\right)}=\frac{T_{s} L^{2} L_{s}}{3 E I L_{s}+E A_{s} L^{3}}
$$

Substituindo a 4.89 na Eq. 4.928:

$\phi=N_{d} \frac{3 \rho+k}{3-k} \frac{L^{2} L_{s}}{3 E I L_{s}+E A_{s} L^{3}}$

Lembrando que a rigidez inicial é dada por: 
$S_{i}=\frac{M}{\phi}$

obtém-se, por fim, a rigidez inicial da ligação:

$S_{i}=E \times \frac{M}{N} \times \frac{3-k}{3 \rho+k} \times \frac{3 I L_{s}+A_{s} L^{3}}{L^{2} L_{s}}$

O fato da rigidez inicial depender da força normal aplicada é bastante razoável, pois, como diz LIMA (2003): "... pode-se verificar que, nas ligações onde existe esforço axial de tração ou de compressão atuando juntamente com o momento fletor, as componentes (da ligação) tendem a ter seu comportamento individual afetado, modificando assim, o comportamento global desta ligação. Isto ocorre porque o esforço axial pode provocar um alívio em determinadas componentes ou aumentar a carga em outras".

WALD \& SOKOL (1995), que estudaram a rigidez de bases normalmente consideradas como articuladas, e ERMOPOULOS \& STAMATOPOULOS (1995), que estudaram a rigidez de bases normalmente consideradas como engastadas, também falam da interação entre força axial e momento fletor na rigidez de bases de pilares.

Para determinação da rigidez inicial sugere-se a utilização dos valores de projeto do momento fletor e da força normal utilizados no dimensionamento da base, pois dessa forma pode-se determinar a posição da LN e assim encontrar o ponto onde ocorre o giro da ligação.

\subsubsection{Influência da Ancoragem no Concreto}

Segundo GIONGO (1993), a caracterização da aderência é complexa e depende de fenômenos como a retração, a deformação lenta e a fissuração do concreto. 0 problema costuma ser abordado por meio de ensaios de arrancamento que permitem a determinação de valores médios da tensão de aderência.

Ainda segundo GIONGO (1993), a tensão na barra diminui à medida que a seção transversal ocupa posições afastadas da seção que coincide com a extremidade do bloco de concreto, o que ocorre pelo fato da aderência permitir a transferência das tensões atuantes na barra para o concreto em seu entorno.

Diante disso, o efeito da ancoragem pode ser considerado admitindo um comprimento reduzido para os chumbadores, comprimento este que será aqui chamado de $L_{s}$. Esse comprimento reduzido representa 0 trecho do chumbador onde as tensões de tração não são desprezíveis, e onde este elemento está, de fato, sujeito à deformação axial. Em outras palavras pode-se dizer que $L_{s}$ é 0 comprimento extensível dos chumbadores.

A determinação do comprimento $L_{s}$ requer, naturalmente, uma investigação experimental. No entanto, como tais informações não estão disponíveis no momento, pode-se estimar o comprimento $L_{s}$ como um múltiplo do diâmetro do chumbador, conforme sugerido por ERMOPOULOS \& STAMATOPOULOS (1995). 
Com base no estudo desenvolvido para validar o modelo aqui proposto, cujos resultados serão apresentados mais adiante, concluiu-se que $L_{s}$ pode ser tomado como $10 d_{c h}$, pois com esse valor 0 comportamento momento-rotação da ligação não se mostrou superestimado nas casos avaliados. Como referência pode-se citar o valor adotado por ERMOPOULOS \& STAMATOPOULOS (1996), que foi de $12 d_{c h}$.

\subsubsection{Determinação do Momento Último}

Como dito anteriormente, o projeto de uma base de apoio consiste, basicamente, no cálculo das dimensões da placa de base e dos chumbadores e na verificação da pressão no concreto, de forma que são esses os elementos que mais influenciam o comportamento da ligação.

Em aparelhos de apoio devidamente projetados a placa de base e os chumbadores apresentam resistências "equilibradas", o que significa que nenhum deles irá romper enquanto 0 outro ainda apresentar elevada reserva de resistência. Sendo assim, pode-se fazer uma estimativa razoável do momento último desse tipo de ligação considerando apenas a resistência da placa de base.

Como o dimensionamento desse elemento depende da determinação da posição da linha neutra, e esta, por sua vez, depende da relação $M / N$, propõe-se um processo iterativo para determinação do momento último no qual, para um valor fixo de $N$, o valor de $M$ vai aumentando gradativamente até se constatar o colapso da placa de base. A Figura 4.42 fornece um algoritmo que ilustra o processo descrito anteriormente.

\subsubsection{Bases Totalmente Comprimidas}

Se a base está totalmente comprimida, ou seja, se ela apresenta a distribuição de tensões indicada na Figura 1(b), significa que não ocorre afastamento da placa de base, o que implica em giro nulo na ligação. Se o giro é nulo, a rigidez é infinita (vide Eq. 4.94), e nesse caso a ligação deve ser simulada como engaste perfeito.

\subsubsection{Comparação de Resultados e Validação do Modelo Proposto}

ERMOPOULOS \& STAMATOPOULOS (1996) desenvolveram um modelo teórico para previsão do comportamento momento-normal-rotação de bases de pilares e apresentaram várias curvas que ilustram o comportamento desse tipo de ligação. Consta nesse trabalho a expressão dada a seguir, com a qual é possível reproduzir as curvas apresentadas:

$$
M=a \frac{M_{o} \phi}{\phi_{o}+\phi}
$$

Nessa expressão $a$ é uma constante obtida por técnicas de ajuste de curva, e $M_{o}$ e $\phi_{o}$ são coordenadas de um ponto característico da curva, não sendo fornecidas maiores informações sobre seus valores ou como eles são determinados.

Das várias curvas apresentadas por ERMOPOULOS \& STAMATOPOULOS (1996) seis foram selecionadas para comparação com o modelo proposto nesta seção do trabalho. Os dados dessas curvas e das bases que as originaram estão apresentadas nas Tabelas 4.61 e 4.62 . 


\section{Entrada de Dados}

a) Informações sobre a placa de base

b) Informações sobre os chumbadores

c) Propriedades do aço e do concreto

d) $M_{\text {est }}$ (Estimativa de $M_{u}$, para o qual pode ser adotado uma parcela de $M_{d}$, que é o valor adotado no dimensionamento da placa de base)

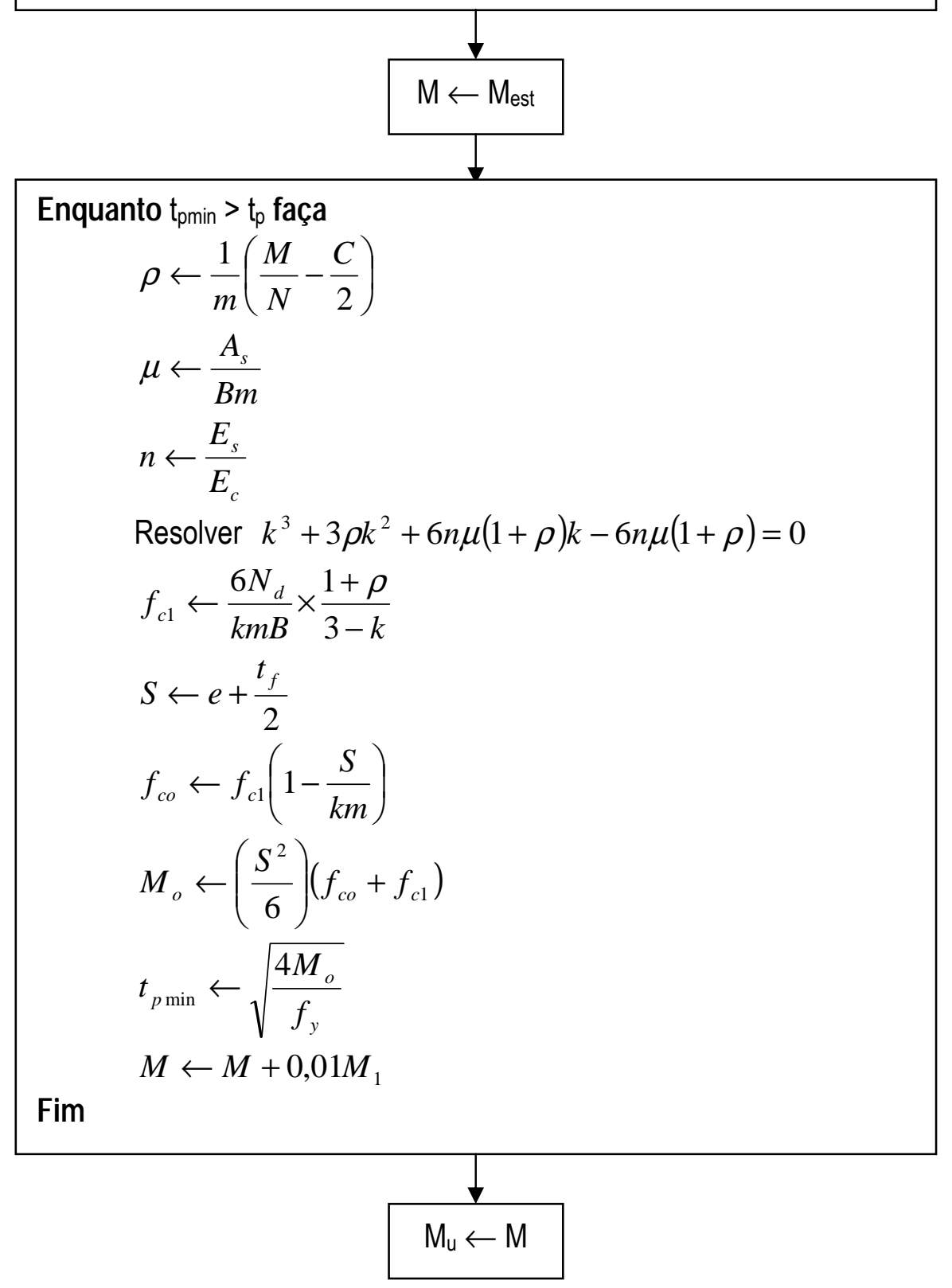

Figura 4.42 - Sugestão de algoritmo para determinação de $M_{u}$ em função da placa de base 
Tabela 4.61 - Dados das curvas plotadas por ERMOPOULOS \& STAMATOPOULOS (1996)

\begin{tabular}{c|c|c|c|c}
\hline Exemplo & $\boldsymbol{P}$ & $\boldsymbol{M}_{\boldsymbol{o}}$ & $\boldsymbol{\phi}_{\boldsymbol{o}}$ & $\boldsymbol{a}$ \\
\hline $\mathbf{1}$ & $400 \mathrm{kN}$ & $6.000 \mathrm{kN} . \mathrm{cm}$ & $2,65 \times 10^{-4} \mathrm{rad}$ & 1,447 \\
\hline $\mathbf{2}$ & $400 \mathrm{kN}$ & $5.740 \mathrm{kN} . \mathrm{cm}$ & $2,05 \times 10^{-4} \mathrm{rad}$ & 1,281 \\
\hline $\mathbf{3}$ & $400 \mathrm{kN}$ & $5.700 \mathrm{kN} . \mathrm{cm}$ & $2,28 \times 10^{-4} \mathrm{rad}$ & 1,358 \\
\hline $\mathbf{4}$ & $100 \mathrm{kN}$ & $3.000 \mathrm{kN} . \mathrm{cm}$ & $1,74 \times 10^{-4} \mathrm{rad}$ & 1,418 \\
\hline $\mathbf{5}$ & $200 \mathrm{kN}$ & $3.650 \mathrm{kN} . \mathrm{cm}$ & $1,71 \times 10^{-4} \mathrm{rad}$ & 1,350 \\
\hline $\mathbf{6}$ & $400 \mathrm{kN}$ & $4.680 \mathrm{kN} . \mathrm{cm}$ & $1,54 \times 10^{-4} \mathrm{rad}$ & 1,543 \\
\hline
\end{tabular}

Tabela 4.62 - Dados das bases analisadas (Fonte: ERMOPOULOS \& STAMATOPOULOS (1996))

\begin{tabular}{c|c|c|c|c|c|c|c|c}
\hline Exem. & $\mathbf{C}(\mathbf{m m})$ & $\mathbf{B}(\mathbf{m m})$ & $\mathbf{t}_{\mathbf{p}}(\mathbf{m m})$ & $\mathbf{m}(\mathbf{m m})$ & $\mathbf{b}(\mathbf{m m})$ & $\mathbf{d}_{\mathbf{c h}}(\mathbf{m m})$ & $\mathbf{A}_{\mathbf{s}}\left(\mathbf{c m}^{2}\right)$ & $\mathbf{f}_{\mathrm{ck}}(\mathbf{M P a})$ \\
\hline $\mathbf{1}$ & 600 & 300 & 30 & 100 & 60 & 1,67 & 4,40 & 16 \\
\hline $\mathbf{2}$ & 600 & 300 & 30 & 140 & 100 & 1,67 & 4,40 & 16 \\
\hline $\mathbf{3}$ & 600 & 300 & 30 & 140 & 100 & 3,00 & 14,90 & 16 \\
\hline $\mathbf{4}$ & 600 & 300 & 16 & 100 & 60 & 1,67 & 4,40 & 16 \\
\hline $\mathbf{5}$ & 600 & 300 & 16 & 100 & 60 & 3,00 & 14,90 & 16 \\
\hline $\mathbf{6}$ & 600 & 300 & 16 & 100 & 60 & 1,67 & 4,40 & 30 \\
\hline
\end{tabular}

Aplicando a equação de KISHI \& CHEN (1990) $\operatorname{com} n=0,85$, e avaliando a rigidez inicial das ligações por meio da Eq. 4.91 e momento último pelo algoritmo mostrado na Figura 4.38, pôde-se plotar as curvas mostradas nas Figuras 4.43 a 4.48 , e assim comparar o desempenho do modelo proposto com aquele apresentado por ERMOPOULOS \& STAMATOPOULOS (1996).

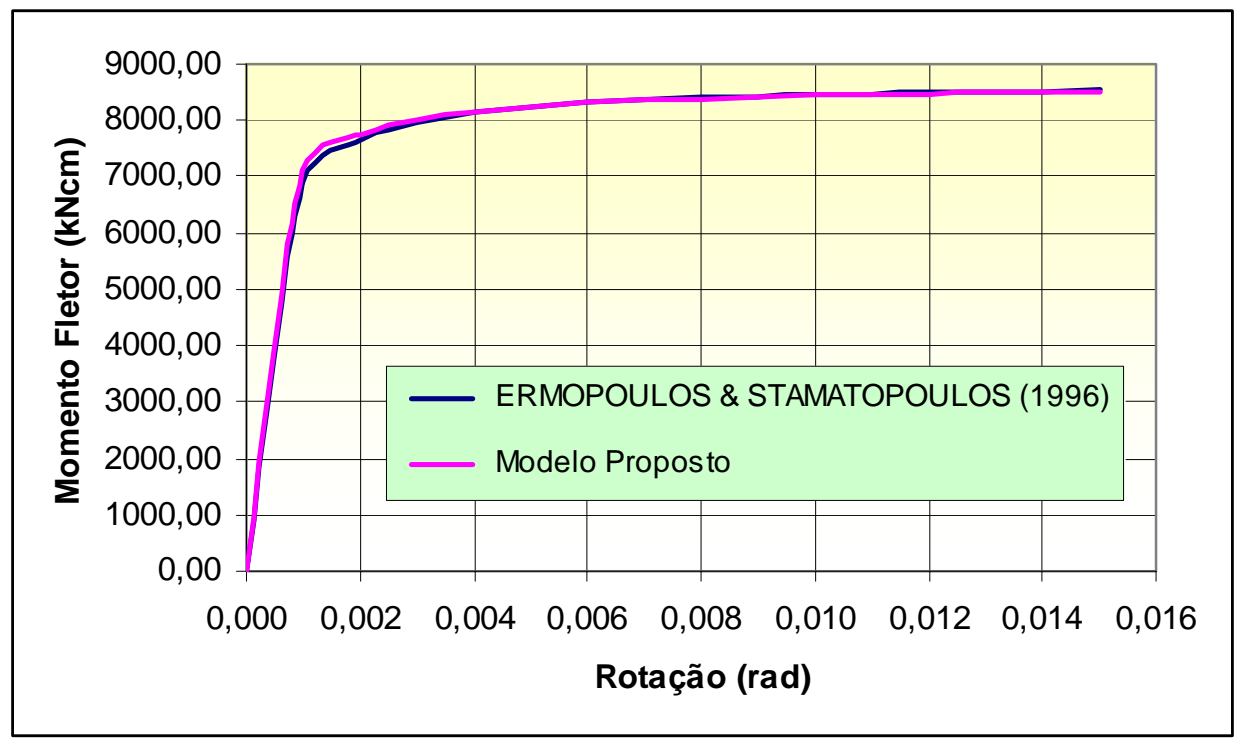

Figura 4.43 - Exemplo 1 (comparação de resultados) 


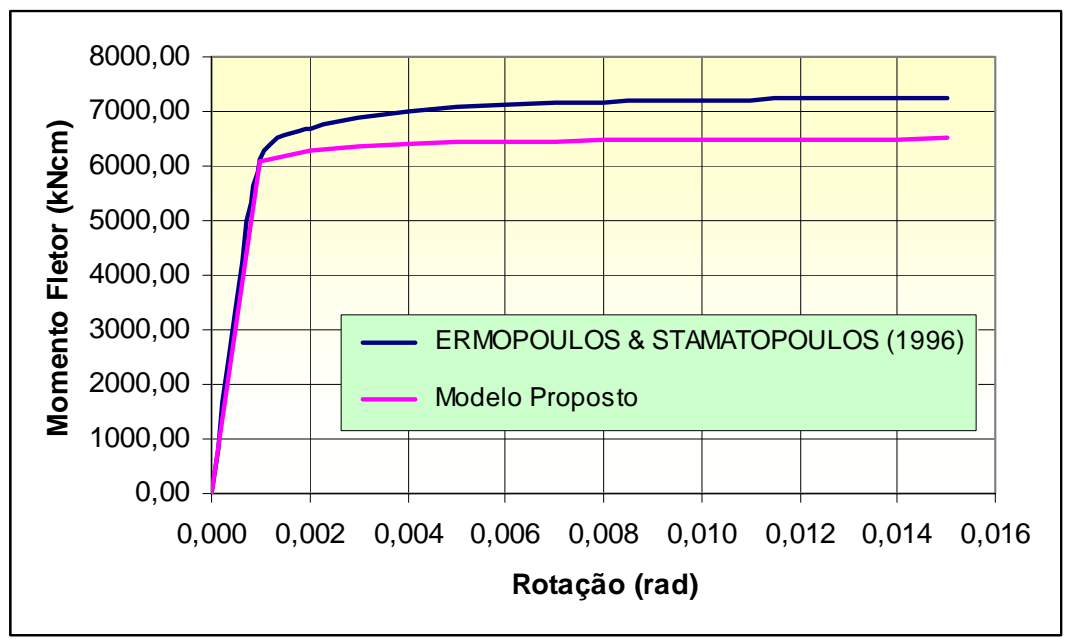

Figura 4.44 - Exemplo 2 (comparação de resultados)

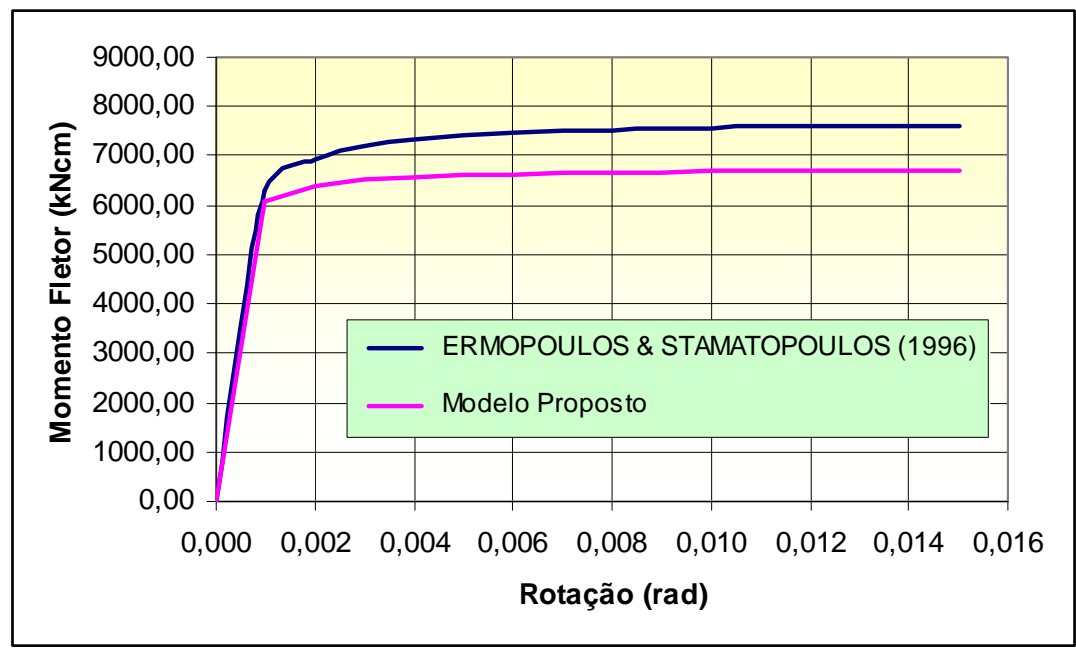

Figura 4.45 - Exemplo 3 (comparação de resultados)

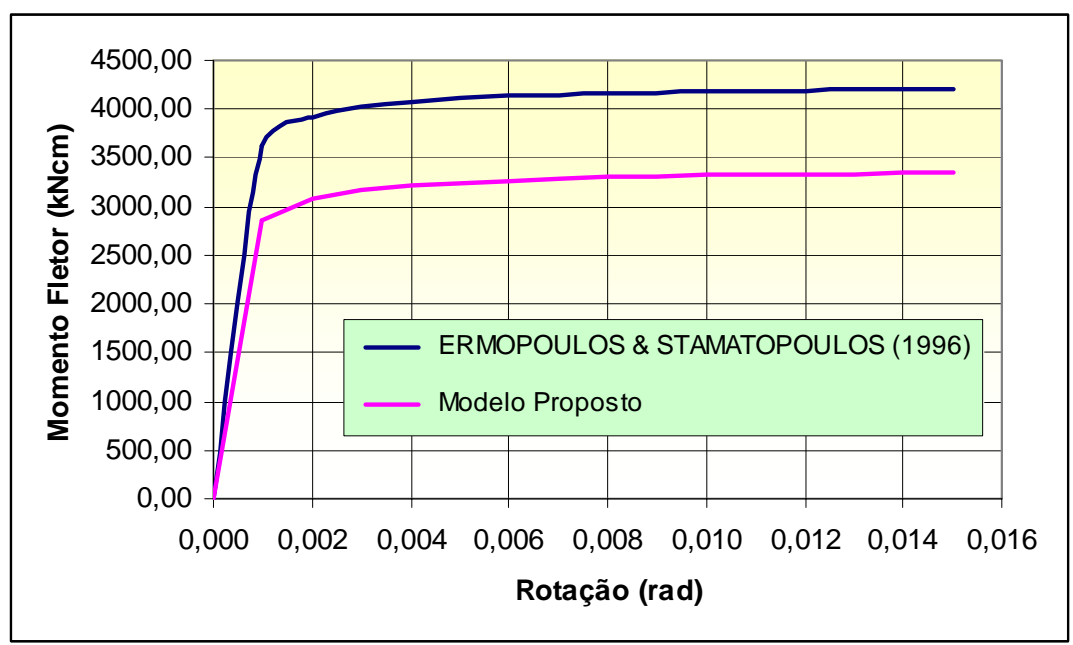

Figura 4.46 - Exemplo 4 (comparação de resultados) 


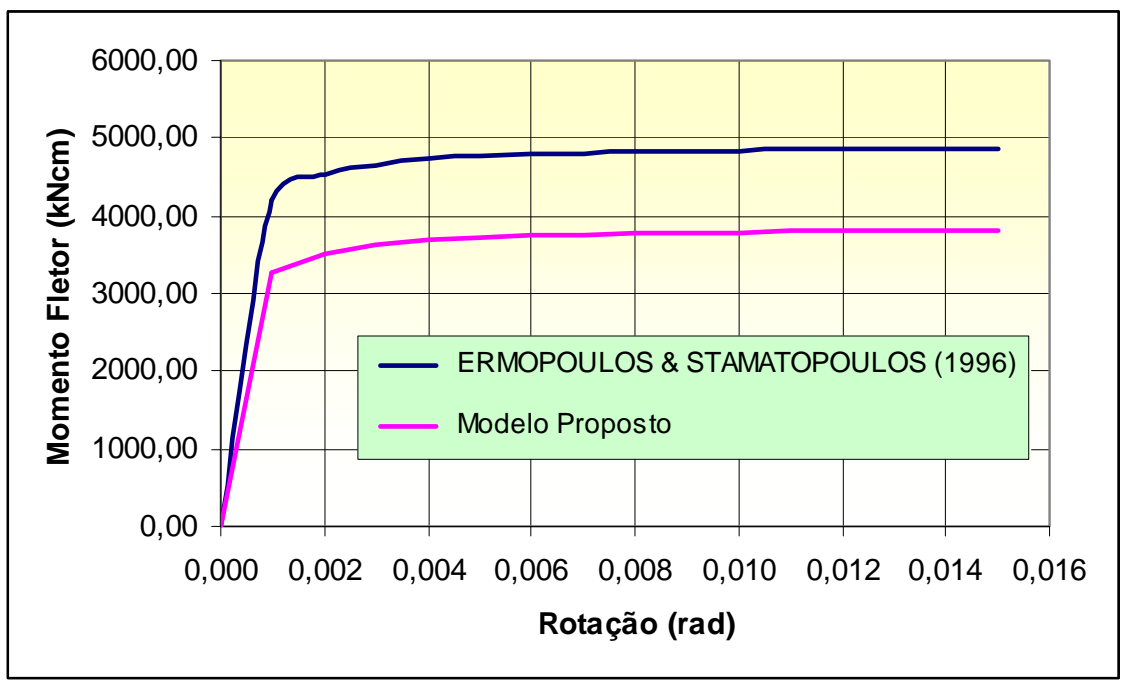

Figura 4.47 - Exemplo 5 (comparação de resultados)

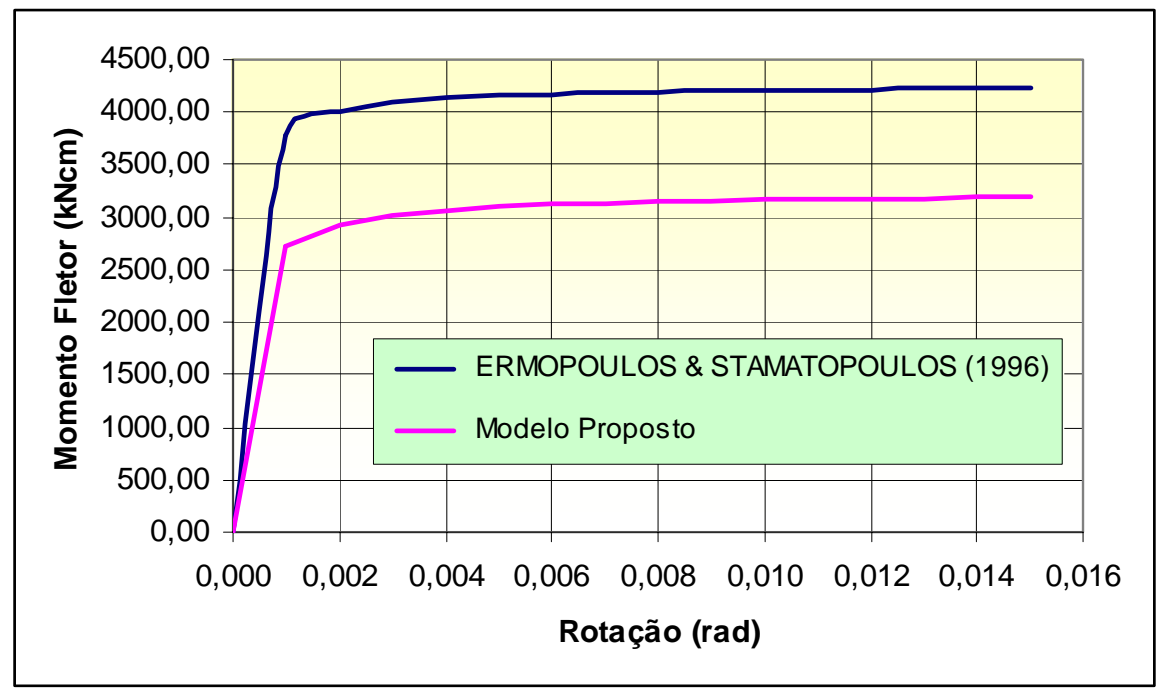

Figura 4.48 - Exemplo 6 (comparação de resultados)

Percebe-se das Figuras 4.43 a 4.48 que o modelo proposto tende a substimar a rigidez da ligação quando comparado ao modelo de ERMOPOULOS \& STAMATOPOULOS (1996). Observou-se, porém, da literatura consultada, que em alguns casos este último modelo superestimou 0 comportamento momento-rotação da ligação quando aplicado a bases de apoio cujos resultados experimentais eram conhecidos. Isso pode ser observado na Figura 4.49, que compara os resultados fornecidos pelo modelo teórico proposto por ERMOPOULOS \& STAMATOPOULOS (1996) e aqueles obtidos experimentalmente por ASTANEH et al. (1992)2.

\footnotetext{
2 ASTANEH et al. (1992). Behaviour and design of base plates for gravity, wind and seismic loads. In AISC, National
} Steel Construction Conference, Las Vegas. apud ERMOPOULOS \& STAMATOPOULOS (1996) 
Tal observação pode ser um indicativo de que em algumas situações o modelo aqui proposto pode representar melhor o comportamento de bases de pilares do que o modelo teórico proposto na literatura supracitada.

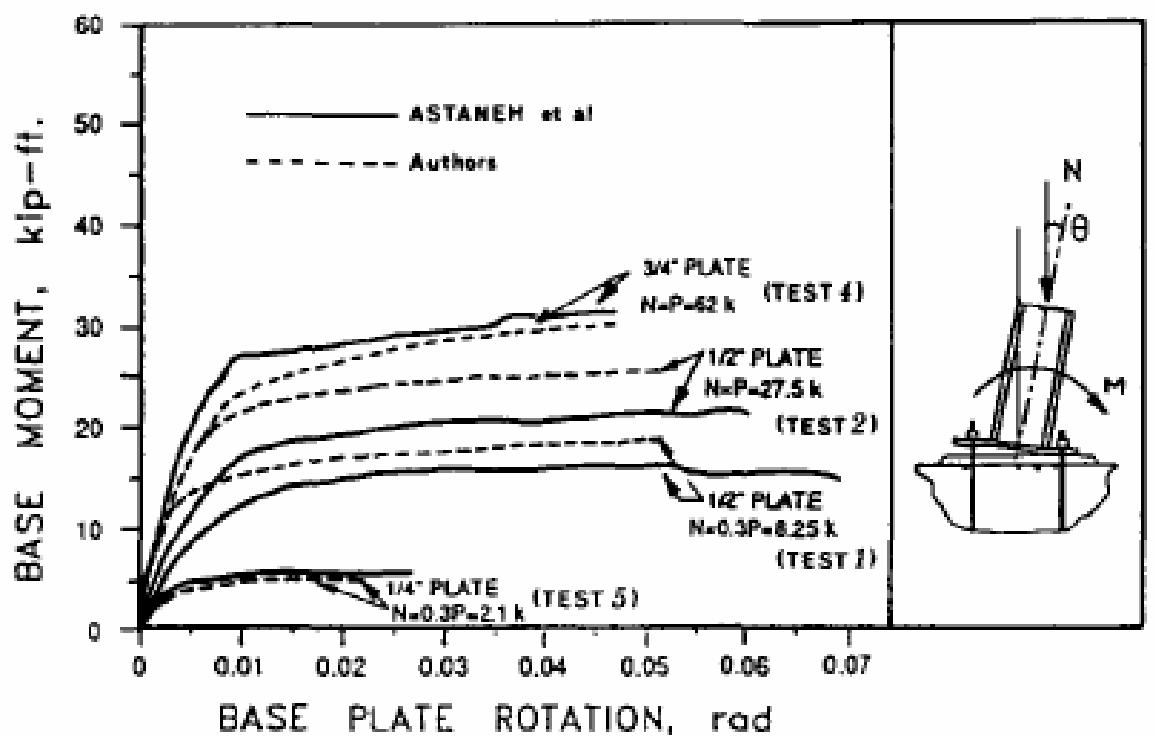

Figura 4.49 - Comparação de resultados - ERMOPOULOS \& STAMATOPOULOS (1996) x ASTANEH et al. (1992) (Fonte: ERMOPOULOS \& STAMATOPOULOS (1996))

Infelizmente não foi possível aplicar o equacionamento proposto às bases ensaiadas por ASTANEH et al. (1992), o que ocorreu pelo fato de não terem sido encontradas na literatura consultada todas as informações necessárias sobre os protótipos ensaiados. De qualquer forma, pode-se afirmar que, para uma validação preliminar do modelo aqui desenvolvido, as comparações feitas com o modelo de ERMOPOULOS \& STAMATOPOULOS (1996) são suficientes, até porque este modelo tem validação experimental.

\subsubsection{Adaptação do Modelo para Bases Nervuradas}

Para aplicar o modelo proposto na estimativa da rigidez inicial de bases nervuradas basta retirar da Eq. 4.91 a parcela que considera a flexão da placa de base, o que se justifica pelo fato das nervuras funcionarem como apoios desse elemento e assim diminuírem o giro da ligação. Adaptando as Eqs. 4.91 a 4.95 encontra-se:

$\delta=\frac{T_{s} L_{s}}{E A_{s}}$

Substituindo a Eq. 4.97 na Eq. 4.90, encontra-se o giro da ligação:

$\phi=\frac{T_{s} L_{s}}{E A_{s} L}$

Substituindo a 4.89 na Eq. 4.98: 


$$
\phi=N_{d} \frac{3 \rho+k}{3-k} \frac{L_{s}}{E A_{s} L}
$$

e daí:

$$
S_{i}=E \times \frac{M}{N} \times \frac{3-k}{3 \rho+k} \times \frac{A_{s} L}{L_{s}}
$$

O momento último e a curva momento-rotação podem ser determinados conforme descrito anteriormente para bases sem nervuras. 


\section{1 - Introdução}

Neste capítulo são apresentados os resultados obtidos na análise de uma cúpula com $91 \mathrm{~m}$ de diâmetro e $13 \mathrm{~m}$ de flecha (altura no centro), para a qual foram admitidas várias hipóteses no comportamento das ligações e do contraventamento. Trata-se de uma estrutura que foi efetivamente projetada e que está atualmente em vias de execução.

As Figuras 5.1 a 5.3 dão uma visão geral dessa estrutura, e a Tabela 5.1 resume os perfis adotados no projeto.

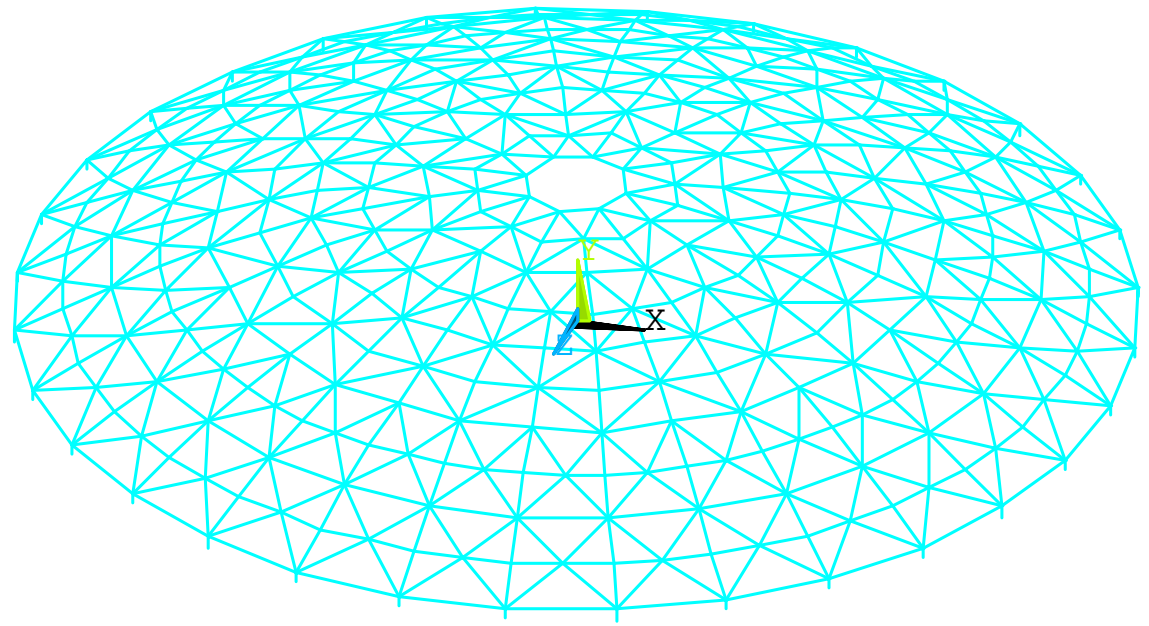

Figura 5.1 - Vista geral da estrutura 


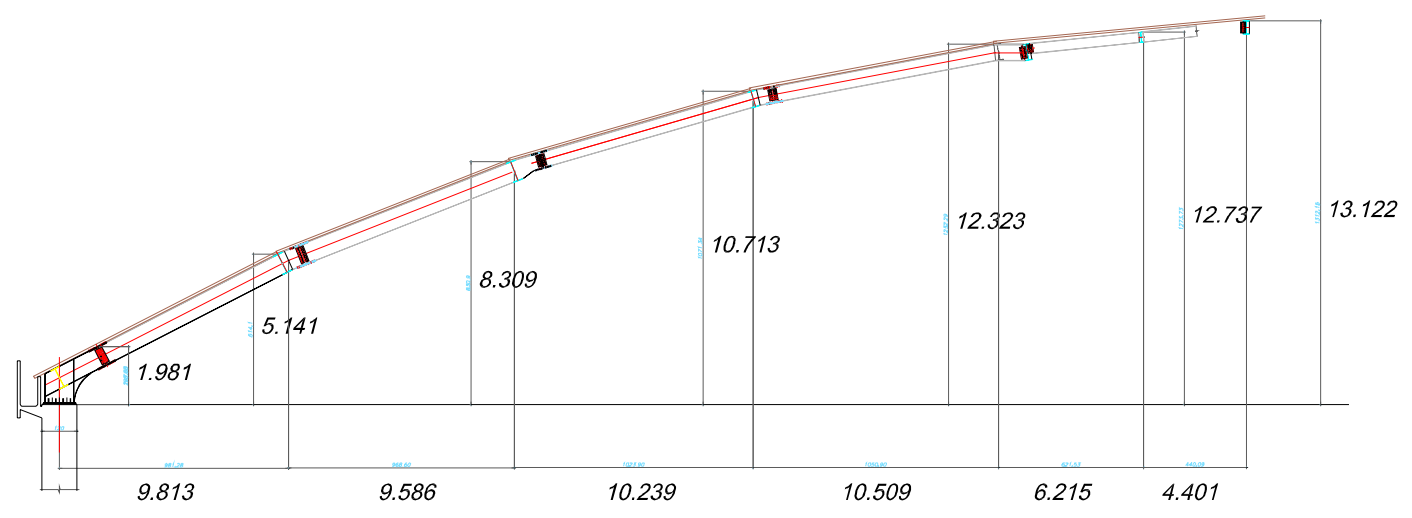

Figura 5.2 - Vista do arco principal

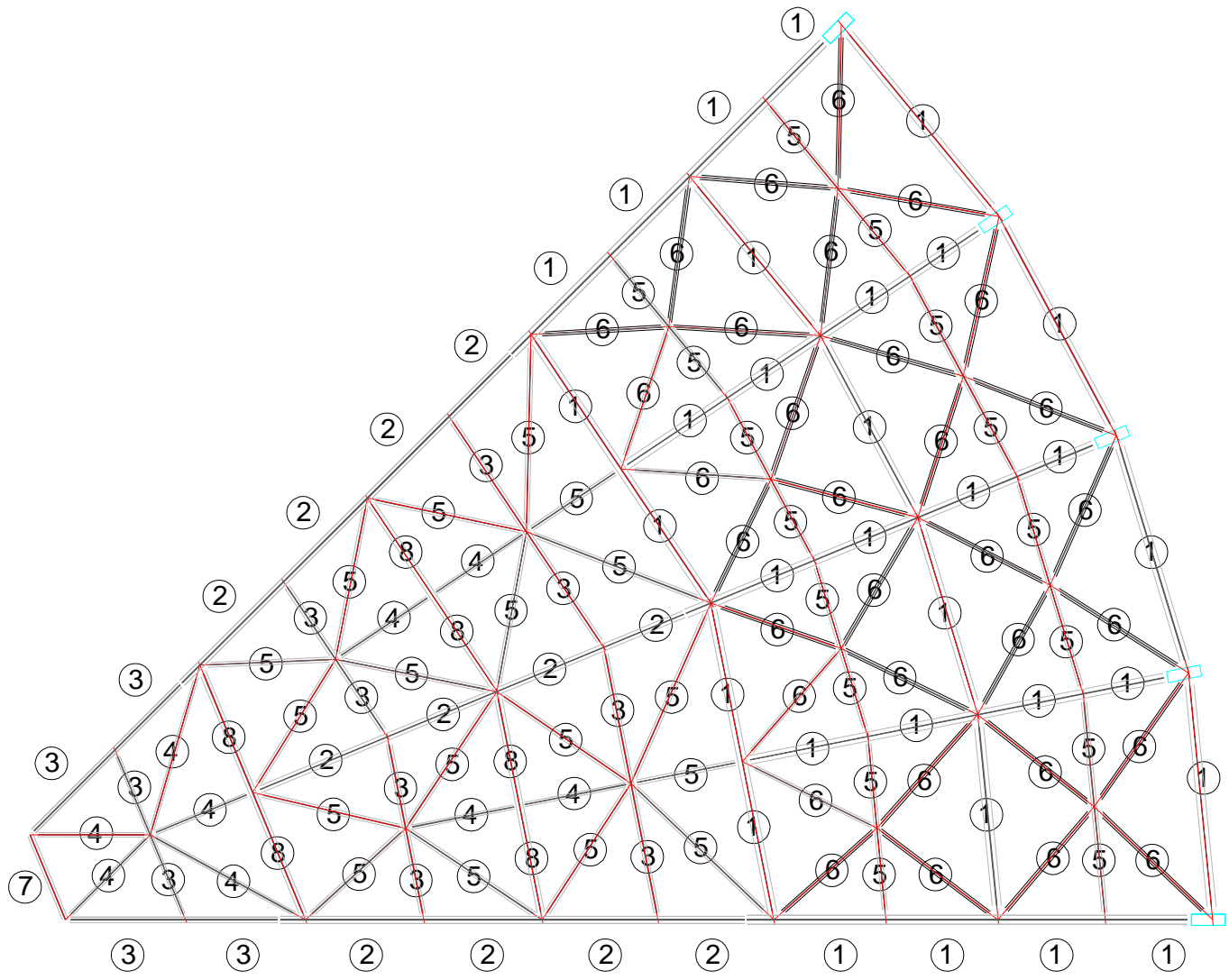

Figura 5.3 - Designação dos perfis empregados na estrutura

Tabela 5.1 - Lista dos perfis utilizados na estrutura

\begin{tabular}{c|c||c|c}
\hline Número & Perfil & Número & Perfil \\
\hline 1 & VS $700 \times 105$ & 5 & VS $375 \times 40$ \\
\hline 2 & VS $550 \times 75$ & 6 & VS $350 \times 31$ \\
\hline 3 & VS $400 \times 53$ & 7 & VS $450 \times 60$ \\
\hline 4 & VS $350 \times 27$ & 8 & VS $550 \times 64$ \\
\hline
\end{tabular}


O projeto foi desenvolvido por escritório de cálculo especializado, e os profissionais encarregados utilizaram o programa computacional STRAP 8.0 para análise e dimensionamento. As normas empregadas foram: NBR 6123 (1986), NBR 8.800 (1988) e EUROCODE 3 (1992).

Um aspecto interessante desse projeto, e de particular interesse para a discussão que vai se realizar neste capítulo, é que os profissionais que o desenvolveram admitiram duas hipóteses para 0 comportamento das ligações dos anéis com os arcos, a primeira delas admitindo ligações articuladas e a segunda admitindo ligações rígidas. Com essas duas hipóteses foi feita a envoltória de esforços que serviu de base para o dimensionamento. 0 dimensionamento das ligações, contudo, foi feito admitindo apenas a situação de ligações articuladas, pois o detalhe adotado na versão final do projeto ligava apenas as almas dos perfis dos anéis.

\section{2 - Ações Consideradas}

As ações utilizadas na análise da estrutura foram aquelas normalmente empregadas no cálculo das estruturas metálicas nacionais, podendo-se listar:

a) Ações Permanentes

a. Peso próprio da estrutura

b. Peso próprio do sistema de vedação (telhas).

c. Instalações para eventos (som, iluminação, etc.)

b) Ações Variáveis

a. Sobrecarga no telhado

b. Efeito da variação da temperatura.

c) Ações devidas ao Vento

Nesse tipo de estrutura é relativamente comum a fixação de plataformas para instalação de equipamentos e circulação de pessoas, no entanto, como o projeto tomado para estudo neste trabalho não contemplou esse tipo de situação, a influência dessas plataformas foi deixada para estudo em trabalhos futuros.

\subsection{1 - Ações permanentes}

A primeira parcela da ação permanente é composta pelo peso próprio da estrutura, que nos modernos programas computacionais utilizados atualmente já podem ser avaliados automaticamente, bastando, para isso, fornecer o peso específico do material após a geometria da estrutura ter sido definida.

A segunda parcela da ação permanente é composta pelo peso próprio do sistema de vedação, que normalmente varia de 3 a $30 \mathrm{kgf} / \mathrm{m}^{2}$, dependendo do tipo de telha empregado. No projeto em estudo foram adotadas telhas do tipo sanduíche, compostas por duas chapas de aço e enchimento em plurietano, cujo peso estimado é de $12 \mathrm{kgf} / \mathrm{m}^{2}$.

Resumindo, a ação permanente considerada foi:

Peso próprio da estrutura Gerado automaticamente pelo programa

Peso próprio das telhas $0,12 \mathrm{kN} / \mathrm{m}^{2}\left(12 \mathrm{kgf} / \mathrm{m}^{2}\right)$ 


\subsection{2 - Ações variáveis}

\subsubsection{1 - Sobrecarga no Telhado}

Para a sobrecarga no telhado foi considerada a especificação do anexo B, item B-3.6.1, da NBR 8800 (1986), que diz: "nas coberturas comuns, não sujeitas a acúmulos de quaisquer materiais, e na ausência de especificações em contrário, deve ser prevista uma sobrecarga nominal mínima de $0,25 \mathrm{kN} / \mathrm{m}^{2}$, em projeção horizontal."

\subsubsection{2 - Variação de Temperatura}

A variação da temperatura ambiente, admitida constante ao longo de toda a estrutura, foi avaliada em $\pm 10^{\circ} \mathrm{C}$ para a região onde a estrutura foi projetada. Esse tipo de ação também pode ser gerado automaticamente pelo programa, sendo necessário para isto fornecer o coeficiente de dilatação térmica do material.

\subsubsection{3 - $\underline{\text { Ação do Vento }}$}

\section{a) Determinação da Pressão de Obstrução}

O cálculo da pressão de obstrução $(q)$ devida ao vento utilizada no dimensionamento e na análise das estruturas está resumido na Tabela 5.2:

Tabela 5.2 - Cálculo da Pressão de Obstrução

\begin{tabular}{l|l}
\hline$V_{0}=40 \mathrm{~m} / \mathrm{s}$ & Velocidade básica do vento na cidade de São Carlos (SP) - Gráfico de Isopletas \\
\hline $\mathrm{S}_{1}=1,00$ & Fator topográfico para terreno plano \\
\hline & $\begin{array}{l}\text { Fator de rugosidade média do terreno e de dimensões da edificação } \\
\mathrm{S}_{2}=0,95\end{array}$ \\
\hline $\begin{array}{l}\text { - Terreno plano com edificações baixas e esparsas / Categoria III } \\
\text { - Maior dimensão da edificação é maior ou igual a 50m / Classe C }\end{array}$ \\
\hline$S_{3}=1,00$ & Fator estatístico de segurança / Edificação com alto fator de ocupação \\
\hline Velocidade & $\begin{array}{l}V_{k}=V_{0} \times S_{1} \times S_{2} \times S_{3}=40 \times 1,00 \times 0,95 \times 1,00 \\
V_{k}=38 \mathrm{~m} / \mathrm{s}\end{array}$ \\
\hline Paracterística & $q=0,613 \times V k^{2}=0,613 \times 43^{2}$ \\
Obstrução & $q=885,17 \mathrm{~N} / \mathrm{m}^{2} \rightarrow q=0,89 \mathrm{kN} / \mathrm{m}^{2}$ \\
\hline
\end{tabular}

b) Determinação dos coeficientes de pressão externa $\left(C_{p e}\right)$

Segundo a NBR 6123 (1986), devido à variação da distribuição de pressões com as características do vento, da relação entre as dimensões da edificação e da superfície externa da cúpula, só é possível fornecer valores aproximados de $C_{p e}$. No caso de cúpulas apoiadas sobre paredes cilíndricas a variação dos coeficientes de pressão externa é ainda maior do que quando assente diretamente ao solo. Nesse caso, um trabalho bastante interessante foi desenvolvido por CARRIL JÚNIOR et al. (2004), que realizaram ensaios em túnel de vento de uma cobertura em cúpula com planta oval. 
As linhas isobáricas dos coeficientes de pressão para cúpulas apoiadas sobre paredes cilíndricas são determinadas em função das dimensões da edificação, mais precisamente em função das relações $f / d$ e $h / d$, onde $f, d$ e $h$ estão indicados na Figura 5.4:

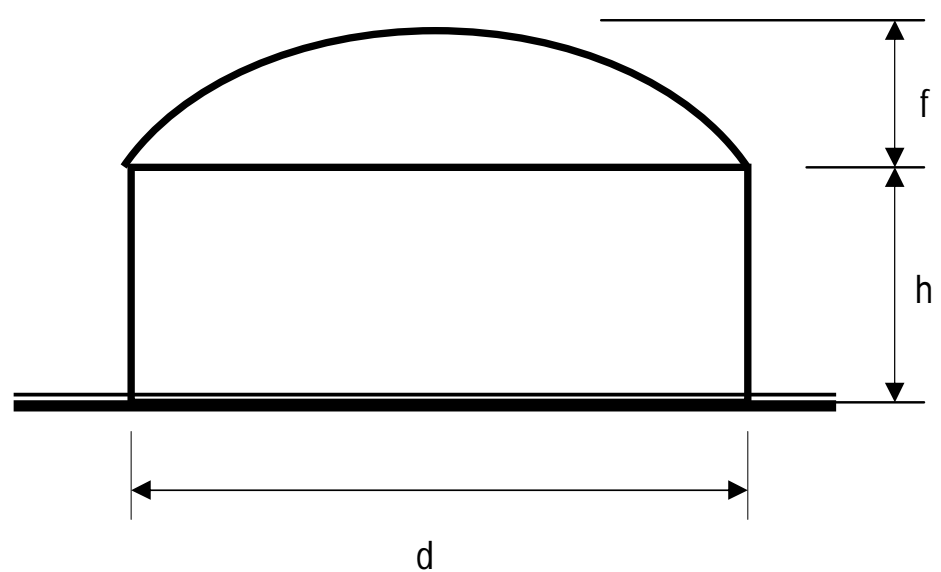

Figura 5.4 - Esquema da elevação de uma cúpula apoiada sobre paredes cilíndricas

As figuras a seguir apresentam as linhas isobáricas dos coeficientes de pressão externa para os casos onde $f / d=1 / 2$ e $h / d=1 / 2$, e $f / d=1 / 10$ e $h / d=1$. Para relações intermediárias de $f / d$ e $h / d$ os coeficientes são obtidos por interpolação linear com os valores limites apresentados na Tabela 5.3.

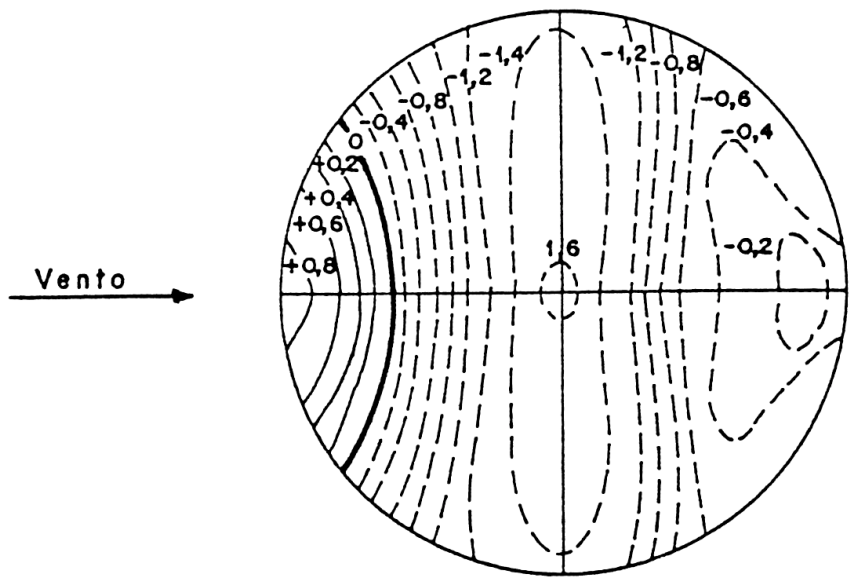

Figura 5.5 - Linhas isobáricas dos coeficientes de pressão externa para f/d $=1 / 2$ e $h / d=1 / 2$

(Fonte: NBR 6123 (1984)) 


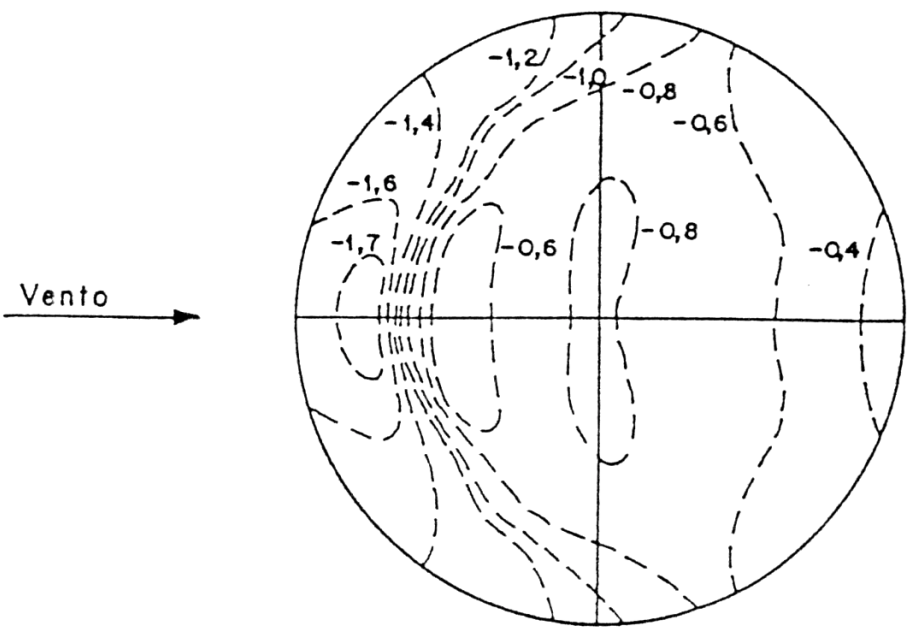

Figura 5.6 - Linhas isobáricas dos coeficientes de pressão externa para f/d =1/10 e h/d = 1

(Fonte: NBR 6123 (1984))

Tabela 5.3 - Valores Limites dos Coeficientes de Pressão Externa $C_{p e}$ para Cúpulas sobre Paredes Cilíndricas (Fonte: NBR 6123 (1984))

\begin{tabular}{|c|c|c|c|c|}
\hline \multirow{2}{*}{ f/d } & \multirow{2}{*}{$\mathrm{h} / \mathrm{d}$} & \multicolumn{3}{|c|}{ Cpe } \\
\hline & & \multicolumn{3}{|c|}{ a barlavento no topo lateralmente } \\
\hline \multirow{3}{*}{$1 / 2$} & $1 / 4$ & $+0,9$ & $-1,5$ & $-0,4$ \\
\hline & $1 / 2$ & $+0,8$ & $-1,7$ & $-0,4$ \\
\hline & 1 & $+0,8$ & $-1,7$ & $-0,5$ \\
\hline $1 / 6$ & \multirow{4}{*}{$1 / 4$} & $-0,1$ & $-0,9$ & $-0,4$ \\
\hline $1 / 10$ & & $-1,2$ & $-0,6$ & $-0,3$ \\
\hline $1 / 15$ & & $-1,4$ & $-0,5$ & $-0,3$ \\
\hline $1 / 20$ & & $-1,4$ & $-0,4$ & $-0,2$ \\
\hline $1 / 6$ & \multirow{4}{*}{1} & $-1,4$ & $-1,1$ & $-0,4$ \\
\hline $1 / 10$ & & $-1,7$ & $-0,8$ & $-0,4$ \\
\hline $1 / 15$ & & $-1,5$ & $-0,5$ & $-0,4$ \\
\hline $1 / 20$ & & $-1,4$ & $-0,5$ & $-0,4$ \\
\hline
\end{tabular}

\section{c) Determinação dos coeficientes de pressão interna $\left(C_{p i}\right)$}

A avaliação do coeficiente de pressão interna será feita com o auxílio do item 6.2 .6 da NBR 6123 (1986), que diz: "para edificações efetivamente estanques e com janelas fixas que tenham uma probabilidade desprezível de serem rompidas por acidentes, considerar o mais nocivo entre os valores $C_{p i}=-0,2$ ou $C_{p i}=0$ ". 
Conhecidos os coeficientes de pressão externa e interna, calculou-se o coeficiente de pressão total, dado por $C_{p}=C_{p e}+C_{p i}$, para dos diversos setores da cobertura. A Figura 5.7 resume os valores de $C_{p}$ obtidos para a estrutura em estudo.

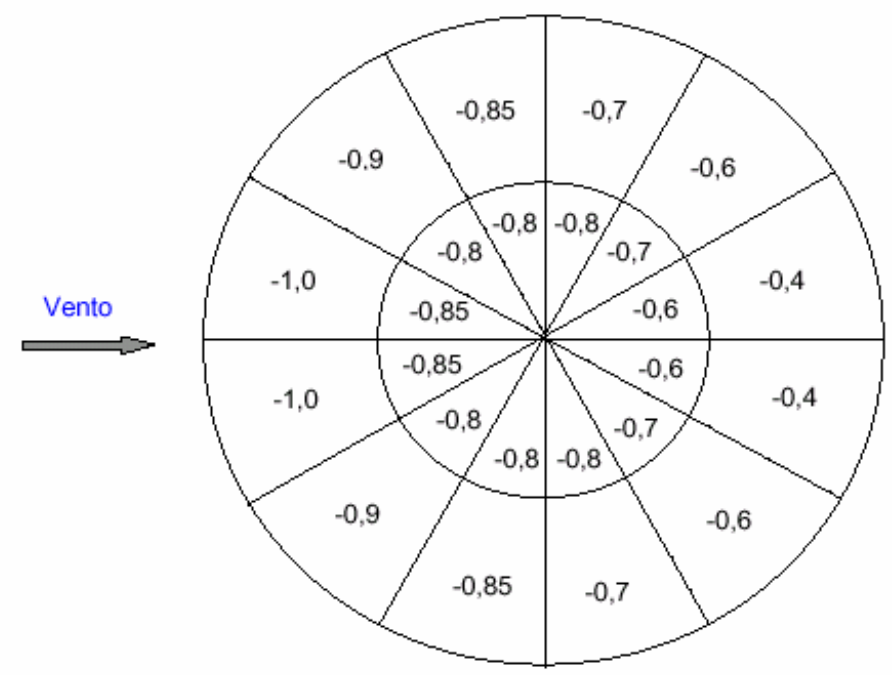

Figura 5.7 - Coeficientes de pressão total na cúpula tomada como exemplo

Multiplicando a carga de obstrução pelos coeficientes de pressão total, foram obtidos os valores da ação do vento na cobertura.

\subsection{3 - Combinações de Ações}

Foram consideradas duas combinações de ações, a primeira delas chamada de combinação positiva, na qual foram consideradas todas as cargas gravitacionais, e a segunda chamada de combinação negativa, na qual foram consideradas as cargas permanentes e as cargas devidas ao vento, que resultaram de sucção.

A comparação de resultados foi feita considerando os valores nominais dos carregamentos, ou seja, toda a discussão sobre o comportamento da estrutura foi feito tendo por base o comportamento em serviço.

O efeito da variação de temperatura foi avaliado separadamente, e comparado com o efeito exercido pelo peso próprio da estrutura.

\section{3 - Características das Ligações}

O comportamento momento-rotação das ligações que compunham a cobertura estudada neste capítulo foi descrito pelo acoplamento do modelo proposto no item 4.2 para ligações com dupla tala de alma com o modelo de COLSON (1991).

\section{4 - Sobre a Análise Estrutural}

A análise estrutural permite ao engenheiro conhecer a resposta de uma estrutura submetida aos mais diversos tipos de ações. 
Em termos gerais, entende-se como resposta da estrutura os deslocamentos e os esforços internos que surgem por ocasião da aplicação do carregamento. O conceito de reposta estrutural, porém, pode abranger outros parâmetros, como a freqüência de vibração sob a atuação de cargas dinâmicas, por exemplo.

De posse dos resultados da análise estrutural, o engenheiro pode dimensionar adequadamente a estrutura para que ela não apresente deslocamentos excessivos e nunca venha a ser solicitada além de sua capacidade, assegurando-se, assim, o conforto e a segurança dos usuários.

A análise estrutural pode ser classificada de três maneiras. A primeira forma de classificação referese à variação das ações com o tempo; a segunda à posição da estrutura em que o equilíbrio é estabelecido (posição deslocada ou indeslocada), e a terceira refere-se ao comportamento adotado para o material.

Com relação à variação das ações com o tempo a análise pode ser classificada como estática ou dinâmica.

Com relação à posição da estrutura em que o equilíbrio é estabelecido, a análise pode ser classificada como de primeira ordem, quando o equilíbrio é estabelecido na posição indeslocada da estrutura, de forma que os deslocamentos provocados pelos carregamentos não introduzem esforços adicionais, e de segunda ordem, quando o equilíbrio é estabelecido na posição deslocada, ou seja, quando os deslocamentos introduzem esforços adicionais na estrutura. A análise de segunda ordem também é conhecida como análise não-linear geométrica (NLG).

Com relação ao comportamento do material, pode-se admitir comportamento elástico-linear, o que significa que o material apresenta resistência infinita e capacidade infinita de deformação, ou podese admitir que o material apresenta um comportamento elasto-plástico, que pode ser do tipo perfeito ou com encruamento.

Quando o comportamento elasto-plástico do material é considerado a análise é conhecida como análise com não-linearidade física, ou simplesmente análise não-linear física (NLF).

\subsection{1 - Critérios para Escolha do Tipo de Análise Estrutural}

A análise estrutural mais simples, e conseqüentemente a mais utilizada no meio profissional, é ao mesmo tempo estática, de primeira ordem (sem NLG) e elástica (sem NLF). Obviamente uma análise desse tipo apresenta muitas limitações e, dependendo do tipo de problema que se pretende estudar, pode não reproduzir com precisão o comportamento da estrutura.

QUEIROZ (1988) afirma que as normas relativas aos diversos tipos de construção orientam 0 calculista a respeito da necessidade ou não de uma análise mais completa. Essas orientações estão fundamentadas em estudos e comparações feitas em trabalhos científicos, e em recomendações de projeto feitas por calculistas experientes que se tornaram usuais ao longo do tempo. Mesmo assim, a escolha do tipo de análise a ser adotado depende essencialmente do bom senso do calculista, pois a grande variedade de sistemas estruturais e os vários tipos de ações atuantes não permitem criar regras rígidas para se definir o tipo de análise mais adequada.

Ainda segundo QUEIROZ (1988), o calculista pode seguir as seguintes orientações para escolha do tipo de análise a ser feita: 
a) Análise estática $x$ análise dinâmica: a análise dinâmica é aconselhável nos casos onde a estrutura apresenta amortecimento muito pequeno ou é muito sensível às ações que variam rapidamente com o tempo. É o caso das estruturas de aço que suportam máquinas ou que irão absorver impactos.

b) Análise linear $x$ análise com não-linearidade geométrica: recomenda-se a análise com nãolinearidade geométrica nos casos de estruturas com esbeltez elevada, ou quando 0 comportamento da estrutura for fortemente influenciado pelos deslocamentos decorrentes da aplicação das ações. Segundo QUEIROZ (1988) as estruturas em arco ou poligonal, as cascas abatidas, as estruturas estaiadas, as pontes pênseis e as estruturas suportando grandes cargas verticais no topo necessitam de análise não-linear geométrica.

c) Análise elástica $x$ análise com não-linearidade física: a não-linearidade física não costuma ser considerada no dimensionamento das estruturas de aço, pois, mesmo havendo tensões residuais decorrentes do processo de fabricação, as estruturas normalmente trabalham com tensões abaixo do limite de proporcionalidade do material, não havendo, portanto, necessidade de sofisticar a análise por ocasião do dimensionamento. No caso de estruturas metálicas, a não-linearidade física é importante quando se deseja conhecer o comportamento da estrutura na iminência do colapso, quando toda a capacidade resistente do material está sendo utilizada.

Diante do que foi dito anteriormente, percebe-se que, em um primeiro momento, não há necessidade de realizar análises mais sofisticadas do tipo de estrutura abordado neste trabalho. Tal estudo poderia até ter sido desenvolvido com relativa facilidade, uma vez que os programas computacionais utilizados neste trabalho contemplam esse tipo de análise. No entanto, optou-se por enfatizar a investigação da influência das ligações e da utilização de barras rígidas no contraventamento, efeitos estes que são desconhecidos para o sistema estrutural em estudo.

O efeito das não-linearidades no comportamento de estruturas metálicas já é bem conhecido, podendo-se citar SÁLES (1995), LAVALL (1996), SÁLES et al. (1997) e SANTOS et al. (2002) como referências que podem ser consultadas nesse assunto. Consta em alguns desses trabalhos que em estruturas devidamente dimensionadas o acréscimo nos esforços internos e nos deslocamentos não costuma atingir $10 \%$ daqueles obtidos em análises lineares, o que não chega a representar grande preocupação para os projetistas.

Estando estabelecido que foram realizadas apenas análises estáticas, elásticas e de primeira ordem, lista-se na Tabela 5.4 as características gerais das quatorze simulações que foram empreendidas para a estrutura em questão.

Vê-se, então, que, mesmo não tendo sido desenvolvidas análises não-lineares, não foram poucos os resultados obtidos para comparação. Além disso, com a restrição dos tipos de análises realizadas, foi possível concentrar esforços na investigação de alguns efeitos julgados mais importantes, que eram aqueles decorrentes da influência das ligações e do contraventamento. 
Tabela 5.4 - Análises Realizadas

\begin{tabular}{c|c|c|c}
\hline \multirow{2}{*}{$\begin{array}{c}\text { Número da } \\
\text { Análise }\end{array}$} & \multicolumn{2}{|c|}{ Ligações } & Características do \\
\cline { 2 - 3 } & Anéis I Arcos & Apoios & Contraventamento \\
\hline 01 & Flexíveis & Engaste & Com Barras Rígidas \\
\hline 02 & Flexíveis & Engaste & Com Barras Flexíveis \\
\hline 03 & Flexíveis & Engaste & Sem Contraventamento \\
\hline 04 & Rígidas & Engaste & Com Barras Rígidas \\
\hline 05 & Rígidas & Engaste & Com Barras Flexíveis \\
\hline 06 & Rígidas & Engaste & Sem Contraventamento \\
\hline 07 & Semi-rígidas & Engaste & Com Barras Rígidas \\
\hline 08 & Semi-rígidas & Engaste & Com Barras Flexíveis \\
\hline 09 & Semi-rígidas & Engaste & Sem Contraventamento \\
\hline
\end{tabular}

\section{5 - Sobre os Elementos Finitos Utilizados}

Neste trabalho foram utilizados dois programas computacionais que utilizam o método dos elementos finitos, foram eles: o STRAP 8.0 (2000) e o ANSYS 7.1 (2000). Cada um desses programas possui uma biblioteca própria de elementos, de forma que será necessário descrever aqueles que foram utilizados em cada um deles. A descrição, no entanto, será sucinta, pois não há necessidade de descrever toda a formulação desses elementos.

A utilização de dois programas diferentes permitiu a aferição de resultados entre eles, o que facilitou sobremaneira 0 ajuste dos modelos e a eliminação de erros na modelagem.

\subsection{1 - Elementos do Programa STRAP 8.0 (2000)}

O STRAP 8.0 (2000) foi empregado no dimensionamento da estrutura e na análise dos modelos onde não foi considerada a rigidez das ligações. Nesse programa foi selecionado um elemento de viga no espaço, o qual considera a contribuição da rigidez axial, da rigidez à flexão nos dois planos principais e a rigidez torcional em sua formulação. A Figura 5.8 mostra os eixos locais e os graus de liberdade desse elemento.

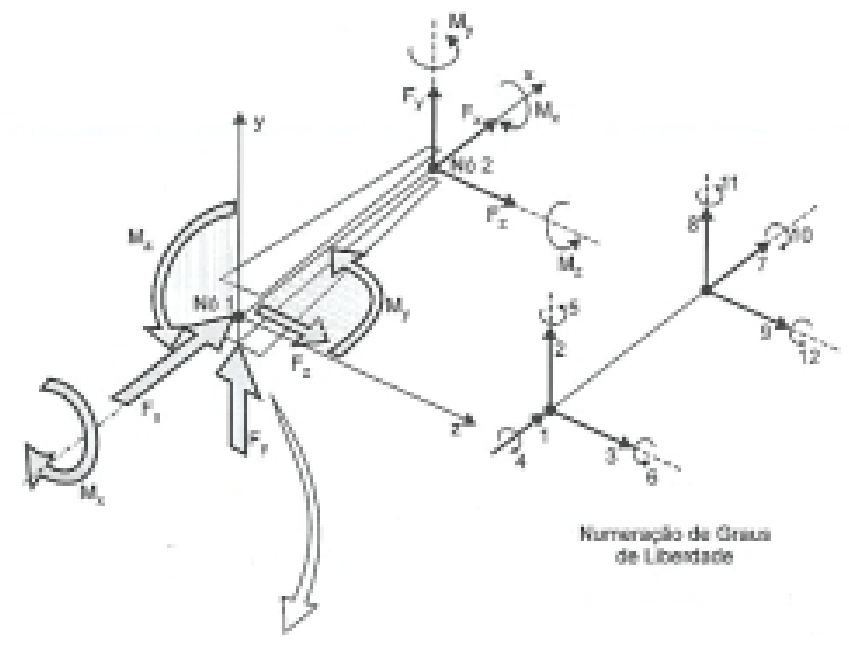

Figura 5.8 - Elemento finito de viga no espaço (Fonte: ALVES FILHO (2000)) 
Um recurso bastante interessante do STRAP 8.0 chama-se "Beams-End-Releases". Com esse recurso é possível liberar quaisquer restrições nas barras e em qualquer uma de suas extremidades. A Figura 5.9 mostra a tela apresentada pelo programa para 0 usuário quando essa função é ativada.

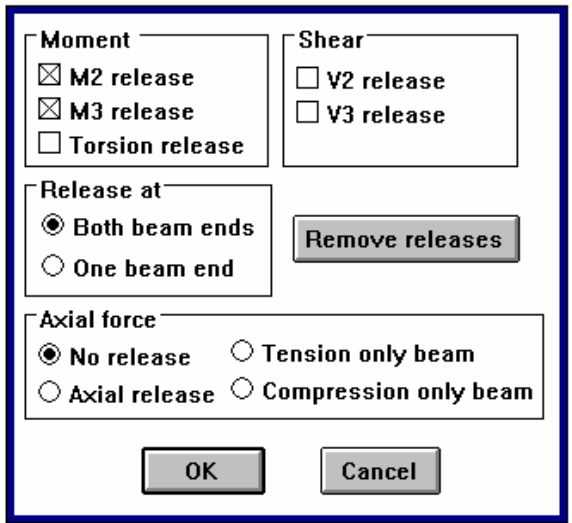

Figura 5.9 - Recurso "Beams-End-Releases" (Fonte: STRAP 8.0)

Além disso, por ser uma ferramenta de cálculo estrutural bastante utilizada na prática, esse programa fornece muitos recursos de visualização de resultados, o que facilitou bastante 0 trabalho de coleta de dados.

\subsection{2 - Elementos do Programa ANSYS 7.1 (2000)}

No ANSYS 7.1(2000) foram desenvolvidas as simulações considerando a rigidez/flexibilidade das ligações. As barras dos arcos e dos anéis foram discretizadas utilizando o elemento BEAM4, mostrado na Figura 5.10. Trata-se, como se pode perceber, de um elemento espacial de viga semelhante àquele utilizado no STRAP 8.0 (2000).

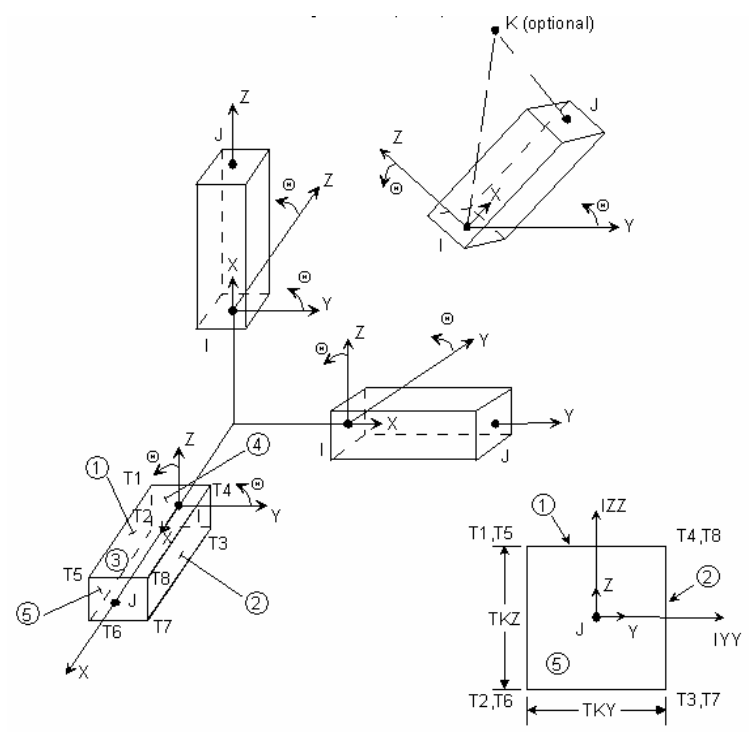

Figura 5.10 - Elemento BEAM4 (Fonte: ANSYS Help System)

Exemplos de aplicação desse elemento podem ser encontrados em MOAVENI (2003). 
As barras do contraventamento foram simuladas com os elementos LINK8 e LINK10, mostrados nas Figuras 5.11(a) e 5.11(b).

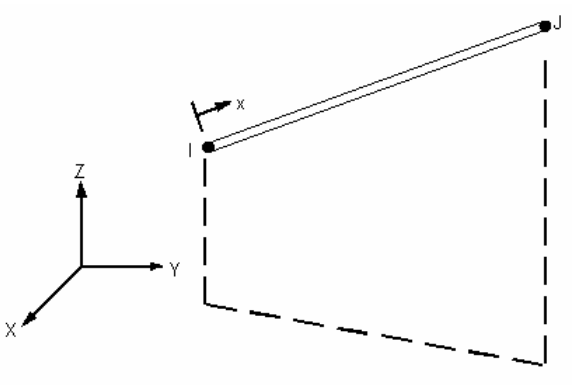

(a) Elemento LINK8

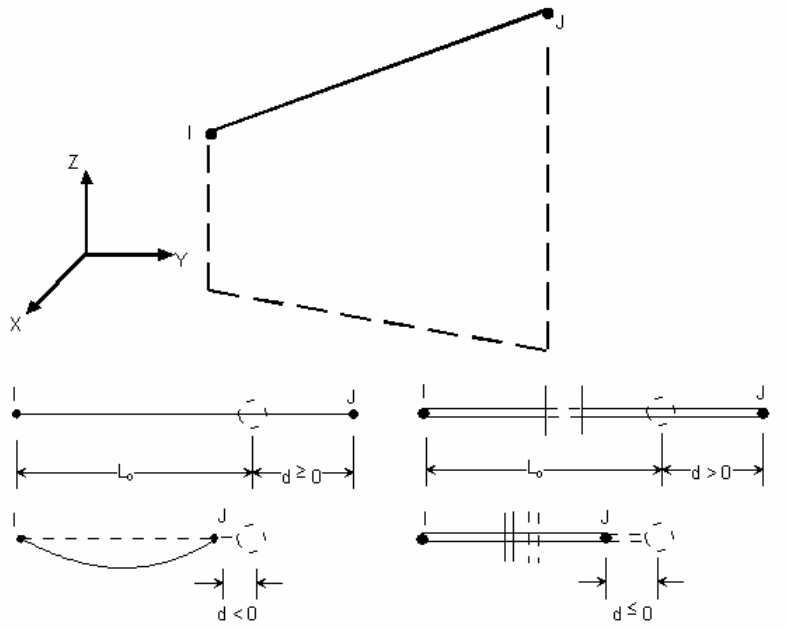

(b) Elemento LINK10

Figura 5.11 - Elementos LINK8 e LINK10 (Fonte: ANSYS Help System)

Ambos são elementos que trabalham apenas sob esforços axiais, sendo que o primeiro deles permite que sejam desenvolvidas forças de tração e de compressão, e 0 segundo que sejam desenvolvidas apenas forças de tração.

A influência das ligações foi considerada nas análises por meio do acoplamento do elemento BEAM4 com o elemento COMBIN39 Nonlinear Spring, também disponível na biblioteca do ANSYS (2000).

O COMBIN39 é um elemento unidirecional que pode apresentar comportamento não-linear para relações força $x$ deslocamento, e que admite dois ou três graus de liberdade em cada nó. A Figura 5.12 ilustra esse elemento.
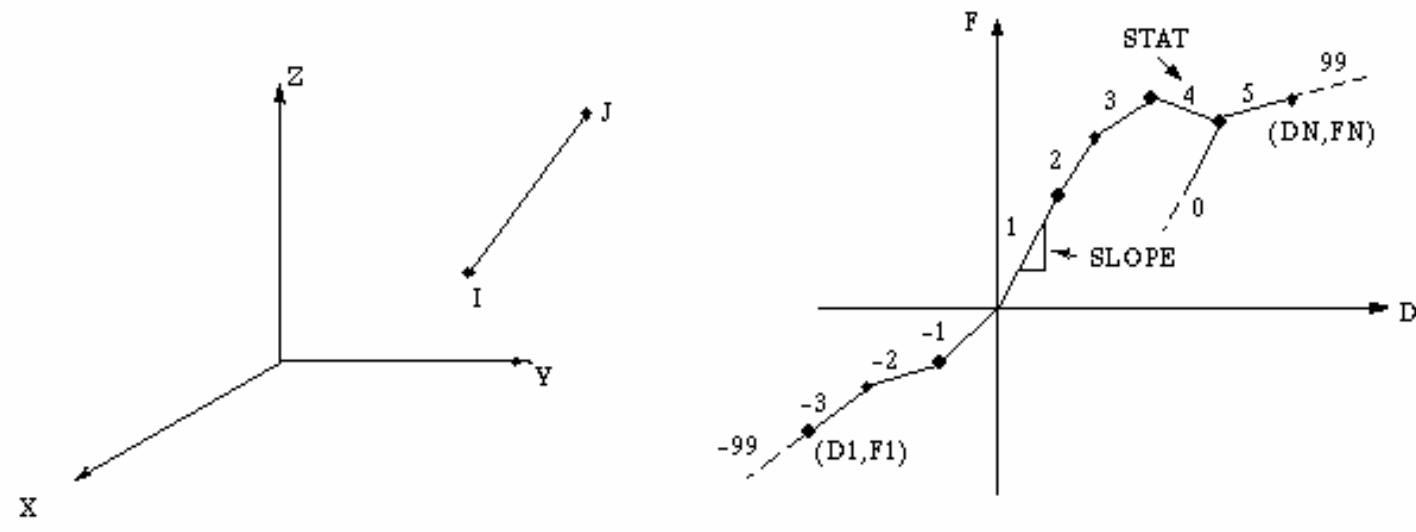

Figura 5.12 - Elemento COMBIN39 (Fonte: ANSYS Help System) 
As curvas momento-rotação das ligações da estrutura foram plotadas com auxílio do modelo de COLSON (1991), que teve os parâmetros de rigidez inicial e momento último avaliados conforme 0 modelo proposto no item 4.2 .

\section{6 - Influência do Tipo de Contraventamento}

\subsection{1 - Comparação dos Deslocamentos Máximos}

A Tabelas 5.5 apresenta os deslocamentos máximos fornecidos pelo STRAP 8.0 (2000) em modelos considerando ligações rígidas e articuladas, sob três diferentes formas de contraventamento: a) com barras rígidas; b) com barras flexíveis; e c) sem barras de contraventamento.

Tabela 5.5 - Deslocamentos máximos

\begin{tabular}{c|c|c|c|c|c|c}
\hline \multirow{2}{*}{ Comb. } & \multicolumn{3}{|c|}{ Modelos com Ligações Articuladas } & \multicolumn{3}{c}{ Modelos com Ligações Rígidas } \\
\cline { 2 - 7 } & $\begin{array}{c}\text { Contravent. } \\
\text { Rígido }\end{array}$ & $\begin{array}{c}\text { Contravent. } \\
\text { Flexível }\end{array}$ & $\begin{array}{c}\text { Sem } \\
\text { Contravent. }\end{array}$ & $\begin{array}{c}\text { Contravent. } \\
\text { Rígido }\end{array}$ & $\begin{array}{c}\text { Contravent. } \\
\text { Flexível }\end{array}$ & $\begin{array}{c}\text { Sem } \\
\text { Contravent. }\end{array}$ \\
\hline+ & 3,313 & 4,626 & 14,602 & 2,822 & 4,371 & 7,409 \\
\hline- & 3,152 & 3,169 & 19,563 & 2,473 & 2,493 & 16,050 \\
\hline
\end{tabular}

A posição dos nós listados na Tabela 5.5 está mostrada na Figura 5.13.

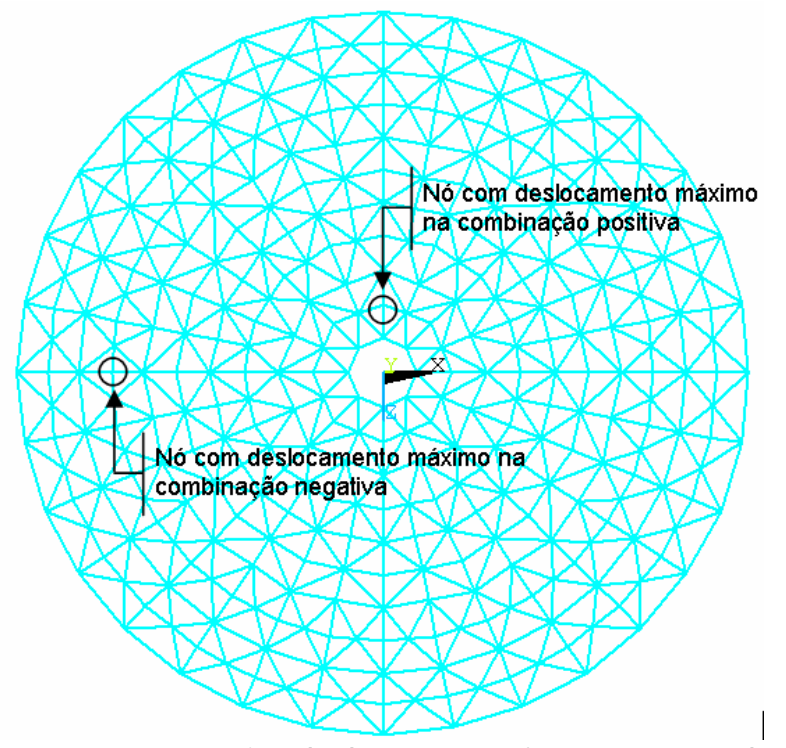

Figura 5.13 - Nós cujos deslocamentos foram comparados

Dos resultados apresentados nesta tabela podem ser feitas as seguintes comparações:

a) Ligações Rígidas x Ligações Articuladas

Comparando os deslocamentos máximos dentro de cada condição de contraventamento é possível avaliar a influência do enrijecimento das ligações. A Tabela 5.6 resume os resultados dessa comparação. 
Tabela 5.6 - Comparação entre os deslocamentos máximos (Dados de origem na Tabela 5.5)

\begin{tabular}{c|c|c|c}
\hline Comb. & Contraventamento Rígido & Contraventamento Flexível & Sem Contraventamento \\
\hline+ & $15 \%$ & $6 \%$ & $49 \%$ \\
\hline- & $22 \%$ & $21 \%$ & $18 \%$ \\
\hline
\end{tabular}

Analisando inicialmente os resultados dos modelos que continham barras de contraventamento, quer seja rígido ou flexível, vê-se que, na combinação positiva, o enrijecimento das ligações promoveu uma redução do deslocamento máximo de $15 \%$. Já na combinação negativa a redução foi um pouco maior, chegando a atingir uma diferença de $22 \%$.

Convém observar, porém, que na estrutura em estudo, a combinação crítica no dimensionamento foi a positiva, de forma que a utilização de ligações articuladas mostrou-se mais vantajosa nesse caso, pelo fato dos detalhes serem mais simples e menos onerosos.

Em situações práticas cabe ao projetista estudar as duas formas de execução das ligações e determinar qual delas é a mais apropriada. Embora os deslocamentos máximos não sejam o único aspecto a ser observado ele é um bom indicativo do comportamento da estrutura, e se a diferença entre os modelos com ligações rígidas e articuladas não é acentuada, é um sinal de que o modelo com ligações flexíveis pode ser o mais apropriado.

Nos modelos sem barras de contraventamento vê-se que 0 enrijecimento das ligações teve influência considerável no comportamento da estrutura, pois chegou a reduzir em $76 \% 0$ deslocamento máximo. Tal influência pode ser considerada previsível, uma vez que na ausência do contraventamento a rigidez da estrutura passa a depender essencialmente dos detalhes construtivos adotados nas ligações.

Convém observar, porém, que o modelo sem contraventamento e com ligações articuladas permitiu a ocorrência de deslocamentos exagerados, da ordem de 1/260 do vão, 0 que inviabiliza sua construção e cujo redimensionamento conduziria a seções transversais exageradamente robustas.

\section{b) Influência do Contraventamento}

A Tabela 5.7 apresenta a relação entre os deslocamentos obtidos nos modelos com o mesmo tipo de ligação e diferentes formas de contraventamento, de modo a permitir a avaliação da influência desses elementos no comportamento da estrutura.

Tabela 5.7 - Comparação entre os deslocamentos máximos (Dados de origem na Tabela 5.5)

\begin{tabular}{c|c|c|c|c}
\hline \multirow{2}{*}{ Combinação } & \multicolumn{2}{|c|}{ Modelos com Ligações Articuladas } & \multicolumn{2}{c}{ Modelos com Ligações Rígidas } \\
\cline { 2 - 5 } & $\delta_{\mathrm{CF}} / \delta_{\mathrm{CR}}$ & $\delta_{\mathrm{SC}} / \boldsymbol{\delta}_{\mathrm{CR}}$ & $\delta_{\mathrm{CF}} / \delta_{\mathrm{CR}}$ & $\boldsymbol{\delta}_{\mathrm{SC}} / \boldsymbol{\delta}_{\mathrm{CR}}$ \\
\hline+ & 2,23 & 12,03 & 2,25 & 3,17 \\
\hline- & 1,01 & 6,21 & 1,01 & 6,49 \\
\hline
\end{tabular}

Legenda: $\mathrm{CR}=$ Contraventamento rígido / CF = Contraventamento flexível / SC = Sem contraventamento

Estabelecendo os modelos com contraventamentos rígidos como base de comparação, percebe-se que a mudança na forma de contraventamento teve influência nos deslocamentos máximos dos modelos analisados. Tanto nos modelos com ligações articuladas quanto nos modelos com ligações rígidas, a mudança de contraventamento rígido para flexível aumentou em mais de duas vezes 0 deslocamento máximo. 
Comparando agora os modelos com contraventamento rígido com aqueles sem contraventamento, percebe-se que a diferença nos deslocamentos chegou a ser de mais de doze vezes, um valor que ilustra muito bem a importância desses elementos no comportamento desse tipo de estrutura.

Conclui-se, então, que, na estrutura estudada, a forma de contraventamento teve mais influência nos deslocamentos verticais do que o tipo de ligação empregado.

\subsection{2 - Comparação dos Esforços Internos nos Arcos}

Daqui por diante serão tomados apenas os resultados correspondentes à combinação positiva, que, como foi dito anteriormente, foi crítica para o dimensionamento.

A Figura 5.14 ilustra os quatro grupos de barras dos arcos cujos esforços máximos foram tomados para comparação. O resultados fornecidos pelo STRAP 8.0 estão apresentados nas Tabelas 5.8 e 5.9 .

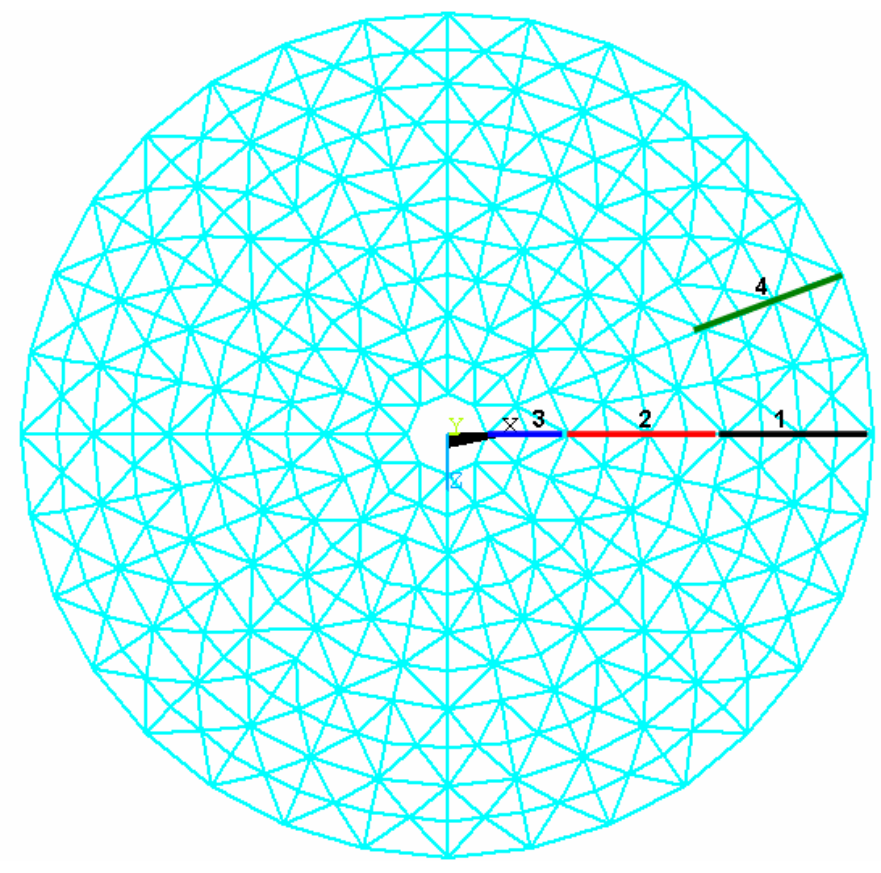

Figura 5.14 - Barras cujos esforços internos foram comparados

Tabela 5.8 - Comparação da Força Axial (Combinação Positiva)

\begin{tabular}{|c|c|c|c|c|c|c|}
\hline \multirow[b]{2}{*}{ Grupo } & \multicolumn{3}{|c|}{ Modelos com Ligações Articuladas } & \multicolumn{3}{|c|}{ Modelos com Ligações Rígidas } \\
\hline & $\begin{array}{l}\text { Contravent. } \\
\text { Rígido }\end{array}$ & $\begin{array}{l}\text { Contravent. } \\
\text { Flexível }\end{array}$ & $\begin{array}{c}\text { Sem } \\
\text { Contravent. }\end{array}$ & $\begin{array}{l}\text { Contravent. } \\
\text { Rígido }\end{array}$ & $\begin{array}{l}\text { Contravent. } \\
\text { Flexível }\end{array}$ & $\begin{array}{c}\text { Sem } \\
\text { Contravent. }\end{array}$ \\
\hline 1 & 420,46 & 588,58 & 521,73 & 434,90 & 697,33 & 554,98 \\
\hline 2 & 286,04 & 527,79 & 345,80 & 319,48 & 676,75 & 379,62 \\
\hline 3 & 168,28 & 185,87 & 194,13 & 189,84 & 340,73 & 223,45 \\
\hline 4 & 358,74 & 354,79 & 325,16 & 352,85 & 333,37 & 307,37 \\
\hline
\end{tabular}


Tabela 5.9 - Comparação do Momento Fletor (Combinação Positiva)

\begin{tabular}{c|c|c|c|c|c|c}
\hline \multirow{2}{*}{ Grupo } & \multicolumn{2}{|c|}{ Modelos com Ligações Articuladas } & \multicolumn{2}{c}{ Modelos com Ligações Rígidas } \\
\cline { 2 - 7 } & $\begin{array}{c}\text { Contravent. } \\
\text { Rígido }\end{array}$ & $\begin{array}{c}\text { Contravent. } \\
\text { Flexível }\end{array}$ & $\begin{array}{c}\text { Sem } \\
\text { Contravent. }\end{array}$ & $\begin{array}{c}\text { Contravent. } \\
\text { Rígido }\end{array}$ & $\begin{array}{c}\text { Contravent. } \\
\text { Flexível }\end{array}$ & $\begin{array}{c}\text { Sem } \\
\text { Contravent. }\end{array}$ \\
\hline 1 & $12.347,79$ & $12.078,48$ & $11.119,72$ & $13.134,42$ & $16.712,85$ & $13.136,83$ \\
\hline 2 & $3.626,89$ & $3.590,70$ & $2.179,18$ & $4.264,43$ & $3.677,71$ & $3.476,55$ \\
\hline 3 & $3.639,95$ & $3.874,73$ & $3.237,28$ & $4.400,05$ & $5.024,26$ & $3.967,30$ \\
\hline 4 & $12.944,63$ & $15.875,99$ & $13.711,28$ & $12.231,27$ & $14.362,30$ & $11.461,96$ \\
\hline \multicolumn{4}{|c|}{} & \multicolumn{4}{c}{ (Valores em kNcm) }
\end{tabular}

a) Ligaccões Rígidas x Ligações Articuladas

A Tabela 5.11 compara os esforços normais nos modelos com ligações rígidas e articuladas. Percebe-se que, de uma maneira geral, o enrijecimento das ligações fez com os esforços normais nos arcos aumentem. A diferença ficou em torno de 10 a $12 \%$ para os modelos com contraventamento rígido e sem contraventamento, e chegou a aumentar em mais de $80 \%$ nos modelos com contraventamento flexível.

Tabela 5.11 - Comparação entre os esforços normais nos arcos (Dados de origem na Tabela 5.8)

\begin{tabular}{c|c|c|c}
\hline Grupo & Contraventamento Rígido & Contraventamento Flexível & Sem Contraventamento \\
\hline 1 & $3 \%$ & $18 \%$ & $6 \%$ \\
\hline 2 & $12 \%$ & $28 \%$ & $10 \%$ \\
\hline 3 & $13 \%$ & $83 \%$ & $15 \%$ \\
\hline 4 & $-2 \%$ & $-6 \%$ & $-5 \%$ \\
\hline
\end{tabular}

A Tabela 5.12 compara os momentos fletores nos modelos com ligações rígidas e articuladas. Percebe-se que, a exemplo do que ocorreu com o esforço normal, o enrijecimento das ligações fez com que os momento fletores nos arcos aumentassem. A diferença ficou em torno de $20 \%$ para os modelos com contraventamento rígido, em torno de 30 a $40 \%$ nos modelos com contraventamento flexível, e chegou a $60 \%$ nos modelos sem contraventamento.

Tabela 5.12 - Comparação entre os momentos fletores nos arcos (Dados de origem na Tabela 5.9)

\begin{tabular}{c|c|c|c}
\hline Grupo & Contraventamento Rígido & Contraventamento Flexível & Sem Contraventamento \\
\hline 1 & $6 \%$ & $38 \%$ & $18 \%$ \\
\hline 2 & $18 \%$ & $2 \%$ & $60 \%$ \\
\hline 3 & $21 \%$ & $30 \%$ & $23 \%$ \\
\hline 4 & $-6 \%$ & $-10 \%$ & $-16 \%$ \\
\hline
\end{tabular}

Conclui-se, então, que, o enrijecimento das ligações tende a aumentar os esforços nos arcos, podendo atingir acréscimos que chegam a mais de $80 \%$ no esforço axial, e a $60 \%$ no momento fletor. 
b) Influência do Contraventamento

Observa-se da Tabela 5.9 que, nos modelos com contraventamento rígido, os momentos fletores nos arcos tendem a ser menores do que nas outras duas situações (com contraventamentos flexíveis e sem contraventamentos).

$\mathrm{Na}$ presença de contraventamentos flexíveis os momentos assumem valores intermediários entre aqueles obtidos nos modelos com contraventamentos rígidos e sem contraventamentos, tanto para ligações rígidas quanto para ligações rotuladas.

As Tabelas 5.13 e 5.14 apresentam resultados que resumem a influência da forma do contraventamento na distribuição de esforços nos arcos. A exemplo do que foi feito para os deslocamentos, os modelos com contraventamento rígido foram tomados como base para comparação.

Tabela 5.13 - Comparação entre os Esforços Axiais (Dados de origem na Tabela 5.8)

\begin{tabular}{c|c|c|c|c}
\hline \multirow{2}{*}{ Grupo } & \multicolumn{2}{|c|}{ Modelos com Ligações Articuladas } & \multicolumn{2}{c}{ Modelos com Ligações Rígidas } \\
\cline { 2 - 5 } & $\mathrm{N}_{\mathrm{CF}} / \mathbf{N}_{\mathrm{CR}}$ & $\mathrm{N}_{\mathrm{SC}} / \mathbf{N}_{\mathrm{CR}}$ & $\mathrm{N}_{\mathrm{CF}} / \boldsymbol{\delta}_{\mathrm{CR}}$ & $\mathrm{N}_{\mathrm{SC}} / \boldsymbol{\delta}_{\mathrm{CR}}$ \\
\hline $\mathbf{1}$ & $40 \%$ & $24 \%$ & $60 \%$ & $28 \%$ \\
\hline $\mathbf{2}$ & $85 \%$ & $21 \%$ & $112 \%$ & $19 \%$ \\
\hline $\mathbf{3}$ & $10 \%$ & $15 \%$ & $79 \%$ & $18 \%$ \\
\hline $\mathbf{4}$ & $-1 \%$ & $-9 \%$ & $-6 \%$ & $-13 \%$ \\
\hline \multicolumn{2}{r}{ Legenda: CR = Contraventamento rígido / CF = Contraventamento flexível / SC = Sem contraventamento }
\end{tabular}

Tabela 5.14 - Comparação entre os Momentos Fletores (Dados de origem na Tabela 5.9)

\begin{tabular}{c|c|c|c|c}
\hline \multirow{2}{*}{ Grupo } & \multicolumn{2}{|c|}{ Modelos com Ligações Articuladas } & \multicolumn{2}{c}{ Modelos com Ligações Rígidas } \\
\cline { 2 - 5 } & $\mathrm{N}_{\mathrm{CF}} / \mathbf{N}_{\mathrm{CR}}$ & $\mathrm{N}_{\mathrm{SC}} / \mathbf{N}_{\mathrm{CR}}$ & $\mathrm{N}_{\mathrm{CF}} / \boldsymbol{\delta}_{\mathrm{CR}}$ & $\mathrm{N}_{\mathrm{SC}} / \boldsymbol{\delta}_{\mathrm{CR}}$ \\
\hline $\mathbf{1}$ & $-2 \%$ & $-10 \%$ & $27 \%$ & $0 \%$ \\
\hline $\mathbf{2}$ & $-1 \%$ & $-40 \%$ & $-14 \%$ & $-18 \%$ \\
\hline $\mathbf{3}$ & $6 \%$ & $-11 \%$ & $14 \%$ & $-10 \%$ \\
\hline $\mathbf{4}$ & $23 \%$ & $6 \%$ & $17 \%$ & $-6 \%$ \\
\hline
\end{tabular}

Legenda: CR = Contraventamento rígido / CF = Contraventamento flexível / SC = Sem contraventamento

Em relação ao esforços axiais os esforços aumentaram de 10 a 85\% quando 0 contraventamento passou de rígido a flexível, e variaram de -18 a 17\% quando passou da condição de contraventamento rígido para sem contraventamento. Para os momentos fletores a variação observada foi de -40 a $27 \%$.

De uma maneira geral pode-se dizer que os esforços axiais aumentaram com a modificação do contraventamento, e que os momentos fletores ora aumentaram ora diminuíram em parcelas praticamente equivalentes.

\subsection{3 - Comparação dos Esforços Internos nos Anéis}

A Figura 5.15 ilustra os quatro grupos de barras dos arcos cujos esforços máximos foram tomados para comparação. O resultados fornecidos pelo STRAP 8.0 estão apresentados nas Tabelas 5.9 e 5.10 . 


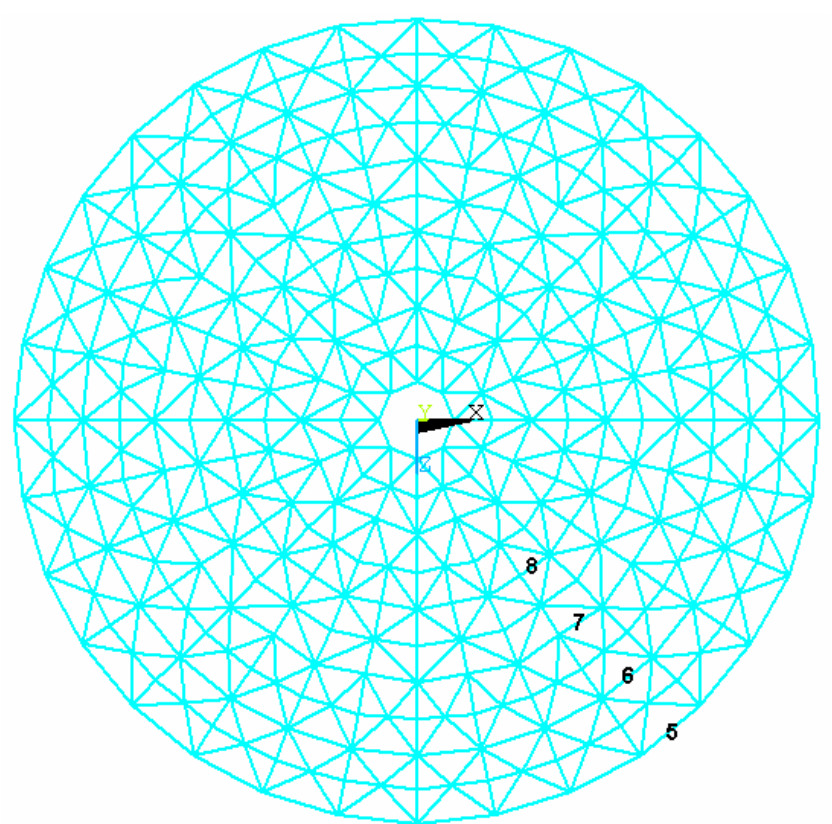

Figura 5.15 - Barras cujos esforços internos foram comparados

Tabela 5.9 - Comparação do Esforço Axial (Combinação Positiva)

\begin{tabular}{c|c|c|c|c|c|c}
\hline \multirow{2}{*}{ Grupo } & \multicolumn{3}{|c|}{ Modelos com Ligações Articuladas } & \multicolumn{2}{c}{ Modelos com Ligações Rígidas } \\
\cline { 2 - 7 } & $\begin{array}{c}\text { Contravent. } \\
\text { Rígido }\end{array}$ & $\begin{array}{c}\text { Contravent. } \\
\text { Flexível }\end{array}$ & $\begin{array}{c}\text { Sem } \\
\text { Contravent. }\end{array}$ & $\begin{array}{c}\text { Contravent. } \\
\text { Rígido }\end{array}$ & $\begin{array}{c}\text { Contravent. } \\
\text { Flexível }\end{array}$ & $\begin{array}{c}\text { Sem } \\
\text { Contravent. }\end{array}$ \\
\hline 5 & 83,56 & 66,27 & 62,43 & 82,68 & 69,47 & 63,46 \\
\hline 6 & 102,21 & 153,14 & 124,83 & 91,04 & 166,14 & 113,18 \\
\hline 7 & 215,87 & 294,05 & 232,27 & 219,60 & 310,54 & 245,78 \\
\hline 8 & 239,60 & 296,45 & 262,59 & 242,26 & 294,78 & 270,40 \\
\hline
\end{tabular}

Tabela 5.10 - Comparação do Momento Fletor (Combinação Positiva)

\begin{tabular}{c|c|c|c|c|c|c}
\hline \multirow{2}{*}{ Grupo } & \multicolumn{3}{|c|}{ Modelos com Ligações Articuladas } & \multicolumn{2}{c}{ Modelos com Ligações Rígidas } \\
\cline { 2 - 7 } & $\begin{array}{c}\text { Contravent. } \\
\text { Rígido }\end{array}$ & $\begin{array}{c}\text { Contravent. } \\
\text { Flexível }\end{array}$ & $\begin{array}{c}\text { Sem } \\
\text { Contravent. }\end{array}$ & $\begin{array}{c}\text { Contravent. } \\
\text { Rígido }\end{array}$ & $\begin{array}{c}\text { Contravent. } \\
\text { Flexível }\end{array}$ & $\begin{array}{c}\text { Sem } \\
\text { Contravent. }\end{array}$ \\
\hline 5 & $2.853,10$ & $3.371,57$ & $3.228,34$ & $2.903,91$ & $3.354,35$ & $3.161,59$ \\
\hline 6 & $2.695,52$ & $2.695,52$ & $2.695,52$ & $2.214,84$ & $5.082,74$ & $3.333,30$ \\
\hline 7 & $8.980,80$ & $10.360,57$ & $8.476,62$ & $4.968,48$ & $6.718,13$ & $4.436,29$ \\
\hline 8 & $4.917,93$ & $3.834,75$ & $4.230,03$ & $2.768,48$ & $5.256,59$ & $2.505,22$ \\
\hline
\end{tabular}

\section{a) Ligações Rígidas x Ligações Articuladas}

De uma maneira geral, a diferença nos esforços axiais entre os resultados fornecidos pelos modelos com ligações rígidas e flexíveis não apresentaram grandes divergências, a variação observada foi de -5 a $12 \%$. 
Já para os momentos fletores observou-se pequenas diferenças para os grupos 5 e 6 , e uma variação mais acentuada para os grupos 7 e 8 .

b) Influência do Contraventamento

A forma do contraventamento teve, mais uma vez, grande influência na distribuição dos esforços internos, como mostram as Tabelas 5.11 e 5.12 . Os esforços axiais variaram de -50 a $25 \%$ nos modelos com ligações articuladas, e de -82 a $23 \%$ no caso de ligações rígidas. Os momentos fletores variaram de -18 a $22 \%$ nos modelos com ligações articuladas, e de -129 a $11 \%$ no caso de ligações rígidas.

\subsection{4 - Considerações Finais}

Observou que a utilização de contraventamentos rígidos tornou a estrutura menos sensível à influência das ligações, tanto com relação aos deslocamentos nodais quanto com relação aos esforços internos em arcos e anéis.

Observou-se também que a utilização de ligações rígidas diminuiu muito pouco a deslocabilidade vertical da estrutura, melhoria esta que não chega a compensar o gasto com material e mão-deobra para enrijecê-las.

Com relação aos modelos com contraventamento flexível, observou-se uma necessidade de aumento das seções transversais das barras em relação àquelas necessárias para viabilizar os modelos com barras rígidas. Esta é uma observação plausível, uma vez que a perda de rigidez devida ao contraventamento precisa ser compensada de alguma outra forma.

\section{7 - Influência da Rigidez das Ligações}

A Figura 5.16 mostra os elementos COMBIN39 que representam o comportamento semi-rígido das ligações da cúpula. Vê-se que praticamente todos os nós da estrutura foram modelados esse tipo de elemento.

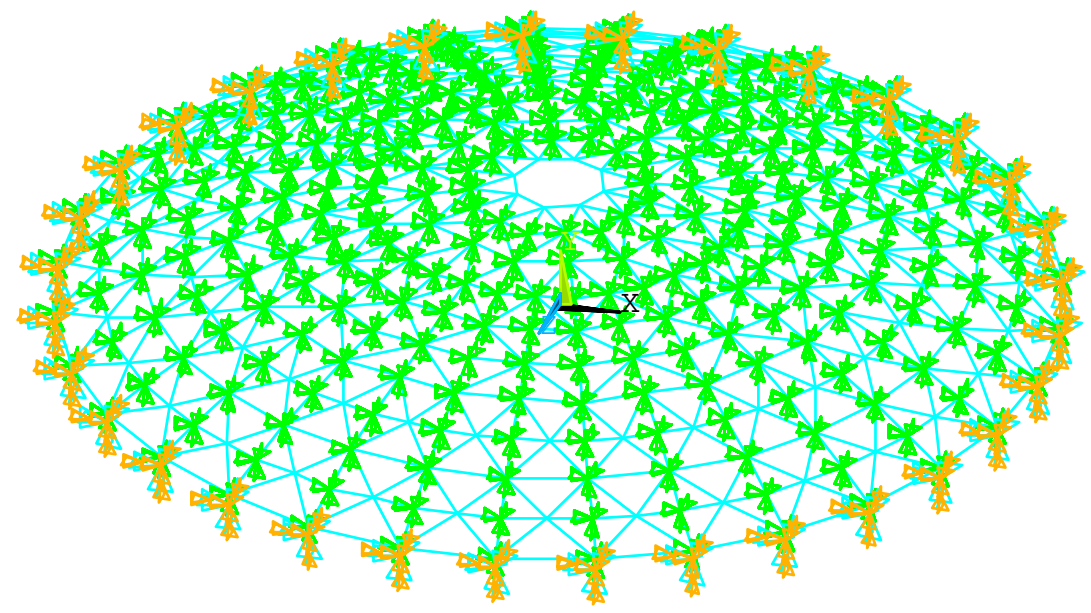

Figura 5.16 - Elementos COMBIN39 representando as ligações semi-rígidas 
A fim de observar melhor a influência da rigidez das ligações e de confrontar com a influência exercida pela forma de contraventamento, os modelos com contraventamento flexível e sem contraventamento foram divididos em dois tipos cada, conforme mostrado na Figura 5.17.

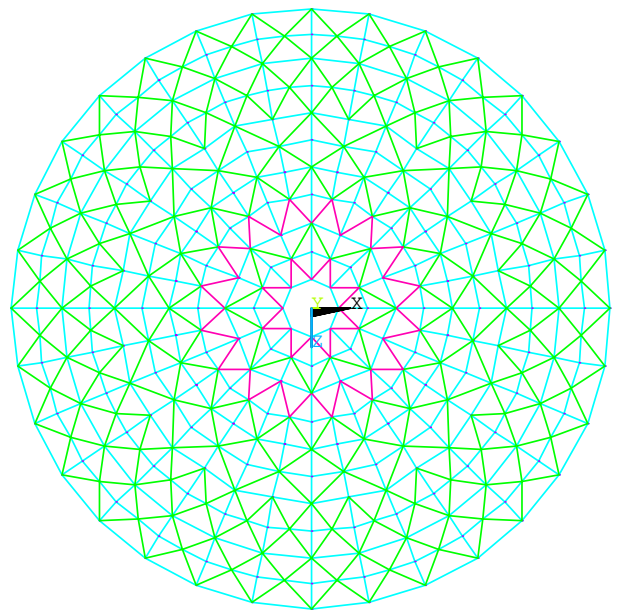

a) Contraventamento Flexível 1

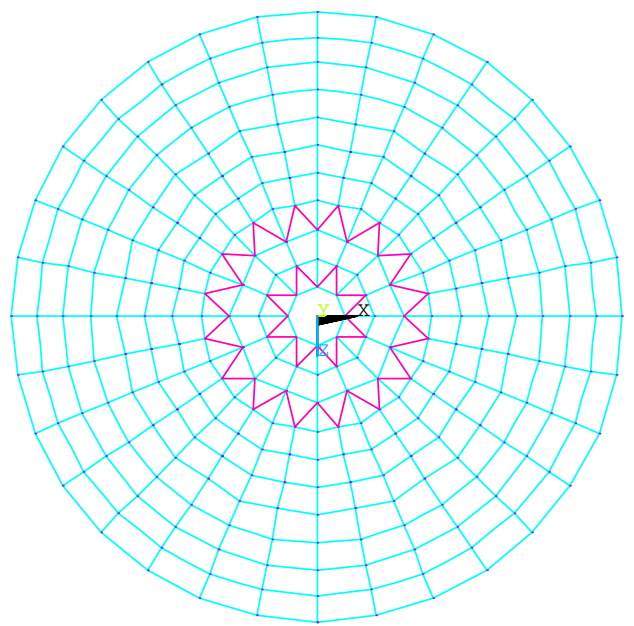

c) Sem Contraventamento 1

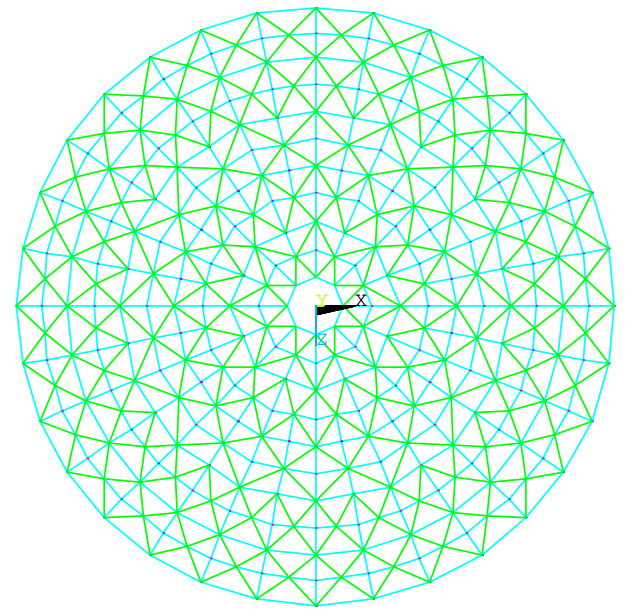

b) Contraventamento Flexível 2

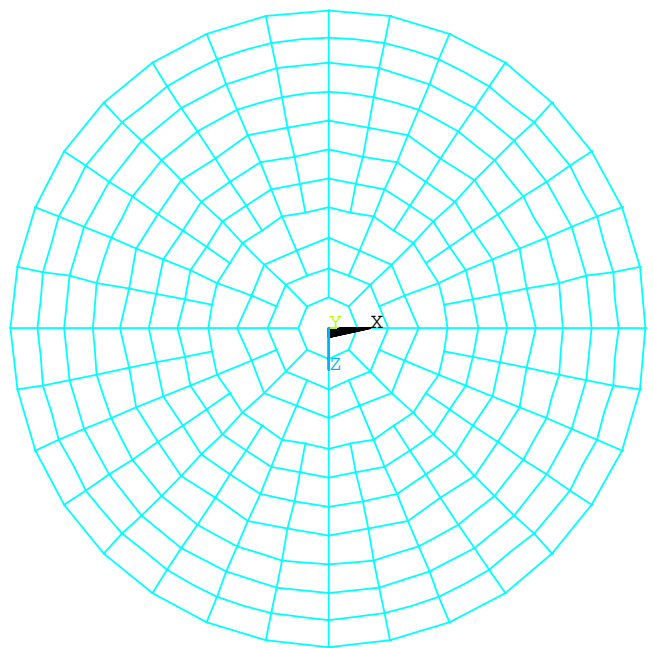

d) Sem Contraventamento 2

Figura 5.17 - Subdivisão dos modelos com contraventamento flexível sem contraventamento

Nos modelos mostrados na Figura 5.17(a) e 5.17(c) foram inseridas barras rígidas entre os anéis 1 e 3, contados a partir do centro da cobertura. 0 modelo da Figura 5.17(b) contém apenas barras flexíveis e o da Figura 5.17(d) não contém nenhum tipo de contraventamento.

\subsection{1 - Comparação dos Deslocamentos Máximos}

A Tabela 5.11 apresenta os resultados fornecidos pelo ANSYS 7.1 para o deslocamento no nó 5 (ver Figura 5.13). Esses resultados mostram claramente que a consideração da rigidez das ligações e que o enrijecimento do contraventamento, mesmo que parcial, promovem a redução dos deslocamentos da estrutura. 
Tabela 5.11 - Deslocamentos máximos

\begin{tabular}{c|c|c|c}
\hline Características do & \multicolumn{3}{|c}{ Características das Ligações } \\
\cline { 2 - 4 } Contraventamento & Rotuladas & Semi-Rígidas & Rígidas \\
\hline Rígido & 3,3129 & 3,1144 & 2,8928 \\
\hline Flexível 1 & 4,5339 & 3,9230 & 3,3204 \\
\hline Flexível 2 & 7,2908 & 5,3332 & 5,0003 \\
\hline Sem Contraventamento 1 & 5,2342 & 4,0713 & 3,2429 \\
\hline Sem Contraventamento 2 & 25,630 & 9,9868 & 8,4415 \\
\hline \multicolumn{4}{|c}{} \\
\hline
\end{tabular}

Vê-se que a consideração da rigidez das ligações permitiu reduzir em $6 \%$ os deslocamentos máximos no sistema com contraventamento rígido, em $13 \%$ no sistema com contraventamento flexível 1, e em 22\% no sistema sem contraventamento 1 . Observa-se também a intensa influência das ligações no modelo sem contraventamento 2. Conclui-se, então, mais uma vez, que quanto mais rígido o contraventamento, menor a influência da rigidez das ligações, e que na ausência desses elementos a influência das ligações passa a ser mais proeminente.

\subsection{2 - Comparação dos Esforços Internos nos Arcos}

O ANSYS 7.1 (2000) não fornece envoltória de esforços nem indica quais os esforços máximos em um determinado grupo de barras, como faz o STRAP 8.0 (2000). Sendo assim, foram escolhidas as barras indicadas na Figura 5.18 para comparação de resultados.

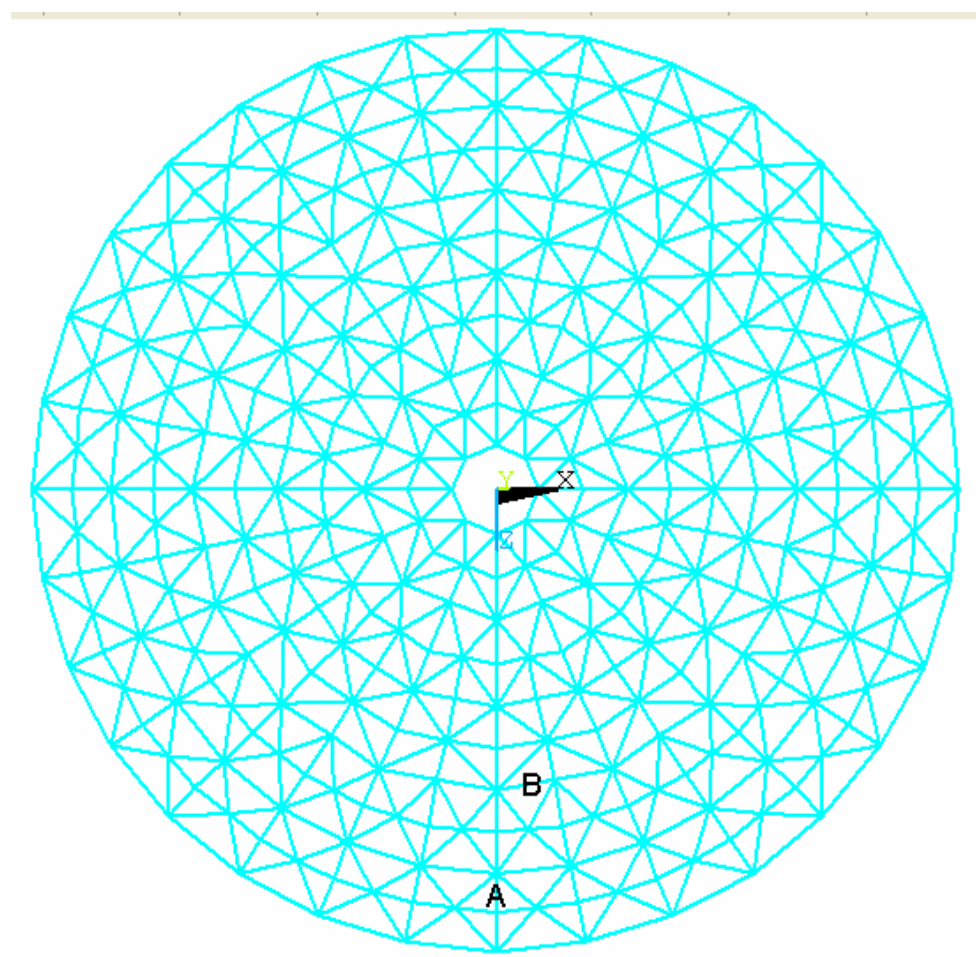

Figura 5.18 - Barras escolhidas para comparação de resultados

As Tabelas 5.12 e 5.13 fornecem os esforços máximos na barra $A$, pertencente aos arcos da cobertura. 
Tabela 5.12 - Comparação do Esforço Axial nos Arcos

\begin{tabular}{c|c|c|c}
\hline Sistema de & \multicolumn{3}{|c}{ Ligações } \\
\hline Contraventamento & Articuladas & Semi-Rígidas & Rígidas \\
\hline Rígido & 308,20 & 307,05 & 302,85 \\
\hline Flexível 1 & 453,47 & 461,89 & 488,20 \\
\hline Flexível 2 & 469,31 & 485,04 & 512,16 \\
\hline Sem Contraventamento 1 & 463,56 & 467,80 & 500,43 \\
\hline Sem Contraventamento 2 & 623,03 & 695,36 & 867,48 \\
\hline
\end{tabular}

Tabela 5.13 - Comparação do Momento Fletor nos Arcos

\begin{tabular}{c|c|c|c}
\hline Sistema de & \multicolumn{3}{|c}{ Ligações } \\
\hline Contraventamento & Articuladas & Semi-Rígidas & Rígidas \\
\hline Rígido & $2.787,50$ & $2.795,80$ & $2.880,10$ \\
\hline Flexível 1 & $2.732,80$ & $2.831,50$ & $3.047,40$ \\
\hline Flexível 2 & $2.605,20$ & $2.791,50$ & $3.018,50$ \\
\hline Sem Contraventamento 1 & $2.603,80$ & $2.818,00$ & $3.096,70$ \\
\hline Sem Contraventamento 2 & $4.104,10$ & $3.019,90$ & $2.825,20$ \\
\hline
\end{tabular}

Comparando os modelos com nós semi-rígidos e rotulados vê-se que, nos modelos com contraventamento rígido, a rigidez das ligações reduziu levemente o esforço axial e aumentou levemente o momento fletor. A diferença em ambos os casos ficou em torno de $0,3 \%$.

Nos demais casos, ou seja, nos modelos com contraventamento flexível e sem contraventamentos, os esforços aumentaram levemente, da ordem de 3\% para 0 esforço axial e $8 \%$ para o momento fletor. Apenas o caso 5 apresentou variações mais elevadas, que ficaram em torno de $12 \%$ para 0 esforço axial e $26 \%$ para o momento fletor.

Exceto no caso 5, os esforços internos também não diferiram muito daqueles fornecidos pelos modelos com nós rígidos, os quais tendem, de uma forma geral, a fornecerem esforços internos maiores. Isso é mais um indicativo de que em relação aos arcos os detalhes rotulados são mais apropriados do que os detalhes rígidos, isso tanto pela simplicidade das ligações, o que permite reduzir os custos de fabricação, quanto pelo fato de fornecerem esforços menores, ou pelo menos da mesma ordem de grandeza, daqueles fornecidos pelos detalhes rígidos.

\subsection{3 - Comparação dos Esforços Internos nos Anéis}

A Tabela 5.14 fornece os momentos fletores máximos na barra $B$, pertencente aos arcos da cobertura. Não são apresentados os valores de força normal porque estes praticamente coincidiram, independentemente do comportamento admitido para as ligações.

Tabela 5.14 - Comparação do Momento Fletor em Barra dos Anéis

\begin{tabular}{c|c|c|c}
\hline Sistema de & \multicolumn{3}{|c}{ Ligações } \\
\cline { 2 - 4 } Contraventamento & Articuladas & Semi-Rígidas & Rígidas \\
\hline Rígido & $10.401,0$ & $5.904,2$ & $2.533,5$ \\
\hline Flexível 1 & $11.588,0$ & $8.100,4$ & $3.002,4$ \\
\hline Flexível 2 & $12.331,0$ & $9.596,6$ & $3.253,8$ \\
\hline Sem Contraventamento 1 & $11.736,0$ & $9.169,0$ & $3.002,4$ \\
\hline Sem Contraventamento 2 & $32.330,0$ & $29.776,0$ & $6.621,6$ \\
\hline
\end{tabular}


Os resultados mostram que os momentos máximos nos anéis ocorrem nos modelos com ligações rotuladas, como era de se esperar, enquanto os modelos com ligações rígidas fornecem valores bem menores para esse esforço. A consideração da rigidez das ligações permitiu reduzir esse esforço em valores que variaram de 8 a $43 \%$.

\section{8 - Influência da Variação de Temperatura}

A influência da variação de temperatura foi investigada tendo como parâmetro de comparação os esforços produzidos pelo peso próprio da estrutura. A Tabela 5.15 apresenta os resultados obtidos.

Tabela 5.15 - Comparação do Momento Fletor em Barra dos Anéis

\begin{tabular}{c|c|c|c|c}
\hline \multirow{2}{*}{$\begin{array}{c}\text { Grupo de } \\
\text { Barras }\end{array}$} & \multicolumn{2}{|c|}{ Modelos com Ligações Articuladas } & \multicolumn{2}{c}{ Modelos com Ligações Rígidas } \\
\cline { 2 - 5 } & Peso Próprio & Temperatura & Peso Próprio & Temperatura \\
\hline $\mathbf{1}$ & 57,0 & 162,6 & 167,7 & 48,2 \\
\hline $\mathbf{2}$ & 8,2 & 98,5 & 109,8 & 10,4 \\
\hline $\mathbf{3}$ & 2,3 & 41,8 & 48,9 & 19,5 \\
\hline $\mathbf{4}$ & 133,5 & 138,7 & 136,0 & 123,0 \\
\hline $\mathbf{5}$ & 166,3 & 50,1 & 45,6 & 167,4 \\
\hline $\mathbf{6}$ & 33,5 & 104,1 & 105,8 & 32,9 \\
\hline
\end{tabular}

Observa-se que, em alguns dos grupos de barras analisados, a variação de temperatura chegou a fornecer esforços três vezes maiores que aqueles decorrentes do peso próprio, demonstrando que esta é uma ação que precisa ser considerada no projeto deste tipo de cobertura. Informação semelhante é fornecida por REBELLO (2003) para cúpulas monolíticas. 


\section{CONCLUSÕES}

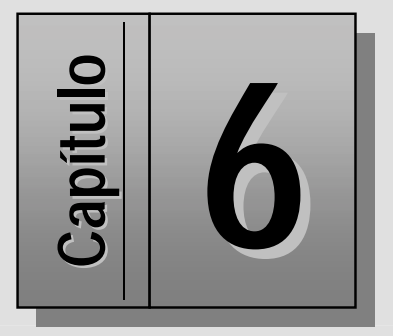

\section{1 - Recapitulação}

Este trabalho abordou, de uma forma geral, os sistemas estruturais normalmente adotados no projeto de cúpulas metálicas. Foi dado ênfase a um arranjo derivado do sistema Schwedler, recentemente utilizado em projetos desenvolvidos no interior do estado de São Paulo.

O trabalho pode ser divido em duas partes, a primeira delas versando sobre as ligações que compunham o sistema estrutural objeto de estudo, e a segunda versando sobre a influência dessas ligações no comportamento da estrutura e sobre a influência da forma de contraventamento.

As ligações foram estudadas sob dois aspectos diferentes, que foram: a) revisão e aperfeiçoamento dos critérios de dimensionamento adotados em algumas ligações, e b) proposição de modelos para previsão do comportamento momento-rotação de ligações com dupla tala de alma parafusada e de aparelhos de apoio.

A influência do tipo de contraventamento e da rigidez das ligações foi investigada por meio do efeito exercido nos deslocamentos verticais e na distribuição de esforços internos da estrutura. Para tanto, foram utilizados programas computacionais de uso já consagrado, cujos resultados foram comparados entre si.

\section{2 - Sobre 0 estudo das ligações}

As ligações são objeto de intensos estudos em estruturas metálicas há muito tempo, isso devido à extrema influência que elas exercem no custo, na montagem e no comportamento da estrutura. 
Para as ligações dos anéis com os arcos, que eram compostas por talas parafusadas, foi proposto um modelo teórico, ajustado por simulações numéricas em elementos finitos, que permite a determinação da rigidez inicial e do momento último desse tipo de ligação. Acoplando esse modelo às equações de KISHI \& CHEN (1990) e COLSON (1991) pôde-se plotar curvas momento-rotação e incorporá-las à análise estrutural.

As simulações numéricas em elementos finitos demonstraram que o modelo proposto apresentou uma leve tendência de superestimar a rigidez inicial e de subestimar o momento último. Isso, no entanto, pode não se verificar, ou se mostrar mais acentuado, quando forem feitas comparações com estudos experimentais, uma vez que os modelos numéricos também fornecem resultados aproximados do parâmetro estudado.

Os modelos existentes para cálculo de emendas em perfis I foram revisados e observou-se uma acentuada discordância entre os resultados fornecidos para a força máxima atuante nos parafusos. Foram desenvolvidas simulações numéricas em elementos finitos e isso tornou possível a proposição de um modelo de cálculo mais coerente, que leva em consideração a inércia do perfil e das talas. 0 modelo proposto apresentou bons resultados em todos os casos analisados, embora tenha sido observada uma leve tendência de superdimensionamento da conexão da alma e de subdimensionamento da conexão das mesas.

Para os aparelhos de apoio foi desenvolvido um modelo para avaliação da rigidez ao giro, e um modelo para dimensionamento de detalhes com nervuras de enrijecimento, que apresentou resultados bastante satisfatórios nos casos onde foi aplicado.

\section{3 - Sobre a influência do contraventamento}

No sistema estrutural estudado o contraventamento pode ser executado com barras rígidas, que são aquelas que trabalham sob forças de tração e compressão, ou com barras flexíveis, que são aquelas que resistem apenas a esforços de tração. Podem também, dependendo do diâmetro da estrutura, do detalhe das ligações e das cargas envolvidas, serem projetadas sem elementos de contraventamento.

Foi investigado, neste trabalho, a influência da forma de contraventamento no comportamento global da estrutura. Foram avaliados os deslocamentos verticais e a distribuição de esforços internos nas barras. Foi observado que a utilização de contraventamentos rígidos torna a estrutura menos sensível à influência da rigidez das ligações, e que 0 uso de contraventamentos flexíveis requer seções transversais maiores que aquelas necessárias para viabilizar o sistema com contraventamentos rígidos.

\section{4 - Sobre a influência da rigidez das ligações}

Foi observado que, quanto mais rígido o contraventamento, menor a influência das ligações no comportamento da estrutura. Comparando o modelo com ligações semi-rígidas com o modelo com ligações rotuladas observou-se uma redução de 6 a 22\% nos deslocamentos máximos, e uma redução de 8 a $43 \%$ nos momentos fletores nos anéis.

A influência da rigidez das ligações nos arcos é mínima, principalmente se o contraventamento for rígido. As maiores diferenças foram verificadas nos modelos sem contraventamento e ficou em torno de $12 \%$ para o esforço axial e $26 \%$ para o momento fletor. 
De uma maneira geral as ligações rotuladas mostraram-se mais adequadas que as ligações rígidas, o que se deu basicamente por dois motivos:

a) A diferença nos deslocamentos verticais foi pequena em ambas as situações;

b) Os esforços internos nos anéis tendem a ser menores quando as ligações são rígidas, no entanto os esforços nos arcos tendem a aumentar nessa situação.

Tudo isso, aliado ao fato de que as ligações rígidas encarecem a obra e são mais difíceis de executar, corrobora com a recomendação de que as ligações rotuladas são mais apropriadas.

\section{5 - Sugestões para continuação do trabalho}

Durante o desenvolvimento do trabalho vários tópicos interessantes para estudo foram surgindo, estes, no entanto, não puderam ser atendidos por se desviarem do objetivo central da pesquisa. Apresentam-se alguns deles a seguir, como sugestões para trabalhos futuros.

a) Investigar a influência de recalques nos apoios das cúpulas.

b) Investigar a influência de plataformas fixadas às cúpulas.

c) Desenvolver um programa computacional que permita analisar os modelos com ligações semi-rígidas de forma mais prática, uma vez que o ANSYS 7.1 (2000) exige um trabalho manual exagerado do usuário interessado em realizar tais análises.

d) Realizar estudos dinâmicos nos modelos com ligações semi-rígidas para determinar a influência da rigidez na freqüência natural de vibração da estrutura.

e) Realizar análises não-lineares de cúpulas metálicas treliçadas e em alma cheia.

f) Realizar estudos de colapso incremental nos exemplos analisados e determinar a influência da rigidez das ligações.

g) Estudar as cúpulas onde arcos e anéis são treliçados.

h) Estudar outros sistemas estruturais para cúpulas metálicas e comparar com aquele estudado neste trabalho.

i) Investigar experimentalmente o comportamento das ligações estudadas numericamente neste trabalho e comparar resultados.

j) Simulação numérica e investigação experimental do comportamento dos aparelhos de apoio com mísulas, com e sem variação de seção e com trechos curvos, conforme detalhes mostrados nas Figuras 3.11 a 3.13. 


\section{REFERÊNCIAS BIBLIOGRÁFICAS}

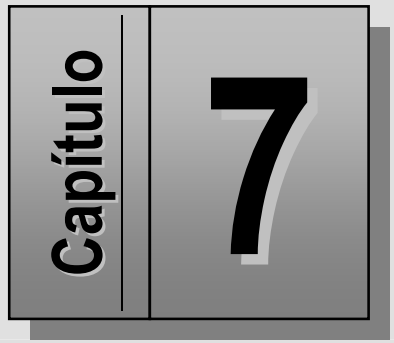

[001] ALVES FILHO, A. (2000). Elementos Finitos: a Base da Tecnologia CAE. Editora Érica

[002] ANDRADE, P.B. (1994). Curso básico de estruturas de aço. 2ạ edição. IEA Editora. Belo Horizonte - MG.

[003] ANSYS 7.1 (2000). Ansys help system.

[004] AMERICAN INSTITUTE OF STEEL CONSTRUCTION (1978). Allowable stress design: specifications for structural buildings. Chicago, AISC.

[005] AMERICAN INSTITUTE OF STEEL CONSTRUCTION (1986). Load and resistance factor design: specifications for structural buildings. Chicago, AISC.

[006] ASSOCIAÇÃO BRASILEIRA DE NORMAS TÉCNICAS - ABNT (1986). NBR 6123 - Efeito de vento em edificações. Rio de Janeiro - RJ.

[007] ASSOCIAÇÃO BRASILEIRA DE NORMAS TÉCNICAS - ABNT (1986). NBR 8800 - Projeto e execução de estruturas de aço de edifícios. Rio de Janeiro - RJ.

[008] ATLAS DO EXTRAORDINÁRIO (1996). Volume 1. Ediciones del Prado. Rio de Janeiro (RJ), Brasil.

[009] BAHARRI, M.R. \& SHERBOURNE, A. N. (1994). Computer modeling of an extend end-plate bolted connection. Computers \& Strucutures, 52, n. 05, pp. 879-893.

[010] BAHARRI, M.R. \& SHERBOURNE (1996). 3D simulation of bolted connections to unstiffened columns - II. Extended end-plate connections. Journal of Constructional Steel 
Research, 40, n. 03, pp. 189-223.

[011] BATISTA, R.C.; BATISTA, E.M. (1997). Determinação experimental dos mecanismos de colapso de uma junta típica de estruturas metálicas reticuladas espaciais. Anais da XXVIII Jornadas Sul-Americanas de Engenharia Estrutural, pp. 665-674.

[012] BATISTA, R.C. et al. (1997). Habilitação via reforços da estrutura metálica de uma grande calota esférica de cobertura. Anais da XXVIII Jornadas Sul-Americanas de Engenharia Estrutural, pp. 1127-1136.

[013] BATISTA, R.C. et al. (2001). Strengthening a reticulated spherical dome against local instabilities. Journal of Constructional Steel Research, 57, pp. 15-28.

[014] BEEDLE et. al. (1951). Connections for welded continuous portal frames. American Welding Society Journal.

[015] BILLINGTON, D.P. (1982). Thin shell concrete structures, 2 ed. McGraw-Hill. USA.

[016] BLEICH, F. (1943). Design of rigid knees. American Institute of Steel Construction.

[017] BLESSMAN, J. (1971). Pressures on domes with several winds profiles. Proc.. 3rd. Int. Conf. Wind Effect on Buildings and Structures. Tokyo. pp. 317-326.

[018] BLODGETT, O. W. (1966). Design of welded structures. The James F. Lincoln Welding Foundation. Cleveland, Ohio, U.S.A.

[019] CARRIL JÚNIOR, C.F.; JABARDO, P.J.S.; NADER, G.; PEREIRA, M.T. (2004). Ação do vento sobre a cobertura do centro de eventos culturais e esportivos Pe. Vitor Coelho. XXXI Jornadas Sudamericanas de Ingeniería Estrutural. Mendonza, Argentina.

[020] CHAN, S.L. (2001). Non-linear behavior and design of steel structures. Journal of Constructional Steel Research, 57, pp. 1217-1231.

[021] CHAN, S.L.; CHUI, P.P.T. (2000). Nonlinear static and cyclic analysis of steel frames with semir-rigid connections. Elsevier, Oxoford.

[022] CHEN, W. F. \& TOMA, S. (1994). Advanced analysis of steel frames: theory, software and applications. CRC Press.

[023] COLSON, A. (1991). Theoretical modeling of semirigid connections behavior. Journal of constructional steel research, n. 19, p. 213-224.

[024] DARKOV, A.V. (1960). Structural mechanics. MIR. Moscow.

[025] DeWOLF, J.T. \& RICKER, D.T. (1990). Column base plates. Steel design guide series 1. American Institute of Steel Construction, AISC, Chicago, U.S.A..

[026] DeWOLF, J.T. \& SARISLEY, E.F. (1980). Column base plates with axial loads and moments. Journal of Structural Division. ASCE. V. 106, No. ST11. pp. 2167-2184.

[027] DIAS, L.A.M. (1997). Estruturas de aço: conceitos, técnicas e linguagem. Zigurate Editora. 
São Paulo (SP), Brasil.

[028] ENGEL, H. (1981). Sistemas de estruturas. Editora Hemus. São Paulo, Brasil.

[029] ERIKSSON, A. \& PACOSTE, C. (1993). On parameter investigations of instabilities in reticulated space frames. In: PARKE, G.A.R. \& HOWARD, C. M. Space structures 4. Volume 1.

[030] ERMOPOULOS, J.C. \& STAMATOPOULOS, G. N. (1995). Moment-rotation curves for semirigid column bases. Proceedings of the $1^{\text {st }}$ European Conference on Steel Structures. Athens, Greece. Edited by Antony N. Kounadis.

[031] ERMOPOULOS, J.C. \& STAMATOPOULOS, G. N. (1997). Interaction curves for column base-plates connections. Journal of Constructional Steel Research, v.44, pp. 69-89.

[032] ERMOPOULOS, J.C. \& STAMATOPOULOS, G. N. (1996). Mathematical modeling of column base plate connections. Journal of Constructional Steel Research, v.36, pp. 79100.

[033] EUROCODE 3 (1992). Design of steel structures: Part 1.1 - General rules and rules for buildings.

[034] FERREIRA, N.S.S. (1999). Estruturas lamelares de madeira para coberturas. Dissertação (Mestrado). Escola de Engenharia de São Carlos, Universidade de São Paulo. São Carlos - SP.

[035] FERREIRA, N.S.S.; CALIL JUNIOR, C. (2000). Recomendações para o dimensionamento de estruturas lamelares de madeira. VII Encontro Brasileiro em Madeiras e em Estruturas de Madeira. São Carlos (SP), Brasil.

[036] FERREIRA, N.S.S.; GESUALDO, F.A.R. (2002). Análise de parâmetros para cúpulas reticuadas de madeira. VIII Encontro Brasileiro em Madeiras e em Estruturas de Madeira. Uberlândia (MG), Brasil.

[037] FICHER, J. W. et al. (1962). Plastic analysis and tests of haunched corner connections. Weld. Res. Counc. Bull. 91.

[038] FIELDING (1994). Frame response considering plastic panel hinges. Engineering Journal, AISC, first quarter.

[039] FRYE, M.J.; MORRIS, G.A. (1975). Analysis of flexibility connections steel frames. Cannadian Journal of Civil Engineering, v. 2, pp. 280-291.

[040] GAYLORD, E. H. et al. (1992). Design of steel structures. Third edition. McGRAW-HILL International Editions.

[041] GERRIN, A. (sem data). Estruturas de concreto armado. Editora Hemus.

[042] GRIFFITHS, J. D. (1948). Single span rigid frames in steel. American Institute of Steel Construction. 
[043] GIONCU, V. \& LENZA, P. (1993). Propagation of local buckling in reticulated shells. In: PARKE, G.A.R. \& HOWARD, C. M. Space structures 4. Volume 1.

[044] GIONGO, J.S. (1993). Concreto armado: ancoragem por aderência. Apostila técnica. Escola de Engenharia de São Carlos da Universidade de São Paulo. São Carlos, Brasil.

[045] HIBBLELER, R.C. (2000). Resistência dos materiais. 3ed. LTC editora. Rio de Janeiro, Brasil.

[046] JONES, S.W.; KIRBY, P.A.; NETHERCOT, D.A. (1983). The analysis of frames with semirigid connections, A state-of-the-art-report. Journal of Constructional Steel Research, v.3, n. 2, pp. 2-13.

[047] JUSTINO FILHO, M.R. (2001). Análise estática não linear última aplica a estruturas de aço. Anais do IV Seminário Internacional "O Uso de Estruturas Metálicas na Construção Civil" e I Congresso Internacional da Construção Metálica - I CICOM. São Paulo - SP.

[048] KATO, S. et al. (1998). Collapse of semi-rigidly jointed reticulated domes with initial geometric imperfections. Journal of Constructional Steel Research, 48, pp. 145-168.

[049] KONTOLEON, M.J.; MISTAKIDIS, C.C.; BANIOTOPOULOS, C.C.; PANAGIATOPOULOS, P.D. (1999). Parametric análisis of the structural response of steel base plate connections. Computeres and structures, 71. pp. 87-103.

[050] KISHI, N. \& CHEN, W.F. (1990). Momento-rotations relations of semi-rigid connections with angles. Journal of Constructional Steel Research, 116(7), pp. 1813-1834.

[051] KISHI, S.E.; CHEN, W.F. (1996). Practical advanced análisis for semi-rigid frame design. Engineering Journal, v.33, n. 4, fourth quarter.

[052] LANDESMANN, A. et al. (2001). Implementação de modelo avançado para análise estrutural com ligações semi-rígidas. Anais do IV Seminário Internacional "O Uso de Estruturas Metálicas na Construção Civil" e I Congresso Internacional da Construção Metálica - I CICOM. São Paulo - SP.

[053] LAVALL, A. C. C. L (1996). Uma formulação consistente para análise não-linear de pórticos planos de aço considerando imperfeições iniciais e tensões residuais. Tese (Doutorado). Escola de Engenharia de São Carlos, Universidade de São Paulo. São Carlos - SP.

[054] LAZANHA, E.C. (2003). Análise dinâmica elasto-plástica de estruturas metálicas sob excitação aleatória do vento. Dissertação (Mestrado). Escola Politécnica da Universidade de São Paulo. São Paulo (SP), Brasil.

[055] LIMA, L.R.O. (2003). Comportamento de ligações com placa de extremidade em estruturas de aço submetidas a momento fletor e força axial. Tese (doutorado). Pontifícia Universidade Católica do Rio de Janeiro. Rio de Janeiro, Brasil.

[056] LIN, T. Y.; STOTESBURY, S.D. (1988). Structural concepts and systems for architects and engineers, 2ed., Van Nostrand Reinhold Co.. New York, USA. 
[057] LORENZ, R.F.; KATO, B.; CHEN, W.F. (1993). Semi-rigid connections in steel frames. Council on tall buildings and urban habitat, comitee 43. McGraw-Hill.

[058] MAGALHÃES, J.R.M. (1996). Sobre o projeto e a construção de estruturas metálicas espaciais. Dissertação de mestrado. Escola de Engenharia de São Carlos da Universidade de São Paulo.

[059] MAGGI, Y. I. (2000). Análise numérica via M.E.F. do comportamento de ligações parafusadas viga-coluna com chapa de topo. Dissertação de mestrado. Escola de Engenharia de São Carlos da Universidade de São Paulo. São Carlos - SP.

[060] MAGGI, Y. I. et al. (2001). A análise de ligações viga-pilar com chapa de topo utilizando elementos finitos. Anais do IV Seminário Internacional "O Uso de Estruturas Metálicas na Construção Civil" e I Congresso Internacional da Construção Metálica - I CICOM. São Paulo - SP.

[061] MAIOLA, C.H. (1999). Análise teórica e experimental de treliças espaciais constituídas por barras com extremidades estampadas. Dissertação de mestrado. Escola de Engenharia de São Carlos da Universidade de São Paulo.

[062] MANUAL BRASILEIRO PARA CÁLCULO DE ESTRUTURAS METÁLICAS - MBCEM (1986). Ministério da Indústria e do Comércio. Secretaria de Tecnologia Industrial. Brasília-DF.

[063] MARTINS, M.M. et al. (2001). Estudo de bases de pilares metálicos pelo método dos elementos finitos. Anais do IV Seminário Internacional "O Uso de Estruturas Metálicas na Construção Civil” e I Congresso Internacional da Construção Metálica - I CICOM. São Paulo - SP.

[064] MAKOWSKI, Z. S. (1984). Analysis, design and construction of braced domes. New York, Nichols Publishing Company.

[065] MAKOWSKI, Z. S. (1989). Estruturas spaciales. McGraw-Hill. Madrid, Espanha.

[066] MARGARIDO, A.F. (2003). Fundamentos de estruturas. 2ed. Editora Zigurate. 334 pp.

[067] MATSUSHITA, F. et al. (1993). Study of the elasto-plastic buckling of single-layer domes. In: PARKE, G.A.R. \& HOWARD, C. M. (1993). Space structures 4. Volume 1.

[068] MOAVENI, S. (2003). Finite Element Analysis: Theory and Applications with ANSYS, Second Edition. Hardcover.

[069] MORAIS, C.S. (2003). Análise teórico-experimental de ligações parahusadas viga-pilar em perfis formados a frio. Dissertação (mestrado). Escola de Minas, Universidade Federal de Ouro Preto. Ouro Preto, Brasil.

[070] MULLORD, P. (1984). Introduction to the analysis of braced domes. In: MAKOWSKI, Z. S. (1984). Analysis, design and construction of braced domes. New York, Nichols Publishing Company. 
[071] MUTOH, I. \& KATO, S. (1993). Comparison of buckling loads between single-layer lattice domes and spherical shells. In: PARKE, G.A.R. \& HOWARD, C. M. Space structures 4. Volume 1.

[072] NOOSHIN, H. (1984). Third international conference on space structures. Elsevier Applied Science Publishers.

[073] OGUEJIOFOR, E. C. \& HOUSAIN, M. U. (1997). Numerical analysis of push-out specimens with perfobond rib connectors. Computers \& Structures. Vol. 62, N. 04, pp. 617-624.

[074] PAKANDAN, P. D. \& SARSHAR, B. (1993). Comparison of the behaviour of three types of braced domes. In: PARKE, G.A.R. \& HOWARD, C. M. (1993). Space structures 4. Volume 1.

[075] PAULA, C. F. (1997). Estudo das descrições lagrangiana e euleriana na análise não-linear geométrica com o emprego do método dos elementos finitos. Dissertação (Mestrado). Escola de Engenharia de São Carlos, Universidade de São Paulo. São Carlos - SP.

[076] PAULA, C. F. (2001). Contribuição ao estudo das respostas numéricas não-lineares estática e dinâmica de estruturas reticuladas planas. 128 p. Tese (Doutorado). Escola de Engenharia de São Carlos, Universidade de São Paulo. São Carlos - SP.

[077] PAULA, C.F.; PROENÇA, S.P.B. (2001). Análise não-linear geométrica de treliças planas. Departamento de Engenharia de Estruturas da Escola de Engenharia de São Carlos, Universidade de São Paulo. São Carlos - SP.

[078] PARKE, G. A R. \& HOWARD, C. M. (1993). Space structures 4 - volumes 1 e 2 . Thomas Telford, London.

[079] PASQUETI, E. (2003). Estabilidade elástica e dinâmica de torres estaiadas. Dissertação (Mestrado). Pontificia Universidade Católica do Rio de Janeiro. Rio de Janeiro, Brasil.

[080] PFEIL, W.; PFEIL, M. (2000). Estruturas de aço, dimensionamento prático. 7ed. LTC Editora. Rio de Janeiro, Brasil.

[081] PFEIL, W. (1986). Estruturas de aço. Volume 1. 4ed. LTC Editora S.A. Rio de Janeiro (RJ). Brasil.

[082] PICARD \& BEAULIEU (sem data). Calcul Aux États Limites des Charpentes d'Acier apud USIMINAS (1988).

[083] PIMENTA, P.M.; FRUCHTENGARTEN, J. (1997). On the computation of critical load of steel domes. Anais da XXVIII Jornadas Sul-Americanas de Engenharia Estrutural, pp. 14071415.

[084] PINHEIRO, L. (2003). Análises não-lineares de sistemas estruturais metálicos rotulados e semi-rígidos. Dissertação (mestrado). Escola de Minas, Universidade Federal de Ouro Preto. Ouro Preto, Brasil.

[085] PINHEIRO, L.; SILVEIRA, R.A.M. (2004). Formulações de elementos finitos semi-rígidos para modelagem de pórticos metálicos. XXXI Jornadas Sudamericanas de Ingeniería 
Estrutural. Mendonza, Argentina.

[086] PRELORENTZOU, P. A. (1991). Um estudo sobre ligações viga-coluna em estruturas de aço. Dissertação de mestrado. Escola de Engenharia de São Carlos da Universidade de São Paulo.

[087] QIAN, R. J. et al. (1993). A study of instabilities mechanisms of reticulated shells and analytical model. In: PARKE, G.A.R. \& HOWARD, C. M. (1993). Space structures 4. Volume 1.

[088] QUEIROZ, G. (1988). Elementos das estruturas de aço. Belo Horizonte - MG. Publicado pelo autor.

[089] RADMZIMINSKI, J. B. \& AZIZINAMINI, A. (1988). Prediction of moment-rotation behaviour of semi-rigid beam-to-column connections. In: BJORHOVDE, R. et al. Connections in steel structures, Elsever, London, pp. 33-40.

[090] REBELLO, Y.C.P. (2003). A Concepção Estrutural e a Arquitetura. 3ed. Editora Zigurate. $271 \mathrm{pp}$.

[091] RIBEIRO, L. F. L. (1998). Estudo do comportamento estrutural de ligações parafusadas viga-coluna com chapa de topo: análise teórico-experimental. Tese de doutorado. Escola de Engenharia de São Carlos da Universidade de São Paulo.

[092] ROBERTS, G. (1951). The structural design of the domes of Discovery. Festival of Britain. Proc. Inst. Civ. Eng. Pp. 377-417.

[093] SAE INFORMÁTICA (2002). Sistemas de análise estrutural. Disponível em: <http://www.sae.eng.br>. Acesso em: 05 de abril de 2002.

[094] SÁLES, J.J. (1995). Estudo do projeto e da construção de edifícios de andares múltiplos com estruturas de aço. Tese de Doutorado. Escola de Engenharia de São Carlos da Universidade de São Paulo.

[095] SÁLES et al. (1994). Construções em aço: projeto. Escola de Engenharia de São Carlos da Universidade de São Paulo.

[096] SÁLES et. Al. (1997). Efeito de segunda ordem em estruturas de aço. Anais da XXVIII Jornadas Sul-Americanas de Engenharia Estrutural, pp. 349 - 356.

[097] SÁLES et. Al. (1997). Comportamento das estruturas de aço à ação dinâmica do vento. Anais da XXVIII Jornadas Sul-Americanas de Engenharia Estrutural, pp. 517-525.

[098] SALMON, C. G. \& JOHNSON, J. E. (1996). Steel structures: design an behaviour 4.ed. New York. Haper \& Row.

[099] SANTOS, L.B. (1998). Influência da rigidez das ligações em estruturas de aço. Dissertação de mestrado. Escola de Engenharia de São Carlos da Universidade de São Paulo.

[100] SANTOS, L.B. (2002). Contribuições ao estudo das cúpulas metálicas. Exame de qualificação (doutorado). Departamento de Engenharia de Estruturas da Escola de 
Engenharia de São Carlos da Universidade de São Paulo. São Carlos, Brasil.

[101] SANTOS, L.B., PITUBA, J.J.C.; TRISTÃO, G.A. (2002). Análise não-linear de arcos metálicos. XXX Jornadas Sul-Americanas de Engenharia Estrutural. Brasília, Brasil.

[102] SANTOS, L.B.; SÁLES, J.J. (1999a). Avaliação da flexibilidade de ligações viga-coluna com chapa de topo. Revista Construção Metálica. V. 37, pp. 23-32.

[103] SANTOS, L.B.; SÁLES, J.J. (1999b). Influência da flexibilidade das ligações viga-coluna com chapa de topo no comportamento de pórticos planos de aço. XX CILAMCE Congresso Ibero Latino-Americano de Métodos Computacionais em Engenharia. São Paulo, Brasil.

[104] SANTOS, L.B.; SÁLES, J.J. (2004). Procedimento prático para dimensionamento de bases nervuradas para pilares metálicos. XXXI Jornadas Sudamericanas de Ingeniería Estrutural. Mendonza, Argentina.

[105] SANTOS, L.B.; SÁLES,J.J., RIBEIRO JÚNIOR, A.S. (2004). Avaliação do cisalhamento máximo nos parafusos de emendas em vigas de aço. XXXI Jornadas Sudamericanas de Ingeniería Estrutural. Mendonza, Argentina.

[106] SMITH, E.B. (1950). The dome - a study in the history of ideas. Princeton Monographs in Art and Archaeology, no. 25, Princeton University Press.

[107] SOUZA, A. S. C. (1998). Contribuição ao estudo das estruturas metálicas espaciais. Dissertação de mestrado. Dissertação (Mestrado). Escola de Engenharia de São Carlos da Universidade de São Paulo. São Carlos (SP), Brasil.

[108] SOUZA, A. S. C. (2003). Análise teórica e experimental de treliças espaciais. Tese (Doutorado). Escola de Engenharia de São Carlos da Universidade de São Paulo. São Carlos (SP), Brasil.

[109] SOUZA, A.S.C.; GONÇALVES, R.M. (2002). Análise de ligações em treliças espaciais pelo método dos elementos finitos. XXX Jornadas Sul-Americanas de Engenharia Estrutural. Brasília, Brasil.

[110] SOARE, M. V. (1984). Investigation of the collapse of a large-span braced dome. In: MAKOWSKI, Z. S. (1984). Analysis, design and construction of braced domes. New York, Nichols Publishing Company.

[111] STRAP 8.0 (2000). Structural analysis programs. Version 8.0.

[112] STRUIK, J.H.A.; BACK, J. (1969). PÁG. 110

[113] SUMEC, J. (1993). Some stability aspects of reticulated shells. In: PARKE, G.A.R. \& HOWARD, C. M. (1993). Space structures 4. Volume 1.

[114] SUPLE, W. J. (1984). Stabitity and collapse analysis of braced domes. In: MAKOWSKI, Z. S. (1984). Analysis, design and construction of braced domes. New York, Nichols Publishing Company. 
[115] THAMBIRATNAN, D. \& PARAMAISVAM, P. (1986). Base plates under axial loads and moments. Journal of Structural Division. ASCE. V. 112, No. 5. pp. 1166-1181.

[116] TIMOSHENKO, S. \& KRIEGER, S.W. (1959). Theory of plates and shells. Second edition. Tokyo, Japan. McGraw-Hill/Kogakusha.

[117] TOADER, I.H.I. et. Al. (1984). Influence of elastically end-restrained bars on the behaviour of curved latticed structures. In: NOOSHIN, H. (1984). Third international conference on space structures. Elsevier Applied Science Publishers.

[118] USIMINAS (1988). Bibliografia técnica para o desenvolvimento da construção metálica Volume II: ligações em estruturas metálicas. Belo Horizonte, Brasil.

[119] USIMINAS (1998). CR ROM Usimetal. [Belo Horizonte]. Usiminas. 1 CD.

[120] VALENCIANI, V.C. (1997). Ligações em estruturas de aço. Dissertação (mestrado). Departamento de Engenharia de Estruturas da Escola de Engenharia de São Carlos da Universidade de São Paulo. São Carlos, Brasil.

[121] VASCONCELOS, A.C. (1991). Estruturas arquitetônicas, apreciação intuitiva das formas estruturais. Ed. Studio Nobel.

[122] VENDRAME, A. M. (1999). Contribuição ao estudo das cúpulas treliçadas utilizando elementos tubulares de aço. Dissertação de mestrado. Escola de Engenharia de São Carlos da Universidade de São Paulo.

[123] VIEIRA, V.L. (2003). Modelo teórico e processos construtivos de estruturas em casca de concreto. Dissertação (Mestrado). Faculdade de Engenharia Civil da Universidade de Campinas. Campinas (SP), Brasil.

[124] WALD, F. \& SOCOL, Z. (1995). The simple column - base stiffness modeling. Proceedings of the 1 st European Conference on Steel Structures. Athens, Greece. Edited by Antony N. Kounadis.

[125] WALKER, H. B. (1984). Design and construction of braced domes. In: MAKOWSKI, Z. S. (1984). Analysis, design and construction of braced domes. New York, Nichols Publishing Company.

[126] YANG, J. G. et al. (2000). Three-dimensional finite element analysis of double angle connections under tension and shear. Journal of Constructional Steel Research, 54, pp. 227-244.

[127] ZIELINSKI, Z. A. et al. (1984). A comparable study of large span circular roof structures. In: Third International Conference on Space Structures. Edited by H. Nooshin. Elsevier Applied Science Publichers.

[128] ZIGNOLI, V. (1959). Construzioni metalliche. 2ed. Torinese. Madrid, Espanha. 